\title{
BIBLIOGRAFÍA DE FILOLOGÍA HISPÁNICA
}

(2014 en adelante)

\author{
Rosnátaly Avelino Sierra \\ JoRge ANDrÉs Kasep RodríguEz \\ Alejandro Rivas \\ Jesús JoRge VALENZUELA \\ El Colegio de México \\ nrfh@colmex.mx
}

LINGÜÍSTICA
OBRAS GENERALES Y MISCELÁNEAS
HISTORIA DE LA LINGÜÍSTICA
NIVELES LINGÜÍSTICOS
FONÉTICA, FONOLOGÍA
Y GRAFEMÁTICA
MORFOLOGÍA Y SINTAXIS
LEXICOLOGÍA
SEMÁNTICA Y PRAGMÁTICA
ANÁLISIS DEL DISCURSO
VARIACIÓN LINGǗ́STICA
CONTEXTO LATINO
YROMÁNICO
LINGÜISTICA HISTÓRICA
GEOLINGÜÍSTICA
SOCIOLINGÜÍSTICA
ESPAÑOL EN CONTACTO
ADQUISICIÓN Y PSICOLINGÜÍSTICA
LINGÜÍSTICA APLICADA
ENSEÑANZA DEL ESPAÑOL
LEXICOGRAFÍA
TRADUCCIÓN
OTROS ESTUDIOS

LITERATURA

OBRAS GENERALES Y MISCELÁNEAS $665-675$

LITERATURA TRADICIONAL

Y POPULAR

Historia DE LA LITERATURA

HISTORIOGRAFÍA

Y ESTUDIOS TEÓRICOS fichas

1-6

7-30

$31-67$

68-125

126-157

$158-224$

225-275

276-291

292-359

360-363

$364-429$

$430-477$

$478-510$

$511-565$

$566-605$

606-653

654-664

$676-687$
$688-723$
EDAD MEDIA

Poesía

Narrativa

Estudios diversos

Autores (y obras anónimas)

SIGLOS DE ORO

Poesía

Teatro

Narrativa

Estudios diversos

Autores (y obras anónimas)

SIGLO XVIII

Poesía

Teatro

Estudios diversos

Autores (y obras anónimas)

$724-727$

728-732

$733-744$

$745-780$

781-785

786-791

$792-797$

$798-813$

814-963

964-966

967,968

969-980

981-990

SIGLO XIX

Poesía

Teatro

Narrativa

Estudios diversos

Autores (y obras anónimas)

\section{SIGLO XX Y SIGLO XXI}

Poesía

Teatro

Narrativa

1059-1072

1073-1099

$1100-1143$

Autores (y obras anónimas) $\quad 1144-1480$

ABReViaturas 356-357

ÍNDICE DE INVESTIGADORES $\quad 357-375$

D.R. ( ) 2017. Nueva Revista de Filología Hispánica Licencia Creative Commons Attribution (CC BY-NC) 4.0 International 
OBSERVACIONES: La Bibliografía recoge la producción en filología hispánica a partir de los materiales resguardados en la Biblioteca Daniel Cosío Villegas de El Colegio de México. Las reseñas se consignan a continuación del libro (o artículo) reseñado. Cuando éste se ha descrito en una entrega anterior de la Bibliografía, se pone entre paréntesis el número de ficha correspondiente. También se hacen referencias a ediciones anteriores de una obra, a tomos anteriores de una obra en curso de publicación, etc. En estos casos, la cifra que precede al número de referencia indica el volumen de la NRFH en que figura la ficha en cuestión. Así, el "núm. 39-39695" corresponde a la ficha 39695, la cual está en el volumen 39 de la NRFH. Cuando no hay cifra inicial, ha de entenderse que el número remite a una ficha incluida en el presente fascículo. 


\section{LINGÜÍSTICA}

\section{OBRAS GENERALES Y MISCELÁNEAS}

65-1. Barriga Villanueva, Rebeca y Esther Herrera Zendejas (eds.) Lenguas, estructuras y hablantes: estudios en homenaje a Thomas C. Smith-Stark. El Colegio de México, México, 2014. 2 ts.: 1197 pp. || ELAp, 2016, núm. 63, 199-205 (Barriga Puente).

65-2. Herrera Soler, Honesto, Rosario Martínez Arias y Marian AMENGUAL Pizarro - Estadística aplicada a la investigación lingüistica. - EOS, Madrid, 2011. 2376 pp. || REsLA, 27 (2014), 239-245 (Díez Bedmar).

65-3. KaBATEK, JOHANNES - "Sobre usos y abusos de la terminología lingüística”. — RLiR, 79 (2015), 331-359.

65-4. Lorenzo GonZÁlez, GuILlermo "Biolingüística: fronteras y síntesis". Verba, 42 (2015), 293-321.

65-5. Martín Zorraquino, María AntoNIA - Filología, gramática, discurso. Artículos escogidos (1976-2013). Ed. de José Luis Aliaga. - Institución "Fernando el Católico", Zaragoza, 2014. 296 pp. || AFA, 70 (2014), 271-285 (Castañer Martín).

65-6. Martínez, Angelita y Lucas GAGLiardi (coords.) - Rutas de la lingüistica en la Argentina. - Universidad, La Plata, 2014. 120 pp. || SESS, 2015, núm. 28, 275-279 (Junquera).

\section{HISTORIA DE LA LINGÜÍSTICA}

65-7. Alvar Ezquerra, Manuel - "La nomenclatura de la inédita Gramática de Lorenzo Hervás y Panduro". CAISPI, 2015, núm. 6, 193-218.

65-8. Álvarez de Miranda, Pedro "Rafael Lapesa: la continuidad de un legado". - Cincuentenario de la AIH, ed. R. Barros Roel (A Coruña, 2014), pp. 89-97.

65-9. Cazorla Vivas, Carmen - Diccionarios y estudio de lenguas modernas en el Siglo de las Luces. Tradición y revolución lexicográfica en el ámbito hispanofrancés. - Liceus, Madrid, 2014. 445 pp. || RLex, 20 (2014), 195-197 (Gar- cía Aranda); RHLE, 9 (2014), 196-200 (Martínez González).

65-10. Ciapuscio, Guiomar Elena "Filología y Lingüistica en los primeros tiempos del Instituto". - Hispanismos del mundo, coord. F. Funes (Buenos Aires, 2016), pp. 259-272.

65-11. García Folgado, M.J. - Los inicios de la gramática escolar en España (1768-1813). Una aproximación historiográfica (N. 63-473). || RILI, 2015, núm. 25, 221-225 (Swiggers).

65-12. González Ollé, Fernando La Real Academia Española en su primer siglo. - Arco/Libros, Madrid, 2014. || RILI, 2015, núm. 26, 223-225 (Freixas).

65-13. Grosse, Sybille, Johannes Funk y RONNY BECKERT - "Entre cuidado de la lengua, normativización y promoción: las academias de la lengua y las instituciones de promoción de las lenguas iberorrománicas". - RILI, 2015, núm. 25, 7-18.

65-14. Hernando García-Cervigón, Alberto - "La presencia del Arte kastellana (1627) de Gonzalo Correas en la primera edición de la GRAE (1771)". - RFE, 95 (2015), 45-73.

65-15. JimÉNez Ríos, E. - La crítica lexicográfica y el "Diccionario" de la Real Academia Española. Obras y autores contra el "Diccionario" (N. 64-1562). || RILI, 2015, núm. 25, 226-228 (Cazorla Vivas).

65-16. Kítova-Vasílieva, María $-E l$ "amor a la palabra". Las fuentes del interés por la lengua desde la antigüedad hasta finales del Renacimiento. - Axac, Lugo, 2013. 574 pp. (Logophiles, 5). || Verba, 42 (2015), 449-456 (Mangado Martínez).

65-17. Leal Abad, Elena - "La lengua como canon y como objeto de crítica en la gramática normativa". - CLAC, 2016, núm. 66, 148-194.

65-18. LERNER, IsAíAs — «Ángel Rosenblat (1904-1984)». — Cincuentenario de la AIH, ed. R. Barros Roel (A Coruña, 2014), pp. 69-71.

65-19. LeVELt, W.J. - A history of psycholinguistics: The pre-Chomskian era $(\mathrm{N}$. 64-15). || EFil, 2014, núm. 54, 196-200 (Silva Villena). 
65-20. Link, DANiEL - "Pedro Henríquez Ureña: filología y comparatismo". - Hispanismos del mundo, coord. F. Funes (Buenos Aires, 2016), pp. 245-258.

65-21. Peñalver Castillo, Manuel "El Prontuario de ortografía de la lengua castellana (1844). Antecedentes y consecuentes". - ALM, 3 (2015), núm. 2, pp. 313-356.

65-22. Pérez Pascual, José Ignacio "Ramón Menéndez Pidal, maestro de filólogos". - Cincuentenario de la AIH, ed. R. Barros Roel (A Coruña, 2014), pp. 23-39.

65-23. Rodrigo, María - "El concepto de oralidad desde el Ordine delle lettere al Diálogo de la lengua". - CAISPI, 2014, núm. 4, 109-126.

65-24. Rojas, Darío - "Diccionario y estandarización lingüística en Hispanoamérica: la visión de Ramón Sotomayor Valdés (1866)”. — EFil, 2014, núm. 53, 109-121.

65-25. RoJAs, Darío - "Normatividad, descripción y autoridad en la lingüística chilena: Voces usadas en Chile (1900) de Aníbal Echeverría y Reyes". - Onomázein, 2016, núm. 33, 206-255.

65-26. San Vicente, Félix, Ana Lourdes de Hériz y María Enriqueta Pérez VÁzQuez (eds.) - Perfiles para la historia y crítica de la gramática del español en Italia: siglos XIX y XX. — Università di Bologna, Bologna, 2015. 384 pp. || CAISPI, 2015, núm. 6, 252-255 (Ariolfo).

65-27. Segovia Gordillo, Ana - "El vocabulario hispano-quechua (1608) de González Holguín, ¿heredero de Nebrija?". — PHisp, 28 (2014), núms. $1 / 2,7-23$.

65-28. SzkwareK, Magdalena - "Las huellas polacas de Ángel Rosenblat”. - Cincuentenario de la AIH, ed. R. Barros Roel (A Coruña, 2014), pp. 435-444.

65-29. Villalba, Manuel J. - "Una carta inédita de Claudio Sánchez-Albornoz a Américo Castro". — Incipit, 35 (2015), 253-258.

65-30. Zuili, Marc — "La larga historia del Tesoro de las dos lenguas española y francesa de César Oudin (ed. princeps: 1607): entre autoridad e inno- vación”. - Hipogrifo, 4 (2016), núm. 1, 271-288.

V. también núms. 600, 768, 769, 956, 1033.

\section{NIVELES LINGÜÍSTICOS}

\section{FONÉTICA, FONOLOGÍA Y GRAFEMÁTICA}

65-31. Aguilar Ruiz, Mary Carmen e IVÁN GALICIA IsASMENDI - "La relación prosódico-gestual en los enunciados de foco contrastivo y declarativos categóricos en el español de Puebla, México". - ELAp, 2016, núm. 63, $37-58$.

65-32. Ávila, Raúl — "La pronunciación del español en la radio de veinte países hispánicos: comentarios deportivos espontáneos". - NRFH, 64 (2016), 495-510.

65-33. Barnes, Hilary \& Jim MichnowICZ - "Broad focus declaratives in Veneto-Spanish bilinguals: Peak alignment and language contact". - SHLL, 8 (2015), 35-57.

65-34. Blecua, Beatriz, Jordi Cicres y JUANA GIL — "Variación en las róticas del español y su implicación en la identificación del locutor". - RFilR, 31 (2014), 13-35.

65-35. Blecua Falgueras, Beatriz y Assumpció Rost Bagudanch "Implicaciones perceptivas de la variación: la fricativa labiodental”. $-R E L$, 45 (2015), 25-44.

65-36. Bongiovanni, Silvina Carla "Neutralización del contraste entre /n/ y /nj/ en el español de Buenos Aires: un estudio de percepción”. SẼS, 2015, núm. 27, 11-46.

65-37. Caballero Meneses, Jonathan Azael - "Organización cerebral de la prosodia”. — ELAp, 2016, núm. 63, 169-196.

65-38. Cabedo Nebot, Adrián — "La función de la atenuación y la configuración prosódica: un estudio a partir de un corpus de español coloquial”. - RILI, 2016, núm. 27, 55-74.

65-39. Carter, Phillip M. \& Tonya WolFORD — "Cross-generational prosodic 
convergence in South Texas Spanish". - SpC, 13 (2016), 29-52.

65-40. Colantoni, Laura - "Fonética y fonología del español de la Argentina”. - SEVS, 2015, núm. 27, 3-10.

65-41. Díaz, Chaxiraxi y Josefa DorTA - “Coexistencia de configuraciones tonales en la variedad de español de La Gomera?”. - CuIF, 41 (2015), 77-101.

65-42. FACE, Timothy L. - “Sp_ToBI and the phonological analysis of Spanish intonation: A critical perspective". SHLL, 7 (2014), 185-210.

65-43. Fernández Planas, Ana María, Josefa Dorta, Paolo Roseano, Chaxiraxi Díaz, Wendy Elvira-GarCía, José ANTONio Martín Gómez y Eugenio Martínez Celdrán - "Distancia y proximidad prosódica entre algunas variedades del español: un estudio dialectométrico a partir de datos acústicos”. — RLA, 53 (2015), núm. 2, 13-45.

65-44. Fernández Trinidad, MarianeLA - "Cualidad de voz y estereotipos vocales”. - REL, 45 (2015), 45-72.

65-45. Frisch, Stefan A. - "A preliminary investigation of quantitative patterns in sonority sequencing". - RdiL, 27 (2015), 9-27. [Se incluye español].

65-46. Gil, Juana y Eugenia San SegunDo - "Nuevas aportaciones al estudio de la percepción del habla”. - REL, 45 (2015), 7-21.

65-47. GonzÁlez, Santiago — "La prosodia audiovisual de la ironía verbal: un estudio de caso". — REL, 45 (2015), 73-103.

65-48. Infante, Patricia — “'Son distintos el creak y la voz creaky?”. - REL, 45 (2015), 105-128.

65-49. Marrero Aguiar, Victoria "La percepción del habla en ruido. Estudio experimental sobre una aplicación para la evaluación audiológica infantil”. — REL, 45 (2015), 129-151.

65-50. Martin, Philippe — «Similarités prosodiques entre langues romanes». - RFilR, 31 (2014), 99-112.

65-51. Martín Butragueño, Pedro "A veces lloro mis lágrimas. Acercamiento multivariable a la prosodia de los actos de habla expresivos en el espa- ñol de México”. — ELAp, 2016, núm. 63, 59-102.

65-52. MAs, Lluís — "Patrones entonativos de los titulares de informativos en los canales de televisión españoles". - Onomázein, 2016, núm. 33, 327-342.

65-53. Melero García, Fernando - "Análisis acústico de la vibrante múltiple en el español de Valencia (España)”. — SHLL, 8 (2015), 183-206.

65-54. Mendoza VázQuez, Érika y Josaphat Guillén Escamilla "Sobre la imbricación de las funciones de la entonación y marcadores discursivos en la afasia de Wernicke”. - ELAp, 2016, núm. 63, 133-152.

65-55. Miranda Márouez, Gonzalo "Distancia lingüística, a nivel fonéticofonológico, entre las lenguas china y española”. - PHisp, 28 (2014), núms. 1/2, 51-68.

65-56. Móccero, María Leticia - "Prosodia y narración: el incremento de significado que aporta la altura tonal a los fragmentos narrativos en la conversación coloquial”. - LMod, 2015, núm. 46, 45-62.

65-57. Murrieta Bello, Laura - "Acercamiento al análisis experimental del umbral de percepción entonativa en el español del centro de México". ELAp, 2016, núm. 63, 153-166.

65-58. Orozco, LeONOR — “Aproximación a la entonación de enunciados declarativos en Guadalajara". — ELAp, 2016, núm. 63, 13-35.

65-59. Penas Ibáñez, M.A. (ed.) - Panorama de la fonética española actual $(\mathrm{N}$. 63-1544). || Dicenda, 32 (2014), 357361 (Hernando García-Cervigón); RILCE, 32 (2016), 279-282 (Polo); Oralia, 18 (2015), 343-349 (Ridao Rodrigo). - V. 64-1621.

65-60. Peña Arce, Jaime - "Despalatalización de /n/ en el español de Yucatán”. — CLECM, 3 (2016), núm. 2, 105-129.

65-61. Pérez Giménez, Montserrat "Las construcciones suspendidas o actos suspendidos: ensayo de caracterización pragmaprosódica”. — Oralia, 18 (2015), 213-234.

65-62. Planas Morales, Sílvia - "Percepción de los enunciados interroga- 
tivos de duda y de enfado sin apoyo visual, en alumnos chinos de ELE". REL, 45 (2015), 153-174.

65-63. Santamaría Busto, EnriQue "Percepción y evaluación de la pronunciación del español como L2”. - REL, 45 (2015),.

65-64. Strycharczuk, Patrycja, MaRiJN VAN 'T VeEr, Martine Bruil \& KATHRIN Linke - "Phonetic evidence on phonology-morphosyntax interactions: Sibilant voicing in Quito Spanish”. - $J L, 50$ (2014), 403-452.

65-65. Thornberry, Philip A. — "Tonal crowding effects in Buenos Aires Spanish: An experimental study". SHLL, 7 (2014), 369-394.

65-66. VAres GonzÁlez, Elena - "Prominencia estructural y prominencia fonética en el funcionamiento de la memoria fonológica a corto plazo". - REsLA, 28 (2015), 273-289.

65-67. Velásquez Upegui, Eva Patricia — "Diferencias prosódicas en la realización de vocativos: datos del español hablado en Colombia”. - ELAp, 2016, núm. 63, 103-132.

V. también núms. 77, 98.

\section{MORFOLOGÍA Y SINTAXIS}

65-68. Alcoba, Santiago, Cristina Buenafuentes y Gloria Clavería (eds.) - Los lindes de la morfología. - Universidade, A Coruña, 2016. 224 pp. (Anexos de Revista de Lexicografía, 37).

65-69. Armstrong, Grant — "Pronominal verbs in Spanish". - SHLL, 9 (2016), 29-65.

65-70. Batiukova, Olga — "Restricciones léxico-semánticas y mecanismos composicionales en la morfología derivativa: el caso de -iza(r)". - Cuestiones de morfología léxica, eds. C. Buenafuentes, G. Clavería e I. Pujol (MadridFrankfurt/M., 2016), pp. 101-165.

65-71. Batllori, Montserrat, Cristina Buenafuentes, Gloria Clavería, Margarita Freixas, Sheila Huertas, Carolina Julià, Laura Muñoz, Ana Paz, Marta Prat, Isabel Pujol, Assumpaió Rost y JoAn TorRuella — "La morfología léxica en el Por- tal de léxico hispánico: resultados del proyecto de investigación (FFI201124183)". - Cuestiones de morfología léxica, eds. C. Buenafuentes, G. Clavería e I. Pujol (Madrid-Frankfurt/M., 2016), pp. 167-229.

65-72. Belloro, Valeria — "Estudios sobre la interfaz sintaxis-pragmática en español y lenguas en América”. SEFS, 2014, núm. 25, 3-7.

65-73. Benítez Rosete, Valeria A. "Expresiones demostrativas como marcadores de accesibilidad referencial en español mexicano: una interfaz sintaxis-pragmática”. - $S \mathcal{E} S$, 2014, núm. 25, 59-83.

65-74. Bermúdez, FernANdo - “<ir $a+$ infinitivo $>$ Modalidad y aspecto en el futuro del castellano rioplatense". RILI, 2016, núm. 27, 173-194.

65-75. Buenafuentes de la Mata, CrisTINA - "Sobre la naturaleza categorial y morfológica de medio en español". - Verba, 42 (2015), 135-166.

65-76. Buenafuentes, Cristina, Gloria Clavería e Isabel Pujol (eds.) - Cuestiones de morfología léxica. Iberoamericana-Vervuert, MadridFrankfurt/M., 2016. 232 pp.

65-77. Camus Bergarache, Bruno "Entre la morfología, la fonología y la sintaxis: el origen del material morfológico". - Los lindes de la morfología, eds. S. Alcoba, C. Buenafuentes y G. Clavería (A Coruña, 2016), pp. 17-38.

65-78. Cano, María Ángeles - "De cómo las propiedades morfológicas, sintácticas y aspectuales de los derivados tienen reflejo en su significado". - Los lindes de la morfología, eds. S. Alcoba, C. Buenafuentes y G. Clavería (A Coruña, 2016), pp. 39-62.

65-79. Cerrudo Aguilar, Alba — “ Cyclic transfer in the derivation of complete parenthetical clauses". - Borealis, 5 (2016), 59-85.

65-80. Cidrás, Francisco — "Sobre la categorización de las relaciones gramaticales". - RILI, 2015, núm. 26, 145-169.

65-81. Esher, Louise — “Autonomous morphology and extramorphological coherence". - YM, 24 (2014), 325350. [Se incluye español]. 
65-82. FÁBREGAS, ANTONIO - "A note on how and why "state + aorist $=$ achievement'”. — Onomázein, 2016, núm. 33, $57-68$.

65-83. FÁbregas, Antonio - "Del subjuntivo como forma regente". - $A F B$, 4 (2014), 15-42.

65-84. FÁbregas, Antonio - "Direccionales con con y marcado diferencial de objeto". — RRo, 50 (2015), 163-190.

65-85. FÁbregas, Antonio - "On the locative reading of dimensional adjectives in the internal syntax of estar". SHLL, 7 (2014), 3-41.

65-86. Felíu Arquiola, Elena - "Proyecto de investigación Problemas de demarcación en morfología y sintaxis". Los lindes de la morfología, eds. S. Alcoba, C. Buenafuentes y G. Clavería (A Coruña, 2016), pp. 135-144.

65-87. Fernández Rubiera, Francisco José - "CP-complements to assertive predicates: Their syntax and interpretation”. - RILI, 2015, núm. 26, 187202.

65-88. GIORdAno, Roberta - "Las oraciones impersonales: un análisis comparativo español-italiano”. — ERM, 24 (2015), 145-156.

65-89. González Vergara, Carlos "Las oraciones reflexivas con se del español: una propuesta de análisis desde la gramática del papel y la referencia”. - SESS, 2014, núm. 25, 133158.

65-90. Granvik, Anton - "Oraciones completivas de sustantivo: un análisis contrastivo entre portugués y español". — Verba, 42 (2015), 347-401.

65-91. Guerrero Hernández, Noemí — "Aproximación a las condiciones de uso de los dativos sin copia clítica en español de México”. — SESS, 2014, núm. 25, 85-103.

65-92. Gutiérrez Ordóñez, Salvador — "La familia de las ecuacionales". RILI, 2015, núm. 26, 15-37.

65-93. Harrington, Sophie \& Ana TereSa Pérez Leroux - "Subjunctive and subject pronoun realization: A study of (Yo) no creo que". — Borealis, 5 (2016), 87-106.

65-94. Heidinger, StefFen - "Causalness and the encoding of the caus- ative-anticausative alternation in French and Spanish”. - JL, 51 (2015), 562-594.

65-95. Herrero Ruiz de Loizaga, FranCISCO JAVIER - "Según + interrogativo con valor de indefinido". - Verba, 42 (2015), 239-268.

65-96. Ibáñez, Sergio y Chantal Melis — "Ambivalencia transitiva y estructura argumental: resultados de un estudio de uso". - ALM, 3 (2015), núm. 2, 153-197.

65-97. Kuguel, Inés y Carolina OGgiaNI — "La interpretación de sintagmas preposicionales escuetos introducidos por la preposición en". - CLECM, 3 (2016), núm. 2, 5-34.

65-98. Lloret, M. RosA - "La interfaz fonología-morfología”. — Los lindes de la morfología, eds. S. Alcoba, C. Buenafuentes y G. Clavería (A Coruña, 2016), pp. 63-88.

65-99. Marchis Moreno, Mihaela y Mario Navarro - "El verbo causativo hacer en el español loísta: nuevas perspectivas para la Nueva gramática de la lengua española”. — RILI, 2015, núm. 25, 183-197.

65-100. MARE, MARÍA — "Sobre las concordancias alternantes en español”. SHLL, 9 (2016), 175-206.

65-101. Marqueta Gracia, Bárbara "Sintagmas con modificadores dentro de palabras". - Los lindes de la morfología, eds. S. Alcoba, C. Buenafuentes y G. Clavería (A Coruña, 2016), pp. 159-172.

65-102. Mendívil Giró, José Luis «¿De dónde vienen los morfemas? Una explicación moderna para una intuición antigua». - Los lindes de la morfología, eds. S. Alcoba, C. Buenafuentes y G. Clavería (A Coruña, 2016), pp. 173-186.

65-103. Muñoz Pérez, Carlos — "Una nota acerca del uso de juicios en teoría gramatical”. - SESS, 2014, núm. 26, 107-120.

65-104. O'Neill, Paul — "The morphome in constructive and abstractive models of morphology". - YM, 24 (2014), 25-70. [Se incluye español]. 65-105. OJea López, Ana Is abel"Categorías mixtas truncadas: la nomi- 
nalización defectiva en las cláusulas relativas existenciales modales". RLA, 54 (2016), núm. 1, 129-147.

65-106. Pérez Vázquez, María EnriQUETA - "Metalenguaje en la NGLE (oralidad y escrituridad)". — CAISPI, 2014, núm. 4, 91-107.

65-107. Quintana Hernández, Lucía — "Verbos recíprocos". — Dicenda, 32 (2014), 265-312.

65-108. Rico, Paвlo — “A syntactic approach to the Spanish $a l+$ infinitive construction". - Borealis, 5 (2016), 31-57.

65-109. Rifón SÁnchez, Antonio "Bloqueo y competición entre sufijos en la formación de sustantivos deadjetivales del español". - Cuestiones de morfología léxica, eds. C. Buenafuentes, G. Clavería e I. Pujol (MadridFrankfurt/M., 2016), pp. 35-62.

65-110. Rodríguez Ramalle, Teresa MARÍA - "Conexiones discursivas y subordinación: recursos sintácticos y conjunciones". — SEFS, 2014, núm. 25, 261-283.

65-111. Roy, IsABELLE - Nonverbal predication: Copular sentences and the syntax-semantics interface. - Oxford University Press, Oxford, 2013. xiv + 214 pp. (Oxford Studies in Theoretical Linguistics, 45). ॥JL, 50 (2014), 255260 (Geist). [Se incluye español].

65-112. Ruiz Tinoco, Antonio - "Análisis de más con adverbios negativos en un corpus de twitter". - LEA, 37 (2015), 201-214.

65-113. Santana Suárez, Octavio, José R. Pérez Aguiar, Is abel SánCHEz BERriel y Virginia Gutiérrez Rodríguez — "Predicado-argumentos: aplicación en un corpus del español”. — LEA, 37 (2015), 279-303.

65-114. Seco, María Alejandra — "El pasado perifrástico en variedades del español americano: panorama de los estudios recientes". - SESS, 2015, núm. 28, 211-235.

65-115. Serra Sepúlveda, Susana "Una nota sobre la combinatoria del verbo hacer en español”. — Onomázein, 2016, núm. 33, 201-205.

65-116. Serrano, María José - "Cognición y estilo comunicativo: el sujeto posverbal y el objeto sintáctico". EFil, 2014, núm. 54, 139-156.

65-117. Serrano Dolader, DAVID - "Viejas y nuevas aproximaciones al concepto de parasíntesis". - Cuestiones de morfología léxica, eds. C. Buenafuentes, G. Clavería e I. Pujol (MadridFrankfurt/M., 2016), pp. 9-34.

65-118. ŠInková, MonikA - "La morfología paradigmática y la motivación lingüística: el caso de los derivados parasintéticos en des- en el español moderno". - Los lindes de la morfología, eds. S. Alcoba, C. Buenafuentes y G. Clavería (A Coruña, 2016), pp. 187-200.

65-119. Stehlík, Petr - Aspectos problemáticos de la prefijación en español. Masarykova Univerzita, Brno, 2011. 80 pp. || RRo, 49 (2014), 355-358 (Svobodová).

65-120. TANGHE, SANne y Marlies JanSEGERS — "Marcadores del discurso derivados de los verbos de percepción. Un análisis comparativo entre el español y el italiano". - RRo, 49 (2014), 1-31.

65-121. Torres Martínez, Marta "Formación de palabras y diccionario: dificultades en la codificación lexicográfica”. - Los lindes de la morfología, eds. S. Alcoba, C. Buenafuentes y G. Clavería (A Coruña, 2016), pp. 109-132.

65-122. Treinsoutrot, Pascal "L'hypothèse d'un signifié en puissance: llamada, llamado, llamamiento". - ERM, 24 (2015), 211-224.

65-123. Trommer, Jochen (ed.) - The morphology and phonology of exponence. - Oxford University Press, Oxford, 2012. 538 pp. || YM, 24 (2014), 71-82 (Fábregas). [Se incluye español].

65-124. VANDERSCHUEREN, C. - Infinitivo y sujeto en portugués y español. Un estudio empírico de los infinitivos adverbiales con sujeto explícito (N. 64-99). || RILI, 2015, núm. 25, 242-245 (Schulte).

65-125. Zacarías Ponce de León, RAMón F. - “Análisis morfológico y semántico del sufijo -iza y sus implicaciones lexicográficas". — SESS, 2015, núm. 27, 247-266.

V. también núms. 224, 1425. 


\section{LEXICOLOGÍA}

65-126. Arnal Purroy, M. Luisa "Léxico regional y diccionarios: la definición «seudoperifrástica»" - AFA, 70 (2014), 227-247.

65-127. BArrio de la Rosa, Florencio DEL - Ejercicios de lexicología del español. - Lincom, München, 2014. 191 pp. || CAISPI, 2015, núm. 6, 237-240 (Bermejo Calleja).

65-128. Cáceres Lorenzo, M. TeresA - "Elementos diferenciales en el español atlántico. Andalucismos y occidentalismos en el canario". RRo, 50 (2015), 279-292.

65-129. Chavarría Vargas, Juan AntoNio y Virgilio Martínez EnAMORADo - De la Ragua a Sacratif. Miscelánea de topónimos andalusies al sur de Granada. - Academia Scientiarum Fennica, Helsinki, 2009. 152 pp. || PHisp, 28 (2014), núms. 1/2, 69-74 (Ruhstaller).

65-130. Crida Álvarez, Carlos Alberto y Julia Sevilla Muñoz — "La problemática terminológica en los estudios paremiológicos". - AFB, 5 (2015), 67-77.

65-131. Ferraz Castán, Vicente - Vocabulario del dialecto que se habla en la Alta Ribagorza. Notas biográficas de Fernado García Mercadal e introd. de José Antonio Saura Rami. - Aladra, Zaragoza, 2013. 152 pp. (Biblioteca de las Lenguas de Aragón, 13). \| AFA, 70 (2014), 306-308 (Montes Fano).

65-132. Ferreira, Anita, Pedro SalceDo y María del Valle - "Estudio de disponibilidad léxica en el ámbito de las matemáticas”. — EFil, 2014, núm. 54, 69-84.

65-133. García Aranda, M. Ángeles "La explicación al lenguaje común de las artes y oficios: el léxico de la construcción y su tratamiento en la lexicografía española”. — PHisp, 29 (2015), núms. 1/2, 7-35.

65-134. García Pérez, Rafael — «Les dimensions multiples du sens lexical». - CLex, 2014, núm. 104, 69-97. [Se incluye español].

65-135. Guerra Salas, Luis, M. Elena Gómez SÁnchez y Martín BasterreCHEA - "Cuantificación y representa- ción de las asociaciones léxicas en las listas de disponibilidad: el índice de contigüidad de los vocablos". — LEA, 37 (2015), 265-277.

65-136. Gutiérrez Rodilla, Bertha M. — "El estudio y comprensión del léxico de la medicina a la luz de su devenir histórico". - CLex, 2014, núm. 104, 177-193.

65-137. Hipperdinger, Yolanda "Pronunciación extranjera en importaciones léxicas: convencionalización puntual en español bonaerense". Onomázein, 2016, núm. 33, 310-326.

65-138. Iglesias Ovejero, Ángel — "El árbol paremiológico de Pedro”. $A F B, 5$ (2015), 79-108.

65-139. JoRdAN NúÑEz, KenNeTH — "Los préstamos en la prensa escrita chilena: su origen etimológico y su valor como marca de identidad del estrato socioeconómico del lector". - SESS, 2014, núm. 26, 69-92.

65-140. LuQue, Rocío - “Los zoónimos como recurso coloquial". — EAc, 2014, núm. 102, 77-89.

65-141. Marimón Llorca, Carmen "De la «pasión» a la «emoción»: la construcción verbal (y social) de las emociones en español”. — SESS, 2016, núm. 29, 131-156.

65-142. Matteis, Lorena M.A. DE "Señoritas en busca de nombre: jerarquización de una profesión a través del léxico". - RLex, 20 (2014), 77-106.

65-143. Miguel, Elena de - "La lexicología en España. Tendencias y proyectos en curso". - CLex, 2014, núm. 104, 17-44.

65-144. Molina Sangüesa, Itziar "Binomio y binómino, la confluencia de dos nombres en textos matemáticos renacentistas: algunas consideraciones etimológicas sobre la designación de las expresiones algebraicas". - RLex, 20 (2014), 107-119.

65-145. Molina SANGÜESA, ItzIAR - "En torno a las designaciones de raíz y sus notaciones: una muestra de la consolidación del álgebra sincopada en el Renacimiento hispano". - Verba, 42 (2015), 323-346.

65-146. Molina SANGüesA, ItzIAR - "En torno a las incógnitas del álgebra: $\cos a$, 
segunda cosa y cantidad. Análisis de una terminología matemática renacentista”. — CAISPI, 2015, núm. 6, 127-146.

65-147. Morant Marco, Ricardo "Denominación, alternancia onomástica y redenominación de animales domésticos". — RILCE, 32 (2016), 201-224.

65-148. Núñez Román, Francisco "La expresión fraseológica de la ira en italiano y español: un estudio cognitivo". - PHisp, 28 (2014), núms. 3/4, 213-233.

65-149. Pérez Aguilar, Raúl ArístiDES - "Coincidencias léxicas entre el español de Canarias y el de la península de Yucatán”. - NRFH, 64 (2016), 403-428.

65-150. Portilla, Mario - "Etimologías del español americano". - RFLUCR, 2014, núm. 40, 35-55.

65-151. Quirós García, Mariano y José Luis Ramírez Luengo - "Observaciones sobre el léxico del español de Yucatán (1650-1800)". — RFE, 95 (2015), 182-210.

65-152. Ramírez Luengo, José Luis "Algunas notas sobre el léxico médico en la Nueva España dieciochesca: voces cultas y populares en la denominación de enfermedades". - CuDie, 16 (2015), 291-310.

65-153. Santos Rovira, José María "Nuevos datos sobre la herencia africana del español caribeño. Estudio de campo en República Dominicana”. ALM, 3 (2015), núm. 2, 237-271.

65-154. Tabares Plasencia, EncarnaCIÓN — "Fraseología jurídica y variación topolectal”. — Onomázein, 2016, núm. 33, 1-15.

65-155. UedA, Hiroto - "Analizador lingüístico común con reglas gramaticales y diccionario, preparados por el usuario. Una aplicación para el análisis tipológico del léxico español". LEA, 37 (2015), 241-263.

65-156. VÁzQuez Amador, María, CARMEN LARIO y PALOMA LóPez — "Los anglicismos en la prensa deportiva de los 50". - EFil, 2015, núm. 55, 157-176.

65-157. Veland, ReidAR - "Locuzioni preposizionali «evidenziative» del tipo a dimostrazione che / di e costruzio- ni equivalenti con l'infinito in italiano, francese e spagnolo". - RRo, 50 (2015), 51-67.

V. también núms. 466, 470.

\section{SEMÁNTICA Y PRAGMÁTICA}

65-158. Aaron, Jessi E. — “A certain future: Epistemicity, prediction and assertion in Iberian Spanish future expression". - SHLL, 7 (2014), 215240.

65-159. Albelda Marco, Marta "Sobre la incidencia de la imagen en la atenuación pragmática". - RILI, 2016, núm. 27, 19-32.

65-160. Albelda Marco, Marta y M. Jesús BARros García - La cortesía en la comunicación. - Arco/Libros, Madrid, 2013. 96 pp. (Cuadernos de Lengua Española, 117). \| AFB, 4 (2014), 201-203 (Robles Garrote).

65-161. Alvarado Ortega, Belén "Enunciación y percepción: la evidencialidad en los textos turísticos del español”. - Onomázein, 2016, núm. $33,327-342$.

65-162. Alvarado Ortega, M. Belén "Independencia y fórmulas rutinarias: reestructuración de la esfera III". REsLA, 28 (2015), 1-16.

65-163. Barrios Sabador, María José — "Uso de indicativo y subjuntivo en los adverbios de modalidad epistémica de la incertidumbre. Estudio en un corpus informatizado". - - -AESLA, 2 (2016), 260-273.

65-164. BERMúdez, FERNANdo - "Rumores y otros malos hábitos. El condicional evidencial en español". - CLECM, 3 (2016), núm. 2, 35-69.

65-165. Borreguero Zuloaga, MargaRITA - "El gato, que ha tirado un vaso: ¿Construcciones escindidas en el español coloquial?”. — RILI, 2015, núm. 26, 101-122.

65-166. Borreguero Zuloaga, MargaRITA - "Focalizadores aditivos escalares y posición enunciativa: un estudio contrastivo español / italiano". PHisp, 28 (2014), núms. 3/4, 13-57.

65-167. Bravo, Diana — "Nuevos avances en el estudio de la cortesía y la des- 
cortesía en Latinoamérica". - $S \mathcal{E} S$, 2014, núm. 26, 3-6.

65-168. Cabezas Holgado, Emilio "Entre la locación y la colección: sobre las propiedades léxicas de una preposición bivalente". - Dicenda, 32 (2014), 7-31.

65-169. Cabezas Holgado, Emilio "Expresiones no verbales como enunciados realizativos: construcciones preposicionales y apelaciones enfáticas". - CLAC, 2016, núm. 66, 3-22.

65-170. Cable, Seth - "Reflexives, reciprocals and contrast". - JSem, 31 (2014), 1-41. [Se incluye español].

65-171. Cegarra, Juan José - "La categoría de tema en la lingüística sistémico-funcional: discusión sobre su realización clausular y su proyección textual". — SESS, 2015, núm. 27, 107141.

65-172. Cortés Rodríguez, Francisco J. - "Aspectual features in role and reference grammar: A layered proposal". — REsLA, 27 (2014), 23-53.

65-173. CorTés Rodríguez, LuIS - "El aplauso al presidente Aznar: estructuras sintáctico-pragmáticas que lo propician". - ALM, 3 (2015), núm. 2, 25-63.

65-174. De Cock, Barbara y Daniel Michaud Maturana - "La expresión de la agentividad en el Informa Retting (Chile, 1991)". — RILI, 2014, núm. 23, 123-140.

65-175. Escamilla Morales, Julio, Grandfield Henry Vega, Efraín Morales Escorcia, Josefa SAMper SuÁrez y Luz Marina Torres RoNCALLO - "Humor, imágenes discursivas y (anti)cortesía en conversaciones estudiantiles universitarias". - $S \mathcal{E} S$, 2014, núm. 26, 49-68.

65-176. Estévez Rionegro, Noelia "Valor semántico y uso de los verbos de cita directa en español. Estudio de corpus". - Cincuentenario de la AIH, ed. R. Barros Roel (A Coruña, 2014), pp. 267-275.

65-177. Estigarribia, Bruno - "La estructura informacional en la triplicación con clíticos del español rioplatense". - SESS, 2014, núm. 25, 105-132.
65-178. Feldhausen, IngO y María del Mar VANRell - "Oraciones hendidas y marcación del foco estrecho en español: una aproximación desde la teoría de la optimidad estocástica". - RILI, 2015, núm. 26, 39-59.

65-179. FernÁndez LoRences, T. - Gramática de la tematización en español $(\mathrm{N}$. 61-1296). || RILI, 2014, núm. 23, 210214 (Azpiazu).

65-180. Flores Treviño, María EugeNIA - "Copresencia de la atenuación e intensificación en el uso de bastante y su derivación en el habla del noreste de México". - RILI, 2016, núm. $27,137-156$.

65-181. Fuentes Rodríguez, Catalina — "Pragmagramática de es que: el operador de la intensificación". - EFil, 2015, núm. 55, 53-76.

65-182. Galera Masegosa, Alicia \& Aneider Iza Erviti - "Conceptual complexity in metaphorical resemblance operations revisited". - REs$L A, 28$ (2015), 48-72.

65-183. Gallego, Ángel J. y JuAn URIAGEREKA - "Estar $=$ Ser $+X "$. - Borealis, 5 (2016), 123-156.

65-184. García, C. y M.E. Placencia (dirs.) - Estudios de variación pragmática en español (N. 63-155). || SESS, 2014, núm. 26, 129-135 (Julián).

65-185. Gibert Sotelo, Elisabeth \& Isabel Pujol Payet - "Semantic approaches to the study of denominal parasynthetic verbs in Spanish". - YM, 25 (2015), 439-472.

65-186. Grande Alija, Francisco Javier - "Creer y no creer: modalidad apelativa y aserción en el lenguaje". - EFil, 2014, núm. 54, 85-110.

65-187. Hanegreefs, Hilde - "La capacidad de «perspectivización» de la pasiva con verse". - Verba, 42 (2015), 9-32.

65-188. Hernández, Gabriel - "Manifestación de la descortesía y anticortesía en jóvenes de la Provincia de Buenos Aires, Argentina: usos y representaciones de «malas palabras» e insultos". - SEFS, 2014, núm. 26, 23-47.

65-189. Heros, Susana de los "Humor étnico y discriminación en 
La paisana Jacinta". — $\mathrm{PrSc}, 4$ (2016), 74-107.

65-190. Huelva UnternbäUmen, ENRIQUE - "Hacia una definición de lo «inter» de la interacción comunicativa intercultural". - LinALFAL, 32 (2016), núm. 1, 95-101.

65-191. Hurtado, Luz Marcela - "El predominio de uno en Bogotá, Colombia: ¿estrategia para desfocalizar o para subjetivizar?". - ALM, 3 (2015), núm. 2, 105-151.

65-192. IbARRETXe ANTUÑano, Iraide y Rosario Caballero - "Una aproximación al estudio de los eventos de movimiento metafórico desde la tipología semántica y el género". - $A F B$, 4 (2014), 139-155.

65-193. Jaque Hidalgo, Matías - "Relaciones entre aspecto y modalidad epistémica: algunas consecuencias de las restricciones temporales sobre la evaluación de predicados". - Onomázein, 2016, núm. 33, 130-155.

65-194. Julián, Gisele — "Conversación de contacto en ventanillas de instituciones de la salud y la educación en español bonaerense". - SEVS, 2015, núm. 27, 171-196.

65-195. Kornfeld, Laura Malena "Una propuestita astuta: el diminutivo como recurso atenuador". - RILI, 2016, núm. 27, 123-136.

65-196. Lavric, Eva - “iAy, Señor/ qué juventud esta! Atenuar e intensificar con determinantes (en un corpus escrito y otro conversacional)". - RILI, 2016, núm. 27, 33-54.

65-197. Llopis CARdona, ANA — "De la indeterminación a la atenuación: de alguna manera / forma / modo". - RILI, 2016, núm. 27, 105-122.

65-198. MacArthur, Fiona, José Luis Oncins Martínez, Manuel SánChez García \& Ana María PiQuer PÍRIz - Metaphor in use: Context, culture and communication. - John Benjamins, Amsterdam-Philadelphia, 2012. $\mathrm{x}+379$ pp. || JMMD, 36 (2015), 548-550 (Deignan). [Se incluye español].

65-199. Marcovecchio, Ana M., Hilda Albano y Andrés Kaller - " $" D e+$ infinitivo»: entre la modalidad deón- tica y la condicionalidad". $-S \mathcal{E} S$, 2014, núm. 25, 215-229.

65-200. Martín Padilla, Kenia — "Los corpus lingüísticos al servicio de la semántica: su empleo en la delimitación de sentidos contextuales". Scriptum, 4 (2015), 165-185.

65-201. Martínez Atienza, María Tiempos verbales del indicativo en espanol e italiano. Significado y uso. - Celid, Torino, 2015. 80 pp. \| SESS, 2016, núm. 29, 253-256 (Ariolfo).

65-202. Mejías Bikandi, Errapel "Entailments, pragmatic assertion and mood in Spanish complements". Borealis, 5 (2016), 107-122.

65-203. Mihatsch, Wiltrud y Marta Albelda Marco - "La atenuación y la intensificación desde una perspectiva semántico-pragmática”. - RILI, 2016, núm. 27, 7-18.

65-204. Moreno Lara, María Ángeles — "Representaciones multimodales de metáforas y metonimias en las etiquetas de vino de la D.O.ca.Rioja". REsLA, 27 (2014), 454-468.

65-205. Pérez Sabater, Carmen - "The rhetoric of online support groups: A sociopragmatic analysis English-Spanish". - REsLA, 28 (2015), 465-485.

65-206. Pérez Saldanya, Manuel "Paradigms as triggers of semantic change: Demonstrative adverbs in Catalan and Spanish". — CatJL, 2015, núm. 14, 113-135.

65-207. Pinto, Derrin y Carlos de Pablos-Ortega - Seamos pragmáticos: introducción a la pragmática española. - Yale University Press, New Haven, 2014. 263 pp. || $\operatorname{PrSc}, 4$ (2016), 145-147 (Flores Ohlson).

65-208. Pose Furest, Francisca — "Actos truncados estratégicos: aspecto formal. Hacia el reconocimiento de sus tipos". - Oralia, 18 (2015), 259-280.

65-209. Posio, Pekka - "Alcance referencial y variabilidad de las construcciones impersonales con referencia humana en español peninsular hablado: sey la tercera persona del plural". - $S p C, 12$ (2015), 373-395.

65-210. Quiroz, Beatriz - "Convenciones de notación sistémica". - Onomázein, 2016, núm. 33, 412-426. 
65-211. Rey Quesada, Santiago Del "¿Qué es lo que oigo? Historia de una fórmula conversacional en el diálogo literario castellano". - RILI, 2015, núm. 26, 81-100.

65-212. Rubio Alcalá, Carlos - "Topic extraction from adverbial clauses". - Borealis, 5 (2016), 1-30. [Se incluye español].

65-213. Ruiz Gurillo, L. y M.B. AlvaRADO OrTega (eds.) - Irony and humor: From pragmatics to discourse $(\mathrm{N}$. 64-1808). || RILI, 2014, núm. 23, 218222 (Fernández Jaén).

65-214. Serra Pfenning, Isabel - "Definición y uso de expresiones coloquiales de la vida cotidiana”. - EAc, 2014, núm. 102, 123-129.

65-215. Silveira Moura, Fernanda y Paulo Pinheiro Correa - "Hendidas y otras construcciones focalizadoras en español argentino y portugués brasileño: un estudio de producciones audiovisuales". - SEFS, 2014, núm. 26, 93-105.

65-216. Soler Bonafont, M. Amparo - "La función atenuante en los verbos doxásticos del español”. - RILI, 2016, núm. 27, 75-90.

65-217. Speranza, Adriana - Evidencialidad en el español americano. La expresión lingüistica de la perspectiva del hablante (N. 64-375). || NRFH, 64 (2016), 552-560 (Fernández Ruiz).

65-218. Storti Garcia, Talita y BárbaRA Ribeiro FAnte - "Las estructuras concesivas introducidas por a pesar de (que) en el español hablado desde la perspectiva de la gramática discursivo-funcional”. - SE्SS, 2015, núm. 27, 223-245.

65-219. VAlenzuela Manzanares, Javier - "Cognitive linguistics in the law". AFB, 4 (2014), 185-200.

65-220. Van Gorp, Lise y Nicole DelBECQUE - "La dimensión subjetiva en el uso del verbo pseudocopulativo de cambio hacerse". - RILI, 2016, núm. 27, 195-214.

65-221. Vázquez Carranza, Ariel "Aceptación y resistencia: un análisis de $a h$ y ay como indicadores de cambio de estado". - CLECM, 3 (2016), núm. 2, 71-103.
65-222. Veleiro, ANA - "Aproximación al aspecto léxico de los verbos de cambio: pruebas para determinar su carácter delimitado". - Cincuentenario de la AIH, ed. R. Barros Roel (A Coruña, 2014), pp. 461-474.

65-223. Villalba ibáñez, CristiNA - "Las formas de tratamiento nominales y fórmulas apelativas convencionalizadas en los juicios orales: ¿elementos ritualizados o estrategias de atenuación?". - RILI, 2016, núm. 27, 91-104.

65-224. Villar Díaz, María Belén "Los términos de parentesco en la expresión de la posesión: cuestiones de semántica y sintaxis". - Cincuentenario de la AIH, ed. R. Barros Roel (A Coruña, 2014), pp. 475-487.

V. también núms. 31, 38, 61, 72-74, 78, 242, 245, 383, 587.

\section{ANÁLISIS DEL DISCURSO}

65-225. Agüero San Juan, Claudio "Conforman las sentencias penales un género discursivo?». - EFil, 2014, núm. 53, 7-26.

65-226. Álvarez Rosa, VAnEsa - "Notas acerca de la estrategia ejemplificadora en el discurso homilético de hoy". Oralia, 18 (2015), 311-325.

65-227. Anaya Revuelta, Inmaculada - "El análisis del discurso protocolario: elaboración y conceptualización". - EFil, 2014, núm. 54, 7-29.

65-228. Cancino Cabello, Nataly "La acomodación en los sermones de Luis de Valdivia (1621)”. — EFil, 2014, núm. 54, 31-48.

65-229. Cortés Rodríguez, Luis "La secuencia desarrollo y sus unidades temático-textuales en los discursos políticos". - Oralia, 18 (2015), 7-44.

65-230. Cortés Rodríguez, Luis "Sobre inicios y cierres en el discurso político". - EFil, 2014, núm. 53, 55-69.

65-231. Crespo Fernández, Eliecer El lenguaje de los epitafios. - Universidad de Castilla La Mancha, Cuenca, 2014. 191 pp. || I, 82 (2015), 257-260 (Luján García). 
65-232. Cuenca, Maria Josep y Maria JOSEP MARÍN — "La representación discursiva del adversario en el debate electoral". - Oralia, 18 (2015), 45-79.

65-233. De Cort, Stephenie, An De Schutter \& Lieve VANGehuchten - "The perception of the AfricanAmerican community through the eyes of the Hispanic media in the U.S.: A discourse analysis of the reporting of the death of Michael Brown". CLAC, 2016, núm. 66, 51-85.

65-234. Dvoskin, Gabriel — "Medios y realidad: formaciones discursivas en disputa”. - SESS, 2015, núm. 27, 143-169.

65-235. Espinosa Guerri, GuadaluPE — "Dientes de sierra: una herramienta para el estudio de la estructura interactiva del discurso dialógico". Normas, 6 (2016), 13-27.

65-236. Ferrari, Ángela y Margarita Borreguero ZuloAgA - La interfaz lengua-texto: un modelo de estructura informativa. - Biblioteca Nueva, Madrid, 2015. 344 pp. || RILI, 2015, núm. 26, 220-222 (Duttenhofer).

65-237. Fuentes Rodríguez, Catalina - "Los marcadores de límite escalar: argumentación y «vaguedad» enunciativa”. - RILCE, 32 (2016), 106-133.

65-238. Gallardo Paúls, Beatriz "Programas de tertulia política en Twitter: un modelo neurocomunicativo de análisis del discurso". — CLAC, 2016, núm. 66, 86-147.

65-239. Gallardo Paúls, B. - Usos politicos del lenguaje. Un discurso paradójico (N. 64-194). || Oralia, 18 (2015), 329334 (Santos López).

65-240. Garcés Gómez, María Pilar "Nouvelles perspectives dans l'analyse des marqueurs discursifs". - CLex, 2014, núm. 104, 155-176.

65-241. Gates Tapia, Anna M. \& DOUglas BIBER - "Lexico-grammatical stance in Spanish news reportage: Socio-political influences on que-complement clauses and adverbials in Ecuadorian broadsheets". - REsLA, 27 (2014), 208-237.

65-242. GaViño Rodríguez, ViCTORIANO - "Las actitudes del enunciador y su codificación lingüística en partículas discursivas". — EAc, 2014, núm. 102, 13-35.

65-243. Gómez GonzÁlez, María de los Ángeles \& Ana Patricia García VARELA - "Discourse-organizational patterns in English and Spanish: Some notes on the thematic management of news reports". - REsLA, 27 (2014), 87-117.

65-244. Hennemann, AnJA — "Una discusión del portugués penso eu y español pienso yo como marcador del discurso". - e-AESLA, 2 (2016), 148-156.

65-245. Infante Bonfiglio, José María y María Eugenia Flores Treviño (eds.) - La (des) cortesía en el discurso: perspectivas interdisciplinarias (imagen, actos de habla y atenuación). — UANLEDICE, Monterrey-Stockholm, 2014. 406 pp. || PrSc, 4 (2016), 140-144 (Padilla Herrada).

65-246. Kaul de Marlangeon, Silvia — "Delimitación de unidades extralingüísticas de análisis del discurso de (des) cortesía”. - SESS, 2014, núm. 26, 7-22.

65-247. Kern, JosePH - "Como in commute: The travels of a discourse marker across languages". - SHLL, 7 (2014), 275-297.

65-248. LABORDA GIL, XAVIER - Lágrimas de cocodrilo. Análisis del discurso politico. - UOC, Barcelona, 2012. 149 pp. || CAISPI, 2014, núm. 4, 236-240 (Mateu Serra).

65-249. Laborda Gil, Xavier — "Praxis comunicativa y publicidad engañosa de electricidad y gas en 2009". — Oralia, 18 (2015), 163-183.

65-250. Llopis Cardona, Ana - Aproximación funcional a los marcadores discursivos. Análisis y aplicación lexicográfica. - Peter Lang, Frankfurt/M., 2014. 284 pp. || $A L M, 3$ (2015), núm. 2, 357 365 (Salameh Jiménez).

65-251. López SERENA, ArAcELI — "De la oralidad fingida a la oralidad simuladora de realidad. Reflexiones en torno a la coloquialización del discurso como estrategia mediática". - EAc, 2014, núm. 102, 37-75.

65-252. MAldonAdo, Ricardo \& Rocío GuZMÁn — "Luego entonces. An argu- 
mentative intersubjective marker". CatJL, 2015, núm. 14, 59-77.

65-253. Márouez Guerrero, María - "La alternancia atenuación-intensificación: estrategias de refuerzo argumentativo". - Oralia, 18 (2015), 185-211.

65-254. Martín Gascueña, Rosa "La conversación guasap". - PrSc, 4 (2016), 108-134.

65-255. Medina López, Javier - "Discurso institucional e imagen en los mensajes de Navidad del rey de España (1975-2013)". — PrSc, 4 (2016), 25-73.

65-256. Meza, Paulina y Omar Sabaj "Funciones discursivas de consenso y disenso en tesis de lingüística”. Onomázein, 2016, núm. 33, 385-411.

65-257. Montolío Durán, Estrella “«En teoría, es perfecto». La partícula en teoría: debilitamiento asertivo, marcación argumentativa de tipo predictivo y patrones discursivos". - $R L A, 54$ (2016), núm. 1, 13-36.

65-258. Narvaja, Elvira y Verónica ZACCARI (eds.) - Discurso y política en Sudamérica. - Biblos, Buenos Aires, 2015. 402 pp. || SESS, 2016, núm. 29, 263-272 (Godoy).

65-259. Navarro, Federico - "Análisis de la crítica negativa en el discurso científico-académico: el caso del Instituto de Filología de Buenos Aires (1939-1989)". — SESS, 2014, núm. 25, 231-259.

65-260. Olza, Inés, Oscar Loureda \& Manuel Casado Velarde (eds.) - Language use in the public sphere: Methodological perspectives and empirical applications. - Peter Lang, Frankfurt/M., 2014. 564 pp. \|SpC, 13 (2015), 163-168 (Jimeno Zuazu).

65-261. ORNA MONTESINOS, CONCEPCIÓN — "The discourses of sustainability in news magazines: The rhetorical construction of journalistic stance". REsLA, 28 (2015), 442-464.

65-262. Parodi, Giovanni y Gina BurDILES - "Encapsulación y tipos de coherencia referencial relacional: el pronombre ello como mecanismo encapsulador en el discurso escrito de la economía”. - Onomázein, 2016, núm. 33, 107-129.
65-263. Pinuer Rodríguez, Claudio y Teresa Oteíza Silva - "Los adverbios en -mente como factor de valoración en el discurso de la historia". - Verba, 42 (2015), 99-134.

65-264. Porroche Ballesteros, MargaRITA - "Sobre el marcador discursivo a ver". - EAc, 2014, núm. 102, 91-110.

65-265. Portolés Lázaro, José - "Razón de más como inversor argumentativo". - RILI, 2016, núm. 27, 157-172.

65-266. Quintero Ramírez, SARA "Identificación de los conectores discursivos de más alta frecuencia en notas periodísticas deportivas". RLA, 53 (2015), núm. 2, 47-71.

65-267. Quintrileo Llancao, CeciLIA - "Esquemas argumentales en un debate parlamentario chileno: el caso del reconocimiento constitucional de los pueblos indígenas". - Oralia, 18 (2015), 281-307.

65-268. Rodríguez Muñoz, Francisco J. - "Análisis discursivo del ciberconsejo en el género foro virtual de discusión / consulta médica no especializada". - REsLA, 28 (2015), 486510.

65-269. Sainz, Eugenia (ed.) - De la estructura de la frase al tejido del discurso. Estudios contrastivos español / italiano. - Peter Lang, Bern, 2014. 305 pp. || CAISPI, 2015, núm. 6, 249-252 (Landone).

65-270. San Martín Núñez, Abelardo — "Variantes y equivalentes funcionales de al final: los reformuladores de recapitulación en el habla santiaguina”. - RLA, 53 (2015), núm. 2, 97-119.

65-271. Silva, Silmara Dela \& Karoline Da Cunha Teixeira - " "Abrindo a felicidade»: Sobre sujeitos e sentidos em propagandas multinacionais". - SESS, 2014, núm. 25, 159-179. [Se incluye español].

65-272. Solsona Martínez, Carmen "Valores metatextuales de cioè en el marco de la gramática contrastiva italiano / español: de la reformulación a la conexión deductiva". - PHisp, 28 (2014), núms. 3/4, 245-278.

65-273. Triano López, Patricia y Manuel Triano López - "Análisis del trata- 
miento por parte de la prensa española de las noticias sobre mujeres asesinadas por sus (ex) parejas sentimentales". e-AESLA, 2 (2016), 169-178.

65-274. Von Stecher, Pablo — “¿Cómo curar en argentino? Representaciones de la lengua en tres momentos del discurso médico nacional (1870, 1900, 1930)". — SEFS, 2015, núm. 28, 237-257.

65-275. Westall, Debra - "El País coverage of childhood obesity in 2013”. - e-AESLA, 2 (2016), 179-187.

V. también núms. 321, 344, 387.

\section{VARIACIÓN LINGÜÍSTICA}

\section{CONTEXTO LATINO Y ROMÁNICO}

65-276. Acedo Matellán, Víctor "Preverbs llatins: aspectes morfosintàctics i semàntics”. - Cuestiones de morfología léxica, eds. C. Buenafuentes, G. Clavería e I. Pujol (MadridFrankfurt/M., 2016), pp. 63-99.

65-277. Campos Vargas, Henry — "Del latín vulgar al latín clásico”. - RFLUCR, 2014, núm. 40, 119-125.

65-278. Cenname, Anne - "El romance andalusí y los trasvases demográficos y culturales en la Iberia medieval". Normas, 6 (2016), 3-11.

65-279. Conca, Maria \& Josep Guia "Europeismes fràsics en el Llibre de paraules e dits de savis e filòsofs. Estudi diacrònic i contrastiu". $-A F B, 5$ (2015), 53-65.

65-280. Cruschina, Silvio, Martin MaiDen \& John Charles Smith (eds.) - The boundaries of pure morphology: Diachronic and synchronic perspectives. - Oxford University Press, Oxford, 2013. xiii + 319 pp. \| JL, 51 (2015), 245-249 (Namer).

65-281. Fuenzalida, Mauricio - "Enfocando el castellano $\operatorname{mar}(h)$ ojo, asturiano marfueyu, gallego y portugués mar(a)follo a través del cat. marfull, ¿continuadores del lat. millefolium”. - Verba, 42 (2015), 167-237.

65-282. Gallego, Ángel J. — "A phasetheoretic approach to cliticization in Romance”. - SHLL, 9 (2016), 67-94.
65-283. García SÁnchez, Jairo Javier — "Brasas: carbones (CGL III, 598, 7). $\mathrm{El}$ discutido origen del fr. braise, it. brace y esp. brasa". — RLiR, 79 (2015), 461-473.

65-284. JePpesen Kragh, K. \& J. LindsCHOUW (eds.) - Deixis and pronouns in Romance languages (N. 64-260). \| RILI, 2015, núm. 25, 229-232 (Rosemeyer).

65-285. Jiménez, Jesús y María Rosa LLORET - "Efectos graduales de la sonorización en las lenguas romances". — RFilR, 31 (2014), 55-82.

65-286. Prieto Entrialgo, Clara EleNA - Los relativos en el asturiano medieval. - Peter Lang, Bern, 2015. (Fondo Hispánico de Lingüística y Filología, 20). || RILI, 2016, núm. 26, 229-231 (Matute Martínez).

65-287. RaAB, Matthias — "Latinismos neológicos en el siglo xv: una propuesta metodológica a partir de la lingüística de corpus". - Scriptum, 4 (2015), 187-207.

65-288. Recasens, D. - Coarticulation and sound change in Romance (N. 64-1936). || RLiR, 79 (2015), 527-533 (Sampson).

65-289. SANGorrín GuAllar, FrancisCO - "Algunos problemas en torno a la versión aragonesa del Libro de Marco Polo (siglo XIV)". — AFA, 70 (2014), 59-85.

65-290. Tomasin, Lorenzo - "Su un' equivoca «legge» dell'italiano antico e sul concetto di «legge» nella linguistica storica romanza". - $R L i R, 80$ (2016), 45-71.

65-291. Vito Luigio, Castrignanò "A proposito di un'epigrafe salentina in volgare (Nardò, entro il 1456)”. RLiR, 80 (2016), 195-207.

\section{LINGÜÍSTICA HISTÓRICA}

65-292. Arias Álvarez, Beatriz, María Guadalupe Jú́rez Cabañas y JuAN Nadal Palazón - Mosaico de estudios coloniales (I Coloquio Internacional de Lenguas y Culturas Coloniales, 2008). UNAM, México, 2013. 532 pp. \| ALM, 3 (2015), núm. 2, 367-371 (Mendoza Posadas). 
65-293. BARrio de la Rosa, Florencio DEL - "Factores externos y cambio lingüístico: la pérdida de la distinción genérica en los posesivos del español antiguo". - RHLE, 9 (2014), 3-26.

65-294. Bartol Hernández, J.A., A. ÁlvaREz Tejedor y J.R. Morala (eds.) Los cartularios de Valpuesta. Estudios (N. 64-271). || Verba, 42 (2015), 429-433 (Carrete Montaña); RHLE, 9 (2014), 189-195 (Rodríguez Toro).

65-295. BeAuclair, Nicolas — "La Relación de Santa Cruz Pachacuti Yamqui: un reflejo de la ética andina”. LexisL, 40 (2016), 143-166.

65-296. Bertolotti, Virginia - A mí de vos no me trata ni usted ni nadie. Sistemas e historia de las formas de tratamiento en la lengua española en América. UNAM, México, 2015. 484 pp. || ALM, 3 (2015), núm. 2, 373-386 (Cepeda Ruiz); LinALFAL, 32 (2016), núm. 1, 125-135 (González Zunini).

65-297. Blas Arroyo, José Luis y JuAN González Martínez — “ "¿Qué tengo que / de hazer?»: variación y cambio lingüístico en el seno de las perífrasis de infinitivo a partir de textos escritos de impronta oral en el español clásico". - SHLL, 7 (2014), 241-274.

65-298. Blas Arroyo, José Luis y Margarita Porcar Miralles - "Patrones de variación y cambio en la sintaxis del Siglo de Oro: un estudio variacionista de dos perífrasis modales en textos de inmediatez comunicativa”. - RILCE, 32 (2016), 47-81.

65-299. Calderón Campos, Miguel - El español del reino de Granada en sus documentos (1492-1833). Oralidad y escritura. - Peter Lang, Bern, 2015. 273 pp. (Fondo Hispánico de Lingüística y Filología, 22). || RILI, 2015, núm. 26, 205207 (Sánchez González de Herrero).

65-300. Campos Souto, Mar — “-Fobia y -fobo, $a$ en el siglo xIx: entre la morfología léxica diacrónica y la historia de la lengua”. - CLex, 2014, núm. 104, 45-68.

65-301. Carabias Orgaz, Miguel "¿Por qué unos fueros escritos en lengua romance? La redacción primigenia de los Fueros de Aragón”. AFA, 70 (2014), 15-34.
65-302. Carrasco Cantos, Inés (ed.) - Aportaciones al estudio del español del siglo XVIII. Granada. - Comares, Granada, 2016. 344 pp. || RILI, 2016, núm. 27, 221-222 (Romero Manzanares).

65-303. Castillo Lluch, Mónica y Elena Diez del Corral Areta - "El fondo Balbueno de la Universidad Lausana”. - Scriptum, 4 (2015), 109123.

65-304. Castro Ferrer, María Inés - "Puerto Rico. Breve panorama histórico-lingüístico de un pueblo hispanohablante”. - CuH, 2016, núm. 789, 64-73.

65-305. Cllavería, Gloria, Cecilio Garriga, Carolina Julià, FranCESC RoDríguez y JoAn TORRUella (eds.) - Historia, lengua y ciencia: una red de relaciones. - Peter Lang, Frankfurt/M., 2013. || RILI, 2014, núm. 23, 223-229 (García Cornejo).

65-306. Company Company, ConcepCIóN — "Estandarización cultural y marginalidad lingüística. El siglo XvII: una gran paradoja en la historia de la lengua española”. — Hispanismos del mundo, coord. F. Funes (Buenos Aires, 2016), pp. 131-158.

65-307. Company Company, C. (dir.) Sintaxis histórica de la lengua española. Tercera parte: Preposiciones, adverbios y conjunciones. Relaciones interoracionales (N. 63-1631). || CLECM, 3 (2016), núm. 2, 131-210 (Ramírez Luengo).

65-308. Díaz Moreno, Rocío y Belén Almeida Cabrejas (eds.) - Estudios sobre la historia de los usos gráficos en español. - Axac, Lugo, 2014. 210 pp. || RILI, 2015, núm. 26, 208-209 (Pedrote Romero); RHLE, 9 (2014), 200-205 (Torres Martínez).

65-309. Diez del Corral Areta, Elena - Los conectores consecutivos en documentos coloniales de la Audiencia de Quito (1563-1822). — Iberoamericana-Vervuert, Madrid-Frankfurt/M., 2015. (Textos y Documentos Españoles y Americanos, 8). || RILI, 2015, núm. 26, 210216 (Narbona).

65-310. Dworkin, S.N. - A history of the Spanish lexicon: A linguistic perspective (N. 60-293). || RILI, 2014, núm. 24, 
188-191 (Álvarez de Miranda). - V. 64-1548.

65-311. Eberenz, Rolf — "El vocabulario castellano de la culinaria medieval y renacentista. Las fuentes tratadísticas y sus rasgos léxicos". — RLiR, 79 (2015), 495-523.

65-312. ECHENIQUe Elizondo, M.T. y F.J. Satorre Grau (eds.) - Historia de la pronunciación de la lengua castellana (N. 63-227). || RFE, 95 (2015), 368-372 (Rodríguez Molina).

65-313. Fernández JaÉn, Jorge "Aspectos cognitivos y construcciones de la evolución semántica del verbo tocar". — AFB, 4 (2014), 93-118.

65-314. Fernández JaÉn, Jorge — "El olfato como fuente de conocimiento: origen histórico de los usos evidenciales del verbo oler". — Onomázein, 2016, núm. 33, 16-33.

65-315. Gago Jover, Francisco - "La Biblioteca Digital de Textos del Español Antiguo (BiDTEA)". — Scriptum, 4 (2015), 5-36.

65-316. Garachana Camarero, Mar "Restricciones léxicas en la gramaticalización de las perífrasis verbales". - RILCE, 32 (2016), 134-158.

65-317. Garcés Gómez, María Pilar - Diacronía de los marcadores y representación en un diccionario histórico. Universidade, A Coruña, 2014. 226 pp. (Anexos de Revista de Lexicografía, 28). || RLex, 20 (2014), 199-203 (Gutiérrez Cuadrado).

65-318. Garcés Gómez, María Pilar "Gramaticalización y tradiciones discursivas. El proceso de creación de los marcadores de confirmación". - RRo, 49 (2014), 264-292.

65-319. Garcés Gómez, M.P. (ed.) - Los adverbios con función discursiva: procesos de formación y evolución (N. 63-1644). || RILI, 2014, núm. 23, 215-217 (Garachana Camarero); Oralia, 18 (2015), 335342 (Montañez Mesas). - V. 64-1662.

65-320. García Godoy, M.T. (ed.) - El español del siglo XVIII. Cambios diacrónicos en el primer español moderno (N. 61-347). || RLiR, 79 (2015), 548-557 (Rodríguez Molina).

65-321. GARrido Martín, BlancA — "La historia de vale decir como un marca- dor discursivo de reformulación”. CEHM, 38 (2015), 187-206.

65-322. Gille, Johan — "On the development of the Chilean Spanish discourse marker cachái”. — RRo, 50 (2015), 3-29.

65-323. Girón Alconchel, J.L. y D.M. SÁez Rivera (eds.) - Procesos de gramaticalización en la historia del español (N. 63-1649). || RILI, 2014, núm. 24, 199-201 (Barrio de la Rosa); RHLE, 9 (2014), 205-211 (Garachana Camarero).

65-324. Gómez Seibane, SARa - Los pronombres átonos (le, la, lo) en español: aproximación histórica. - Arco/Libros, Madrid, 2013. || RILI, 2014, núm. 24, 202-204 (Pericchi Pagá).

65-325. González Ollé, F. - Continuidad histórica ininterrumpida de la forma "-ra” indicativo. Tradiciones discursivas y sintaxis (N. 61-97). || RILI, 2014, núm. 23, 207-209 (Rodríguez Molina). V. 62-167.

65-326. González Ollé, Fernando "Los verbos con radical terminado por $/ \theta(\mathrm{k}) /$, no etimológico, en algunas formas de sus presentes. Examen histórico". - RHLE, 9 (2014), 27-58.

65-327. Gutiérrez, CÉsAr — "Las variantes de vimey el proceso de castellanización en el dominio leonés". - RHLE, 9 (2014), 59-78.

65-328. Hernández Díaz, Axel — "Funciones discursivas de las oraciones existenciales en español". — $A F B, 4$ (2014), 119-138.

65-329. JiménEz Ríos, ENRIQUE - "La historia de desapercibido por inadvertido". - ALM, 3 (2015), núm. 2, 199-235.

65-330. Julián Mariscal, Olga "Excepto que: una locución a caballo entre la excepción y la condición”. RHLE, 9 (2014), 79-97.

65-331. Kawasaki, Yoshifumi — "Datación crono-geográfica de documentos medievales españoles". — Scriptum, 3 (2014), 29-63.

65-332. Kordic RiQuelme, Raïssa y TAnia Avilés Vergara — «نVariante lingüística o error de copista?". Hipogrifo, 4 (2016), núm. 1, 199-215. 65-333. LARA, L.F. - Historia mínima de la lengua española (N. 62-1324). || Uni- 
verSOS, 2014, núm. 11, 214-217 (Calvo Pérez). - V. 64-1948.

65-334. LÜDTKe, Jens - "Nuevos saberes y tradiciones discursivas: el saber elocucional en la historia del español de Canarias y América”. - RHLE, 9 (2014), 99-125.

65-335. Moral del Hoyo, María del CARMEN - "Hacia una dialectología gramatical del castellano medieval: cuestiones morfológicas del imperfecto y futuro de subjuntivo". - Scriptum, 4 (2015), 143-164.

65-336. Morala, José Ramón — "Datos para la historia del neutro de materia en castellano". - RFE, 95 (2015), 307-337.

65-337. MORALa Rodríguez, José RamóN - "El CorLexIn, un corpus para el estudio del léxico histórico y dialectal del Siglo de Oro". - Scriptum, 3 (2014), 5-28.

65-338. Moret Oliver, María Teresa y Guillermo Tomás Faci - El pleito del guiaje ganadero de Ribagorza (13161319). Ed. y est. histórico-lingüístico. - Institución "Fernando el Católico", Zaragoza, 2013. 171 pp. (Fuentes Históricas Aragonesas, 70). \| AFA, 70 (2014), 289-292 (Albesa Pedrola).

65-339. Navarro Gala, R. - El libro de protocolo del primer notario indigena (Cuzco, siglo XVI). Cuestiones filológicas, discursivas y de contacto de lenguas $(\mathrm{N}$. 64-1887). || RILI, 2016, núm. 27, 223224 (Rodríguez Manzano).

65-340. Navarro Gala, Rosario - "Los notarios Pedro Quispe y Pedro de la Carrera: variación lingüística en el Cuzco del siglo xvi". - LexisL, 40 (2016), 41-72.

65-341. Nieuwenhuijsen, Dorien "Variación sintáctica en las construcciones pasivas con ser. Las preposiciones introductoras del agente". - RFE, 95 (2015), 97-125.

65-342. Pérez Toral, Marta - "Huellas de lo oral en documentos notariales turolenses del Siglo de Oro". - AFA, 70 (2014), 145-168.

65-343. Pons Rodríguez, Lola - "Palabras para un ideal lingüístico: los nombres de la lengua elaborada en la historia del español". — RFE, 95 (2015), 153-181.
65-344. Pons Rodríguez, Lola, Eva Bravo García, Blanca Garrido Martín y Állvaro Octavio de Toledo y Huerta - "La edición de textos de quejas: propuestas preliminares en torno a un corpus histórico discursivo". - Scriptum, 3 (2014), 183-200.

65-345. Porcar Miralles, Margarita - "Un recurso de oralidad en la prédica: el uso de la interjección en sermonarios del siglo xviı". — Oralia, 18 (2015), 235-257.

65-346. Pujol Payet, Isabel — "Abocar, embocar, desbocar: polisemia regular en los verbos parasintéticos". — RHLE, 9 (2014), 127-150.

65-347. Ramos, Miguel - "Continuity and change: First person singular subject pronoun expression in earlier Spanish". - SpC, 13 (2016), 103-127.

65-348. Recasens, DANIEL - "Interpretación de algunos cambios fonéticos en las lenguas romances". - RFilR, 31 (2014), 135-150.

65-349. Rey Quesada, Santiago del "Corpus de traducción para la historia de la lengua: una cala en la prosa dialógica erasmiana". - Scriptum, 4 (2015), 37-107.

65-350. Rifón, Antonio - "Evolución del significado morfológico de los prefijos supra- e infra-". - EFil, 2014, núm. 53, 85-107.

65-351. Rodríguez, Mercet, Leyre Martín Aizpuru y RaQuel SÁnchez Rомо - Textos para la historia del espanol IX. Documentos medievales de Miranda de Ebro. - Universidad, Alcalá de Henares, 2015. 358 pp. || RILI, 2015, núm. 25, 237-238 (Morala); RHLE, 9 (2014), 223-230 (Rodríguez Molina). 65-352. San Segundo Cachero, RosaBEL - "El origen exaptativo de los clíticos pronominales". - Verba, 42 (2015), 59-98.

65-353. Sánchez GonzÁlez de HerreRo, M. Nieves (dir.) - Documentos medievales de Miranda de Ebro (Archivos Municipal de Miranda de Ebro e Histórico Provincial de Burgos). 2 ts. - Luso-Española Ediciones, Salamanca, 2014. || RILI, 2015, núm. 25, 235-237 (Morala). 65-354. SÁnCHEZ JiménEz, S.U. - Entre lo uno y lo indefinido. Aproximación dia- 
crónica a las estructuras de indeterminación del tipo "no sé qué" en español (N. 64-1956). || RFE, 95 (2015), 215-218 (Espinosa Elorza).

65-355. Simonatti, Selena — "La Peña Camasía (y sus diablos): ¿un lugar recuperado?". — RFE, 95 (2015), 339358. [Sobre el sintagma Peña Camasía y sus variaciones en textos del Siglo de Oro].

65-356. UEdA, Hiroto - "Lexical variation in Medieval Spanish: Applying quantitative methods to Spanish biblical texts". - Scriptum, 3 (2014), 133-151.

65-357. VAlle, J. DEL (ed.) - A political history of Spanish: The making of a language (N. 63-260). || SE์S, 2015, núm. 27, 277-291 (Lauria).

65-358. WEHr, Barbara \& Frédéric NicoLOSI (eds.) - Pragmatique historique et syntaxe / Historische Pragmatik und Syntax. - Peter Lang, Frankfurt/M., 2012. xxvi + 323 pp. || RLiR, 80 (2016), 229233 (Lebsanft). [Se incluye español].

65-359. Zielinski, Andrzej - "Sobre el proceso de lexicalización de las fórmulas honoríficas con el sufijo -is(s)imo en español". — AFB, 5 (2015), 1-18.

V. también núms. 462, 750, 758, 800, 855, 1337.

\section{GEOLINGÜÍSTICA}

65-360. Álvarez Pérez, Xosé Afonso — "Distribución geográfica de los refranes: notas para el análisis geoparemiológico". - AFB, 5 (2015), 25-52.

65-361. Aponte Alequín, Héctor y Luis

A. Ortiz López - "Variación dialectal e interfaz sintáctica / semántica / pragmática: la anteposición de sujetos en cláusulas subordinadas en infinitivo". — SpC, 12 (2015), 396-418.

65-362. Gomila Albal, Marina "Sobre el origen y la difusión geográfica de las formas nosotros y vosotros en castellano". - I, 83 (2016), 103-125.

65-363. Méndez Vallejo, Dunia CataliNA - "Ser focalizador: variación dialectal y aceptabilidad de uso". — RILI, 2015, núm. 26, 61-79.

V. también núms. 365, 395.

\section{SOCIOLINGÜÍSTICA}

65-364. Avilés, Tania - "Poro: una variante del español vulgar de Chile en cartas de comienzos del siglo xx". - I, 82 (2015), 218-239.

65-365. Azpiazu Torres, Susana — "La variación antepresente / pretérito en dos áreas del español peninsular”. Verba, 42 (2015), 269-292.

65-366. Barriga Villanueva, R. y P. Martín Butragueño (dirs.) - Historia sociolingüística de México. T. 3: Espacio, contacto y discurso político (N. 63-1693). || RILI, 2014, núm. 24, 185187 (Puente). - V. 64-298.

65-367. Bugel, Talia - "Actitudes ante el español, el portugués y el guaraní en Argentina, Brasil y Uruguay". SESS, 2015, núm. 28, 3-7.

65-368. Bugel, TAlia — "Actitudes ante los ingleses a través de su uso del español: caracterizaciones en el semanario El Aguacero, Montevideo, Uruguay, 1823”. - SEVS, 2015, núm. 28, 9-36.

65-369. Canale, Germán y MagdaleNA COLL - "Actitudes hacia variedades del español del Uruguay en los medios: análisis de la producción de dos spots publicitarios políticos". SEFS, 2015, núm. 28, 37-63.

65-370. Canale, Germán y MagdaleNA COLL - "Historia y presente del yeísmo (rehilado) en el Uruguay". LexisL, 40 (2016), 5-40.

65-371. Caravedo, R. - Percepción y variación lingüistica. Enfoque sociocognitivo (N. 64-1977). || Onomázein, 2016, núm. 33, 34-38 (Bleorțu).

65-372. Cerrón Palomino, Álvaro "Resumption or contrast?: Non-standard subject pronouns in Spanish relative clauses". - $S p C, 12$ (2015), 349-372.

65-373. Clanes, Jeroen — "La pluralización de haber presentacional y su distribución social en el español de La Habana, Cuba. Un acercamiento desde la gramática de construcciones". RILI, 2014, núm. 23, 165-188.

65-374. Clates, Jeroen - "Sociolingüística comparada y gramática de construcciones: un acercamiento a la pluralización de haber presentacional 
en las capitales antillanas". - REsLA, 27 (2014), 338-364.

65-375. Corral Pérez, Isabel — "Lenguas indígenas, identidad y marco legal en Hispanoamérica: una aproximación ecolingüística”. - $e$-AESLA, 2 (2016), 188-200.

65-376. DíAz Campos, Manuel - Introducción a la sociolingüistica hispánica. - Wiley-Blackwell, Chichester, 2014. 322 pp. || JSLT, 2 (2015), 90-92 (Massaguer Comes).

65-377. Du Bois, Inke \& Nikole BaumGARTEN (eds.) - Multilingual identities: New global perspectives. - Peter Lang, Frankfurt/M., 2013. 179 pp. ॥ LMi, 7 (2015), núm. 1, 127-131 (Fernández Merino).

65-378. EnRIQUE-Arias, ANdrés, MANUEL Gutiérrez, Alazne Landa \& FranCisco OCAMPo (eds.) - Perspectives in the study of Spanish language variation: Papers in honor of Carmen Silva-Corvalán. - Universidade, Santiago de Compostela, 2014. || SpC, 13 (2016), 159-162 (Fafulas; Díaz Campos).

65-379. Fernández García, F., C. Conti García, E. Felíu Arquiola y M. Torres Martínez (eds.) - Lenguas e inmigración en la ciudad de Jaén (N. 63-367). || RILI, 2014, núm. 24, 192198 (Sáez Rivera). - V. 64-306.

65-380. Fernández Juncal, C. - Léxico disponible de Cantabria. Estudio sociolingüistico (N. 63-270). || RILI, 2015, núm. 26, 217-219 (González Pérez). - V. 63-1575.

65-381. Fernández Vitores, David y Aldo J. García - "El español en las relaciones internacionales". - RILI, 2014, núm. 24, 121-134.

65-382. File-Muriel, R. \& R. Orozco (eds.) - Colombian varieties of Spanish (N. 63-272). || RRo, 49 (2014), 164-166 (Fernández).

65-383. Gallucci, María José y Kerlys VARGAS - "El estilo directo e indirecto en el Corpus sociolingüístico de Caracas 1987". - ALM, 3 (2015), núm. 2, 65-103.

65-384. García Abelleira, Naír — "El uso del estándar en relación con la construcción identitaria. Estudio de caso: cuatro grupos de conversación virtual”. - e-AESLA, 2 (2016), 201210.

65-385. García Padrón, Dolores "Procedimientos lingüísticos y sociopragmáticos en la formación de seudogentilicios: machupichu- machupin, na-machupino, na y guachupin, na-guachupino, na". - I, 82 (2015), 240-256.

65-386. Gascón Martín, Eugenio Español coloquial: rasgos, formas y fraseología de la lengua diaria. — Edinumen, Madrid, 2014. ||EAc, 2014, núm. 102, 138-140 (Fragapane).

65-387. Guerrero GonzÁlez, Silvana "Una propuesta de clasificación de los estilos discursivos en narraciones de experiencia personal desde el punto de vista sociolingüístico". — Oralia, 18 (2015), 103-129.

65-388. Hélot, Christine, Monica Barni, Rudi Janssen \& Carla BaGNA (eds.) - Linguistic landscape, multilingualism and social change. - Peter Lang, Frankfurt/M., 2012. || CAISPI, 2015, núm. 6, 240-243 (Mariottini); JMMD, 36 (2015), 214-215 (Ong).

65-389. Herling, SAndra \& Carolin Patzelt (eds.) - Weltsprache Spanisch. Variation, Soziolinguistik und geographische Verbreitung des Spanischen. Handbuch für das Studium der Hispanistik. - Ibidem, Stuttgart, 2013. (Romanische Sprachen und ihre Didaktik, 45). II RILI, 2014, núm. 24, 205-206 (Obrist). 65-390. Hernández, E. y P. Martín Butragueño (eds.) - Variación y diversidad lingüistica. Hacia una teoría convergente (N. 64-2001). || Borealis, 5 (2016), 171-177 (Ivanova).

65-391. Hoff, Mark y Manuel Díaz CAMPOS - "Conciencia y actitudes: el caso de la $a$ acusativa en el español argentino". - SESS, 2015, núm. 28, 89-110.

65-392. Hudgens Henderson, Mary "Prescriptive language attitudes in a dual language elementary school". - PLSA, 1 (2016), 1-15. [Se incluye español].

65-393. Jiménez, JuAn CARlos y ArÁnZAZU NARBONA - "Comercio y distancia lingüística: el español en la internacionalización empresarial". - RILI, 2014, núm. 24, 61-85. 
65-394. Jiménez Morales, Belén - "El tabú en el habla de Granada: análisis sociolingüístico". — Normas, 6 (2016), 29-52.

65-395. Kapovic, Marko - "Reassessing in the influence of word position on the variation of Spanish syllable-final $s$ : Data from Ciudad Real”. - $S p C, 12$ (2015), 419-441.

65-396. LANG-RigAL, JENNIFER — "La percepción del habla de Córdoba, Argentina: una prueba que combina las actitudes con la identificación de dialectos". - SEFS, 2015, núm. 28, 111-138.

65-397. Lewis, Greg \& Amanda BooMERSHINE - "The realization of word-final, preconsonantal /s/ in the Spanish of Mexico City". - SHLL, 8 (2015), 157-182.

65-398. Mancera Rueda, Ana y Ana Pano Alamán - El español coloquial en las redes sociales. - Arco/Libros, Madrid, 2013. 95 pp. || EAc, 2014, núm. 102, 133-137 (Agreda).

65-399. Manso Flores, Ana Alicia "La vitalidad de la fala a partir de un sondeo sociolingüístico en Valverde del Fresno". - e-AESLA, 2 (2016), 211-223.

65-400. Martín Butragueño, Pedro y LeOnor Orozco - Argumentos cuantitativos y cualitativos en sociolingüistica. Segundo coloquio de cambio y variación lingüistica. - El Colegio de México, México, 2014. 802 pp. || ELAp, 2016, núm. 63, 207-213 (Zacarías Ponce de León).

65-401. Martínez, Rocío Anabel y Mariana Morón Usandivaras "El orden del adjetivo en la Lengua de Señas Argentina. Un estudio preliminar". — RLA, 54 (2016), núm. 1, 79-99.

65-402. Mazzaro, Natalia - "Explaining variation and change in Spanish peripheral fricatives". - SHLL, 7 (2014), 299-325.

65-403. MacGregor Mendoza, Patricia - "La palabra enseña, pero el ejemplo arrastra: Profesionista immigrants' views of Spanish and English". _ $S p C$, 12 (2015), 327-348.

65-404. Moreno Fernández, Francisco - "Fundamentos de demografía lingüística. A propósito de la lengua española”. — RILI, 2014, núm. 24, 19-38.

65-405. Morin, ReginA - "Linguistic integration of computer and internet related anglicisms in Spanish language web pages". — SHLL, 7 (2014), 327-367.

65-406. NARbona JimÉnez, A. (coord.) Conciencia y valoración del habla andaluza (N. 61-1456). || RILI, 2014, núm. 23, 237-239 (González Gómez). — V. 64-2007.

65-407. Narvaja de Arnoux, E. y S. Nothstein (eds.) - Temas de glotopolítica: integración regional sudamericana y panhispanismo (N. 63-338). || SESS, 2015, núm. 27, 297-302 (Sartori).

65-408. Orozco, RAFAEL — "Subject pronoun expression in Mexican Spanish: ¿Qué pasa en Xalapa?”. — PLSA, 1 (2016), 1-15.

65-409. Perna, Carlos Gabriel Variedades lingüísticas en la Pampa (Argentina, 1860-1880). - Iberoamericana-Vervuert, Madrid-Frankfurt/M., 2015. 349 pp. || RILI, 2016, núm. 26, 225-228 (Castilla).

65-410. Pöll, Bernhard — "Caribbean Spanish $=$ Brazilian Portuguese? Some comparative thoughts on the loss of pro-drop". - SHLL, 8 (2015), 317-354.

65-411. Pons Rodríguez, L. - El paisaje lingüistico de Sevilla. Lenguas y variedades en el escenario urbano hispalense (N. 62-1340). || RILI, 2014, núm. 23, 239-241 (Franco Rodríguez). - V. 64-2011.

65-412. Quintanilla, José y JuAn RodRíGUEZ - "El voseo en la publicidad de Costa Rica: un análisis de las actitudes de los hablantes". — RILI, 2014, núm. 23, 109-122.

65-413. Rodríguez Barcia, Susana y Fernando Ramallo - "Graffitiy conflicto lingüístico: el paisaje urbano como espacio ideológico". — RILI, 2015, núm. 25, 131-153.

65-414. Rogers, Brandon M.A. — "The influence of linguistic and social variables in the spirantization of intervocalic /b,d,g/ in Concepción, Chile”. — SHLL, 9 (2016), 207-237. 
65-415. RoJAs, DARío - "Unidad y diversidad del español: actitudes de hablantes de Santiago (Chile)". - RILI, 2014, núm. 23, 9-24.

65-416. Rojas Berscia, Luis Miguel "Lóxoro, traces of a contemporary Peruvian genderlect”. — Borealis, 5 (2016), 157-170.

65-417. Romera, Magdalena - "Métodos de investigación en variación morfosintáctica: el uso de la observación no participante". — RILI, 2015, núm. 25, 199-218.

65-418. Rost, Assumpció - "Una panorámica del yeísmo: ¿un proceso acabado o en construcción?”. - RILI, 2014, núm. 23, 141-164.

65-419. Ruiz GonzÁlez, NAtAlia — "Sistema de tratamiento en el español de Canarias. Estudio sociolingüístico en una comunidad semiurbana”. - Normas, 6 (2016), 53-67.

65-420. Sánchez, Mercedes y María Gabriela Pauer González — “El español y las tecnologías de la comunicación: el español en la red". — RILI, 2014, núm. 24, 135-153.

65-421. Sancho Pascual, María - Integración sociolingüistica de los inmigrantes ecuatorianos en Madrid. - Universidad, Alcalá de Henares, 2014. 363 pp. || RILI, 2014, núm. 24, 208-211 (Torres Martínez).

65-422. Schwenter, Scott A. \& Rena Torres Cacoullos - "Competing constraints on the variable placement of direct object clitics in Mexico City Spanish". - REsLA, 27 (2014), 514536.

65-423. Scrivner, Olga \& Manuel Díaz CAMPOS — "Language variation suite: A theoretical and methodological contribution for linguistic data analysis". — PLSA, 1 (2016), 1-15. [Se incluye español].

65-424. Sobrino Triana, Roxana "Actitudes lingüísticas del hablante cubano hacia el español de las Antillas". — SESS, 2016, núm. 29, 157-182.

65-425. Stockler, Sarah — "Mexican immigrants' views on the Spanish dialects in Mexico: A language attitudes study". — LMi, 7 (2015), núm. 2, 49-73.
65-426. VALDEZ, JUAN R. — "Lenguas confrontadas: la representación ideológica del lenguaje en Hispaniola”. — RILI, 2014, núm. 23, 189-206.

65-427. Vila Rubio, N. (ed.) - De "parces y troncos". Nuevos enfoques sobre los argots hispánicos (N. 62-8). || RILI, 2014 , núm. 24, 211-213 (García Platero); NRFH, 64 (2016), 548-552 (Palacios).

65-428. VILAR SÁNCHEz, KARIN — “Ir y volver. $Y$ volver a $i r$. La lengua como clave de éxito en la (r)emigración". — $L M i$, 7 (2015), núm. 1, 7-27.

65-429. Zimmermann, Kiaus (ed.) - Prácticas y políticas lingüisticas. Nuevas variedades, normas, actitudes y perspectivas. - Iberoamericana-Vervuert, MadridFrankfurt/M., 2014. 448 pp. (Nuevos Hispanismos, 18). || RILI, 2015, núm. 25, 246-249 (Méndez G. de Paredes).

V. también núms. 34, 35, 139, 194, $511,583$.

\section{ESPAÑOL EN CONTACTO}

65-430. Alonso, José Antonio, Jorge Durand y Rodolfo GutiérRez "Persistencia del español en los colectivos hispanos de los Estados Unidos”. - RILI, 2014, núm. 24, 39-58.

65-431. Andreani, Héctor - "Clase, masculinidad y lenguas en el trabajo migrante santiagueño". - SESS, 2016, núm. 29, 103-129.

65-432. ARnAU, JOAQUIM - Reviving Catalan at school: Challenges and instructional approaches. - Multilingual Matters, Bristol, 2013. xvi + 197 pp. || JMMD, 36 (2015), 770-772 (Leone).

65-433. Balam, OSmer — "Code-switching and linguistic evolution: The case of «hacer $+\mathrm{V}$ » in Orange Walk, Northern Belize". — LMi, 7 (2015), núm. 1, 83-109.

65-434. BARnes, Sonia — "Perceptual salience and social categorization of contact features in Asturian Spanish". - SHLL, 8 (2015), 213-241.

65-435. BARnEs, SONIA - "Variable final back vowels in urban Asturian Spanish". - SpC, 13 (2016), 1-28.

65-436. BeAudrie, S.M. \& M. FAirCLOUGH - Spanish as a heritage lan- 
guage in the United States: The state of the field (N. 63-362). IIJMMD, 35 (2014), 618-620 (Garcia). - V. 63-1704.

65-437. Blestel, Élodie - "Contacto lingüístico y transcategorización: el uso adverbial de habia sido en castellano paraguayo". - RILI, 2015, núm. 26, 171-186.

65-438. Bonne Bravo, Arcilio y Mercedes Causse Cathcart — “"Es que nuestro idioma es mejor que el vuestro»: contacto lingüístico españolfrancés en el siglo xix en Santiago de Cuba a través de las páginas de $E l$ Redactor". — AFB, 4 (2014), 1-14.

65-439. Brown, Esther L. \& Mark Amengual — "Fine-grained and probabilistic cross-linguistic influence in the pronunciation of cognates: Evidence from corpus-based spontaneous conversation and experimentally elicited data”. - SHLL, 8 (2015), 59-83.

65-440. Bruyèl Olmedo, Antonio \& Maria JuAn-Garau - "Minority languages in the linguistic landscapes of tourism: The case of Catalan in Mallorca”. - JMMD, 36 (2015), 598619.

65-441. Camus Bergareche, Bruno y Sara Gómez Seibane (eds.) - El castellano del País Vasco. - Universidad del País Vasco, Bilbao, 2012. 288 pp. (Anejos del Anuario de Filología Vasca "Julio de Urquijo", 70). || RFE, 95 (2015), 359-363 (Hualde).

65-442. Camus Bergareche, Bruno y Sara Gómez Seibane — "La diversidad del español en Álava: sistemas pronominales a partir de las encuestas COSER". — RFE, 95 (2015), 279-306.

65-443. Canuto Castillo, Felipe "Otomíes en la ciudad de México. La pérdida de un idioma en tres generaciones". - LMi, 7 (2015), núm. 1, 53-81.

65-444. Casanova, Emili y Pep Aparicio AguAdas - Camins, terres $i$ paraules. II Jornades sobre els altres parlars valencians de base castellano-aragonesa (Énguera, 2013). — Denes Ediciones, València, 2014. 556 pp. || AFA, 70 (2014), 308312 (Albesa Pedrola).

65-445. Censabella, Marisa — "Codi- ficación del nombre colectivo en el español hablado por tobas: un análisis exploratorio desde la teoría de gramaticalización inducida por contacto". RILI, 2015, núm. 25, 155-181.

65-446. Cruz EnríQuez, Maura "Migrantes cubanos en Montreal: una adaptación vista desde el habla". LMi, 7 (2015), núm. 2, 29-48.

65-447. Dulfano, Isabel \& Fernando Rubio - "Reset or forge ahead? Is there a future and «value» in the study of Spanish? Historical trends and calculations of the merit or dollar worth of the language". - JMMD, 35 (2014), 139-150.

65-448. Enzinna, NAOMi - "Spanishinfluenced rhythm in Miami English". - PLSA, 1 (2016), 1-15.

65-449. Esteban-Guitart, Moisés, Maria Àngels Viladot \& Howard GILES — "Perceived institutional support among young indigenous and mestizo students from Chiapas (México): A group vitality approach". - JMMD, 36 (2015), 124-135.

65-450. Fuller, JANET M. - Spanish speakers in the USA. - Multilingual Matters, New York, 2013. $174+$ xiii pp. || $S p C, 12$ (2015), 442-448 (Serrano).

65-451. Gandulfo, Carolina " "Hablan poco guaraní, saben mucho»: una investigación en colaboración con niños y maestros en un contexto bilingüe de Corrientes, Argentina”. - SESS, 2016, núm. 29, 79-102.

65-452. Gandulfo, Carolina y LuCI Nussbaum — "Hablantes bi / plurilingües y prácticas educativas: perspectivas etnográficas e interaccionistas". — SESS, 2016, núm. 29, 5-10.

65-453. HipPERDINGER, YolANDA — "Ethnic revival: actitudes, políticas y usos lingüísticos de los alemanes del Volga en la Argentina”. — LMi, 7 (2015), núm. 2, 7-27.

65-454. HofFman, ZsuzsA - Ways of the world's words: Language contact in the age of globalization. - Peter Lang, Bern, 2011. 334 pp. || JMMD, 35 (2014), 289291 (Melchers). [Se incluye español]. 65-455. LAmy, Delano S. - "A variationist account of voice onset time (VOT) 
among bilingual West Indians in Panama”. - SHLL, 9 (2016), 113-141.

65-456. Lasagabaster Herrarte, David — "El español y las lenguas cooficiales en el Estado español: actitudes lingüísticas en un contexto multilingüe". RILI, 2014, núm. 23, 25-40.

65-457. Léglise, I. \& C. Chamoreau (eds.) - The interplay of variation and change in contact settings (N. 64-353). || ELAp, 2016, núm. 63, 215-219 (Torres).

65-458. Lipski, John M. — "La lengua palanquera juvenil: contacto y conflicto de estructuras gramaticales". UniverSOS, 2014, núm. 11, 191-207.

65-459. Llompart Esbert, Júlia "Enseñar lengua en la superdiversidad: de la realidad sociolingüística a las prácticas de aula". - SEFS, 2016, núm. 29, 11-32.

65-460. Llompart, MiQuel - "Subjectverb order variation with unaccusative verbs of change of location in Mexico and Southern Arizona". - SHLL, 9 (2016), 143-173.

65-461. Medina Rivera, ANTONio - "El español en Cleveland: actitudes lingüísticas y variedades en contacto". RILI, 2014, núm. 23, 61-76.

65-462. Mendoza Posadas, Mauro AlberTo - "Voces indígenas en letras españolas: algunos aspectos morfosintácticos del contacto colonial". LexisL, 40 (2016), 167-184.

65-463. Montes Alcalá, Cecilia y LindSey Sweetnich - "Español en el sureste de EE.UU.: el papel de las actitudes lingüísticas en el mantenimiento o pérdida de la lengua". - RILI, 2014, núm. 23, 77-92.

65-464. Montoya Abat, Brauli — "Del chauchau al fufifa: la llengua dels emigrants valencians i els seus descendents establits a Isla Mayor (Andalusia)". - RLiR, 80 (2016), 161-194.

65-465. Montrul, S. - El bilingüismo en el mundo hispanohablante (N. 63-379). || SpC, 13 (2016), 149-158 (Avelino); SHLL, 7 (2014), 175-182 (Prada Pérez).

65-466. Muñoz Basols, Javier \& Danica SALAZAR - "Cross-linguistic lexical influence between English and Spanish". — SpC, 13 (2016), 80-102.
65-467. Ornelas de Avelar, Juanito e Laura Álvarez López (eds.) - Dinâmicas afro-latinas: língua(s)e história(s) (link is external). - Peter Lang, Frankfurt/M., 2015. 265 pp. ॥ LinALFAL, 32 (2016), núm. 1, 141-145 (Guimaraes Savedra).

65-468. Perna, Carlos Gabriel - "El lenguaraz y la comunicación en la frontera argentina en el siglo xIx". - LexisL, 40 (2016), 99-139.

65-469. Ribeiro Berger, Isis - "Atitudes de professores brasileiros diante da presença do spanhol e do guarani em escolas na fronteira Brasil-Paraguay: elemento à gestao de línguas". - SESS, 2015, núm. 28, 169-185.

65-470. Rodríguez Medina, María Jesús - "An approach to the study of the use of English in the activities of Spanish gyms". - SpC, 13 (2016), 128-148.

65-471. Sessarego, Sandro - Chota Valley Spanish. - IberoamericanaVervuert, Madrid-Frankfurt/M., 2013. 124 pp. (Lengua y Sociedad en el Mundo Hispánico, 33). || RILI, 2015, núm. 25, 239-241 (Michnowicz).

65-472. Smith, Daniel - "Social factor comparisons of noun and verb insertion patterns in Spanish and English bilingual clauses". - Normas, 6 (2016), 69-75.

65-473. Vallejo Rubinstein, Claudia — "Prácticas plurilingües «transgresoras» en un programa extraescolar de refuerzo de la lectura". - $S \mathcal{E} S$ S, 2016, núm. 29, 33-61.

65-474. VelázQuez, Isabel, Marisol Garrido \& Mónica Millé́n - "Heritage speakers of Spanish in the US Midwest: Reported interlocutors as a measure of family language". JMMD, 36 (2015), 386-403.

65-475. Villa, Daniel J., Naomi Lapidus Shin \& Eva Robles Nagata "La nueva frontera: Spanish-speaking populations in central Washington". - SHLL, 7 (2014), 149-172.

65-476. Weber, Andrea - "Diversidade linguística em jornais fronteiriços: política de línguas e decisões editoriais". - SEVS, 2015, núm. 28, 259273. 
65-477. ZaVAla, Virginia - "Ideologías sobre el quechua desde el poder: una aproximación discursiva". - SESS, 2016, núm. 29, 207-234.

V. también núms. 33, 39, 338.

\section{ADQUISICIÓN Y PSICOLINGÜÍSTICA}

65-478. Arancibia Gutiérrez, Beatriz, Marcela Bizama Muñoz y Katia Sáez Carrillo - "Preferencias de adjunción sintáctica de cláusulas de relativo en escolares". — EFil, 2015, núm. 55, 7-22.

65-479. Arias Trejo, Natalia, Lisa M. Cantrell, Linda B. Smith \& Elda A. Alva Canto - "Early comprehension of the Spanish plural". - JChL, 41 (2014), 1356-1372.

65-480. Bail, Amelie, Giovanna MoriNi \& Rochelle S. Newman - "Look at the gato! Code-switching in speech to toddlers". - JChL, 42 (2015), 10731101.

65-481. BArriga, RebecA (ed.) - Las narrativas y su impacto en el desarrollo lingüistico infantil. - El Colegio de México, México, 2014. 786 pp. II NRFH, 64 (2016), 560-564 (Ceballos Domínguez).

65-482. BARrios, Elvira — "Spanish preservice teachers of English: Perceived use of language learning strategies and its relationship with proficiency". - REsLA, 28 (2015), 48-72.

65-483. Blanco Canales, Ana y MarTA F. Nogueroles López — "Errores fónicos de producción en español / L2: una propuesta de categorización”. - REsLA, 27 (2014), 255-274.

65-484. Bongiovanni, Silvina, Avizia Y. Long, Megan Solon \& Erik W. WILLIS - "The effect of short-term study abroad on second language Spanish phonetic development". SHLL, 8 (2015), 243-283.

65-485. Borreguero Zuloaga, MargaRITA - "Anteposiciones focales en italiano y español L2”. — CAISPI, 2014, núm. 4, 21-47.

65-486. Bustos Gisbert, José M. y José J. Gómez Asencio (eds.) - Procedimientos de conexión discursiva en espa- ñol: adquisición y aprendizaje. - Peter Lang, Bern, 2014. 347 pp. || Verba, 42 (2015), 435-441 (Enríquez Martínez).

65-487. D'Alessio, Josefina y VirgiNIA JAICHENCO - "Acerca del rol de la morfología derivativa en la lectura: investigaciones psicolingüísticas en español". — SESS, 2016, núm. 29, 235-251.

65-488. Dehaene, Stanislas - El cerebro lector: últimas noticias sobre neurociencias de la lectura, la enseñanza, el aprendizaje y la dislexia. — Siglo XXI, Buenos Aires, 2014. 448 pp. || SESS, 2015, núm. 27, 267-275 (Fumagalli).

65-489. Dewaele, JeAn-Marc \& James MaCloskey - "Attitudes towards foreign accents among adult multilingual language users". - JMMD, 36 (2015), 221-238. [Se incluye español].

65-490. Domínguez, LAura - Understanding interfaces: Second language acquisition and first language attrition of Spanish subject realization and word order variation. - John Benjamins, Amsterdam, 2013. || SHLL, 7 (2014), 397-404 (Judy).

65-491. Galeote, Miguel, Pilar Soto, Eugenia Sebastián, Elena Checa \& Concepción Sánchez Palacios - "Early grammatical development in Spanish children with Down syndrome". - JChL, 41 (2014), 111-131.

65-492. Galván Reyes, Zurisadai, Mery Mendivelso Mogollón y Yamileth Betancourt Córdoba - "La estructura narrativa en el discurso infantil: un enfoque psicolingüístico". — L inL, 2015, núm. 68, 37-56.

65-493. Geeslin, K.L. (ed.) - The handbook of Spanish second language acquisition (N. 62-237). || NRFH, 64 (2016), 564-570 (Avelino); SpC, 12 (2015), 449-457 (Ivanova).

65-494. Geeslin, Kimberly L. \& Aarnes Gudmestad — "Subject expression in Spanish: Contrasts between native and non-native speakers for first and second-person singular referents". SpC, 13 (2016), 53-79.

65-495. Gómez Soler, Inmaculada "Acquisitional patterns of Spanish anticausative $s e$. The end of the road". - REsLA, 28 (2015), 349-381. 
65-496. Gudmestad, AArnes — "The case of the conditional and the imperfect in variable mood-choice contexts in second-language and native-speaker Spanish”. — REsLA, 28 (2015), 118144.

65-497. Herd, Wendy, Joan Sereno \& Allard Jongman — "Cross-modal priming differences between native and nonnative Spanish speakers". SHLL, 8 (2015), 135-155.

65-498. Hernández Sacristán, Carlos — "Sobre datos conversacionales en la evaluación de la afasia: déficit lingüístico y función ejecutiva". — Oralia, 18 (2015), 131-161.

65-499. Judy, Tiffany \& Silvia Perpiñán (eds.) - The acquisition of Spanish in understudied language pairings. - John Benjamins, Amsterdam, 2015. || SHLL, 9 (2016), 239-242 (Leal).

65-500. Mackenzie, J. Lachlan \& Elena Martínez CARo - Compare and contrast: An English grammar for speakers of Spanish. - Comares, Granada, 2014. 298 pp. || REsLA, 27 (2014), 246-253 (Rodríguez Arrizabalaga).

65-501. Malovrh, Paul A. - "Variability and systematicity in the interlanguage development: An analysis of mode and its effect on L2 Spanish morphology". - SHLL, 7 (2014), 43-78.

65-502. Mayr, Robert \& Simona MontaNARI - "Cross-linguistic interaction in trilingual phonological development: The role of the input in the acquisition of the voicing contrast". - JChL, 42 (2015), 1006-1035. [Se incluye español].

65-503. Pascual y Cabo, Diego "Issues in Spanish heritage morphosyntax". - SHLL, 8 (2015), 389-401.

65-504. RAo, RajIV \& REBEcca RonQUEST — "The heritage Spanish phonetic / phonological system: Looking back and moving forward". - SHLL, 8 (2015), 403-414.

65-505. Rowe, Lindsey, RebecCA JACOBSON \& MEgAN M. SAYLOR - "Differences in how monolingual and bilingual children learn second labels for familiar objects". - JChL, 42 (2015), 1219-1236. [Se incluye el español].
65-506. Salazar Campillo, Patricia "Effect of textual enhancement on idioms: An exploratory study with Spanish students". - REsLA, 28 (2015), 258-272.

65-507. Sánchez Rufat, Anna \& FranCisco Jiménez Calderón - "New perspectives on the acquisition and teaching of Spanish vocabulary / Nuevas perspectivas sobre la adquisición y la enseñanza del vocabulario del español". — JSLT, 2 (2015), 99-111.

65-508. Silva-Corvalán, Carmen Bilingual language acquisition: Spanish and English in the first six years. - Cambridge University Press, New York, 2014. 408 pp. || JSLT, 2 (2015), 83-84 (Cenoz).

65-509. Stafford, Catherine A. \& ClaRA S. AzEVEDo - "Variation in Spanish heritage speakers' bilingualism and cognition". - SHLL, 8 (2015), 429-439.

65-510. TeIXeIra, ANNAlisA - "The role of aural recognition in L2 Spanish mood selection". - REsLA, 28 (2015), 555-587.

V. también núm. 37.

\section{LINGÜÍSTICA APLICADA}

ENSEÑANZA DEL ESPAÑOL

65-511. Ariolfo, RosAna - Actitudes lingüisticas, inmigración y escuela: un aporte para la reflexión y la práctica educativa. — Libellula Edizioni, Lecce, 2015. 271 pp. || LMi, 7 (2015), núm. 2, 117-119 (Mariscal Ríos).

65-512. ASención-Delaney, Yuly, Joseph G. Collentine, Karina Collentine, Jersus Colmenares \& Luke Plonsky — "El potencial de la enseñanza del vocabulario basada en corpus: optimismo con precaución”. - JSLT, 2 (2015), 140-151.

65-513. Barcroft, Joe — "El método IBI en la enseñanza del léxico: teoría, investigación y nuevas perspectivas". - JSLT, 2 (2015), 112-125.

65-514. Blake, Robert J. y Eve C. Zyzik - El español y la lingüística aplicada. — Georgetown University Press, Washington, DC, 2016. 224 pp. 
65-515. Bosch Andreu, Emma, Silvia Burset Burillo y Vicenta GonzÁlez ARGÜELlO - "El componente visual para el desarrollo del aprendizaje del léxico en materiales digitales interactivos". - e-AESLA, 2 (2016), 29-34.

65-516. Bravo García, E., E. Gallardo Saborido, I. SANTOS DE la Rosa y A. Gutiérrez (eds.) - Investigaciones sobre la enseñanza del español y su cultura en contextos de inmigración (N. 64-2114). || LMi, 7 (2015), núm. 2, 109-115 (Rodríguez Rubio).

65-517. Brennan, Brian y Daniel SánCHEZ - De tú a tú. Español para clases privadas (A2-B1). - Difusión, Barcelona, 2013. 160 pp. || JSLT, 2 (2015), 95-96 (Soler Montes).

65-518. Cáceres Lorenzo, M. TereSA — "Variables en el desarrollo de la reflexión metalingüística (L1) de alumnos plurilingües en el primer año universitario". - REsLA, 27 (2014), 275-296.

65-519. Carrera Troyano, Miguel — "La dimensión económica de la enseñanza del español como lengua extranjera. Un quinquenio de oportunidades y desafíos para las políticas públicas (2009-2014)". - RILI, 2014, núm. 24, 105-117.

65-520. Castañeda, Alejandro, Zeina Alhmoud, Irene Alonso, Jordi Casellas, M. Dolores Chamorro, Lourdes Miquel y Jenaro Ortega (coords.) - Enseñanza de gramática avanzada de ELE. Criterios y recursos. SGEL, Madrid, 2014. 359 pp. ||JSLT, 2 (2015), 96-98 (Sánchez Rufat).

65-521. Chatterjee, Avik, Li Qin, María de la Paz García \& Jaideep S. TAlWAlKar — "Improving linguistic and cultural competence in the health sector: A medical Spanish curriculum for resident physicians". - JSLT, 2 (2015), 36-50.

65-522. Cruz Piñol, MAR - "Léxico y ELE: enseñanza / aprendizaje con tecnologías". - JSLT, 2 (2015), 165-179.

65-523. Delicado Cantero, Manuel \& William Steed — "La enseñanza de la pronunciación del español en Australia: creencias y actitudes de los profesores". - JSLT, 2 (2015), 18-35.
65-524. Dussias, Paola E., Carla ConTEMori \& PAtricia Román - "Processing ser and estar to locate objects and events: An ERP study with L2 speakers of Spanish". - REsLA, 27 (2014), 54-86.

65-525. FAfulas, Stephen — "Progressive constructions in native-speaker and adult-acquired Spanish". SHLL, 8 (2015), 85-133.

65-526. Fernández, Julieta — "General extender use in spoken Peninsular Spanish: Metapragmatic awareness and pedagogical implications". JSLT, 2 (2015), 1-17.

65-527. Fernández, Susana S. y Johan FAlK (eds.) - Temas de gramática española para estudiantes universitarios. Una aproximación cognitiva y funcional. - Peter Lang, Bern, 2014. 317 pp. |IJSLT, 2 (2015), 88-90 (Ibarretxe Antuñano); RRo, 50 (28015), 326-329 (Vinther).

65-528. Ferreira Cabrera, Anita \& Nahum Lafleur - "Analyse et description des erreurs prépositionnelles les plus fréquentes en espagnol L2". - LinL, 2015, núm. 68, 57-79.

65-529. Ferreira Martins, Viviane "Las políticas lingüísticas de enseñanza y difusión de español / lengua extranjera (ELE) en el Mercosur". Onomázein, 2016, núm. 33, 174-188.

65-530. Grümpel, Claudia, Pamela Stoll \& José Luis Cifuentes HonRuBIA — "L3-Task: Language acquisition in a multilingual context: Blended tandems, L3-German / Spanish and a common second language (English)". - REsLA, 27 (2014), 382-404.

65-531. Hsueh Lu, Lo - "Colocaciones usadas en las pruebas de lectura DELE B1”. — CLAC, 2016, núm. 66, 210-243. 65-532. IbÁñez, Romualdo, Andrea Santana y Felipe Cornejo - "La dirección y la distancia en el establecimiento de la coherencia referencial durante el procesamiento de textos académicos escritos en español". RLA, 53 (2015), núm. 2, 145-170.

65-533. Jiménez Catalán, Rosa María — "Vocabulary profiles in English as a foreign language at the end of Spanish primary and secondary edu- 
cation". - RLA, 54 (2016), núm. 1, $37-50$.

65-534. Juan Lázaro, Olga - "Efectividad de la mensajería externa en la adquisición de la competencia comunicativa en un modelo de aprendizaje autónomo y a distancia en español como lengua extranjera". - RLA, 53 (2015), núm. 2, 121-143.

65-535. Lara Barbosa-Paiva, Crisciene - "El chat educacional como nuevo modo de comunicación en el siglo XXI para la enseñanza del español como lengua extranjera: análisis del uso estratégico de inserciones parentéticas para la comprensión textual". - e-AESLA, 2 (2016), 128-136.

65-536. Lara Barbosa-Paiva, CRisciene — "La versatilidad lingüística en el lenguaje de un nuevo género digital dirigido a la enseñanza del español como lengua extranjera en el siglo xxi: los usos más allá de la gramática tradicional". - e-AESLA, 2 (2016), 137-147.

65-537. Lasagabaster, David, Aintzane DoIz \& Juan M. SiERra - Motivation and foreign language learning: From the theory to practice. - John Benjamins, Amsterdam, 2014. 189 pp. (Language Learning E Language Teaching, 40). \| LMod, 2015, núm. 46, 125-127 (Fontecilla). [Se incluye español].

65-538. Leow, Ronald P. \& Johnathan D. Mercer - "Depth of processing in L2 learning: Theory, research, and pedagogy". - JSLT, 2 (2015), 69-82.

65-539. Llopis García, Reyes - "Las preposiciones y la metáfora del espacio: aportaciones y potencial de la lingüística cognitiva para su enseñanza”. - JSLT, 2 (2015), 51-68.

65-540. López Pérez, María Victoria y María Camino Bueno-Alastuey - "Una experiencia de enseñanza combinada en un curso universitario de español / L2: percepciones de los estudiantes sobre el efecto de las TIC en sus aprendizajes". - REsLA, 28 (2015), 213-233.

65-541. Lozano, Cristóbal - "Learner corpora as a research tool for the investigation of lexical competence in L2 Spanish". - JSLT, 2 (2015), 180193.
65-542. Lucha, Rosa M. y Lourdes Díaz — " ¿Progreso en mis textos escritos?»: análisis de la riqueza y densidad léxica en producciones escritas mediante software informático". e-AESLA, 2 (2016), 1-10.

65-543. Magaña, Dalia — "From pedagogy to communities: Issues within and beyond the Spanish heritage language classroom". - SHLL, 8 (2015), 375-388.

65-544. Marácz, Lászió \& Mireillee Rosello (eds.) - Multilingual Europe, multilingual Europeans. - Rodopi, Amsterdam, 2012. 323 pp. || JMMD, 35 (2014), 298-302 (Bugarski). [Se incluye español].

65-545. Marcos Miguel, Nausica "Voluntad y viabilidad en la enseñanza de morfología léxica en el aula de español como L2". - Los lindes de la morfología, eds. S. Alcoba, C. Buenafuentes y G. Clavería (A Coruña, 2016), pp. 145-158.

65-546. Martí Sánchez, Manuel y Sara Fernández Gómiz - Los marcadores discursivos. Para estudiantes y profesores. Español como lengua extranjera. - Edinumen, Madrid, 2013. || RILI, 2014, núm. 23, 230-231 (Pérez Salazar).

65-547. Mayoral Hernández, RoberTO - "El futuro del hispanismo y los estudios interdisciplinares: la interfaz entre ELE y la lingüística teórica”. Cincuentenario de la AIH, ed. R. Barros Roel (A Coruña, 2014), pp. 329-341.

65-548. MaDonough, Kim \& Alison Mackey (eds.) - Second language interaction in diverse educational contexts. - John Benjamins, AmsterdamPhiladelphia, 2013. 318 pp. (Language Learning $\mathcal{E}$ Language Teaching, 34). || ELAp, 2016, núm. 63, 221-231 (García Landa).

65-549. Mehrez, Nagwa - "Perspectiva de la lengua española en Egipto". Cincuentenario de la AIH, ed. R. Barros Roel (A Coruña, 2014), pp. 343-346. 65-550. Metzeltin, Michael - "Estructuras mentales, estructuras sintácticas y enseñanza de lenguas". - LMod, 2015, núm. 46, 27-44.

65-551. Montes Hernández, Alma LauRA - "Tratamiento de errores y fal- 
tas por medio de muestras auténticas de lengua (grabaciones individuales y grupales)". - $e$-AESLA, 2 (2016), 244-259.

65-552. Muñoz Basols, J., E. Gironzetti e Y. PÉrez - ¡A debate! Estrategias para la interacción oral (N. 64-2147). || LMod, 2015, núm. 46, 123-124 (Cívico Lyons).

65-553. Pellicer Sánchez, Ana "Developing automaticity and speed of lexical access: The effects of incidental and explicit teaching approaches". - JSLT, 2 (2015), 126-139.

65-554. Pérez Cabrera, Ana Beatriz y MAFra BARRETo - "La transferencia léxica en la interlengua escrita de estudiantes brasileños del español como lengua extranjera". - $e$-AESLA, 2 (2016), 23-28.

65-555. Pinuer Rodríguez, Claudio y Teresa Oteíza Silva - "La construcción léxico-gramatical de significación histórica en manuales escolares chilenos”. - RLA, 54 (2016), núm. 1, 51-77.

65-556. Porroche Ballesteros, MargaRITA — Aspectos de gramática del español coloquial para profesores de español como L2. - Arco/Libros, Madrid, 2009. 357 pp. || EAc, 2014, núm. 102, 141-144 (Baena Bradaschia).

65-557. Real ACAdemia Española y AsoCIACIÓN DE ACADEMIAS DE LA LENGUA EsPaÑola - El buen uso del español (N. 63-27). || JSLT, 2 (2015), 84-86 (Castañeda Castro).

65-558. Regueiro Rodríguez, M.L. y D.M. SÁEz Rivera - El español académico. Guía práctica para la elaboración de textos académicos (N. 64-2156). || PHisp, 28 (2014), núms. 1/2, 74-77 (Perea Siller); JSLT, 2 (2015), 93-94 (Yúfera Gómez).

65-559. Romo Simón, Francisco — "La imagen metalingüística de sery estar". - REsLA, 28 (2015), 234-257.

65-560. Schmidt, Lauren B. - "Contextual variation in L2 Spanish: Voicing assimilation in advanced learner speech". - SHLL, 7 (2014), 79-113.

65-561. Serrano Avilés, Javier (ed.) La enseñanza del español en África Subsahariana. — La Catarata, Madrid, 2014.
640 pp. || PHisp, 29 (2015), núms. 1/2, 106-110 (Olivieri).

65-562. Solon, Megan \& Matthew KANWIT - "The emergence of future verbal morphology in Spanish as a foreign language". - SHLL, 7 (2014), 115-147.

65-563. Stengers, Helene \& Frank BOERs - "Exercises on collocations: A comparison of trial-and-error and exemplar-guided procedures". JSLT, 2 (2015), 152-164.

65-564. Toledo Vega, Gloria - "Desarrollo pragmático en la interlengua de inmigrantes: el caso de haitianos aprendientes de español en Chile”. LMod, 2015, núm. 46, 81-103.

65-565. VÁzouez Cano, Esteban y Elena Martín Monje - Nuevas tendencias en la elaboración y utilización de materiales digitales para la enseñanza de lenguas. - MacGraw-Hill-Interamericana de España, Madrid, 2014. 184 pp. II REsLA, 27 (2014), 559-563 (Sánchez Suárez).

V. también núms. 62, 63, 486, 501, 507.

\section{LEXICOGRAFÍA}

65-566. Acín Villa, Esperanza - "Los adverbios en -mente en diccionarios actuales del español”. - Cincuentenario de la AIH, ed. R. Barros Roel (A Coruña, 2014), pp. 203-215.

65-567. BAldissera, AndreA — "Hacia un gran diccionario español-italiano / italiano-español: observaciones crítico-metodológicas sobre tres diccionarios mayores". - CAISPI, 2015, núm. $6,15-36$.

65-568. Blanco, XAvier - «Inventaire lexicographique d'une sous-classe de phrasèmes délaissée: les pragmatèmes». — CLex, 2014, núm. 104, 133153.

65-569. Buzex, Ivo - "Diccionario de mejicanismos de Félix Ramos i Duarte (1895): fuente para la historia del léxico de origen gitano en el español mexicano". - RILI, 2015, núm. 26, 125-144.

65-570. CARPI, ElenA — "El español de la pintura y los recursos lexicográficos y 
terminológicos: cómo traducir al español tempera y guazzo". — CAISPI, 2015, núm. 6, 111-125.

65-571. Clavería Nadal, Gloria - De "vacunar" a "dictaminar": la lexicografía académica decimonónica y el neologismo. - Iberoamericana-Vervuert, MadridFrankfurt/M., 2016. 324 pp. (Lingüistica Iberoamericana, 61).

65-572. Conde Noguerol, María EugeNIA - "Aproximación al tratamiento lexicográfico de los verbos de cambio en tres diccionarios generales del español”. - ALM, 3 (2015), núm. 2, 5-23.

65-573. Corbella, Dolores - "La selección de canarismos en el DRAE". RLiR, 80 (2016), 101-160.

65-574. D’Angelis, Antonella — "Il suffisso -zione / -ción in italiano ed in spagnolo: analisi e trattamento dei dati per inclusione del DIES / DEIS (Diccionario italiano-español de sufijos / Diccionario español-italiano de sufijos)". — PHisp, 28 (2014), núms. 3/4, 129-154.

65-575. Diccionario básico de la lengua española. Primaria. — SM, Madrid, 2014. || RLex, 20 (2014), 189-194 (Hernández).

65-576. Fernández de Gobeo Díaz de Durana, Nerea - "La lexicografía vasco-románica del siglo xIX: el Vocabulario vasco-castellano de Eugenio de Aranzábal". - RLex, 20 (2014), 19-33.

65-577. Fuertes Olivera, Pedro \& SVEN TARP - Theory and practice of specialised online dictionaries. Lexicography and terminography. - De Gruyter, Berlin, 2014. || IJLex, 28 (2015), 124-130 (L'Homme). [Se incluye español].

65-578. García Aranda, M. Ángeles — "La exposición breve, concisa y concreta de los conceptos usados en todas las ciencias: el Diccionario universal de la lengua castellana, ciencias y artes (1875-1881) dirigido por Nicolás M. Serrano”. - RLex, 20 (2014), 35-56.

65-579. García Rodríguez, JosepH "La evolución de la fraseología española en los diccionarios bilingües". - e-AESLA, 2 (2016), 383-392.

65-580. Garriga Escribano, Cecilio y Pilar Pardo Herrero - "El Dic- cionario tecnológico hispanoamericano, un nuevo intento en la institucionalización de la lengua de la ciencia y de la técnica en español”. - IJLex, 27 (2014), 201-240.

65-581. Gómez-Pablos, Beatriz — "Germanismos en el Diccionario de autoridades". - RLex, 20 (2014), 57-76.

65-582. González Jurado, MargariTA - "Una propuesta de estructuración del diccionario ideográfico y semántico de valoraciones utilitarias". - LinALFAL, 32 (2016), núm. 1, 103-111.

65-583. Heredia, Lerdys y Alfonso Ortega (dirs.) - Diccionario LID. Migración y extranjería. - LID, Madrid, 2014. 256 pp. || LMi, 7 (2015), núm. 1, 111-125 (Grupo FITISPos).

65-584. Hernán-Gómez Prieto, Beatriz - Esbozo del "Diccionario de bable del centro y oriente de Asturias" de José García Peláez "Pepín de Pría". - Academia de la Llingua Asturiana, Uviéu, 2015. 376 pp. || CAISPI, 2015, núm. 6, 244-245 (Prieto Entrialgo).

65-585. Huisa Téllez, José Carlos "Sobre el artículo del diccionario: apuntes de teoría y técnica lexicográfica”. - CAISPI, 2015, núm. 6, 171-190.

65-586. Jacinto García, Eduardo José — "La información sintagmática en la lexicografía española actual: unidades pluriverbales, ejemplos lexicográficos y otras indicaciones cotextuales". CAISPI, 2015, núm. 6, 147-170.

65-587. Lara, Luis Fernando - Teoría semántica y método lexicográfico. El Colegio de México, México, 2016. 283 pp.

65-588. Martos García, Paula - "Propuesta de un modelo lexicográfico para un diccionario histórico de colocaciones verbo + sustantivo CD". RHLE, 9 (2014), 159-173.

65-589. Martos Núñez, E. y M. Campos FERNÁNDEZ-FígARES (coords.) - Diccionario de nuevas formas de lectura y escritura. - Santillana, Madrid, 2013. 713 pp. || SEFS, 2015, núm. 27, 293296 (Rearte).

65-590. Mazzocchi, Giuseppe — "El Diccionario de americanismos (DA) de la Asociación de Academias de la 
Lengua Española (ASALE)". — CAISPI, 2015, núm. 6, 53-74.

65-591. Morimoto, Yuko - «Alternances de diathèses et ambivalences aspectuelles dans les dictionnaires didactiques d'espagnol». — CLex, 2014, núm. 104, 99-111.

65-592. Pavón Lucero, María Victoria - “À propos des locutions prépositionnelles et des dictionnaires: deux cas de l'espagnol". - CLex, 2014, núm. 104, 113-132.

65-593. Pérez Pascual, José Ignacio — "El décalage entre la sustitución de disciplinas y los cambios del léxico correspondiente a ellas en los diccionarios. A propósito de albeitería y veterinaria". - CLex, 2014, núm. 104, 195-216.

65-594. Pérez Serrano, Mercedes “Son indispensables los diccionarios combinatorios?”. — RLex, 20 (2014), 121-145.

65-595. Renau Araque, Irene — "De nuevo sobre la gramática en el diccionario: el caso de los verbos con $s e$ ". CLAC, 2016, núm. 66, 340-381.

65-596. SÁEz Godoy, LeOPOLdo — " Chilenismos y diccionarios académicos: una (h) ojeada”. — EFil, 2014, núm. 53, 123-140.

65-597. SÁnchez Martín, Francisco JAVIER - "La actuación lexicográfica en el Diccionario de la lengua española (DRAE): estudio de las novedades para la 23a edición”. — AFB, 4 (2014), 43-69.

65-598. Santamaría Pérez, Isabel "Diseño, implementación y elaboración de una terminología multilingüe del ámbito del turrón, mazapanes y otros dulces". - CAISPI, 2015, núm. 6, 75-93.

65-599. Santos López, Luis Javier "Las relaciones entre terminología, lexicografía y tecnología en el proyecto Parole per mangiare". - CAISPI, 2016, núm. 6, 95-110.

65-600. Stala, EWA - "El diccionario de Terreros y Pando como fuente del Waaren lexicon de Ph. A. Nemnich (1797)". — RLex, 20 (2014), 147-166.

65-601. Tabares Plasencia, EncarnaCIÓN - "El tratamiento de los genti- licios en el Diccionario panhispánico de dudas". — RLex, 20 (2014), 167-186.

65-602. VAlero Gisbert, María JoAQUiNA - "Consideraciones sobre el tratamiento lexicográfico de unidades fraseológicas desde la perspectiva de la marcación pragmática”. - CAISPI, 2015, núm. 6, 37-52.

65-603. VÁzquez Amador, María — "El tratamiento de un corpus de anglicismos de la prensa mexicana del siglo xx en los diccionarios de la RAE". ALM, 3 (2015), núm. 2, 273-311.

65-604. ZariQuiey, Roberto y David W. FLECK - Animales y plantas del pueblo kaka-taibo. Diccionario trilingüe (kakataibo, español, inglés) con identificaciones biológicas, índice alfabético castellanokakataibo, clasificación semántica, nombres regionales y definiciones etnobiológicas, con la colaboración de Alfredo Estrella, Emilio Estrella, Salomón Estrella, Ricardo Odicio y Ricardo Pereira. Lincom Europa, München, 2013. 267 pp. || LexisL, 40 (2016), 194-197 (Prieto Mendoza).

65-605. Zur Lexikographie der romanischen Sprachen. Romanistisches Kolloquium XXVIII. Hrsg. Wolfgang Dahmen, Günter Holtus, Johannes Kramer, Michael Metzeltin, Wolfgang Schweickard und Otto Winkelmann.- Narr, Tübingen, 2014. 266 pp. || RLiR, 80 (2016), 219-221 (Variano). [Se incluye español].

V. también núms. 9, 15, 121, 126, 133, 142, 250, 316, 526, 641, 956, 1463

\section{TRADUCCIÓN}

65-606. Agost, Rosa \& Pilar Ordóñez LóPEz - "Translation theory: Myths, prejudices and realities". — Babel, 61 (2015), 361-380. [Se incluye español]. 65-607. Álvarez Jurado, Manuela "Un acercamiento a la preocupación decimonónica por los fraudes alimentarios: la traducción y recepción en España del Dictionnaire des altérations et falsifications des substances alimentaires de Alphonse Chevallier". - Onomázein, 2016, núm. 33, 289-309. 
65-608. Ancira, Selma - "De traducción y viajes”. - CuH, 2015, núm. 777, 82-88.

65-609. Andújar Moreno, Gemma "Los estereotipos sociales a través del filtro de la traducción: algunos referentes culturales en las traducciones de L'Élégance du hérisson de Muriel Barbery”. — Babel, 60 (2014), 216-233.

65-610. Anfuso, Matteo y Mara MorelLI — "Oralidad y situación comunicativa en interpretación consecutiva: un estudio exploratorio". - CAISPI, 2014, núm. 4, 129-147.

65-611. Bertozzi, Michela - "Analisi delle disfluenze del discorso durante l'interpretazione simultanea da italiano a spagnolo". - CAISPI, 2014, núm. 4, 149-164.

65-612. Bolaños Medina, Alicia — "La tolerancia de la ambigüedad y los procesos cognitivos del traductor". Babel, 61 (2015), 147-169.

65-613. Brandimonte, Giovanni "Breve estudio contrastivo sobre las fórmulas rutinarias psicosociales en italiano y en español". — CAISPI, 2014, núm. 4, 49-67.

65-614. Cámara Aguilera, Elvira y Pamela Faber - "Distintos enfoques al traducir y su efecto en el receptor". - REsLA, 27 (2014), 297-322.

65-615. Capponi, Paola — "Usi traslati di termini astronomici. Bolide nella stampa italiana e spagnola del xx secolo". — PHisp, 28 (2014), núms. 3/4, 93-115.

65-616. Carrera Díaz, Manuel — "Linguistica contrastiva e traduzione letteraria. Italiano e spagnolo". - PHisp, 28 (2014), núms. 3/4, 117-127.

65-617. Casas-Tost, Helena — "El estilo del traductor en el tratamiento de las onomatopeyas del chino al español: el caso de la novela ; Vivir!". — Babel, 60 (2014), 445-463.

65-618. Díaz Peralta, Marina, Gracia Piñero Piñero, María J. García Domínguez \& Geraldine Boylan — "Metaphor and symbol: The portrait of Montezuma II in the work of W.H. Prescott and its translation into Spanish by J. Navarro". — Babel, 61 (2015), 242-264.
65-619. Díaz Pérez, Francisco Javier - "The translation of identity on the frontera. Sandra Cisneros in Mexican Spanish, Galician and Catalan". Babel, 60 (2014), 325-346.

65-620. EnríQuez Aranda, Mercedes — "Translation norms in the light of practical research in literary translation”. - Onomázein, 2016, núm. 33, 88-106.

65-621. EnríQuez Aranda, Mercedes \& Nieves Jiménez Carra — “Training translators through the use of audiovisual ads: Didactic exploitation and cultural implications". — Babel, 61 (2015), 411-432. [Se incluye español]. 65-622. Errico, Elena \& Elisa BallesTRAZZI - "When the speaker is a great performer: A case study on the role of the interpreter in consecutive interpreting”. - REsLA, 27 (2014), 365-381. [Se incluye español].

65-623. Fernandez, Francesc \& MartA ARUmi Ribas - "Ongoingly redesigning metacognitive questionnaires helping trainees to self-evaluate their translating". — Babel, 60 (2014), 371396. [Se incluye español].

65-624. Fernandez Rodriguez, Aurea \& IOlanda Galanes Santos — "La crise hypothécaire et ses dénominations". - Babel, 61 (2015), 265-282. [Se incluye español].

65-625. Flores Acuña, Estefanía — "El corpus como herramienta para la traducción especializada italiano / español: una experiencia con textos de la industria cosmética”. - PHisp, 28 (2014), núms. 3/4, 155-182.

65-626. Flores AcUÑa, Estefanía — "El español coloquial en la traducción para el doblaje y subtitulación del cine italiano: análisis de Una jornada particular". —EAc, 2014, núm. 102, 113-122.

65-627. García Gual, Carlos - "La primera traducción de la Odisea”. CuH, 2015, núm. 784, 127-135.

65-628. García Jiménez, Rocío - "El concepto de oralidad en la traducción de la música ligera italiana: dos aproximaciones". — CAISPI, 2014, núm. 4, 183-196.

65-629. Gogazeh, Ziyad Mohammad "La problemática de la traducción de 
la terminología jurídica en el libro Manual de traducción jurídica árabe-español". — PHisp, 28 (2014), núms. 1/2, 25-34.

65-630. Gómez Castro, Cristina "Thorny issues in translation: The case of The Thornbirds in the Spanish society of the seventies". - Babel, 60 (2014), 281-302.

65-631. Hernández Guerrero, María José - "La traducción de letras de canciones en la web de aficionados Lyrics Translate.com". — Babel, 60 (2014), 91-108.

65-632. Ku, Menghsuan - "Enfoque por tareas en el aula universitaria de traducción español-chino". - $e$-AESLA, 2 (2016), 274-284.

65-633. Mateo, José — "Neonyms for a crisis: Cognitive, terminological and socio-pragmatic aspects in the translation of new financial terms into Spanish". - Babel, 60 (2014), 405-424.

65-634. Mateo Palacios, AnA — "Aragonesismos y catalanismos en la traducción castellana realizada por Gonzalo García de Santa María de Las vidas de los sanctos religiosos de Egipto". — AFA, 70 (2014), 87-114.

65-635. Moga, Eduardo - "La carreta y el cuervo. Un ejercicio de traducción comparada”. - CuH, 2015, núms. 781/782, 174-185. [Traducción de Walt Whitman].

65-636. Molés-Cases, Teresa - "Compilación y análisis de un corpus paralelo para la investigación en traducción. Proyecto con Déjà Vu, Tree Tagger e IMS Open Corpus Workbench". — RLA, 54 (2016), núm. 1, 149-174.

65-637. Naranjo Sánchez, Beatriz "Translating blackness in Spanish dubbing”. — REsLA, 28 (2015), 416-441.

65-638. NAVARro ANdúgar, JUAN — "La identidad social en la novela contemporánea: la traducción de la variación lingüística en Trainspotting de Irvine Weish". - e-AESLA, 2 (2016), 364-373.

65-639. Oakes, Michael P. \& Meng Ji (eds.) - Quantitative methods in corpusbased translation studies. - John Benjamins, Amsterdam, 2012. x + 361 pp. || Babel, 60 (2014), 258-264 (Fu). [Se incluye español].
65-640. Paleologos, Konstantinos "Canon literario y traducción literaria. El caso de la traducción de la literatura española al griego". — Cincuentenario de la AIH, ed. R. Barros Roel (A Coruña, 2014), pp. 369-380.

65-641. Prieto Ramos, Fernando y Mariana Orozco Jutorán - "De la ficha terminológica a la ficha traductológica: hacia una lexicografía al servicio de la traducción jurídica”. Babel, 61 (2015), 110-130.

65-642. Ramón, Noelia — "Comparing original and translated Spanish: A corpus-based analysis of adjective position”. - Babel, 61 (2015), 527-551.

65-643. Rodríguez Martín, Gustavo A. - "The Simpsons: Visual phraseological units and translation". - Babel, 61 (2015), 1-21. [Se incluye español].

65-644. Rubio Tovar, J. - Literatura, historia y traducción (N. 64-489). || Incipit, 35 (2015), 286-294 (Rodríguez Temperley).

65-645. Russo, Mariachiara - "Fenomeni dell'oralità critici per l'interpretazione simultanea: un'analisi contrastiva spagnolo-italiano basata sul corpus EPIC". - CAISPI, 2014, núm. 4, 165-181.

65-646. Santaemilia Ruiz, José \& BetLEM SOLER PARDO — "Translating film titles: Quentin Tarantino, on difference and globalisation". - Babel, 60 (2014), 193-215. [Se incluye español].

65-647. Scliar Cabral, LeOnOR - "Os mortos eu escuto, olhos despertos: homenagem a Moacyr Scliar". LinALFAL, 32 (2016), núm. 1, 79-93. [Se incluye español].

65-648. Sinatra, Chiara - "Il passaggio dall'oralità alla scrittura in ambito forense e giudiziario". - CAISPI, 2014, núm. 4, 197-212. [Se incluye español].

65-649. Tonin, RafFAella — “ «Un poquito de por favor»: la sfida dell'oralità alle limitazioni del sottotitolo". — CAISPI, 2014, núm. 4, 213-227.

65-650. Uclés Ramada, Gloria — "La traducción de las referencias a la variedad diatópica en el doblaje al español”. — Normas, 6 (2015), 77-91. 
65-651. Valdeón, Robert A. - Translation and the Spanish empire in the Americas. - John Benjamins, Amsterdam-Philadelphia, 2014. xii + 272 pp. || RLiR, 80 (2016), 256-261 (Rey Quesada).

65-652. VILAR SÁNCHEz, KARIN — "Microfunction combination patterns and linguistic adequacy in specialised texts". — Babel, 60 (2014), 70-90. [Se incluye español].

65-653. YADA, YoKO - "Linguistic representation and Japanese expression in Almodóvar's film La flor de mi secreto. -Transmission of the connotative messages-". - SLT, 2015, núm. 63, 173-189.

V. también núms. 570, 655, 1124, 1317.

\section{OTROS ESTUDIOS}

65-654. Almeida, Erica, Afranio Barbosa \& Dinah Callou - "Reflexões metodológicas para a identificação social de redatores em corpora: percurso nos arquivos históricos". RILI, 2014, núm. 24, 157-182. [Se incluye español].

65-655. Faya Ornia, Goretti - "Revisión y propuesta de clasificación de corpus". - Babel, 60 (2014), 234-252.

65-656. Fernández Pérez, Milagros (coord.) - Lingüística y déficit comunicativos. ¿Cómo abordar las disfunciones verbales? - Síntesis, Madrid, 2014. 288 pp. || CLAC, 2016, núm 66, 402406 (Rodríguez Muñoz).

65-657. Fernández Urouiza, Maite y Beatriz Gallardo Paúls - "Adaptación del formato chat para la transcripción y codificación de los datos de lenguaje patológico del corpus PerLA". - Oralia, 18 (2015), 81-102.

65-658. Lacorte, M. (ed.) - The Routledge handbook of Hispanic applied linguistics (N. 64-2251). || JSLT, 2 (2015), 86-88 (Gironzetti); SHLL, 8 (2015), 207-212 (Shively).

65-659. Moreno Sandoval, Antonio y Leonardo Campillos Llanos "Combinación de estrategias léxicas y estadísticas para el reconocimiento automático de términos: su aplicación a un corpus de medicina". - LEA, 37 (2015), 175-199.

65-660. Moreno Torres, Ignacio "The emergence of productive speech and language in Spanish-learning paediatric cochlear implant users". JChL, 41 (2014), 575-599.

65-661. Nicolás Martínez, Carlota — "Análisis de las concordancias con etiqueta de reinicio en C-Or-DiAL: contextos dialógicos". - LEA, 37 (2015), 215-239.

65-662. Rainey, Vanessa R., Valerie Flores, Robert G. Morrison, E.J.R. David \& Rebecca L. Silton - "Mental health risk factors associated with chilhood language brokering". $J M M D, 35$ (2014), 463-478. [Se incluye español].

65-663. Robles Garrote, Pilar "Aportaciones de la lingüística de corpus al estudio de la conferencia como género académico de divulgación científica”. - Chimera, 2016, núm. 3, 1-21.

65-664. Torres Bustos, Valeska y JaImE Soto BARba - "Ajustes fonéticofonológicos en niños con transtornos específicos del lenguaje mixto (TEL Mixto)". - Onomázein, 2016, núm. 33, 69-87.

V. también núms. 200, 330, 336, 343, 625.

\section{LITERATURA}

\section{OBRAS GENERALES Y MISCELÁNEAS}

65-665. Alvarado Borgoño, Miguel - El vuelo de la calandria. Analogías estéticas y comprensión transcultural latinoamericana. - Narr, Tübingen, 2015. 327 pp. || Ibero, 2016, núm. 61, 305-307 (Valenzuela Rettig).

65-666. Barros Roel, Rocío (ed.) Cincuentenario de la Asociación Internacional de Hispanistas. A Coruña, del 11 al 13 de diciembre de 2012. - Universidade, A Coruña, 2014. 503 pp.

65-667. Bizarri, Hugo O. - "El hispanismo en la senda de la crítica textual". - Cincuentenario de la AIH, ed. R. Barros Roel (A Coruña, 2014), pp. $167-180$. 
65-668. Díaz NARBOnA, InMAGulaDA (ed.) - Literaturas hispanoafricanas: realidades y contextos. - Verbum, Madrid, 2015. 384 pp. || NRFH, 64 (2016), 604-609 (Berty).

65-669. Funes, LEONARDo (coord.) Hispanismos del mundo. Diálogos y debates en (y desde) el Sur. - Miño y Dávila Editores, Buenos Aires, 2016. 384 pp.

65-670. Garrido Gallardo, M.A. (dir.) - La biblioteca de Occidente en contexto hispánico. Actas del Congreso Internacional celebrado en Madrid-Logroño (N. 62-1587). || NRFH, 64 (2016), 571-576 (Rivas Velázquez).

65-671. MAIner, José CARlos - Historia mínima de la literatura española. - Turner-El Colegio de México, Madrid, 2014. 273 pp. || CuH, 2015, núm. 778, 116-120 (Sánchez Robayna).

65-672. Pueyo, Carlos Miguel — "El hispanismo en cincuenta años: la lengua tiene palabra”. - Cincuentenario de la AIH, ed. R. Barros Roel (A Coruña, 2014), pp. 347-354.

65-673. Rodríguez Freire, Raúl "Literatura y heteronomia: mito y archivo". - EFil, 2014, núm. 54, 127138.

65-674. Santos, Manuel y Ernesto PieDRAS - "Las industrias culturales en español”. — RILI, 2014, núm. 24, 87-104.

65-675. Volpe, Germana (ed.) - Amistades que son ciertas. Studi in onore di Giovanni Battista de Cesare. — Think Thanks Edizioni, Napoli, 2015. 252 pp. || CAISPI, 2016, núm. 7, 186-190 (Campese).

\section{LITERATURA TRADICIONAL Y POPULAR}

65-676. Alonso, Álvaro - "Sobre el texto y las fuentes del romance «Mira Nero de Tarpeya»". — RFE, 95 (2015), 9-23.

65-677. Beltrán Almería, Luis — "Las formas simples del romancero hispánico". - RFE, 95 (2015), 25-44.

65-678. Carranza Vera, C. y M. Zavala Gómez del Campo (eds.) -
Temas y motivos de formas narrativas de la literatura tradicional de México (N. 64-545). || NRFH, 64 (2016), 576581 (Rodilla).

65-679. Casas-Delgado, Inmaculada — "La pervivencia del bandido generoso. Del asesino nato a la víctima de las injusticias sociales". - CuIR, 22 (2016), 35-56.

65-680. Cid, Jesús Antonio - "La falsa poesía popular. Fantasías, inventos y mixtificaciones vascas". - I Ins, 2015, núm. 827, 12-15.

65-681. Gomis Coloma, JuAn — "Los rostros del criminal: una aproximación a la literatura de patíbulo en España”. - CuIR, 22 (2016), 9-33.

65-682. Gomis Coloma, JuAn - Menudencias de imprenta. Producción y circulación de la literatura popular (Valencia, siglo XVIII). - Institució Alfons el Magnànim, Valencia, 2015. 557 pp. II CuIR, 22 (2016), 515-517 (Serrano).

65-683. Guinot Ferri, Laura — “"Viva el señor San Antonio, pues que tanto nos ampara»: los santos y su representación en la literatura popular de los siglos XVIII y XIX”. - CuIR, 22 (2016), 129-157.

65-684. López Torres, Nora Danira — "La sátira al clérigo en el cantar popular «No lo puedo desir desire» (Nc 1856)". — NRFH, 64 (2016), 511526.

65-685. Pédeflous, Justine - "Sacrilegios y crímenes rituales: el judío como encarnación de la infamia en los romances de ciego españoles (1700-1850)". - CuIR, 22 (2016), $159-178$.

65-686. Ramírez-Pimienta, Juan Carlos — "El tema de la traición en tres corridos de narcotráfico y narcotraficantes: «Carga blanca», «Contrabando y traición» y «Chuy y Mauricio»". — HiJ, 36 (2015), núm. 2, 161-177.

65-687. Sinclair, Alison — "Historias de dos desgraciadas. Estereotipos de la culpa en la literatura popular española de los siglos XVIII y XIX". - CuIR, 22 (2016), 57-78.

V. también núms. 360, 965. 


\section{HISTORIA DE LA LITERATURA}

\section{HISTORIOGRAFÍA Y ESTUDIOS TEÓRICOS}

65-688. Álvarez Barrientos, J. - El crimen de la escritura. Una historia de las falsificaciones literarias españolas (N. 62-1442). || Ibero, 2015, núm. 60, 207209 (Bersett); CuIR, 21 (2015), 333337 (Durán López); Íns, 2015, núm. 825, 28-29 (Gil-Albarellos Pérez-Pedrero). - V. 64-2296.

65-689. Álvarez Barrientos, JoAQuín - "Literatura apócrifa e historia literaria”. - Íns, 2015, núm. 827, 37-40.

65-690. Álvarez Barrientos, JoAQuín y Maria Rosell - "Lo falso como símbolo cultural". - Íns, 2015, núm. 827, 2-3.

65-691. Bautista, Juan José - ¿Qué significa pensar desde América Latina? Hacia una racionalidad transmoderna y postoccidental. - Akal, Madrid, 2014. 285 pp. || Ibero, 2016, núm. 61, 307-310 (Cancino Troncoso).

65-692. Borsò, Vittoria, Yasmin TemeLli y Karolin Viseneber (eds.) México: migraciones culturales-topográficas transatlánticas. Acercamiento a las culturas desde el movimiento. - Iberoamericana-Vervuert, Madrid-Frankfurt/M., 2012. 342 pp. || Ibero, 2015, núm. 59, 256-258 (Sánchez Carbó).

65-693. Botta, Patrizia - "El comparatismo de Franco Meregalli”. - Cincuentenario de la AIH, ed. R. Barros Roel (A Coruña, 2014), pp. 125-138.

65-694. Campra, R. - Travesías de la literatura gauchesca. De Concolocorvo a Fontanarrosa (N. 64-563). || CAISPI, 2014, núm. 3, 239-241 (Bravo Herrera).

65-695. Camayd-Freixas, Erik - Etnografía imaginaria. Historia y parodia en la literatura hispanoamericana. F\&G Editores, Guatemala, 2012. 233 pp. || Ibero, 2015, núm. 60, 228-230 (Tedeschi).

65-696. Compagnon, Antoine - El demonio de la teoría. Literatura y sentido común. Trad. de Manuel Arranz. Acantilado, Barcelona, 2015. || CuH, 2016, núm. 788, 72-85 (Matamoro).
65-697. Diego, José LuIS DE - La otra cara de Jano. Una mirada crítica sobre el libro y la edición. - Ampersand, Buenos Aires, 2015. 356 pp. || Ibero, 2016, núm. 62, 261-264 (Larraz).

65-698. EgIDo, Aurora - "Edward M. Wilson, sentido y sensiblidad crítica”. - Cincuentenario de la AIH, ed. R. Barros Roel (A Coruña, 2014), pp. 73-88.

65-699. Escandell Montiel, Daniel "Industria y agentes culturales: cambios en el paradigma editorial ante la esfera digital". - Inti, 78/79 (2014), 215-234.

65-700. GARRALÓN, ANA - "Los precursores". - CuH, 2015, núm. 776, 4-13.

65-701. Hernández Lorenzo, Laura — "Dido: el personaje virgiliano y su transmisión en la literatura española". - PHisp, 29 (2015), núms. 1/2, 51-65.

65-702. Llosa SANZ, Álvaro - Más allá del papel. El hilo digital de la ficción impresa. - Academia del Hispanismo, Vigo, 2013. 244 pp. (Biblioteca Giambattista Vico, 32). || Ibero, 2015, núm. 59, 240242 (Escandell).

65-703. López Poza, Sagrario "Humanidades digitales hispánicas". - Cincuentenario de la AIH, ed. R. Barros Roel (A Coruña, 2014), pp. 151-166.

65-704. LosAda Goya, J.M. y A. LiPSCOMB (dirs.) - Mito e interdisciplinariedad. Los mitos antiguos, medievales y modernos en la literatura y las artes contemporáneas (N. 63-686). || Dicenda, 32 (2014), 397399 (Couceiro). - V. 64-2792.

65-705. Maestro, Jesús G. - Contra las musas de la ira. El materialismo filosófico como teoría de la literatura. - Pentalfa Ediciones, Oviedo, 2014. 460 pp. || CuIF, 41 (2015), 219-223 (Lozano Rodríguez).

65-706. Mainer, José Carlos (dir.) Historia de la literatura española. T 4: Razón y sentimiento. El siglo de las luces. Ed. de M.D. Albiac (N. 62-461). \| AFA, 70 (2014), 251-269 (Ayerbe Betrán).

65-707. Montero Reguera, José "Isaías Lerner o la elegancia de la filología". - Cincuentenario de la AIH, ed. R. Barros Roel (A Coruña, 2014), pp. 491-503. 
65-708. Montesinos, Toni - Melancolía y suicidios literarios: de Aristóteles a Pizarnik. - Fórcola, Madrid, 2014. 190 pp. || CuH, 2015, núm. 776, 120123 (Roffé).

65-709. Neila, Manuel - "Formas breves: aforismos, máximas y fragmentos". - CuH, 2015, núm. 778, 43-53.

65-710. Noguerol, Francisca, María Ángeles Pérez López y Vega SánCHEZ APARICIO (eds.) - Letras y bytes. Escrituras y nuevas tecnologías. - Reichenberger, Kassel, 2015. 244 pp. (Problemata Literaria, 77). || Ibero, 2016 , núm. 61, 298-303 (Moreno).

65-711. Pablo Núñez, Luis (ed.) Escritorios electrónicos para las literaturas. Nuevas herramientas digitales para la anotación colaborativa. — Universidad Complutense de Madrid, Madrid, 2013. 178 pp. || RILI, 2014, núm. 24, 206-208 (Spence).

65-712. Raposo, Berta y Ferrán Robles (eds.) — "El Sur también existe". Hacia la creación de un imaginario europeo sobre España. - Iberoamericana-Vervuert, Madrid-Frankfurt/M., 2014. 238 pp. || Ibero, 2016, núm. 62, 235-237 (Sánchez Jiménez).

65-713. Redondo, Augustin - "La España erasmista de Marcel Bataillon”. - Cincuentenario de la AIH, ed. R. Barros Roel (A Coruña, 2014), pp. 57-68.

65-714. Riera Sans, Jaume - "El auxiliar del falsario”. - Íns, 2015, núm. 827, 7-11.

65-715. Rojo, GRÍNOR - De las más altas cumbres. Teoría crítica latinoamericana moderna. - Lom, Santiago de Chile, 2012. 362 pp. || I, 82 (2015), 260-266 (García).

65-716. Romera Castillo, José — "Hispanismo y semiótica: A Coruña, lugar de encuentros". - Cincuentenario de la AIH, ed. R. Barros Roel (A Coruña, 2014), pp. 181-192.

65-717. Romero Tobar, Leonardo "Falsificaciones goyescas como argumento literario". - Íns, 2015, núm. 827, 15-18.

65-718. SÁseta NARANJo, RAFAel — "Un aspecto de la recepción literaria de Marco Bruto: la resistencia contra el orden cósmico". — PHisp, 29 (2015), núms. 1/2, 37-50.

65-719. Spence, PAUl — "Siete retos en edición digital para las fuentes documentales". - Scriptum, 3 (2014), 153181.

65-720. Vauthier, B. y J. Gamba CorraDINE (eds.) - Crítica genética y edición de manuscritos hispánicos contemporáneos. Aportaciones a una "poética de transición entre estados” (N. 62-446). II Incipit, 35 (2015), 276-286 (Rodas). - V. 64-1036.

65-721. Vivanco Roca Rey, Lucero de - Historias del más acá. Imaginario apocalíptico en la literatura peruana. - Instituto de Estudios Peruanos, Lima, 2013. 222 pp. || Ibero, 2015, núm. 60, 230-231 (Remiro Fondevilla).

65-722. WEInBERG, LiLiAna - El ensayo en busca del sentido. - UNAM-Iberoamericana-Vervuert, México-MadridFrankfurt/M., 2014. 190 pp. (Bibliotheca Ibero-Americana, 159). II CuA, 2015, núm. 153, 185-188 (Gutiérrez de Velasco).

65-723. ZapATA, JuAN (comp.) - La invención del autor: nuevas aproximaciones al estudio sociológico y discursivo de la figura autorial. - Universidad de Antioquia, Medellín, 2014. 280 pp. II ELC, 2016, núm. 38, 209-213 (Martín Colorado).

\section{EDAD MEDIA}

\section{Poesía}

65-724. Barletta, Vincent, Mark L. Bajus \& Cici Malik (eds.) - Dreams of waking. An anthology of Iberian lyric poetry, 1400-1700. - The University of Chicago Press, Chicago, 2013. 432 pp. || Ibero, 2016, núm. 61, 281-283 (García Santo-Tomás).

65-725. Marti, Melisa Laura - "Formas de debate en la poesía castellana en pareados del siglo xiI: Elena y María y Razón de amor con los denuestos del agua y el vino". — Incipit, 35 (2015), 127-145.

65-726. Mosquera Novoa, Lucía "«iComiença, mi voluntat, a des- 
amar!»: estudio de un debate ficticio del Cancionero de Palacio (SA7)". Cincuentenario de la AIH, ed. R. Barros Roel (A Coruña, 2014), pp. 355-367.

65-727. Zubillaga, CARINA - "Acercando las distancias: clerecía y juglaría castellanas en la transmisión conjunta de los poemas del Ms. Esc. K-III-4". —Incipit, 35 (2015), 147-176.

\section{Narrativa}

65-728. Bautista, Francisco - "La segunda parte de la Crónica de Juan II: borradores y texto definitivo". CEHM, 37 (2014), 105-138.

65-729. Benítez Guerrero, Carmen "Manuscritos y cronistas: los problemas del trabajo en torno a la Crónica de Fernando IV de Castilla". - CEHM, 37 (2014), 77-88.

65-730. Coduras Bruna, María - "Por el nombre se conoce al hombre". Estudios de antroponimia caballeresca. - Universidad, Zaragoza, 2015.372 pp. || RFE, 95 (2015), 363-367 (Alvar).

65-731. Fuentes, Juan H. y Pablo E. SARACINO - "Autógrafos de Florián de Ocampo en la Biblioteca Capitular y Colombina de Sevilla". - Incipit, 35 (2015), 235-249.

65-732. Garcia, Michel - "Le chroniqueur face à sa tâche. À propos de la Première Partie de la Chronique de Jean II de Castille (1406-1420)". - CEHM, 37 (2014), 89-103.

\section{Estudios diversos}

65-733. Alvar, Carlos - "Alan D. Deyermond, medievalista”. - Cincuentenario de la AIH, ed. R. Barros Roel (A Coruña, 2014), pp. 139-148.

65-734. Bautista, Francisco - "Diálogo en la muerte de Aristóleles: una versión castellana cuatrocentista del Liber de pomo". - CEHM, 38 (2015), 167-185.

65-735. Burgoyne, JONATHAN - "La corónica: una revista laica hoy y mañana". Hispanismos del mundo, coord. F. Funes (Buenos Aires, 2016), pp. 281-285.
65-736. Company, Concepción, Aurelio GONZÁlez y LiLLIAN VON DER WALDE Moheno (eds.) - Aproximaciones y revisiones medievales. Historia, lengua y literatura (N. 62-456). || NRFH, 64 (2016), 581-586 (Luna Mariscal).

65-737. Couceiro, María del Pilar "Vigencia de los personajes infernales en la literatura medieval y renacentista (III). Caronte y los guardianes del Hades". - Cincuentenario de la AIH, ed. R. Barros Roel (A Coruña, 2014), pp. 253-266.

65-738. Esteras Martínez, José Ángel y Josemi Lorenzo Arribas - "Siete arcos, siete infantes. Leyendas en torno al origen de las galerías porticadas románicas". - CEHM, 37 (2014), 215-232.

65-739. Francomano, Emily C. - "Nuevas perspectivas en los estudios hispanomedievales: celebrando 40 años de $L a$ corónica. A Journal of Medieval Hispanic Languages, Literatures and Cultures". Hispanismos del mundo, coord. F. Funes (Buenos Aires, 2016), pp. 275-279.

65-740. Heusch, Carlos - "Polysémie de l'amour dans le Moyen Âge ibérique". - CEHM, 38 (2015), 13-27.

65-741. Lacarra Lanz, Eukene - "El «amor que dicen hereos» o aegritudo amoris". - CEHM, 38 (2015), 29-44.

65-742. Martos, Josep Lluís - "Juan Martín Cordero en Flandes: humanismo, mecenazgo e imprenta". - RFE, 95 (2015), 75-96.

65-743. Pascual Argente, Clara — "La huella de las Sumas de historia troyana en la Confessio amantis castellana”. RFE, 95 (2015), 127-152.

65-744. Pensado Figueiras, Jesús "En torno a la edición crítica del Libro de los grados de las espeçias e de las yerbas". - Cincuentenario de la AIH, ed. R. Barros Roel (A Coruña, 2014), pp. 393-406.

\section{Autores (y obras anónimas)}

$$
\text { Alfonso Xel Sabio }
$$

65-745. BARros Dias, ISABEL - La identidad de la historiografía. Criterios aplicados 
en la composición de la "Estoria de Espanna" alfonsí respecto de las materias épicas y de devoción. - Cilengua, San Millán de la Cogolla, 2013. 198 pp. || Incipit, 35 (2015), 271-275 (Funes).

65-746. Bautista, Francisco - "El final de la General estoria". — RFE, 95 (2015), 251-278.

65-747. Breva Iscla, María E. — “De las Estorias de Alfonso el Sabio a los libros de caballerías. Ovidio, heroínas y cartas". - Cincuentenario de la AIH, ed. R. Barros Roel (A Coruña, 2014), pp. 229-239.

65-748. Cristóbal, Vicente — “Orfeo y otros mitos eróticos en la General estoria". — CEHM, 38 (2015), 65-89.

65-749. González Martínez, Deborah - "E fisica que fezesse nulla prol non lle fazia. Médicos e medicina nas Cantigas de Santa Maria". — ERM, 20 (2015), 157-171.

65-750. Hart, SARAH - "The loss of the Old Spanish -udo participle as seen in the Alfonso X corpus". - SHLL, 9 (2016), 95-112.

65-751. Hijano Villegas, Manuel "Monumento inacabado: la Estoria de España de Alfonso VII a Fernando III". - CEHM, 37 (2014), 13-44.

65-752. Lacomba, Marta - “¿Miseria y esplendor en la obra alfonsí?”. CEHM, 37 (2014), 63-75.

65-753. Salvo García, Irene - "Historiografía y cartas de amor: la recepción de las Heroidas de Ovidio en Francia y en España”. - CEHM, 38 (2015), 45-63.

65-754. Salvo García, Irene — "Ovidio y la compilación de la General Estoria". - CEHM, 37 (2014), 45-61.

Auto de los Reyes Magos

65-755. Giles, RyAN — "Las nuevas y viejas tecnologías del manuscrito: comentarios sobre el códice digital del Auto de los reyes magos". — Hispanismos del mundo, coord. F. Funes (Buenos Aires, 2016), pp. 287-294.
Baladro del sabio Merlín

65-756. Casais, Alejandro - "Los cultismos de las Profecías de Merlín en los Baladros castellanos". - Incipit, 35 (2015), 179-212.

Berceo, Gonzalo de

65-757. Hamlin, Ginthia María “¿«Sobre yelo escrives»?: el protagonismo de lo escrito (y otras lecturas metapoéticas) en los milagros «La casulla de Ildefonso» y «Teófilo» de Berceo". — Incipit, 35 (2015), 71-102.

\section{Fernández de Heredia, Juan}

65-758. Ayerbe Betrán, María José "Distribución discursiva y sintáctica del uso del futuro de indicativo por los presentes de indicativo o de subjuntivo en la Grant crónica de Espanya de Juan Fernández de Heredia”. AFA, 70 (2014), 35-58.

\section{Flor de virtudes}

65-759. Flor de virtudes. Ed. introd. y notas de Ana Mateo Palacios. - Universidad, Zaragoza, 2013. lviii + 163 pp. (Larumbe. Textos Aragoneses, 77). I $A F A, 70$ (2014), 292-295 (Santonocito). [Estudio filológico de un bestiario medieval traducido al castellano, s. XV].

\section{Juan Manuel}

65-760. Martín Iglesias, José Carlos "El denominado Cronicón latino de don Juan Manuel: nueva edición y estudio”. - CEHM, 38 (2015), 133-165.

Leyenda de los Infantes de Lara

65-761. Martín, Óscar - "La venganza en la tradición de los Siete infantes de Salas". — CEHM, 37 (2014), 153-169. 
65-762. Martínez Diez, Gonzalo - "El Cantar de los siete infantes de Lara: la historia y la leyenda". - CEHM, 37 (2014), 171-189.

\section{Libro de Alexandre}

V. núm. 773

Lulio, Raimundo

65-763. Llull, R. - The book of the order of chivalry. Trad. by N. Fallows (N. 61-2040). || NRFH, 64 (2016), 590-591 (Luna Mariscal).

\section{Madrigal, Alfonso de}

65-764. Juste, Mélanie — “«Un feu caché au fond des entrailles»: la théorisation de l'amour par Alfonso de Madrigal, dit «El Tostado» (1404/14010-1455)”. - CEHM, 38 (2015), 91-116.

\section{Marmolejo, Juan}

65-765. Tosar López, Javier - "Mosén Juan Marmolejo: una figura desconocida del Cancionero de Palacio (SA7)". - Cincuentenario de la AIH, ed. R. Barros Roel (A Coruña, 2014), pp. 445-451.

\section{Moncayo, Mosén Juan de}

65-766. López Drusetta, Laura "Notas para el estudio de la figura y la obra de Mosén Moncayo, poeta del Cancionero de Palacio (SA7)". - Cincuentenario de la AIH, ed. R. Barros Roel (A Coruña, 2014), pp. 295-305.

\section{Nebrija, Antonio de}

65-767. Nebrija, Antonio de - Epithalamivm en honor de las bodas de la infanta Isabel de Castilla y el príncipe Alfonso de Portugal. Ed. de Ruth Martínez Alcor- lo. - Ediciones Clásicas, Madrid, 2013. 165 pp. || Dicenda, 32 (2014), 361-364 (Zamarreño).

65-768. Pellen, R. y F. Tollis - La «Gramática castellana» d'Antonio de Nebrija: grammaire d'une langue, langue d'une grammaire (N. 61-2056). \| RLiR, 79 (2015), 542-548 (Ridruejo). - V. $63-897$.

65-769. Rodrigo Mora, María - "Antonio de Nebrija y las controversias lingüísticas promovidas por Leon Battista Alberti”. - Cincuentenario de la $A I H$, ed. R. Barros Roel (A Coruña, 2014), pp. $415-426$.

V. también núm. 27.

\section{Poema de Fernán González}

65-770. Alcatena, María Eugenia "Plegaria como diálogo vasallático en el Poema de Fernán González". - Incipit, 35 (2015), 35-70.

\section{Poema del Cid}

65-771. Historia de Rodrigo. Trad., introd. y notas de R. Borden Eng (N. 63-900). ॥ NRFH, 64 (2016), 587-590 (Higashi).

65-772. Fernández Durán, DAVID - "La voz alcándara en el Cantar de mio Cid: cetrería hispanoárabe en la literatura española”. - PHisp, 28 (2014), núms. $1 / 2,35-49$.

65-773. JANin, Érika - "Elementos sobrenaturales en el Cantar del mio Cid, Libro de Alexandre, Poema de Fernán González y Mocedades de Rodrigo: manifestaciones y funciones". - Incipit, 35 (2015), 103-125.

65-774. Quero, Alberto - “"Maravilla es del Çid, que su ondra creçe tanto». Argumentación y apartes en el poema de mio Cid". - ERM, 24 (2015), 199-210.

\section{Rojas, Fernando de}

65-775. Alonso, Álvaro - “"Mira Nero de Tarpeya»: el romance, La Celesti- 
na y la poesía italiana”. - RILCE, 32 (2016), 32-46.

65-776. Gargano, Antonio - "La Celestina y el otoño de la Edad Media”. Hispanismos del mundo, coord. F. Funes (Buenos Aires, 2016), pp. 31-52.

\section{Ruiz, Juan (Arcipreste de Hita)}

65-777. Pla Colomer, Francisco P. "De nuevo sobre letra y voz del Arcipreste: en defensa de la edición de J. Corominas". - RHLE, 9 (2014), 175187.

\section{Sarnés}

65-778. Martínez García, Paula "Sarnés, poeta cancioneril del siglo $\mathrm{xv}$ : aproximación a su obra y figura”. - Cincuentenario de la AIH, ed. R. Barros Roel (A Coruña, 2014), pp. 317-327.

\section{Sosa, Lope de}

65-779. Campos Souto, María BegoÑ - "Cómo surgen burlas y risas de un penoso trance (desentrañando la anécdota base ID 2036 «Quantos fuistes y venistes», de Lope de Sosa)". Cincuentenario de la AIH, ed. R. Barros Roel (A Coruña, 2014), pp. 241-252.

\section{Vida de Santa María Egipciaca}

65-780. Zubillaga, Carina - "Configuración espacio-temporal de la santidad femenina medieval en la Vida de santa María Egipciaca". - CuIF, 41 (2015), 33-45.

\section{SIGLOS DE ORO}

\section{Poesía}

65-781. Carreira, ANTONIO - "El conde duque de Olivares y los poetas de su tiempo". - NRFH, 64 (2016), 429-456.
65-782. Eichmann Oehrli, Andrés "Canto religioso, sermones en zonas rurales y urbanas: una mirada desde el sur andino". - Ibero, 2016, núm. 61, 103-122.

65-783. Navascués, JaVIER DE - "Alteridad y mímesis del pirata en la épica colonial". - Hipogrifo, 4 (2016), núm. 1, 43-63.

65-784. Rovira i Cerdà, Helena - "Un romance al tono de "Caballero de armas blancas» más otras obras devotas". - RRo, 49 (2014), 293-317.

65-785. Segas, Lise - "Mujeres indígenas en la épica histórica hispanoamericana". - Hipogrifo, 4 (2016), núm. 1, 119-138.

V. también núm. 724.

\section{Teatro}

65-786. Alcántara Mejía, J.R., A. Ontiveros y D. Cazés GrYJ (coords.) - Dramaturgia y teatralidad del Siglo de Oro: la presencia jesuita (N. 62-1695). || RILCE, 32 (2016), 244246 (Kallendorf).

65-787. Arellano, I. y J.A. Martínez Berbel (eds.) - Violencia en escena y escenas de violencia en el Siglo de Oro (N. 64-2360). || RILCE, 32 (2016), 247-251 (Gutiérrez Pérez).

65-788. Durá Celma, Rosa — “ «Un nuevo arrepentimiento»: La conversión de la Magdalena, una comedia inédita de la colección teatral de Diego Sarmiento de Acuña, Conde de Gondomar". - CuIF, 41 (2015), 7-31.

65-789. Labarre, F. et Roland LabarRe

- Seize aperçus sur le théâtre espagnol du Siècle d'Or (N. 62-579). \| NRFH, 64 (2016), 591-595 (Cazés). — V. 64-594.

65-790. Profeti, Maria Grazia (coord.) - Il teatro dei Secoli d'Oro. - Bompiani, Milano, 2014-2015. 2 ts.: 2436 pp. || CAISPI, 2016, núm. 7, 175-181 (Alviti).

65-791. Vila Carneiro, Zaida y Fátima Faya Cerqueiro - "Consideraciones acerca de la fórmula de despedida $a$ Dios en el teatro del Siglo de Oro". Onomázein, 2016, núm. 33, 39-56.

V. también núms. 821, 995 


\section{Narrativa}

65-792. BARrerA, T. - Por lagunas y acequias. La hibridez de la ficción novohispana (N. 63-1937). || Ibero, 2015, núm. 60, 227-228 (Tedeschi). - V. 64-598.

65-793. Camacho Delgado, José MANUEL - Narrar lo imposible. La crónica indiana desde sus márgenes. - Verbum, Madrid, 2014. 174 pp. || Ibero, 2015, núm. 59, 243-245 (Marroquín Arredondo).

65-794. Donoso, Miguel, Mariela Insúa y Carlos Mata InduRÁin (eds.) - El cautiverio en la literatura del Nuevo Mundo. - IberoamericanaVervuert, Madrid-Frankfurt/M., 2011. 287 pp. || LexisL, 40 (2016), 187-193 (Arias).

65-795. Mancera Rueda, Ana y Jaime Galbarro García - Las relaciones de sucesos sobre seres monstruosos durante los reinados de Felipe III y Felipe IV (15981665). Análisis discursivo y edición. Peter Lang, Bern, 2015. 304 pp. I| PHisp, 29 (2015), núms. 1/2, 101-103 (Orsanic).

65-796. Rodríguez Ramos, Alberto, Is abel Colón Calderón, David Caro Bragado y Clara Marías MarTínez (eds.) - Los viajes de Pampinea: novella y novela española en los Siglos de Oro. - Sial Ediciones, Madrid, 2013. 348 pp. || Dicenda, 32 (2014), 370-373 (Medina Poveda).

65-797. Quinn, MARY B. - The moor and the novel: Narrating absence in Early Modern Spain. - Palgrave MacMillan, New York, 2013. || CER, 35 (2015), núm. 2, 251-254 (García Santo-Tomás).

\section{Estudios diversos}

65-798. Almeida Cabrejas, Belén "Elementos cotidianos posiblemente usados para caracterizar a presuntos judaizantes en textos literarios y no literarios de los siglos Xv y xvi". Cincuentenario de la AIH, ed. R. Barros Roel (A Coruña, 2014), pp. 217-228. 65-799. Ávila Gallego, Daniel De Diálogo del colorado (Salónica, 1601).
Interpretación académica de la escarlatina. Ed., introd. y notas de Pilar Romeu Ferré. - Tirocinio, Barcelona, 2014. 303 pp. || RFE, 95 (2015), 211-213 (Gómez de Enterría). [Estudio filológico].

65-800. Federici, Marco - "La huella de Boccaccio en el Renacimiento español y la recepción de Le piacevoli notti de Straparola”. — Dicenda, 32 (2014), 95-111.

65-801. Fernández de Córdova MiraLLES, ÁlVARO — "Diplomáticos y letrados en Roma al servicio de los Reyes Católicos: Francesco Vitale di Noya, Juan Ruiz de Medina y Francisco de Rojas". — Dicenda, 32 (2014), 113-154.

65-802. García-Quismondo, Judith — "María de Estrada: de la historia a la ficción”. - CuH, 2015, núms. $781 / 782,52-65$.

65-803. Géneros híbridos y libros mixtos en el Siglo de Oro. Mélanges de la Casa de Velázquez, 43-2 (2013). — École des Hautes Études Hispaniques et Ibériques, Madrid, 2013. 344 pp. || Dicenda, 32 (2014), 373-376 (Colón Calderón).

65-804. Hasson, OR — "Locura e ingenio: los frenéticos de Huarte de San Juan entre la teoría (médica) y la práctica (narrativa)". - Hispanismos del mundo, coord. F. Funes (Buenos Aires, 2016), pp. 219-228.

65-805. Imprenta y cultura de interés hispánico en Sicilia en los siglos XVI y XVII. Ed. de Assunta Polizzi. - Peter Lang, Bern, 2013. 267 pp. || CAISPI, 2014, núm. 3, 251-252 (García Galiano).

65-806. Lagos, María Inés — "Inés de Suárez. ¿Fundadora y madre de la nación?". - CuH, 2015, núms. $781 / 782,52-65$.

65-807. López de Mariscal, Blanca - La escritura y el camino. Discurso de viajeros en el Nuevo Mundo. - Bonilla Artigas Editores, México, 2014. 218 pp. || Ibero, 2015, núm. 60, 227-228 (Bellini).

65-808. Martínez Millán, José - "Evolución de la Monarquía hispana: de la Monarchia Universalis a la «Monarquía católica» (siglos XVI-XVII)". Hispanismos del mundo, coord. F. Funes (Buenos Aires, 2016), pp. 107-130. 
65-809. Pena Sueiro, Nieves — "Recursos digitales para la investigación en literatura española: la Biblioteca Digital Siglo de Oro". - Cincuentenario de la AIH, ed. R. Barros Roel (A Coruña, 2014), pp. 381-391.

65-810. Polic Bobic, Mirjana — "Las fronteras de los virreinatos imaginadas y vividas: propuestas para relecturas del mundo misional y su época a través de los diarios de viajes de exploración, cartas edificantes y cartas personales". - Hipogrifo, 4 (2016), núm. 1, 87-101.

65-811. REYNA, IVÁN R. — "Las cartas y memoriales de Alonso de Medina: ¿Es posible hablar de un «sentimiento criollo» en el siglo Xvi?”. - Hipogrifo, 4 (2016), núm. 1, 231-241.

65-812. Rodríguez-Rodríguez, Ana MARÍA - Letras liberadas: cautiverio, escritura y subjetividad en el Mediterráneo de la época imperial española. Visor Libros, Madrid, 2013. || CER, 35 (2015), núm. 1, 231-234 (Gómez Canseco).

65-813. Strosetzki, Christoph — "El invento en el Siglo de Oro español”. - Hispanismos del mundo, coord. F. Funes (Buenos Aires, 2016), pp. 53-74.

\section{Autores (y obras anónimas)}

Aldana, Francisco de

65-814. Gamba Corradine, Jimena "Límites entre filosofía y literatura: del tratado amoroso a la literatura bucólica”. — CEHM, 38 (2015), 117-130.

\section{Alemán, Mateo}

65-815. Jojima, Paula - San Cristóbal Pérez de Herrera: pícaro. Inspiración y némesis de Mateo Alemán. — Brown Dog Books, Bath, UK, 2016. 488 pp.

V. también núm. 923.

\section{Balbuena, Bernardo de}

65-816. Zulaica López, Martín “ Obra toda tejida de una admirable variedad de cosas»: la écfrasis en $E l$ Bernardo de Balbuena”. - Hipogrifo, 4 (2016), núm. 1, 171-181.

\section{Barco Centenera, Martín del}

65-817. Ortiz Gambetta, Eugenia "Heteroglosia y tradiciones discursivas: formas burlescas en la épica de M. del Barco Centenera". - Hipogrifo, 4 (2016), núm. 1, 65-86.

\section{Basurto, Fernando}

65-818. Pedraza García, Manuel José - "Mecenazgo y edición en la primera mitad del siglo xvi: el Florindo de Fernando Basurto (Zaragoza: Pedro Hardouin, 1530)". — RILCE, 32 (2016), 225-243.

Benavente, fray Toribio de, Motolinía

65-819. Benavente, Fray Toribio de (Motolinía) - Historia de los indios de la Nueva España. Ed. de M. Serna y B. Castany (N. 63-921). || Hipogrifo, 4 (2016), núm. 1, (Oteiza Pérez). V. 64-639.

\section{Calderón de la Barca, Pedro}

65-820. Calderón de la Barca, Pedro - La dama y galán Aquiles. (El monstruo de los jardines). Ed. de Tatiana Alvarado Teodorika. - Iberoamericana-Vervuert, Madrid-Frankfurt/M., 2013. (Biblioteca Áurea Hispánica, 90). ॥ Dicenda, 32 (2014), 376-377 (Fernández San Emeterio).

65-821. Cañas Murillo, Jesús — "Pedro Calderón de la Barca en la polémica sobre Du Perron del siglo XVIII: Nasarre Montiano, García de la Huerta”. - CuIR, 21 (2015), 141-162.

65-822. Garrot Zambrana, Juan Carlos - Judios y conversos en el Corpus Christi: la dramaturgia calderoniana. - Brepols, Turnhout, 2013. 490 pp. || RILCE, 32 (2016), 260-265 (Izquierdo). 
65-823. Moro Martín, Alfredo - "Calderón de la Barca en la obra de Mary W. Shelley". — CuIR, 21 (2015), 193203.

65-824. Ramos González, Alicia "Calderón en el gueto". - Íns, 2015, núm. 825, 2-5.

65-825. Ruiz, JULIO JUAN — "Maquiavelo y la razón de estado en dos obras dramáticas de Calderón de la Barca”. Dicenda, 32 (2014), 341-356.

65-826. Vaiopoulos, Katerina - "Calderón en las polémicas italianas del siglo XIX: Carducci, Graf y Martini”. - CuIR, 21 (2015), 183-192.

V. también núms. 1025, 1266.

\section{Cervantes Saavedra, Miguel de}

65-827. Adelmo Giorgini, MassimiLIANO - "Don Quixote in American song: Underground hero and champion of the counterculture". - CER, 35 (2015), núm. 1, 49-76.

65-828. Alcalá-Galán, Mercedes "¿Qué ve Cide Hamete? Omnisciencia y visualidad en Don Quijote II". - El "Quijote" desde América. (Segunda parte), eds. I. Arellano, D. Ayalamacedo y J. Iffland (New York, 2016), pp. 27-40.

65-829. Alvarez Roblin, David — "Las dos caras del doble en el Quijote de 1615". - El "Quijote” desde América. (Segunda parte), eds. I. Arellano, D. Ayalamacedo y J. Iffland (New York, 2016), pp. 41-56.

65-830. Antonucci, Fausta - "La estructura dramática del teatro cervantino de la «primera época»: una propuesta de análisis”. — CAISPI, 2015, núm. 5, 131-145.

65-831. Araújo, Paula Renata de “«Castigat ridendo mores». El patio de Monipodio o la plaza pública. Una lectura de Rinconete y Cortadillo". ABEH, 26 (2016), 179-184.

65-832. Arellano, Ignacio - "Algunas aventuras americanas de don Quijote". — El "Quijote" desde América. (Segunda parte), eds. I. Arellano, D. Ayalamacedo y J. Iffland (New York, 2016), pp. 57-74.
65-833. Arellano, Ignacio, Duilio AyaLAMACEDO Y JAMES IFFLAND (eds.) - El "Quijote" desde América (Segunda parte). - IDEA-IGAS, New York, 2016. 309 pp. (Colección Batihoja, Estudios Indianos, 3).

65-834. Armas, Frederick A. DE — "Don Quijote y Alejandro Magno: vidas paralelas". - CuH, 2016, núm. 790, 32-47.

65-835. BADA, RICARDO - "Altisidora, la lolita del Quijote”. - CuH, 2016, núm. 790, 140-153.

65-836. Blasco, Javier - "La inagotable modernidad del Quijote”. - Ins, 2015, núm. 828, 17-21.

65-837. Borges, AdrIANA DE — “Os livros de cavalaria depois da incineraçao da biblioteca de Dom Quixote: uma notícia de sua atualizaçao no Brasil". ABEH, 26 (2016), 221-233.

65-838. Byrne, SusAN — "Coloquio, murmurar, canes muti: Cervantes y los jesuitas". - CAISPI, 2015, núm. 5, 81-95.

65-839. Calderón Calderón, Manuel - "De la historia verdadera de don Quijote al Romance armorial-popular d'A Pedra do Reino, de Ariano Suassuna”. - ABEH, 26 (2016), 103-124.

65-840. Cerezo Soler, JuAn — “La Conquista de Jerusalén en su contexto: sobre el personaje colectivo y una vuelta más a la atribución cervantina”. — Dicenda, 32 (2014), 33-49.

65-841. Childers, William P. — "Quixote Gumbo". - CER, 35 (2015), núm. 1, 17-47. [El Quijote en la cultura estadounidense].

65-842. Cortínez, VerónicA - "Cervantes y Gentille Alouette de Sergio Castilla”. — I, 83 (2016), 84-102.

65-843. Costa Vieira, Maria Augusta DA - “A Dulcinéia encantada» de Auerbach e o Dom Quixote". - ABEH, 26 (2016), 39-45.

65-844. Costa Vieira, Maria Augusta DA - "El Quijote y los saberes humanísticos". — El "Quijote" desde América. (Segunda parte), eds. I. Arellano, D. Ayalamacedo y J. Iffland (New York, 2016), pp. 75-87.

65-845. Costa Vieira, Maria Augusta DA - "Entre o público e o privado: estudo sobre o episódio dos «bata- 
nes» no Quixote". - ABEH, 26 (2016), 31-36.

65-846. Cuenca, Luis Alberto de "El Quijote de Trapiello". _ Íns, 2015, núm. 828, 26-27.

65-847. CULL, JOHN — " "Los libros son como unos mudos maestros que hablan por señas»: Alexio Venegas, mute preceptor of Cervantes?". - CER, 35 (2015), núm. 2, 129-160.

65-848. D'Onofrio, Julia - "La enfermedad como monólogo, la salud como diálogo. Melancolía, arrogancia y experiencia del otro en El amante liberal de Cervantes". - Hispanismos del mundo, coord. F. Funes (Buenos Aires, 2016), pp. 207-217.

65-849. D’OnofRio, Julia — “ “... más de satírico que de vísperas...». De invenciones e inversiones en los espectáculos de las bodas de Camacho". - El "Quijote" desde América. (Segunda parte), eds. I. Arellano, D. Ayalamacedo y J. Iffland (New York, 2016), pp. 89-105.

65-850. De Santis, Francesca - "E1 soneto de Cervantes al saco de Cádiz «Vimos en julio otra Semana Santa»: edición crítica y notas filológicas". CER, 35 (2015), núm. 1, 203-223.

65-851. Duclos, G. Cory - "Scouting out windmills: Don Quixote in Boy's life". — CER, 35 (2015), núm. 1, 77-110.

65-852. Fernández, Esther y M. ReiNA Ruiz - "Una «mesa de trucos» en escena: metamorfosis dramática de «La española inglesa»". - CER, 35 (2015), núm. 2, 193-213.

65-853. Fine, Ruth - "En torno a la representación de la mujer judía en la obra de Cervantes en el contexto de la literatura del Siglo de Oro español”. - CAISPI, 2015, núm. 5, 33-46.

65-854. Frago Gracia, Juan Antonio "El Quijote y primicias lingüísticas en México hacia la Independencia”. NRFH, 64 (2016), 385-402.

65-855. GERBER, CLEA - " «Deleites imaginados»: ficción y sugestión demoniaca en El Coloquio de los perros de Miguel de Cervantes". - ABEH, 26 (2016), 187-207.

65-856. GiL-OsLe, J.P. - Amistades imperfectas: del Humanismo a la Ilustración con Cervantes (N. 64-671). || CER, 35 (2015), núm. 1, 234-236 (Wyszynski).

65-857. González, Aurelio - "Combates de don Quijote (en la Segunda parte): encuentros y desencuentros". - El "Quijote" desde América. (Segunda parte), eds. I. Arellano, D. Ayalamacedo y J. Iffland (New York, 2016), pp. 107-123.

65-858. GonZÁlez, Aurelio - "El espacio y la representación en los entremeses de Cervantes". - CAISPI, 2015, núm. 5, 147-170.

65-859. González Echevarría, RoberTO - "Sexo y dineros en Boccaccio y Cervantes". - CuH, 2016, núm. 790, $88-107$.

65-860. Greene, Roland - Five words: Critical semantics in the Age of Shakespeare and Cervantes. - Chicago University Press, Chicago, 2013. || CER, 35 (2015), núm. 1, 225-230 (García Santo-Tomás).

65-861. Hopkins Rodríguez, Eduardo — "Verosimilitud en el capítulo 58 de la Segunda parte de El Quijote". - El "Quijote" desde América. (Segunda parte), eds. I. Arellano, D. Ayalamacedo y J. Iffland (New York, 2016), pp. 149-167.

65-862. Hutchinson, Steven - "El fin del Quijote de 1615: hacia una poética de la disolución". - El "Quijote" desde América. (Segunda parte), eds. I. Arellano, D. Ayalamacedo y J. Iffland (New York, 2016), pp. 169-178.

65-863. Illades Aguiar, Gustavo "«Para mi sola nacio don Quixote, y yo para el»: avatares de una errata pertinaz en el último párrafo del Quijote". — El "Quijote" desde América. (Segunda parte), eds. I. Arellano, D. Ayalamacedo y J. Iffland (New York, 2016), pp. 199-217.

65-864. Iwasaki, Fernando - "El Quijote y las dos Españas". - Íns, 2015, núm. $828,21-22$.

65-865. Jiménez Belmonte, Javier "Contra molinos y maestros: la Difesa di Dulcinea de Gherardo Marone y el quijotismo italiano". - CER, 35 (2015), núm. 2, 103-128.

65-866. Lamberti, Mariapia — “ «Un quidam Caporal italiano». Relaciones del Viaje del Parnaso de Cervantes con los 
antecedentes italianos". - CAISPI, 2015, núm. 5, 97-115.

65-867. LARsen, Kevin S. — "Biblical and qur'anic typology in the «Novela del cautivo»". - CER, 35 (2015), núm. 2, 9-49.

65-868. LAYNA Ranz, Francisco - "Cueva de don Quijote y sima de Sancho: las entrañas de una purgación ejemplar en el diseño compositivo del Quijote de 1615". — El "Quijote" desde América. (Segunda parte), eds. I. Arellano, D. Ayalamacedo y J. Iffland (New York, 2016), pp. 219-234.

65-869. López-BARALt, Luce — "El tal de Shaibedraa' (Quijote I, 40)". - Hispanismos del mundo, coord. F. Funes (Buenos Aires, 2016), pp. 193-204.

65-870. LORCA, DANIEL — "The epistemic and emotive foundations of Sancho". — CER, 35 (2015), núm. 2, 77-102.

65-871. Lucía Megías, José Manuel "La mirada cervantina de un maestro: Isaías Lerner (un homenaje a las Novelas ejemplares)". — Hispanismos del mundo, coord. F. Funes (Buenos Aires, 2016), pp. 163-172.

65-872. Lucía Megías, José Manuel "Un personaje llamado Miguel de Cervantes: una lectura crítica de la documentación conservada”. - CAISPI, 2015, núm. 5, 15-32.

65-873. Martín, Adrienne L. - "Cetrería y montería: la caza aristocrática en Don Quijote II". — El “Quijote” desde América. (Segunda parte), eds. I. Arellano, D. Ayalamacedo y J. Iffland (New York, 2016), pp. 235-246.

65-874. Martín Morán, José Manuel — "El peso de la voz. La autoridad del narrador en las Novelas ejemplares". CAISPI, 2015, núm. 5, 65-80.

65-875. MAXEY, BRYCE - "De Nicosia a Roma: las ruinas en El amante liberaly El licenciado Vidriera". - CuH, 2016, núm. 790, 10-31.

65-876. Miguel Magro, Tania de "Fragmentarismo ideológico en El trato de Argel'. - CER, 35 (2015), núm. 1, 181-202.

65-877. Miñana, Rogelio - "Don Quijote de las Américas: activismo, teatro y el hidalgo Quijano en el Brasil contemporáneo". — El "Quijote” desde
América. (Segunda parte), eds. I. Arellano, D. Ayalamacedo y J. Iffland (New York, 2016), pp. 247-260.

65-878. Montero Reguera, José — “Los tres Quijotes ante la poesía: una propuesta sobre el discurso poético de Cervantes". - CAISPI, 2015, núm. 5, 117-129.

65-879. Moreira, Sandra Regina "Cardênio: de personagem novelesco a jornalista do Don Quixote (18951903) de Ángelo Agostini". — $A B E H$, 26 (2016), 81-90.

65-880. Moreira, Sandra Regina "Uma releitura do Quixote de Cervantes pelo Dom Quixote de Ángelo Agostini". - ABEH, 26 (2016), 67-78.

65-881. Nava, G. - Los tres rostros de la plaza pública en el "Quijote" (N. 63-969). ॥ NRFH, 64 (2016), 595-598 (Rodríguez Valle). - V. 64-2479.

65-882. Navarro Flores, CÉlia - "Uma novela exemplar de Cervantes no cordel brasileiro: La fuerza de la sangre". ABEH, 26 (2016), 237-248.

65-883. NúÑ̃z Rivera, V. - Cervantes y los géneros de la ficción (N. 64-678). II CAISPI, 2016, núm. 7, 181-184 (Brioso Santos).

65-884. Olid Guerrero, Eduardo Del teatro a la novela: el ritual del disfraz en las "Novelas ejemplares" de Cervantes. - Biblioteca de Estudios Cervantinos, Alcalá de Henares, 2015. 389 pp.

65-885. Pedraza Jiménez, Felipe B. "La cultura de Cervantes y la construcción de la novela moderna”. - $A B E H$, 26 (2016), 13-27.

65-886. Pérez Martínez, Ángel "Silencios sobre Cervantes en el Perú decimonónico". — El "Quijote" desde América. (Segunda parte), eds. I. Arellano, D. Ayalamacedo y J. Iffland (New York, 2016), pp. 261-270.

65-887. Presas, Adela — "Recreación del Quijote en la ópera italiana: condicionantes y convenciones del género receptor". - CAISPI, 2015, núm. 5, 189-202.

65-888. Presberg, Charles D. - "Silenos divinos en el espejo encantado: el Coloquio de los perros y la poética vital del Quijote, II". — El "Quijote" desde América. (Segunda parte), eds. I. Arella- 
no, D. Ayalamacedo y J. Iffland (New York, 2016), pp. 271-286.

65-889. Presotto, Marco - "El teatro posible de Miguel de Cervantes". Ins, 2015, núm. 828, 24-26.

65-890. Ramírez Santacruz, FrancisCO - "Sancho: los «Panzas", la boca y el habla". — El "Quijote" desde América. (Segunda parte), eds. I. Arellano, D. Ayalamacedo y J. Iffland (New York, 2016), pp. 287-298.

65-891. Rodríguez, Adriana AzuceNA — "El viaje como exploración del carácter español según las Novelas ejemplares". - ABEH, 26 (2016), 251-262.

65-892. Romo Feito, Fernando - "Don Quijote en la Academia”. — Íns, 2015, núm. 827, 22-24.

65-893. Ruffinatto, Aldo - "En el texto del Quijote”. - Hispanismos del mundo, coord. F. Funes (Buenos Aires, 2016), pp. 173-192.

65-894. Ruffinatto, Aldo - "Entre asaduras y salpicones (Joyce y Cervantes)". - CAISPI, 2015, núm. 5, 203-221.

65-895. SÁez, Adrián J. — "Un «pecado tan malo y feo": variaciones cervantinas sobre el suicidio". — I, 82 (2016), 202-217.

65-896. Sánchez Portero, A. - Cervantes y Liñán de Riaza: el autor del otro "Quijote" atribuido a Avellaneda (N. 62-1916). || CER, 35 (2015), núm. 2, 254-257 (Heredia Mantis).

65-897. Scham, Michael — "Che, Quijote: Cervantes y el tango". — El "Quijote" desde América. (Segunda parte), eds. I. Arellano, D. Ayalamacedo y J. Iffland (New York, 2016), pp. 299-309.

65-898. SCHMIDT, RACHEL — "Cervantes's ingenioso hidalgo: Ingenio and the Americas". - CER, 35 (2015), núm. 2, 51-76.

65-899. Sherman, Kátia — "Ungodly miracle or holy rape: Irony and the rule of faith in Cervantes's «La fuerza de la sangre»". — CER, 35 (2015), núm. 2, 215-249.

65-900. Silva Moraes, Valéria da "Entre dois Quixotes: Cervantes e Avellaneda ás voltas com o cómico”. - ABEH, 26 (2016), 211-217.
65-901. Smith, Wendell P. — "What's a name: Andrés Caballero and chivalric romance in «La gitanilla»". - CER, 35 (2015), núm. 1, 153-180.

65-902. Tanico, Matthew S. - "La escritura más allá de la muerte: el lienzo en el Persiles". - CuH, 2016, núm. 790, 48-67.

65-903. Vila, JuAn Diego - «نMurmuración o ejemplaridad? En torno a los juegos elocutivos de las Novelas ejemplares: el caso de los gitanos". - Hispanismos del mundo, coord. F. Funes (Buenos Aires, 2016), pp. 229-242.

65-904. Williamson, EdWin - "Los dos desenlaces del Quijote”. - CuH, 2016, núm. 790, 68-87.

V. también núms. 814, 910, 974, 1059, 1067, 1082, 1247, 1356 .

\section{Cetina, Gutierre de}

65-905. Cetina, G. DE - Rimas. Ed. de J. Ponce Cárdenas (N. 64-688). || Dicenda, 32 (2014), 366-368 (Rodríguez de Ramos). - V. 64-2506.

\section{Delicado, Francisco}

65-906. Delicado, Francisco - Lozana. Portret van de weelderige Andalusische in allerhelderst Spaans in Rome geschreven welk portret vertoont wat zij in Rome beleefde en veel meer dingen bevat dan de Celestina. Vertaald door Henk de Vries. — Verloren, Hilversum, 2016. 258 pp.

\section{Diamante, Juan Bautista}

65-907. Rubio SAn Román, Alejandro y Elena Martínez Carro - Juan Bautista Diamante y su familia judeoconversa. - Hebraica Ediciones, Madrid, 2013. || Dicenda, 32 (2014), 377-380 (Jiménez Fernández).

\section{Díaz del Castillo, Bernal}

65-908. Rodríguez Mansilla, FernanDo - "Las lágrimas de Hernán Cortés 
en la Historia verdadera de Bernal Díaz del Castillo". - Hipogrifo, 4 (2016), núm. 1, 103-117.

\section{Durán, Diego}

65-909. Vargas Montes, Paloma - "El horizonte hermenéutico y el valor etnohistórico en la anotación filológica del Libro de los ritos (1579) de fray Diego Durán (OP)". _- Hipogrifo, 4 (2016), núm. 1, 157-169.

\section{Fernández de Avellaneda, Alonso}

65-910. Álvarez Roblin, David - "El Quijote de Avellaneda: ¿una falsificación literaria?”. —Íns, 2015, núm. 827, 3-7. V. también núms. 895, 899, 924.

\section{Fernández de Oviedo, Gonzalo}

65-911. López de Mariscal, Blanca " "Había mucha falta de tales mujeres de Castilla»". — CuH, 2015, núms. 781/782, 24-37.

\section{Garcilaso de la Vega}

65-912. Fosalba, Eugenia - "El desembarco de Garcilaso en Italia”. - Íns, 2015, núm. 825, 6-8.

\section{Garcilaso de la Vega, el Inca}

65-913. PARRA, RICHARD - La tiranía del Inca. El Inca Garcilaso y la escritura politica en el Perú colonial (1568-1617). Copé, Lima, 2015. 508 pp. || Hipogrifo, 4 (2016), núm. 1, 293-297 (Morong Reyes).

Góngora, Luis de

65-914. Blanco, M. - Góngora heroico. Las "Soledades" y la tradición épica (N. 62-761). || La Perinola, 20 (2016), 365371 (Duarte); RFE, 95 (2015), 213-215 (Jauralde). - V. 63-2431.
65-915. Bonilla Cerezo, R. y P. TangaNELLI — "Soledades" ilustradas: retablo emblemático de Góngora (N. 62-763). ॥ Dicenda, 32 (2014), 368-369 (Colón Calderón); RILCE, 32 (2016), 251-253 (Rojas Castro). - V. 63-2433.

65-916. Dolfi, L. — Luis de Góngora. Cómo escribir teatro (N. 63-1010). || CAISPI, 2014, núm. 3, 244-246 (Ruggeri Marchetti).

65-917. SÁnchez Robayna, Andrés "Poesía y traducción: un soneto de Góngora”. - CuH, 2015, núm. 777, 128-135.

$$
\text { González de Nájera, Alonso }
$$

65-918. Donoso Rodríguez, Miguel — "Noticias sobre Alonso González de Nájera y la edición de su Desengano y reparo de la guerra del Reino de Chile (1614)". — Hipogrifo, 4 (2016), núm. $1,9-21$.

\section{Gracián, Baltasar}

65-919. Arellano, Ignacio - "La erudición variada de Gracián. Nuevas notas al Criticón”. — RFE, 95 (2015), 233-250.

\section{Hurtado de Toledo, Luis}

V. núm. 814.

$$
\text { Jáuregui, Juan de }
$$

65-920. ZEPEDA, Jorge — “Clasicismo, estética, tradición: el Orfeo de Juan de Jáuregui". - NRFH, 64 (2016), 527542.

$$
\text { Juana Inés de la Cruz, sor }
$$

65-921. Calvo, Hortencia y Beatriz Colombi - Cartas de Lysi. La mecenas de sor Juana Inés de la Cruz en correspondencia inédita. - Iberoamericana-Vervuert, Madrid-Frankfurt/M., 2015. 
242 pp. (Parecos y Australes. Ensayos de Cultura de la Colonia, 16). || Ibero, 2016, núm. 62, 259-261 (Sozzi).

65-922. Romero Contreras, Arturo — "Sor Juana, el desocultamiento de América y el espacio de la verdad: una lectura del Neptuno alegórico desde la filosofía política”. - Graffylia, 2015, núm. 21, 5-16.

\section{Liñán de Riaza, Pedro}

V. núm. 895.

López de Úbeda, Francisco

65-923. Tobar Quintanar, María José - "La cita de La pícara Justina en los Sueños: una aguda variante de autor con una posible alusión burlesca a Guzmán de Alfarache”. — La Perinola, 20 (2016), 333-361.

Marti, Juan

(Mateo Luján de Sayavedra)

65-924. Alvarez, D. - De l'imposture à la création: Le «Guzman» et le "Quichotte» apocryphes (N. 64-2399). || CER, 35 (2015), núm. 2, 258-260 (Imperiale).

\section{Mártir de Anglería, Pedro}

65-925. Álvarez Moreno, Raúl et al. (eds.) - Una embajada española al Egipto de principios del siglo XVI: la "Legatio Babilónica" de Pedro Mártir de Anglería. Estudio y edición trilingüe anotada en latín, español y árabe. Est., ed., notas y trad. al español de Raúl Álvarez Moreno, trad. al árabe de Ebtisam Shaban Mursi y rev. de El Sayed Ibrahm Soheim. - Instituto Egipcio de Estudios Islámicos en MadridCantArabia Editorial, Madrid, 2013. 214 pp. || Dicenda, 32 (2014), 364-366 (Alonso).
Mendieta, Jerónimo de

65-926. Serna, Mercedes - "Modelos narrativos y aspectos retóricos del género hagiográfico en la Historia eclesiástica indiana, de Jerónimo de Mendieta”. - Hipogrifo, 4 (2016), núm. 1, $139-156$.

Morales, Cristóbal de

65-927. Carmona Tierno, Juan Manuel - "Violencia y versificación en Renegado, rey y mártir de Cristóbal de Morales". - Hipogrifo, 4 (2016), núm. 1, 183-197.

\section{Pérez de Hita, Ginés}

65-928. Pérez de Hita, Ginés - Historia de los bandos de los zegries y abencerrajes. Ed. crit. e introd. di Mirko Brizi. - Ibis, Como-Pavia, 2011. clviii + 571 pp. || CAISPI, 2014, núm. 3, 248-251 (Leonetti).

\section{Quevedo, Francisco de}

65-929. Quevedo, Francisco DE - Obras completas en prosa. T. 5: Tratados politicos. Dir. de Alfonso Rey. — Castalia, Madrid, 2012. 1258 pp. || La Perinola, 20 (2016), 376-385 (Sánchez Sánchez).

65-930. Quevedo, Francisco De - Providencia de Dios (Tratado de la inmortalidad del alma y Tratado de la divina providencia). Ed. de Sagrario López Poza. - SIELAE, A Coruña, 2015. 379 pp. || La Perinola, 20 (2016), 371-376 (Ettinghausen).

65-931. Quevedo, F. DE - Sueño sobre la muerte, Hrsg. K. Maurer, I. NoltingHauff und K. Ochs (N. 62-791). II NRFH, 64 (2016), 598-600 (Kohut).

65-932. Arellano, Ignacio — "Medios escénicos en los entremeses de Quevedo". — La Perinola, 20 (2016), 273297.

65-933. CAMPa, Mariano de la — “Las dos aves y los dos animales fabulosos. Cua- 
tro romances y un prólogo de Francisco de Quevedo (II)". — Incipit, 35 (2015), 213-232.

65-934. Gargano, Antonio — “ “Verdades diré en camisa». Comicidad y poder en la poesía burlesca de Quevedo". — La Perinola, 20 (2016), 17-51.

65-935. IFFLAND, JAMES — "Una mirada retrospectiva sobre Quevedo y lo grotesco (autocrítica, autobombo y perplejidad)". — La Perinola, 20 (2016), 53-81.

65-936. Llamas, Jaсово — “Quevedo y los duques de Medinaceli: los poemas para la muerte del marqués de Alcalá de la Alameda, Pedro Girón Enríquez de Ribera”. - La Perinola, 20 (2016), 299-312.

65-937. Madroñal, Abraham - "Un verso perdido de Quevedo y alguna nueva lectura de sus entremeses en un manuscrito portugués". - La Perinola, 20 (2016), 83-93.

65-938. Martinengo, Alessandro - $A l$ margen de Quevedo. Paisajes naturales. Paisajes textuales. - IDEA, New York, 2015. 158 pp. || Hipogrifo, 4 (2016), núm. 1, 289-292 (Escudero); La Perinola, 20 (2016), 385-388 (Santa A.).

65-939. Martínez Bogo, EnriQue "Humor y agudeza en Gracias y desgracias del ojo del culo". — La Perinola, 20 (2016), 95-134.

65-940. Nider, VAlentina - "El romance «Cruel llaman a Nerón» de Quevedo y la tradición del elogio paradójico del tirano”. - La Perinola, 20 (2016), 135-156.

65-941. Nider, V. - Una "consolatio de Quevedo": la "Carta a Antonio de Mendoza” (N. 63-1045). || CAISPI, 2014, núm. 3, 246-248 (Sáez).

65-942. Palacio Ortiz, Nortan "Apuntes para una puesta en escena de Cómo ha de ser el privado de Francisco de Quevedo". - La Perinola, 20 (2016), 313-332.

65-943. Plata, Fernando - "Risas de ida y vuelta: León y Arce con Quevedo de viaje a Andalucía”. - La Perinola, 20 (2016), 157-202.

65-944. Rubio Árquez, Marcial "Modelos literarios y parodia quevedesca: algunas notas sobre el Poema heroico de las necedades y locuras de Orlando enamorado". - La Perinola, 20 (2016), 203-220.

65-945. Valdés GázQuez, Ramón "Francisco de Quevedo por las sendas de la sátira menipea”. - La Perinola, 20 (2016), 221-270. V. también núm. 923 .

\section{Robles, Juan de}

65-946. López Bernal, Desirée - "Procedencia árabe de un cuentecillo singular en la obra de Juan de Robles". - Hipogrifo, 4 (2016), núm. 1, 217230.

\section{Ruiz de Alarcón, Juan}

65-947. Ruiz de Alarcón, JuAn - Examen de maridos. Ed. de Maria Grazia Profeti. - Universidad Autónoma de Ciudad Juárez, Ciudad Juárez, 2016. 148 pp. (Obras Dramáticas Completas, 20).

65-948. Ruiz de Alarcón, JuAn - La crueldad por el honor. Ed. de José Montero Reguera y María Jesús Fontela Fernández. — Universidad Autónoma de Ciudad Juárez, Ciudad Juárez, 2015. 162 pp. (Obras Dramáticas Completas, 19).

65-949. Ruiz de Alarcón, J. - La manganilla de Melilla, ed. N. Rodrígue Valle (N. 63-2529). || NRFH, 64 (2016), 600604 (Fernández Guillermo).

Salas Barbadillo, Alonso J. de

65-950. Salas Barbadillo, A.J. de Don Diego de noche. Ed. de E. García Santo-Tomás (N. 63-1062). || RILCE, 32 (2016), 257-260 (Gutiérrez Sanz). - V. 64-743.

\section{Sarmiento de Gamboa, Pedro}

65-951. Eichmann Oehrli, Andrés y JoAquín Zuleta Carrandi - "Edición y traducción de la «Carta a lord 
Burghley» de Pedro Sarmiento de Gamboa". - Hipogrifo, 4 (2016), núm. $1,23-42$.

\section{Teresa de Jesús}

65-952. Garriga Espino, AnA - "La autoridad literaria de Teresa de Jesús". —Íns, 2015, núm. 828, 2-6.

65-953. López Castro, Armando "Teresa de Jesús, el cuerpo de la escritura (1515-2015)". - CuH, 2015, núm. 777, 105-118.

Tirso de Molina (fray Gabriel Téllez)

65-954. Molina, Tirso DE - Amar por arte mayor. Ed. crít., est. y notas de Enrique García Santo-Tomás. IDEA-IET, New York-Madrid-Pamplona, 2015. 176 pp. || Hipogrifo, 4 (2016), núm. 1, 299-302 (Ortiz Lottman).

65-955. LAmARI, NAIMA — "Los espacios paternos en algunas comedias de Tirso de Molina”. - Cincuentenario de la AIH, ed. R. Barros Roel (A Coruña, 2014), pp. 277-286.

65-956. Prieto García-Seco, David Cuatro siglos de lexicografía española. La recepción de Tirso de Molina en los diccionarios del español. - Universidade, A Coruña, 2014. 224 pp. (Anexos de Revista de Lexicografia, 24). || RLex, 20 (2014), 205-207 (Iraceburu Jiménez).

\section{Valdés, Juan de}

65-957. VAldés, J. DE - Diálogo de la lengua. A diplomatic edition by K. Anipa (N. 63-1070). || NRFH, 64 (2016), 543547 (Máynez). — V. 64-2557.

\section{Vega Carpio, Lope de}

65-958. GonzÁlez EcheVArRía, RoberTO - "Improvisación y error en Lope: La niña de plata”. - CuH, 2015, núm. 786, 2-33.

65-959. IZquierdo Domingo, AMPARo Los autos sacramentales de Lope de Vega: clasificación e interpretación. - Academia del Hispanismo, Vigo, 2013. 252 pp. || RILCE, 32 (2016), 265-268 (Faúndez Carreño).

65-960. Rouhi, Leyla - "Lope de Vega and the meanings of book ownership". — Hipogrifo, 4 (2016), núm. 1, 253-269.

65-961. Trambaioli, Marcella - La épica de amor en las comedias de ambientación urbana de Lope de Vega, y su contexto representacional cortesano. - Visor, Madrid, 2015. 484 pp. || CAISPI, 2016, núm. 7, 184-186 (Volpe).

Vélez de Guevara, Luis

65-962. Vélez de Guevara, Luis - Juliano Apóstata. Ed. crít. de William R. Manson y C. George Peale, introd. de Arturo Rodríguez López-Abadía. - Juan de la Cuesta, Newark, DE, 2016. 100 pp.

\section{Zapata, Luis de}

65-963. Rodríguez Cachón, Irene "Autoridad e innovación en la traducción del Ars poetica horaciano de Luis de Zapata”. - Hipogrifo, 4 (2016), núm. 1, 243-254.

\section{SIGLO XVIII}

\section{Poesía}

65-964. Baldellou Monclús, Daniel - "El ascenso de la masculinidad: mujeres transgresoras en la literatura popular del siglo xviII". - CuIR, 21 (2015), 205-236.

65-965. Böhl de FABER, JuAN Nicolás - Floresta de rimas antiguas castellanas. Est. prel. de Belén Molina Huete, Emilia Merino Claros, Francisco Báez de Aguilar González y Fernando Durán López. - Frente de Afirmación Hispanista, México, 2015. 3 ts.: 465, 457, 489 pp. || CuIR, 22 (2016), 529-531 (Lama).

65-966. Bonilla Cerezo, Rafael y Ángel L. Luján Atienza (eds.) - 
Zoomaquias. Épica burlesca del siglo XVIII. - Iberoamericana-Vervuert, MadridFrankfurt/M., 2014. 514 pp. || Ibero, 2015, núm. 59, 231-232 (Hiergeist).

\section{Teatro}

65-967. Bec, Caroline - "La comédienne-chanteuse Rosa Rodríguez: une graciosa dans les drames lyriques madrilènes (1720-1746)". — CuDie, 16 (2015), 21-38.

65-968. Presas, Adela — "No solo ópera. Interacciones generativas en la escena lírica madrileña de la segunda mitad del siglo XviII". — CuDie, 16 (2015), 91-123.

\section{Estudios diversos}

65-969. AstigarragA, Jesús (ed.) The Spanish Enlightenment revisited. - Oxford University-Voltaire Foundation, Oxford, 2015.313 pp. || CuIR, 21 (2015), 341-344 (Villamediana González).

65-970. Calafat Vila, Rosa - "Lenguaje común y simbología en el siglo XviII: Mallorca en el episcopado de Juan Díaz de la Guerra (1772-1777)”. - ERN, 24 (2015), 101-113.

65-971. Díaz Lage, Santiago — "María de Egipto y las egipciacas en algunos textos de la Edad Moderna”. - CuIR, 22 (2015), 101-128.

65-972. Durán López, Fernando - "Las artes de un predicador en guerra con las Luces: teoría y práctica de la oratoria sacra según el epistolario de fray Diego José de Cádiz”. — Dicenda, 32 (2014), 51-81.

65-973. Ebenhoch, Markus y Veronika Österbauer (eds.) - La religión, las letras y las Luces. El factor religioso en la Ilustración española e hispanoamericana. - Peter Lang, Frankfurt/M., 2015. 204 pp. || Ibero, 2016, núm. 62, 240-244 (Gottschalk).

65-974. Ertler, Klaus-Dieter, ElisaBeth Hobisch \& Andrea Maria HuMPL - Die Spectators in Spanien. Die kleinen Schriften der 1780 er Jahre. -
Peter Lang, Frankfurt/M., 2014. 370 pp. || Ibero, 2015, núm. 59, 232-234 (Uzcanga Meinecke).

65-975. Gimeno Puyol, María DoloRES Y ERnesto Viamonte LUCientes (coords.) - Los viajes de la razón. Estudios dieciochistas en homenaje a MariaDolores Albiac Blanco. - Institución "Fernando el Católico", Zaragoza, 2015. 399 pp. || CuIR, 22 (2016), 511514 (Olay Valdés).

65-976. Jurado Santos, Agapita — "El Quijote prerromántico en la Europa occidental: catálogo y propuesta de estudio". - CAISPI, 2015, núm. 5, 171-187.

65-977. Rodríguez Fisher, AnA "Aquellos hombres de peluca blanca”. — CuH, 2015, núm. 784, 92-101.

65-978. RuedA, ANA — "Cartas y cartapacios: la crítica literaria del xvirI ante la «vana erudición» del coleccionismo". - CuIR, 21 (2015), 11-23.

65-979. Solervicens, Josep y Antoni L. Moll (eds.) - La poètica europea de la Illustració. Raó i cànon. - Punctum, Barcelona, 2014. 223 pp. (Poétiques, 4). || CuDie, 16 (2015), 373-375 (García Navarro).

65-980. Villamediana GonZÁlez, LETICIA — “"Prescription for scolding wives»: esposas gruñonas y transgresoras en la prensa inglesa y española del siglo XVIII". — CuIR, 22 (2016), 79-100.

\section{Autores (y obras anónimas)}

Amar y Borbón, Josefa

65-981. Amar y Borbón, J. - Discorso sull'educazione fisica e morale delle donne. Trad. e note di E. Carpi (N. 63-1169). || CAISPI, 2014, núm. 4, 231-233 (Pérez Vicente).

\section{Cadalso, José}

65-982. Cañas Murillo, Jesús — "Una inconfesa novela de la Ilustración: Cartas marruecas, del Coronel Cadalso". - CuIR, 22 (2016), 205-227. 
Feijoo, Benito Jerónimo

65-983. Feijoo, Benito Jerónimo Lidiando con sombras. Antología. Ed. de Elena de Lorenzo Álvarez, Rodrigo Olay Valdés y Noelia García Díaz. - Trea-Instituto Feijoo de Estudios del Siglo XVIII, Oviedo, 2014. 256 pp. || CuIR, 22 (2016), 503-509 (Román López).

65-984. Feijoo, B.J. - Obras completas. T. 2: Cartas eruditas y curiosas 1, eds. I. Urzainqui y E. San José Vázquez (N. 64-2609). || CuIR, 22 (2016), 503-509 (Román López).

65-985. Olay VAldés, Rodrigo — "La poesía y sus constitutivos esenciales según Feijoo”. - CuDie, 16 (2015), 339-369.

65-986. Olay Valdés, Rodrigo - “Treinta y tres poemas inéditos de Feijoo y reconstrucción de la historia textual del corpus poético feijoniano". - CuIR, 22 (2016), 339-433.

\section{Jovellanos, Gaspar Melchor de}

65-987. Lorenzo Álvarez, ElenA de "Aproximaciones al epistolario de G.M. de Jovellanos, con veinticuatro cartas inéditas". - CuIR, 21 (2015), 53-108.

65-988. Lorenzo Álvarez, Elena de "Aproximaciones al epistolario de G.M. de Jovellanos (II): addenda et corrigenda". - CuIR, 22 (2016), 483489.

\section{Valladares de Sotomayor, Antonio}

65-989. Sutherland-Meier, Madeline - "La guerra de Independencia en el escenario: las comedias patrióticas de Antonio Valladares de Sotomayor". Cincuentenario de la AIH, ed. R. Barros Roel (A Coruña, 2014), pp. 427-434.

\section{Viera y Clavijo, José de}

65-990. Galván González, VictoRIA - "Las cartas privadas de Viera y Clavijo al marqués de San Andrés (1770-1792)". — CuIR, 21 (2015), 121139.

\section{SIGLO XIX \\ Poesía}

65-991. Correa Chiarotti, Guadalupe — "Neoclásicos y románticos: disputa literaria en el Río de la Plata (1841) y conciliación en la América poética". CuA, 2015, núm. 151, 63-77.

65-992. Feria, Miguel Ángel — "El canon parnasiano de la poesía modernista mexicana". - NRFH, 64 (2016), 457-494.

65-993. Rocca, PABlo — "Primeros impresos gauchescos: producción y consumo (1818-1830)". — CuA, 2015, núm. 151, 11-36.

\section{Teatro}

65-994. AMEnd, TRACIE - The adulteress on the Spanish stage: Gender and modernity in nineteenth-century romantic drama. - McFarland, Jefferson, NC, 2015. 220 pp. || HiJ, 37 (2016), núm. 1, 157159 (Blackshaw Naberhaus).

65-995. Cuenca Cabeza, Manuel "Adaptación e invención de la leyenda de los infantes de Lara en el teatro español”. — CEHM, 37 (2014), 191214.

65-996. Gutiérrez Sebastián, R. y B. Rodríguez Gutiérrez (eds.) - Desde la platea: estudios sobre el teatro decimonónico (N. 62-1716). || CuIR, 21 (2015), 363-366 (Romero Ferrer).

\section{Narrativa}

65-997. García Moreno, Aitor - Der Rabbi un der Minister. Dos versiones judeoespañolas de la novela alemana. Edición y estudio filológico. - Tirocinio, Barcelona, 2013. 184 pp. || RILI, 2014, núm. 24, 199 (Álvarez López).

65-998. García Suárez, Pedro - "Marcas femeninas en la imagen del hombre 
lector en la novela realista / naturalista española”. — Dicenda, 32 (2014), 185-203.

65-999. SÁnchez, María Carolina "Del orden tradicional a la modernización: personajes delincuentes en la novela argentina de la organización nacional". - CuIR, 22 (2016), 241255.

65-1000. SCHLIEPER, HENDrik - Naturalismus und Kulturkampf in Spanien. Meizinisches Wissen und Pathologisierung des Glaubens im Roman des "naturalismo radical”. - Universitätsverlag Winter, Heidelberg, 2014. 315 pp. || Ibero, 2016, núm. 61, 283-285 (Partzsch).

\section{Estudios diversos}

65-1001. Bruno, Paula — "El Círculo Literario: un espacio de sociabilidad en la Buenos Aires de la década de 1860”. — Ibero, 2015, núm. 59, 45-63.

65-1002. Carreño, Antonio - "La aproximación hermenéutica de Juan López-Morillas a la historia intelectual de finales del siglo XIx". - Cincuentenario de la AIH, ed. R. Barros Roel (A Coruña, 2014), pp. 111-124.

65-1003. Checa Beltrán, José (ed.) La cultura española en la Europa romántica. - Visor, Madrid, 2015. 289 pp. (Biblioteca Filológica Hispánica, 160). || CuIR, 21 (2015), 357-361 (Sánchez Jiménez).

65-1004. Durán López, Fernando Versiones de un exilio. Los traductores españoles de la casa Ackermann (Londres, 1823-1830). — Escolar y Mayo, Madrid, 2015. 224 pp. || CuIR, 22 (2016), 525-528 (Peñas Ruiz).

65-1005. Giné, M., M. Palenque y J.M. GoÑI (eds.) - La recepción de la cultura extranjera en "La Ilustración Española y Americana” (1869-1905) (N. 63-527). || CAISPI, 2015, núm. 5, 234-238 (Russo). - V. 64-802.

65-1006. Loaiza Cano, Gilberto "Una revolución letrada: ensayo sobre la emergencia del lenguaje político de la república en la Nueva Granada, 1807-1811”. - Ibero, 2016, núm. $62,87-106$.
65-1007. Martínez BARo, J. - L a libertad de Morfeo. Patriotismo y politica en los suenos literarios españoles (1808-1814) (N. 64-2643). || CuIR, 21 (2015), 351-355 (Loyola López).

65-1008. Martínez Baro, Jesús (ed.) Desvelos y pesadillas de una nación. Suenos literarios españoles entre 1808 y 1814. - Fundación Municipal de Cultura, Cádiz, 2014. 345 pp. (Biblioteca de las Cortes de Cádiz, 13). || CuIR, 21 (2015), 351-355 (Loyola López).

65-1009. Martino, Luis Marcelo "Las redes clásica y romántica. Intersecciones dinámicas en el Río de la Plata”. - CuIR, 22 (2016), 229-239.

65-1010. Mella, Olga Guadalupe Epistolaridad y realismo. La correspondencia privada y literaria de Juan Valera, Emilia Pardo Bazán y Benito Pérez Galdós. - Universidade, Santiago de Compostela, 2016. 222 pp.

65-1011. Peñas Ruiz, A. - El artículo de costumbres en España (1830-1850) (N. 64-2635). || CuIR, 22 (2016), 533-535 (Muñoz Sempere).

65-1012. Oropesa Márouez, S.A. - Literatura y comercio en España: las tiendas (1868-1952) (N. 64-2799). || HiJ, 37 (2016), núm. 1, 164-165 (Escaja).

65-1013. PAs, Hernán — "La educación por el folletín: prácticas de lectura y escritura en la prensa latinoamericana del siglo xıx". — CuA, 2015, núm. 151, 37-61.

65-1014. Paz Aparicio de Soto, ValenTINA - "El Español (abril de 1810 marzo de 1811): negociaciones del meridiano cultural entre América y España en un espacio de comunicación transatlántica”. - CuIR, 21 (2015), 281-304.

65-1015. Ventura Ramos, Lorena "Ironía romántica: un principio paradójico de representación literaria”. — TdS, 2015, núm. 34, 83-106.

\section{Autores (y obras anónimas)}

\section{Acosta de Samper, Soledad}

65-1016. Arbeláez, Olga — "Salvar la nación: el feminismo doméstico de 
Soledad Acosta de Samper". — ELC, 2016, núm. 38, 57-76.

65-1017. Rodríguez Rodríguez, CATALINA - "Las heroínas de Jane Austen y Soledad Acosta de Samper. Reescribiendo el ideal femenino". - ELC, 2016, núm. 38, 163-180.

\section{Acuña de Figueroa, Francisco}

65-1018. Armand Ugón, Pablo - "Versificar para el común en el siglo XIX: los epigramas de Francisco Acuña de Figueroa”. — CuA, 2015, núm. 151, 79-103.

\section{Alas, Leopoldo (Clarín)}

65-1019. León Rivero, Francisco "Fermín de Pas o la configuración del personaje escindido en La Regenta, de Clarín”. - Cincuentenario de la AIH, ed. R. Barros Roel (A Coruña, 2014), pp. 287-294.

\section{Blanco y Crespo, José María (Blanco White)}

65-1020. Durán López, Fernando "Algo más sobre la infundada atribución a Blanco White de la novela Vargas, de Alexander Dallas, con unas páginas inéditas de Vicente Llorens”. - CuIR, 22 (2016), 483-489.

65-1021. Durán López, Fernando "Blanco White y Demoustier: sobre la traducción del poema «La vida»" - CuIR, 21 (2015), 323-332.

\section{Blest Gana, Alberto}

65-1022. Faúndez, Edson, Fernando IbÁÑeZ y MaRía LUISA MarTíneZ "Martín Rivas: violencia mimética y pensamiento utópico”. — EFil, 2014, núm. 54, 49-67.

\section{Böhl de Faber, Cecilia (Fernán Caballero)}

65-1023. Castillo Cáceres, FernanDo - "Política y sociedad en la obra de Fernán Caballero”. - CuH, 2015, núm. 783, 20-41.

\section{Castro, Rosalía de}

65-1024. GonzÁlez Fernández, Helena y María do Cebreiro Rábade (eds.) - Canon y subversión. La obra narrativa de Rosalía de Castro. - Icaria, Barcelona, 2012. 204 pp. || Ibero, 2015, núm. 59, 234-236 (Paatz).

\section{Castro y Rossi, Adolfo de}

65-1025. Luengo Cuervo, Sara "Aportaciones de Adolfo de Castro a fastos calderonianos de 1881". CuIR, 21 (2015), 163-181.

\section{Dario, Rubén}

65-1026. Darío, RubÉn - Los raros. Ed. crít., introd. y notas de Günther Schmigalle, est. prel. de Jorge Eduardo Arellano. - Verlag Walter FreyTranvía, Berlin, 2015. 454 pp. || Ibero, 2016, núm. 62, 264-267 (Castañón).

65-1027. García, Miguel Ángel — "Los prólogos a Azul... (1890), de Rubén Darío: reflejos y dependencias". RILCE, 32 (2016), 159-181.

65-1028. Ortiz Aguirre, EnriQue "Una aproximación a la poética de Rubén Darío y Juan Ramón Jiménez: erótica poética, poética erótica”. PHisp, 29 (2015), núms. 3/4, 83-96.

V. también núms. 1298, 1373.

Dávila de Ponce de León, Waldina

65-1029. Trujillo Peña, Sandra MileNA - "Los personajes femeninos en la narrativa de Waldina Dávila de Ponce de León”. — ELC, 2016, núm. 38, 77-92.

\section{Espronceda, José de}

65-1030. Piquero Rodríguez, Álvaro — “ "Un carajo impertérrito, que al 
cielo»: acerca de un soneto erótico atribuido a Espronceda". - CuIR, 22 (2016), 491-501.

\section{Flores, Eugenio Antonio}

65-1031. Castañer Martín, Rosa M. "Una ilustre familia aragonesa: Braulio, Francisco y Vicente Foz". - AFA, 70 (2014), 169-199.

\section{Foz, Francisco}

V. núm. 1031.

\section{Gómez Carrillo, Enrique}

65-1032. Ehrlicher, HANno - "Enrique Gómez Carrillo en la red cosmopolita del modernismo". - Ibero, 2015, núm. 60, 41-60.

\section{Hernández, José}

65-1033. Perna, Carlos Gabriel "Fuentes históricas para el estudio de la lengua en la pampa en el siglo XIX (I): el Martín Fierro y la tradición de la gauchesca". - SEFS, 2015, núm. 27, 197-222.

\section{Isaacs, Jorge}

65-1034. VeLÁSQUez VÁsouez, Libia "Antisemitism and its effects on the political career and on intellectual oeuvre of Jorge Isaacs". — ELC, 2016, núm. 38, 93-123.

\section{Lafuente y Zamalloa, Modesto}

65-1035. Fuertes Arboix, M. - La sátira política en la primera mitad del siglo XIX. "Fray Gerundio" (1837-1842) de Modesto Lafuente (N. 64-834). || Ibero, 2016, núm. 62, 238-239 (Ceballos Viro).
Lastarria, José Victorino

65-1036. Ubilla Espinoza, LoRena "Representaciones coloniales en la escritura de Lastarria: Chile, siglo xıx". — EFil, 2015, núm. 55, 143-155.

\section{Mansilla, Lucio Victorio}

65-1037. Mansilla, L.V. - Diario de viaje a Oriente (1850-1851) y otras crónicas del viaje oriental. Ed., introd. y notas de M.R. Lojo (N. 63-2596). || Inti, 78-79 (2014), 329-332 (Graná); RILCE, 32 (2016), 269-272 (Ortiz Gambetta). V. 64-2664.

\section{Mansilla de García, Eduarda}

65-1038. Mansilla de García, EduarDA - Cuentos (1880), ed. H.B. Molina (N. 64-840). || Inti, 78-79 (2014), 333336 (Alloatti).

\section{Martí, José}

65-1039. GonZÁlez Estera, OrLando Animal que escribe. El arca de José Martí. - Vaso Roto, Madrid, 2014. 128 pp. || CuH, 2015, núm. 777, 176-179 (Galán).

65-1040. GonzÁlez-Ocaña, Jaime "Diálogo entre Martí y Maquiavelo: lectura de Nuestra América bajo el prisma de El Príncipe". — CuA, 2015, núm. 154, 53-65.

65-1041. Padrón Iglesias, Wilfredo — "José Martí y Porfirio Díaz: notas sobre una singular relación". - CuA, 2015, núm. 154, 67-87.

65-1042. Santana, Adalberto - "José Martí y la inmigración cubana en Costa Rica". - CuA, 2015, núm. 154, $39-52$

65-1043. Wood, Yolanda - "José Martí: imaginario cultural antillano, caribeño y nuestroamericano". - CuA, 2015, núm. 154, 11-38.

V. también núm. 1311. 
Mesonero Romanos, Ramón

65-1044. Peñas Ruiz, Ana - "El curioso parlante en el teatro de los seudónimos". —Íns, 2015, núm. 827, 18-22.

\section{Nosari, Elvira}

65-1045. Granados Reyes, Nancy "Comentario hermenéutico de Jacinta o el Mártir de la caverna de Elvira Nosari”. — Graffylia, 2015, núm. 21, 79-89.

\section{Pardo Bazán, Emilia}

65-1046. Hoffman, JoAn M. — "The death of the angel: A mother's «failure» in Los pazos de Ulloa and a daughter's "success» in La madre naturaleza". HiJ, 37 (2016), núm. 1, 109-125.

V. también núm. 1009.

\section{Pérez Galdós, Benito}

V. núm. 1009.

\section{Sierra O'Reilly, Justo}

65-1047. Fecht Gris, Crystal — "El suspenso como eje de la ficción en $L a$ hija del judio de Justo Sierra O'Reilly”. - Semiosis, 2015, núm. 21, 63-87.

\section{Valera, Juan}

V. núm. 1009.

\section{Vega, Ventura de la}

65-1048. Schinasi, Michael - Ventura de la Vega and "El hombre de mundo": At the threshold of the realist period in Spain. - Academia del Hispanismo, Vigo, 2015. 151 pp. (Biblioteca de Theatralia, 26). || CuIR, 22 (2016), 537-539 (Fernández-Díaz).

\section{SIGLO XX Y SIGLO XXI}

\section{Poesía}

65-1049. Adricaín, Sergio - "Poesía actual para niños y jóvenes". - $\mathrm{CuH}$, 2015, núm. 776, 21-32.

65-1050. Alcantud, Victoriano Hacedores de imágenes. Propuestas estéticas de las primeras vanguardias en España (1918-1925). — Comares-Universidad de Granada, Granada, 2014. 534 pp. || Ibero, 2016, núm. 61, 287-290 (Ceballos Viro). [Sobre ultraísmo].

65-1051. Bischoff, Christina JohanNa y Annegret Thiem (eds.) - Poesía y silencio. Paradigmas hispánicos del siglo XX y XXI. — Verlag, Münster, 2013. 229 pp. (Ars Poetica Hispanica, 3). ॥ Ibero, 2015, núm. 60, 214-218 (Serrano Navarro).

65-1052. GARcía, M.Á. - La literatura y sus demonios. Leer la poesía social (N. 62-545). || RRo, 49 (2014), 352-354 (Andersen). - V. 64-2716.

65-1053. Riedemann Vásouez, Clemente y Claudia Arellano Hermosilla - Suralidad. Antropología poética del sur de Chile. - Suralidad-Kultrún, Puerto Varas-Valdivia, 2012. 190 pp. || EFil, 2014, núm. 54, 193-195 (Valenzuela).

65-1054. Rosal Nadales, María - "La crítica y las antologías poéticas femeninas. El caso de Las diosas blancas". I, 82 (2015), 137-150.

65-1055. Sáez Delgado, Antonio — "Fernando Pessoa y sus cartas «ultraístas» en la reconstrucción de las relaciones literarias entre España y Portugal". - CAISPI, 2014, núm. 3, 13-25.

65-1056. Sepúlveda Eriz, M. - Ciudad Quiltra. Poesía chilena (1972-2013) (N. 63-2058). || EFil, 2014, núm. 53, 171175 (Figueroa).

65-1057. Sierra, Juan Carlos (ed.) La Generación del 50 para niños y jóvenes. - Ediciones de la Torre, Madrid, 2013. 245 pp. || RILCE, 32 (2016), 290293 (Abril).

65-1058. Sotomayor, Áurea María - "El exquisito viviente: esbozo de la poesía puertorriqueña actual". CuH, 2016, núm. 789, 6-19. 


\section{Teatro}

65-1059. Azcue Castillón, Verónica - "Cervantes, don Quijote y Sancho Panza en el teatro del exilio". - CER, 35 (2015), núm. 2, 161-192.

65-1060. Bellomi, PAOLA — "Teatro digital: ¿realidad o utopía? Nuevas tecnologías en el teatro español actual”. - CAISPI, 2015, núm. 7, 47-61.

65-1061. Dolle, Verena (ed.) - La representación de la "Conquista" en el teatro latinoamericano de los siglos $\mathrm{XX}$ y XXI. - Olms, New York, 2014. 370 pp. (Teoría y Práctica del Teatro, 24). I Ibero, 2016, núm. 62, 271-275 (Gallo González).

65-1062. Feuillastre, Anne-Laure "El Nuevo teatro en su entorno: elementos para su contextualización”. - ERM, 24 (2015), 115-127.

65-1063. Gidi, Claudia - "El temple jocoserio en la dramaturgia contemporánea mexicana”. - Semiosis, 2015, núm. 21, 191-198.

65-1064. Mauro, Karina - "El actor entre la dictadura y la posdictadura. Corporalidades en pugna en el cine y el teatro argentinos durante el retorno democrático (1983-1989)". — Ibero, 2016, núm. 61, 211-232.

65-1065. Oñoro, Cristina y JoAna SÁNCHEZ - "Respuestas del teatro independiente ante la crisis. El ejemplo de La Casa de la Portera (Madrid, 2012-2015)”. - CAISPI, 2016, núm. 7, 63-78.

65-1066. Orazi, Veronica — "Música y nuevas tecnologías en el teatro español del siglo xxI". - CAISPI, 2016, núm. 7, 29-46.

65-1067. Orazi, VERonica — "Reescrituras cervantinas en el teatro español contemporáneo: Els Joglars y el Quijote". - CAISPI, 2015, núm. 5, 47-63.

65-1068. Pérez-Rasilla, Eduardo "Notas para un panorama del teatro actual”. - CAISPI, 2016, núm. 7, 13-28.

65-1069. Romera Castillo, José (ed.) Creadores jóvenes en el ámbito teatral (20 $+13=33)$. - Verbum, Madrid, 2014. 363 pp. || RILCE, 32 (2016), 283-286 (Gutiérrez Meza).
65-1070. Salcedo, Hugo - "Transgresiones, nostalgias e ironías en algunos textos de la dramaturgia joven de México”. - Semiosis, 2015, núm. 21, 199-207.

65-1071. SANTOS SÁnCHEZ, Diego — "Los aparatos teatrales de Estado. Una propuesta teórica para abordar las relaciones entre teatro y dictadura en la España de Franco”. — I, 82 (2015), 170-184.

65-1072. Trecca, Simone - "Historia y memoria en las tablas. La función de la mediación en algunas técnicas metadramáticas del teatro español último”. — CAISPI, 2016, núm. 7, 79-94.

\section{Narrativa}

65-1073. Appratto, Roberto - La ficcionalidad en el discurso literario y en el fílmico. - Yaugurú-Universidad de Uruguay, Montevideo, 2014. 224 pp. || LexisL, 40 (2016), 198-212 (Pollarolo). 65-1074. Caballé, Anna - Pasé la mañana escribiendo. Poéticas del diarismo español. - Fundación José Manuel Lara, Sevilla, 2015. 309 pp. || CuH, 2015, núm. 783, 136-139 (Alberca).

65-1075. Callsen, Berit - Mit anderen Augen sehen. Aisthetische Poetiken in der französischen und mexikanischen Literatur (1963-1984). - Fink, Paderborn, 2014. 279 pp. || I, 82 (2015), 270-273 (Wrobel).

65-1076. Candia Gajá, Andrea (comp.) - Relatos del exilio. Escritores argentinos en México. — Ediciones del Ermitaño, México, 2015. || Hispam, 2015, núm. 132, 118-119 (Ramos Lavalle). [Antología].

65-1077. Casas, Ana (ed.) - El yo fabulado. Nuevas aproximaciones críticas a la autoficción. - Iberoamericana-Vervuert, Madrid-Frankfurt/M., 2014. 312 pp. || Ibero, 2016, núm. 62, 251255 (Leuzinger).

65-1078. Castillo Carrillo, GerarDo - "La narcoficción mexicana, génesis, campo literario y mercado editorial". — Semiosis, 2015, núm. 21, 129-148. 
65-1079. Cuvardic García, Dorde "La narratología desde los años setenta hasta el siglo xxI". - RFLUCR, 2014, núm. 40, 101-116.

65-1080. Díez, Julián y FERnANdo ÁNGEL Moreno (eds.) - Historia y antología de la ciencia ficción española. — Cátedra, Madrid, 2014. 520 pp. || Ibero, 2015, núm. 60, 209-211 (Marcos Fernández).

65-1081. Escartín Gual, Montserrat — "Falseando el yo literario: la autoficción”. —Íns, 2015, núm. 827, 28-33.

65-1082. Gutiérrez, Miguel - "Presencia de Cervantes en narradores latinoamericanos". — El "Quijote" desde América. (Segunda parte), eds. I. Arellano, D. Ayalamacedo y J. Iffland (New York, 2016), pp. 125-147.

65-1083. Haghenbeck, Francisco - "La literatura mexicana en el siglo xxi”. - Inti, 78/79 (2014), 275-284.

65-1084. López Pellisa, Teresa - Patologías de la realidad virtual. Cibercultura y ciencia ficción. — F.C.E., Madrid, 2015. 279 pp. || LinALFAL, 32 (2016), núm. 1, 137-140 (Trevisan).

65-1085. Maeseneer, R. De e I. Logie (eds.) - El canon en la narrativa contemporánea del Caribe y del Cono Sur (N. 64-912). || Ibero, 2015, núm. 60, 232234 (López).

65-1086. Martínez Yépez, Heriberto - "Dictadura de la forma perfecta: crítica canónica, narrativa contemporánea y desautorización de lo narcoliterario en México”. — HiJ, 36 (2015), núm. 2, 87-106.

65-1087. Missana, Sergio - "Emergencias narrativas". - Inti, 78/79 (2014), 237-248.

65-1088. Molina LoRA, Luis — "Tráfico de discursos e intermedialidad transatlántica en la narrativa del tráfico". — HiJ, 36 (2015), núm. 2, 197-214.

65-1089. Mora, Vicente Luis - "Fragmentarismo y fragmentalismo en la narrativa hispánica”. - CuH, 2015, núm. 783, 91-103.

65-1090. Nemrava, Daniel - Entre el laberinto y el exilio: nuevas propuestas sobre la narrativa argentina. - Verbum, Madrid, 2013. 166 pp. || RILCE, 32 (2016), 273-274 (Navascués).
65-1091. NoyARET, N. (ed.) - La narrativa española de hoy (2000-2013). La imagen en el texto (3) (N. 64-932). || Ibero, 2016, núm. 62, 256-258 (Paatz).

65-1092. Reisz, Susana - "Formas de autoficción y su lectura”. — LexisL, 40 (2016), 73-98.

65-1093. Sabo, María José - La "nueva narrativa” en los años noventa. Manifiesto crack en la teoría-crítica latinoamericana. - Editorial Universitaria Villa María, Córdoba, 2015. 205 pp. || Ibero, 2016, núm. 62, 275-277 (Bellini).

65-1094. Serrano Cueto, Antonio (ed.) - Después de Troya. Microrrelatos hispánicos de tradición clásica. - Menoscuatro, Palencia, 2015. || Íns, 2015, núm. 828, 36-38 (González Iglesias).

65-1095. Smith, Paul Julian — "Ficciones de la crisis: novela, cine y televisión”. Hispanismos del mundo, coord. F. Funes (Buenos Aires, 2016), pp. 75-86.

65-1096. Sotelo VÁzquez, Adolfo "Juan Luis Alborg y la crítica literaria contemporánea (notas sobre la novela)". - CuH, 2016, núm. 790, 130-139. 65-1097. TORRES DE LA RosA, DANAÉ Avatares editoriales de un "género": tres décadas de la novela de la Revolución mexicana. - Bonilla Artigas EditoresITAM, México, 2015. 350 pp.

65-1098. VAlenzuela Magaña, JUAn FerNANDO - "Una visión del género policiaco". - CuH, 2015, núm. 778, 30-42.

65-1099. VARA, Ana María - Sangre que se nos va. Naturaleza, literatura y protesta social en América Latina. — CSIC, Sevilla, 2013. || Hispam, 2015, núm. 132, 123-124 (Boccanera).

V. también núm. 884.

\section{Estudios diversos}

65-1100. Adriaensen, BrigitTe - "Turistas sin fronteras: representaciones literarias de viajeros en el territorio del narco". — Hij, 36 (2015), núm. 2, 139159.

65-1101. Alberca, Manuel - "Los pactos del biógrafo”. - CuH, 2015, núm. $786,52-65$.

65-1102. Ardila Ariza, Jineth - Vanguardia y antivanguardia en la crítica y 
en las publicaciones culturales colombianas de los años veinte. - Universidad Nacional de Colombia, Bogotá, 2013. 298 pp. || ELC, 2015, núm. 38, 214-217 (Pineda Buitrago).

65-1103. Caballé, Anna - "Españoles de dos mundos. Apuntes para un estudio". - CuH, 2015, núms. 781/782, 68-83. [Escritores españoles en EE.UU.]

65-1104. Camps, Martín — "Escribir entre las balas: literatura y testimonios de algunos escritores de Ciudad Juárez”. — Hij, 36 (2015), núm. 2, 19-49.

65-1105. Castillón, Juan Carlos "Recuerdos de un librero de la Calle Ocho”. - CuH, 2015, núm. 779, 38-52. [Sobre el exilio cubano].

65-1106. Corral, Wilfrido H. - El error del acierto. Contra ciertos dogmas latinoamericanistas. — Universidad, Valladolid, 2014. 264 pp. || CuH, 2015, núm. 775, 121-124 (Valencia). - V. núm. 60-325.

65-1107. Diego, José LuIS DE — “Libros y literatura en el espacio latinoamericano". - Hispanismos del mundo, coord. F. Funes (Buenos Aires, 2016), pp. 87-106.

65-1108. DJermanovic, Tamara — "Dostoievski en el espejo del pensamiento español". - CuH, 2015, núm. 777, 4-20.

65-1109. Egido, Aurora y Rosa PelliCER - "Ínsula en Buenos Aires. Presentación del monográfico Luces argentinas (Ínsula, 793-4)”. - Hispanismos del mundo, coord. F. Funes (Buenos Aires, 2016), pp. 367-375.

65-1110. Estrada, Oswaldo - Ser mujer y estar presente. Disidencias de género en la literatura mexicana contemporánea. - UNAM, México, 2014. 362 pp. ॥ Ibero, 2016, núm. 61, 319-321 (Martínez Hernández); I, 82 (2015), 266-271 (Vanden Berghe).

65-1111. Estupiñán Serrano, Mary Luz — "Marginalidades: variaciones del testimonio en América Latina". - Hispam, 2015, núm. 132, 101-106.

65-1112. Fernández, NANCY — Poéticas impropias. Escrituras argentinas contemporáneas. - Universidad Nacional de Mar del Plata, Mar del Plata, 2014.
|| Hispam, 2015, núm. 132, 121-122 (Cámara).

65-1113. Gallego Cuiñas, Ana y Érika Martínez (eds.) - Queridos todos: el intercambio epistolar entre escritores hispanoamericanos y españoles del siglo $\mathrm{XX}$. - Peter Lang, Bruxelles, 2013. || Ibero, 2015, núm. 59, 245-248 (Sánchez).

65-1114. García Galiano, Ángel - El fuego sordo. Lecciones de literatura contemporánea. - Ediciones Xorki, Madrid, 2015. 243 pp. || Dicenda, 32 (2014), 395-396 (Batres); CAISPI, 2015, núm. 5, 232-234 (Polizzi).

65-1115. Garralón, Ana - "Temas y modos en la literatura infantil latinoamericana". - CuH, 2015, núm. 776, 33-47.

65-1116. Gelpí, JuAn G. — "La escritura ensayística. Panorama en Puerto Rico”. - CuH, 2016, núm. 789, 38-49.

65-1117. Giusso, Lorenzo - "La tragedia del espíritu español (octubre 1936). Trad. y notas de Juan Argenti”. - CuH, 2016, núm. 789, 74-85.

65-1118. KudAibERGEN, JANIA — "Las editoriales cartoneras y los procesos de empoderamiento en la industria creativa mexicana”. - CuA, 2015, núm. 152, 127-146.

65-1119. López, Magdalena, Ángela Fernandes, Isabel Araújo Branco, Margarida Borges, RaQuel BaltaSAR y SONIA Miceli (eds.) - Literaturas e culturas em Portugal e na América Hispânica. Novas perspectivas em diálogo. — Húmus, Ribeirao, 2014. 296 pp. || Ibero, 2016, núm. 61, 310-314 (Wieser).

65-1120. Martín Gijón, Mario - "Las Españas del exilio”. - CuH, 2015, núm. 785, 18-33.

65-1121. Martínez Salazar, Elisa y Julieta Yelin (eds.) - Kafka en las dos orillas. Antología de la recepción crítica española e hispanoamericana. - Universidad, Zaragoza, 2013. 393 pp. || Ibero, 2016, núm. 61, 285-287 (Gimber).

65-1122. Meseguer, Purificación y Ana Rojo - "Literatura, sexo y censura: traducción y recepción de Amis, Daudet y Renault bajo el régimen franquista”. - REsLA, 27 (2014), 537-558. 
65-1123. Morán, Gregorio - El cura y los mandarines. Historia no oficial del Bosque de los letrados. Cultura y política en España 1962-1996. - Akal, Madrid, 2014. 852 pp. || CuH, 2015, núm. 778, 129-133 (Martín Gijón).

65-1124. Murguía, Verónica — "Desde el fondo de la Matrioshka". - $\mathrm{CuH}$, 2015, núm. 776, 14-24. [Literatura juvenil hispánica].

65-1125. Pérez, Alberto Julín - Literatura, peronismo y liberación nacional. - Corregidor, Buenos Aires, 2014. || Hispam, 2015, núm. 131, 126-127 (González).

65-1126. Perromat, Kevin — "Valor, vigencia y banalidad de la noción de plagio en la escritura contemporánea”. —Íns, 2015, núm. 827, 25-28.

65-1127. Pineda Orejuela, Daniel "La manifestación retórica en el texto audiovisual”. - Semiosis, 2014, núm. 20, 101-126.

65-1128. Pino, José M. DeL - "Voces y ecos del hispanismo estadounidense". - CuH, 2015, núms. 781/782, 84-104.

65-1129. Ramos, Carlos - "Enseñar España como problema. Hispanismo para tiempos líquidos”. - $\mathrm{CuH}, 2015$, núms. 781/782, 121-136. [Hispanismo en EE.UU.].

65-1130. Ripoll Sintes, Blanca "Rafael Vázquez Zamora, agente cultural en la España de la Posguerra”. - CuIF, 41 (2015), 181-201.

65-1131. Rojas, RAFAEL - "La geografía del corazón ausente. Tres momentos del exilio literario cubano". - $\mathrm{CuH}$, 2015, núm. 779, 4-11.

65-1132. ROJAS, RAFAEL - La vanguardia peregrina. El escritor cubano, la tradición y el exilio. - F.C.E., México, 2014. || CuH, 2015, núms. 781/782, 213-216 (Fernández Fe).

65-1133. Rolle, Carolina - "Fundar Eloísa Cartonera es como hacer un film sobre los marcianos en villa 21". Hispam, 2015, núm. 132, 35-42. [Proyecto editorial].

65-1134. Romero López, Dolores (ed.) - Los márgenes de la modernidad. Temas y creadores raros y olvidados en la Edad de Plata. — Punto Rojo Libros, Sevilla,
2014. 306 pp. || Dicenda, 32 (2014), 386-389 (Álvarez Touriño).

65-1135. Rosal Nadales, María "Antorcha de paja en el contexto de la Transición”. - CuH, 2015, núm. 784, 112-121. [Revista 1973-1983].

65-1136. RosAl, MARÍA — "Los editoriales de la revista Antorcha de Paja". RRo, 50 (2015), 293-310.

65-1137. Siskind, Mariano - Cosmopolitan desires. Global modernity and world literature in Latin America (N. 63-1818). || Ibero, 2016, núm. 61, 314-316 (Castany Prado).

65-1138. Sosenski, Susana - “Vida y milagros de Lorín, el perico detective: violencia, crimen y justicia en la mirada de dos niños mexicanos a principios del siglo xx". — Ibero, 2015, núm. 60, 133-153.

65-1139. Tenorio Trillo, Mauricio "La $c$ por la $k$. El Barret Mexicà en las Ramblas". - CuH, 2015, núms. 781/782, 105-120. [Hispanismo en EE.UU.].

65-1140. VAlencia, Roberto - Todos somos autores y público. Conversaciones sobre la creación contemporánea. - IFC, Zaragoza, 2014. 331 pp. || Ibero, 2016, núm. 61, 294-298 (Moreno).

65-1141. Velykodna, Olena — "La recepción de la literatura española del siglo xx en Rusia”. - CuH, 2015, núm. 777, 54-72.

65-1142. Villanueva, Darío - "Posmodernidad y filología”. - Cincuentenario de la AIH, ed. R. Barros Roel (A Coruña, 2014), pp. 193-199.

65-1143. Wolfson Reyes, Gabriel "Último round: la revista Plural como respuesta sintáctica a Casa de las Américas". — Ibero, 2016, núm. 61, 189-210.

\section{Autores (y obras anónimas)}

Abad, Antonio M.

65-1144. Cajero VázQuez, Antonio "El campeón, de Antonio M. Abad: avatares de una edición”. - Semiosis, 2015, núm. 21, 211-217. 
65-1145. Abad Faciolince, Héctor La Oculta. - Alfaguara, Madrid, 2015. 344 pp. || CuH, 2016, núm. 788, 110113 (Juristo). [Novela].

65-1146. García Ríos, BeAtriz — "Héctor Abad Faciolince: «La literatura pone a combatir las distintas versiones de la realidad»". - CuH, 2016, núm. 788, 94-107. [Entrevista].

\section{Abbati, Hugo}

65-1147. Авваті, Hugo - Dos conversan (donde Beckett perdió el poncho). — Ediciones de Aquí, Benalmádena, 2015. 300 pp. || CuH, 2016, núm. 790, 174176 (Valenzuela Magaña). [Novela].

\section{Aira, César}

65-1148. Aira, CÉSAR - Continuación de ideas diversas. - Universidad Diego Portales, Santiago de Chile, 2014. || Hispam, 2015, núm. 131, 121 (Brescia). [Ensayos].

\section{Alarcón, Orfa}

65-1149. Muñoz, Alicia — "Submission, aggression, consumption: Navigating subjectivity through love and violence in Orfa Alarcón's Perra brava". - HiJ, 36 (2015), núm. 2, 69-85.

\section{Alonso, Dámaso}

65-1150. Botrel, JeAn-FrançOIS "Dámaso Alonso, entre maestría y creación”. - Cincuentenario de la AIH, ed. R. Barros Roel (A Coruña, 2014), pp. $41-56$.

\section{Amara, Luigi}

65-1151. González Arce, Teresa "Autorretratos. La construcción del yo en tres ensayistas mexicanos". Semiosis, 2015, núm. 21, 89-106.
65-1152. Pereyra, Marisa - "Berlín es un cuento: la escritura y la lengua como idearios utópicos”. - Hij, 37 (2016), núm. 1, 67-79.

\section{Ángel Marulanda, Albalucía}

65-1153. Botero, Mary Luz — “Albalucía Ángel en sus propias palabras”. - ELC, 2016, núm. 38, 199-205. [Entrevista].

\section{Aparicio, Juan Pedro}

65-1154. Aparicio, JuAn Pedro - London Calling. - Páginas de Espuma, Madrid, 2015. 177 pp. || CuH, 2015, núm. 784, 146-149 (Juristo). [Cuentos].

\section{Aparicio Belmonte, Juan}

65-1155. Aparicio Belmonte, JuAn Ante todo criminal. — Siruela, Madrid, 2015. 236 pp. || CuH, 2016, núm. 787, 134-137 (Sanz Villanueva). [Novela].

Arenas, Reinaldo

65-1156. MAdDox, JoHn — "La retórica antiesclavista de Reinaldo Arenas". Hij, 37 (2016), núm. 1, 47-66.

Arguedas, José María

65-1157. Becerra Méndez, Claudia — "De árboles y Arguedas". — Inti, $78 / 79$ (2014), 105-116.

\section{Argullol, Rafael}

65-1158. Galán, Julio CÉsar - "Horizontes sobre el ensayo de Rafael Argullol”. - CuH, 2015, núm. 785, 102-111. 
Asturias, Miguel Ángel

65-1159. Villalobos Villalobos, Carlos Manuel - "Degustación semiótica de un pulique cultural: el discurso culinario en Hombres de maíz". — RFLUCR, 2014, núm. 40, 11-22.

\section{Atencia, María Victoria}

65-1160. Carnero, Guillermo - "Más prodigiosa cuanto más sencilla. La poesía de María Victoria Atencia”. CuH, 2015, núms. 781/782, 148-158.

Atxaga, Bernardo

65-1161. Atxaga, Bernardo - Días de Nevada. - Alfaguara, Madrid, 2014. || Íns, 2015, núm. 825, 47-51 (Kortazar). [Novela].

\section{Aub, Max}

65-1162. Aub, Max - Versiones y perversiones. Ed. de Xelo Candel. - Cuadernos del Vigía, Granada, 2015. 104 pp. || CuH, 2016, núm. 788, 122-125 (Moga).

\section{Ayala, Francisco}

65-1163. Ayala, Francisco - Obras completas. Ed. de C. Richmond. Galaxia Gutenberg, Barcelona, 20122014. 7 ts. || Íns, 2015, núm. 828, 31-34 (Krauel). - V. núm. 58-2937.

65-1164. Jasinski, IsABel — "Para além das fronteiras: hispanismo em debate em meados do século xx". - $A B E H$, 26 (2016), 167-176.

Azorín (José Martínez Ruiz)

65-1165. Fuster García, Francisco "Azorín y Baroja: una extraña pareja”. - CuH, 2015, núm. 779, 92-103.
Azúa, Felix de

65-1166. Azúa, Félix de — Génesis. Random House, Barcelona, 2015. 192 pp. || CuH, 2015, núm. 780, 124-126 (Juristo). [Novela].

\section{Baquero, Gastón}

65-1167. Barbáchano, Carlos - "El hombre que ansiaba las estrellas". CuH, 2015, núm. 775, 9-37.

65-1168. Matamoro, Blas - "Gastón, en la memoria”. - CuH, 2015, núm. $775,4-8$.

\section{Baroja, Pio}

65-1169. Viamonte Lugientes, Ernesто - "Los caprichos de la suerte. Baroja, creador crepuscular”. - Íns, 2015, núm. 828, 7-10.

V. también núms. 1165, 1207.

\section{Barral, Carlos}

65-1170. Barral, Carlos - Memorias. Ed. de Andreu Jaume. — Lumen, Barcelona, 2015. 985 pp. || CuH, 2016, núm. 789, 122-125 (Juristo).

\section{Barrenechea, Ana María}

65-1171. Romanos, Melchora - "Ana María Barrenechea: la primera mujer Presidenta de la AIH". - Cincuentenario de la AIH, ed. R. Barros Roel (A Coruña, 2014), pp. 99-109.

\section{Bellatín, Mario Alfredo}

65-1172. Tobar, Carolina - "Mario Bellatín”. - Hispam, 2015, núm. 132, 63-68. [Entrevista].

\section{Belli, Gioconda}

65-1173. Eusebio, Carmen de - "Gioconda Belli: «El goce de nuestro 
cuerpo nos ha costado mucho más a las mujeres»". - CuH, 2015, núm. 775, 98-105.

\section{Benavides, Jorge Eduardo}

65-1174. Benavides, Jorge EduARdo El enigma del convento. - Alfaguara, Barcelona, 2014. 485 pp. || CuH, 2015, núm. 776, 95-97 (Juristo). [Novela].

65-1175. Eusebio, CARMEN DE - "Jorge Eduardo Benavides: «Un escritor no debe olvidar que lo que escribe es un acto de prestidigitación»" - $-\mathrm{CuH}$, 2015, núm. 776, 84-93.

\section{Benet, Juan}

65-1176. Machín Lucas, Jorge — " "Los palimpsestos de Jenofonte, de la mística y de Nietzsche en la narrativa de Juan Benet". —Íns, 2015, núm. 825, 8-11.

V. también núm. 1331.

\section{Bioy Casares, Adolfo}

65-1177. Tapia, Miguel — "Ficciones epistémicas de Adolfo Bioy Casares. Las teorías del conocimiento como materia narrativa". - Graffylia, 2015, núm. 21, 90-100.

\section{Blanc, Felicidad}

V. núm. 1369.

\section{Bolaño, Roberto}

65-1178. Adriaensen, Brigitte "Memoria, ironía y comunidad: 2666 de Roberto Bolaño". — I, 82 (2015), 125-136.

65-1179. Crusat, Cristian - "Roberto Bolaño. Misteriosas virtudes del exilio". - CuH, 2015, núm. 775, 58-68.

65-1180. Espinosa H., Patricia - "Bildungsroman y Modernidad en los Detectives salvajes de Roberto Bolaño". —Inti, 78/79 (2014), 137-150.
65-1181. Vásquez, Malva Marina "Apocalipsis posmoderno y política de la memoria en la narrativa de Roberto Bolaño". - Hispam, 2015, núm. 132, 111-116.

V. también núm. 1308.

\section{Bombal, María Luisa}

65-1182. Díaz y Morales, Magda "Semiótica de la violencia. Una representación literaria”. - Semiosis, 2015, núm. 21, 149-165.

\section{Borges, Jorge Luis}

65-1183. Castany Prado, B. - Que nada se sabe: el escepticismo en la obra de Jorge Luis Borges (N. 62-964). \| RILCE, 32 (2016), 254-257 (Gutiérrez Meza).

65-1184. Cervera Salinas, Vicente Borges en la ciudad de los inmortales. Renacimiento, Sevilla, 2014. 352 pp. || Hispam, 2015, num. 131, 122-123 (García-Caro); Ibero, 2015, núm. 59, 252256 (Ruiz Barrionuevo).

65-1185. D'Alessandro, María Natalia — "Reivindicaciones del anonimato y la oralidad en Borges y Literal". - - Hispam, 2015, núm. 131, 3-10.

65-1186. GÁMEz García, MAR - "El rastro de Oscar Wilde en la obra de Jorge Luis Borges y Julio Cortázar: el doble como elemento lúdico". - Semiosis, 2014, núm. 20, 9-28.

65-1187. Liviu, Lutas - "Paradoja y metalepsis narrativa en el cuento «El otro», de Jorge Luis Borges". — TdS, 2015, núm. 34

65-1188. Mazzucchelli, Aldo - "En torno al joven Borges: un discurso de resistencia a la Modernidad". — Hispam, 2015, núm. 132, 17-26.

65-1189. Olea Franco, R. (ed.) - El legado de Borges (N. 63-1297). || NRFH, 64 (2016), 609-614 (Corral).

65-1190. Tacconi, Maria del Carmen - "España y su cultura en la obra lírica de Jorge Luis Borges". — ABEH, 26 (2016), 151-163.

V. también núm. 1224. 
65-1191. GonzÁlez Muñoz, Irene "La influencia de la teosofía en el ars poetica de Roberto Brenes Mesén”. RFLUCR, 2014, núm. 40, 59-71.

\section{Brodsky Baudet, Roberto}

65-1192. Brodsky, Roberto - Casa chilena. - Random House, Santiago de Chile, 2015. || Hispam, 2015, núm. 132, 117-118 (Cánovas). [Autobiografía ficcional].

\section{Buero Vallejo, Antonio}

65-1193. Katona, Eszther - "Libertad artística y autoritarismo. De El sueño de la razón de Buero Vallejo a Cartas de amor a Stalin de Mayorga". - CAISPI, 2016, núm. 7, 109-124.

\section{Caballero Bonald, José Manuel}

65-1 194. Caballero Bonald, José Manuel - Descrédito del héroe. Manual de infractores. Ed. de Julio Neira. Cátedra, Madrid, 2015. 355 pp. II CAISPI, 2015, núm. 5, 227-230 (Flores Requejo). [Poesía].

V. también núm. 1319.

\section{Cabrera, Lydia}

65-1195. Cuesta, Mabel - "Lydia Cabrera entre amigas: un tren de sores para una ciénega cementada”. - $\mathrm{CuH}$, 2015, núm. 779, 12-23.

\section{Cabrera Infante, Guillermo}

65-1196. Cabrera Infante, Guillermo - Mea Cuba, antes y después. Escritos políticos y literarios. Ed. de Antoni Mumné. - Galaxia Gutenberg, Barcelona, 2015. 1300 pp. || CuH, 2015, núm. 786, 126-129 (Juristo).
65-1197. Gutiérrez Plaza, Arturo "Cadenas: travesía hacia una sabiduría del no saber”. - CuH, 2015, núm. $780,9-16$.

65-1198. Isava, Luis Miguel — "Ética y poética en la obra de Rafael Cadenas". - CuH, 2015, núm. 780, 17-30.

65-1199. López Ortega, Antonio "Rafael Cadenas: "La realidad es el misterio absoluto»". - CuH, 2015, núm. 780, 4-8. [Entrevista].

65-1200. Palacios, María Fernanda "Otro temple. Sobre Rafael Cadenas". - CuH, 2015, núm. 780, 31-36.

65-1201. Pérez Zúñiga, Ernesto "Encadenados". - CuH, 2015, núm. 780, 46-49.

65-1202. Saraceni, Gina - "Isla y desvanecimiento". - CuH, 2015, núm. $780,37-45$.

\section{Camba, Julio}

65-1203. MARQuÉS, JUAN — "La avalancha de Julio Camba”. - CuH, 2015, núm. 783, 104-113.

\section{Canicio, Victor}

65-1204. GonzÁlez-Allende, Iker "The migrant family man: Masculinity, work, and migration in Víctor Canicio's Vida de un emigrante español". Ibero, 2016, núm. 62, 131-147.

\section{Cantón, Dario}

65-1205. Paredes, Demian — "Darío Cantón y ASEMAL”. - Hispam, 2015, núm. 131, 115-119.

\section{Carranza, José Israel}

V. núm. 1151. 
Carrión, Miguel de

65-1206. Ramírez Castellanos, Ronald Antonio - "Androginia e intertextualidad tarótica en El milagro”. — EFil, 2015, núm. 55, 93-108.

\section{Cela, Camilo José}

65-1207. Cela, Camilo José - Recuerdo de don Pío Baroja. Ed. de Francisco Fuster. — Fórcola, Madrid, 2016. 122 pp. || CuH, 2015, núm. 790, 174-176 (Eusebio).

\section{Cercas Mena, Javier}

65-1208. Cercas, Javier - El impostor. Random House, Barcelona, 2014. 420 pp. || CuH, 2015, núm. 779, 155-158 (Sanz Villanueva). [Novela].

\section{Cernuda, Luis}

65-1209. Galán, Julio César — "Luis Cernuda y su concepción de la crítica literaria”. - CuH, 2015, núm. 780, 84-90.

65-1210. Martín Gijón, M. y J.A. LleRA (eds.) - Luis Cernuda. Perspectivas europeas y del exilio (N. 62-2191). I| Ibero, 2015, núm. 60, 211-214 (Loyola López).

\section{Chacel, Rosa}

65-1211. GARcía, Miguel ÁNGel — "Holzwege. La construcción historiográfica del 27 en los artículos de Rosa Chacel". - I, 83 (2016), 3-15.

65-1212. Silvestri, Laura - "El epistolario Chacel-Moix: historia de dos vocaciones". - CAISPI, 2014, núm. 3, 125-142.

\section{Chejfec, Sergio}

65-1213. Oliver, María Paz — "Los pasos de la memoria: representacio- nes de la caminata urbana en Cynthia Rimsky, Sergio Chejfec y Eduardo Halfon". - I, 83 (2016), 16-34.

Cohen, Marcelo

65-1214. Cohen, M. - Relatos reunidos (N. 63-2739). || CuH, 2015, núm. 780, 117-119 (Cassara).

\section{Colinas, Antonio}

65-1215. Clark, Ben (ed.) - Bajo las raíces (40 años de "Sepulcro de Tarquinia"). - La Isla de Sitolá, Sevilla, 2015. || Íns, 2015, núm. 828, 44-47 (Martínez).

Conde, Carmen

65-1216. Díez de Revenga, Francisco JAVIER - "Carmen Conde y los inicios de Pilar Paz de Pasamar a través de un epistolario inédito". — CAISPI, 2014, núm. 3, 77-90.

\section{Cortázar, Julio}

65-1217. Aletto, Carlos Daniel — "Los almanaques de Julio Cortázar”. — Inti, 78/79 (2014), 11-20.

65-1218. Amícola, José — “Rayuela antes y después”. - Inti, 78/79 (2014), 71-84.

65-1219. Bernárdez, A. y C. Álvarez Garriga (eds.) - Cortázar de la A a la Z. Un álbum biográfico (N. 64-2859). || Inti, 78-79 (2014), 323-325 (Pérez Calarco).

65-1220. Bocchino, Adriana A. "Fotos. J.C.". — Inti, 78/79 (2014), 21-40.

65-1221. Bocchino, Adriana A. "Rayuela. 50 años". - Hispanismos del mundo, coord. F. Funes (Buenos Aires, 2016), pp. 305-318.

65-1222. Calabrese, Elisa - "El arte de escribir mal”. — Inti, $78 / 79$ (2014), 41-50.

65-1223. Goloboff, Mario - "Cortázar a los 50 años de Rayuela”. - Hispanis- 
mos del mundo, coord. F. Funes (Buenos Aires, 2016), pp. 301-303.

65-1224. Kressner, ILKA - Sites of disquiet. The NonSpace in Spanish American short narratives and their cinematic transformation. - Purdue University Press, West Lafayette, 2013. 170 pp. || Ibero, 2016, núm. 61, 316-319 (Wasem).

65-1225. Sanjinés, José — "ABC para un cuento de Cortázar: relectura de «Vientos alisios»". — Inti, 78/79 (2014), 87-104.

V. también núms. 1186, 1232.

Cuenca, Luis Alberto de

65-1226. Cuenca, Luis Alberto de - Cuaderno de vacaciones. - Visor, Madrid, 2014. || Íns, 2015, núm. 825, 32-35 (Lanz).

\section{d'Ors, Pablo}

65-1227. D'Ors, PABLo - Contra la juventud. - Galaxia Gutenberg, Barcelona, 2015. 417 pp. || CuH, 2015, núm. 779, 140-142 (Juristo). [Novela].

65-1228. Eusebio, Carmen de — "Pablo d'Ors: «Toda novela auténtica es necesariamente una novela de formación»”. - CuH, 2015, núm. 779, 129-138. [Entrevista].

\section{Debravo, Jorge}

65-1229. Chen Sham, Jorge — "De la procreación a la maternidad en Milagro abierto de Jorge Debravo". RFLUCR, 2014, núm. 40, 25-32.

\section{Demaría, Laura}

65-1230. Demaría, Laura - Buenos Aires y las provincias: relatos para desarmar. - Beatriz Viterbo, Rosario, 2014. || Hispam, 2015, núm. 132, 119-121 (Degiovanni).
Demitrópulos, Libertad

65-1231. Abbate, Florencia — "Piano en Bahía Desolación y algunas constantes en la obra de Libertad Demitrópulos”. — Hispam, 2015, núm. 132, 27-33.

\section{Devoto, Daniel}

65-1232. Zonana, Víctor Gustavo "Julio Cortázar / Daniel Devoto: proyecciones literarias de su amistad en Imagen de John Keats". - Inti, 78/79 (2014), 51-70.

\section{Diego, Eliseo}

65-1233. Mitre, EduARdo - "Del retorno en dos poetas cubanos". - $\mathrm{CuH}$, 2015, núm. 780, 59-63.

\section{Diego, Eliseo Alberto}

65-1234. López ForJas, MANuel - "Literatura, psicología y confesión: el Informe contra mi mismo de Eliseo Alberto". — Graffylia, 2015, núm. 21, 17-32.

Diego, Gerardo

65-1235. Díaz De Guereñu, JuAN Manuel y José Luis Bernal Salgado — "Diego y Larrea: cartas de 1917". CAISPI, 2014, núm. 3, 145-168.

$$
\text { Díez, Luis Mateo }
$$

65-1236. Díez, Luis MAteo - La soledad de los perdidos. - Alfaguara, Madrid, 2014. || Íns, 2015, núm. 828, 34-36 (Goñi). [Novela].

\section{Doce, Jordi}

65-1237. Serrano, Julio - "Jordi Doce: "La aparición de la poesía fue una cesura en mi vida»". - CuH, 2015, núm. 783, 115-134. [Entrevista]. 
Droguett, Carlos

65-1238. Coello Gutiérrez, EmiliaNO - "Los asesinados del Seguro Obrero (1939), de Carlos Droguett: el testimonio como novela". - Ibero, 2016, núm. 61, 171-187.

\section{Edwards, Jorge}

65-1239. Benavides, Jorge Eduardo - "Política e intimismo en la narrativa de Jorge Edwards". - CuH, 2016, núm. 787, 24-37.

65-1240. Brickle, Patricio - "La búsqueda de la primera palabra". - $\mathrm{CuH}$, 2016, núm. 787, 70-85.

65-1241. Fernández Fe, Gerardo "Edwards, micrófonos, camarones principescos". - CuH, 2016, núm. $787,52-69$.

65-1242. Franz, Carlos - "Las novelas de la vocación”. - CuH, 2016, núm. 787, 38-51.

65-1243. Malpartida, Juan - "Conversación con Jorge Edwards". - $\mathrm{CuH}$, 2016, núm. 787, 4-15.

65-1244. Serra, Maurizio - "Jorge Edwards, diplomático y escritor, visto por un doble". - $\mathrm{CuH}$, 2016, núm. 787, 16-23.

\section{Elizondo, Salvador}

V. núm. 1076.

\section{Eltit, Diamela}

65-1245. EsPinosa H., PATRICIA - "Fuerzas especiales, de Diamela Eltit: una cartografía de la derrota popular". - Hispam, 2015, núm. 131, 103-108.

\section{Farias, Juan}

65-1246. Valera Tembra, Juan José "El alegato satírico en Por donde pasan las ballenas". - Cincuentenario de la AIH, ed. R. Barros Roel (A Coruña, 2014), pp. 453-460.
Felipe, León

65-1247. IfFland, James - “ «La gran aventura»: don Quijote, León Felipe, Che Guevara". - El "Quijote" desde América. (Segunda parte), eds. I. Arellano, D. Ayalamacedo y J. Iffland (New York, 2016), pp. 179-198.

\section{Ferrer Lerín, Francisco}

65-1248. AzÚA, FÉLIX DE - "Diálogo con Francisco Ferrer Lerín”. — Íns, 2015, núm. 825, 21-27. [Entrevista].

65-1249. Blesa, Túa — "Francisco Ferrer Lerín, una forja de ensueños". - Íns, 2015, núm. 825, 12-15.

65-1250. Riera, CARME - "La chatarra maleable de los sueños". —Íns, 2015, núm. 825, 19-21.

65-1251. Viñuales, Antonio - "La risa de Ferrer Lerín”. — Íns, 2015, núm. 825, 15-18.

\section{Fogwill, Rodolfo}

65-1252. Fogwill, Rodolfo - La gran ventana de los sueños. - Alfaguara, Buenos Aires, 2013. || Hispam, 2015, núm. 131, 123-124 (Ferrero). [Prosa breve].

\section{Fontaine, Arturo}

V. núm. 1255.

\section{Franz, Carlos}

65-1253. Franz, Carlos - Si te vieras con mis ojos. - Alfaguara, Madrid, 2016. 380 pp. || CuH, 2015, núm. 790, 170173 (Juristo). [Novela].

65-1254. Eusebio, Carmen de - "Carlos Franz: «La belleza no está en lo que es, sino en lo que puede o pudo ser»". - CuH, 2016, núm. 790, 154167. [Entrevista].

65-1255. Toro, Alfonso de - "Lo indecible, lo irrepresentable. Topografías: terror e intertextualidad. El desierto de 
Carlos Franz / La vida doble de Arturo Fontaine". — I, 83 (2016), 35-55.

\section{Fuentes, Carlos}

65-1256. Comsa, Minaela - "Aura y La señorita Christina: un diálogo posible”. - Semiosis, 2014, núm. 20, 177-186.

65-1257. García-Caro, Pedro - After the nation. Postnational satire in the works of Carlos Fuentes and Thomas Pynchon. Pról. de Jean Franco. - Northwestern University Press, Evanston, 2014. 304 pp. || Ibero, 2016, núm. 62, 267-270 (Castany Prado).

65-1258. Mihailescu, Calin-Andrei “Carlos Mann”. — Inti, 78/79 (2014), 117-126.

\section{Futoransky, Luisa}

65-1259. Lindstrom, NaOmi — "El discurso profético en la poesía de Luisa Futoransky". - Hispam, 2015, núm. 131, 109-114.

\section{Gálvez, Francisco}

65-1260. GÁlvez, Francisco - El oro fundido. - Pre-Textos, Valencia, 2015. 122 pp. || CuH, 2015, núm. 780, 127129 (Ruiz Pérez). [Poesía].

\section{Gamoneda, Antonio}

65-1261. López Castro, Armando Nueve meditaciones sobre Antonio Gamoneda. - Devenir, Madrid, 2014. 373 pp. || CAISPI, 2015, núm. 5, 238-241 (Pradel).

V. también núm. 1457.

\section{García, Álvaro}

65-1262. García, Álvaro - Ser sin sitio. - Fundación José Manuel Lara, Sevilla, 2014. 62 pp. || CuH, 2015, núm. 775, 118-120 (Romero). [Poesía].
García Calvo, Agustín

65-1263. Bonilla, JUAN — "El concepto de pueblo en la obra de Agustín García Calvo”. - CuH, 2016, núm. 789, 86-105.

\section{García Lorca, Federico}

65-1264. Coleto Camacho, AnA — "Tres cartas inéditas de Carlos dirigidas a García Lorca”. - CuH, 2015, núm. 778, 79-92.

65-1265. Llera, José Antonio - "La perdiz de Federico García Lorca”. CuH, 2015, núms. 781/782, 159-173.

65-1266. López Pielow, Fátima — "El auto sacramental y el teatro de la vanguardia: Calderón y García Lorca”. Cincuentenario de la AIH, ed. R. Barros Roel (A Coruña, 2014), pp. 307-316.

65-1267. ORRINGER, N.R. - Lorca in tune with Falla: Literary and musical interludes (N. 63-2797). || RILCE, 32 (2016), 275279 (San José Lera).

65-1268. Peral Vega, Emilio - Pierrot Lorca. White carnival of black desire. Tamesis, London, 2015. 167 pp. \|Ibero, 2016, núm. 62, 247-251 (Blanco).

65-1269. Rosell, MARIA — "Las estrategias paródicas de Federico García Lorca y sus máscaras". — Íns, 2015, núm. $827,22-25$.

65-1270. Vives, ANNA — Identidad en tiempos de vanguardia. Narcisismo, genio y violencia en la obra de Salvador Dali y Federico García Lorca. - Peter Lang, Bern, 2015. 311 pp. (Hispanic Studies: Culture and Ideas, 62). || Ibero, 2016, núm. 61, 290-292 (Pörtl).

\section{García Márquez, Gabriel}

65-1271. Frisch, MARK — “Cartas del parque de García Márquez y Gutiérrez Alea y el Cyrano de Bergerac: del amor, el artista y la poesía”. - Inti, 78/79 (2014), 151-160.

V. también núm. 1224. 
García Marruz, Fina

V. núm. 1233.

García Ponce, Juan

V. núm. 1076.

García Porta, Antonio

65-1272. García Porta, Antonio - Las dimensiones finitas. — Acantilado, Barcelona, 2015. 197 pp. || CuH, 2015, núm. 789, 133-135 (Juristo). [Novela].

\section{García Vega, Lorenzo}

65-1273. Cussen, Felipe - "El no saber de Lorenzo García Vega”. - Hispam, 2015, núm. 131, 29-35.

\section{Gaspar, Sergio}

65-1274. Gaspar, SERgio - Viento de tramontana. — Edhasa, Barcelona, 2014. 278 pp. || CuH, 2015, núm. 776, 115119 (Moga). [Novela].

\section{Gil, Ildefonso-Manuel}

65-1275. Hernández Martínez, Manuel (coord.) - Sobre una generación de escritores (1936-1960). En el centenario de Ildefonso Manuel Gil. — Institución "Fernando el Católico", Zaragoza, 2013. 125 pp. || AFA, 70 (2014), 302306 (Enguita Utrilla).

\section{Gil de Biedma, Jaime}

V. núm. 1287.

\section{Giménez Caballero, Ernesto}

65-1276. Minardi, Adriana — "Devociones de lo nacional en la obra de Ernesto Giménez Caballero: ensayo, genericidad e imagen”. - $A B E H, 26$ (2016), 265-277.

$$
\text { Glantz, Margo }
$$

65-1277. Glantz, Margo - Simple perversión oral. - La Caja de los Cerillos-CONACULTA, México, 2014. || Hispam, 2015, núm. 131, 124-125 (Viú Adagio). [Cuento ilustrado].

$$
\text { Gómez de la Serna, Ramón }
$$

V. núm. 1446.

\section{González Esteva, Orlando}

65-1278. Fernández Fe, Gerardo "Orlando González Esteva: Miami, pasión razonable”. - CuH, 2015, núm. 779, 53-69. [Entrevista].

\section{González Mello, Flavio}

65-1279. VinCENT, NidiA — "La historia es presente en el teatro de Flavio González Mello”. - Semiosis, 2015, núm. 21, 181-190.

\section{González Sosa, Manuel}

65-1280. González Sosa, Manuel - A pesar de los vientos. Poesía completa. Pról. de Andrés Sánchez Robayna. - Salto de Página, Madrid, 2013. 210 pp. || Íns, 2015, núm. 825, 36-37 (Moga).

\section{Goytisolo, José Agustín}

65-1281. Luti, Francesco - "Pier Paolo Pasolini y José Agustín Goytisolo (Pasolini en Barcelona)". - $\mathrm{CuH}$, 2015, núm. 778, 69-78.

Goytisolo, Juan

65-1282. Alberca, Manuel - "Juan Goytisolo: de Sarriá a Xemáa-El-Fná”. — CuH, 2015, núm. 776, 48-57. 
65-1283. Cattaneo, Simone - “La saga de los Marx de Goytisolo: Marx Kultury Mass Culture en la pantalla televisiva”. - EFil, 2015, núm. 55, 35-51.

65-1284. Lloret, YANnick — "Juan Goytisolo: constelación poética en la migración interior". — CuH, 2015, núm. 783, 42-60.

\section{Greiff, León de}

65-1285. Ramírez Rojas, Marco "León de Greiff y su asimilación de la poesía medieval". — ELC, 2016, núm. 38, 13-37.

\section{Guillén, Jorge}

65-1286. Bou, ENRIC — "Lecturas polifónicas de los epistolarios de Jorge Guillén y Pedro Salinas". — CAISPI, 2014, núm. 3, 59-76.

65-1287. Olmos, M.Á. - Poètes lecteurs (Espagne, 1901-1991). La critique littéraire vue par trois poètes (N. 63-735). II Dicenda, 32 (2014), 385-386 (Alonso).

\section{Halfon, Eduardo}

V. núm. 1213.

\section{Hernández Busto, Ernesto}

65-1288. Hernández Busto, Ernesto La ruta natural. - Vaso Roto, Madrid, 2015. 184 pp. || CuH, 2015, núm. 780, 130-135 (Moga). [Diarios].

\section{Herrera, Yuri}

65-1289. Lombardo, Martín — "Autoridad, transgresión y frontera (sobre la narrativa de Yuri Herrera)". - Inti, 78/79 (2014), 193-214.

\section{Hidalgo Bayal, Gonzalo}

65-1290. Hidalgo Bayal, Gonzalo La sed de sal. — Tusquets, Barcelona,
2013. 328 pp. || CuH, 2015, núm. 776, 108-110 (Martín Gijón). [Novela].

65-1291. Calvo Revilla, Ana — "Poética del laberinto en El cerco oblicuo". RILCE, 32 (2016), 82-105.

\section{Huenún Villa, Jaime Luis}

65-1292. Betancour Sánchez, Sonia y Orietta Geeregat Vera — "Las reducciones en Reducciones de Jaime Luis Huenún”. - EFil, 2015, núm. $55,23-33$.

Insúa, Alberto

65-1293. Fortuño Llorens, SantiaGO - "Alberto Insúa, del folletín a corresponsal de guerra (1915-1917)”. — CuH, 2015, núm. 778, 93-101.

Jara Jiménez, Cronwell

65-1294. Minardi, Giovanna “Cronwell Jara”. - Hispam, 2015, núm. 131, 37-45. [Entrevista].

Jardiel Poncela, Enrique

65-1295. BonILlA, JUAN — "La tragedia del humorista. Sobre Enrique Jardiel Poncela”. - CuH, 2015, núm. 778, $18-29$.

Jarnés, Benjamín

65-1296. Domínguez LASIERRA, JUAN Benjamín Jarnés (1888-1949). Bibliografía. - Institución "Fernado el Católico”, Zaragoza, 2013. 334 pp. || AFA, 70 (2014), 298-301 (Enguita Utrilla).

\section{Jiménez, Juan Ramón}

65-1297. JimÉnEz, JUAN RAMón - Vida. T. 1: Días de mi vida. Est. y notas de M. Juliá y M.Á. Sanz Manzano (N. 
64-1283). || CuH, 2015, núm. 775, 129132 (Fuster).

65-1298. Giuliana, Virginie - "Juan Ramón Jiménez y Rubén Darío: recorrido de un arte azul". - PHisp, 29 (2015), núms. 3/4, 9-21.

65-1299. JENSEN, J. - The poetry of Juan Ramón Jiménez. An example of modern subjectivity (N. 60-1231). \|RRo, 50 (2015), 159-162 (Pellicer).

65-1300. López García, Tibisay - "Los comentarios de Juan Ramón Jiménez sobre métrica en El modernismo. Apuntes de un curso". - PHisp, 29 (2015), núms. 3/4, 23-39.

65-1301. Olmo Iturriarte, AlmudeNA DE - "Los contornos del Diario de un poeta recién casado, de Juan Ramón Jiménez”. - Íns, 2015, núm. 828, 10-14.

65-1302. Puig Guisado, Jaime - "Juan Ramón Jiménez, albacea del Modernismo en el diario El Sol". - PHisp, 29 (2015), núms. 3/4, 55-67.

V. también núms. 1028, 1287, 1373, 1470.

\section{Kartun, Mauricio}

65-1303. Rottenberg, Débora - "El deseo despostado. Una lectura de la ironía en Salomé de chacra de Mauricio Kartun”. - RRo, 50 (2015), 311-325.

\section{Labandeira, Amancio}

65-1304. Labandeira, Amancio - A ambos lados del río Grande (novela histórica). - Fundación Universitaria Española, Madrid, 2012. || Dicenda, 32 (2014), 392-395 (Andrés Gutiérrez).

\section{Lalo, Eduardo}

65-1305. Ríos ÁviLA, RUBÉN - "El flâneur abyecto de Eduardo Lalo". - $\mathrm{CuH}$, 2016, núm. 789, 50-63.

Landero, Luis

65-1306. Landero, LuIs - El balcón de invierno. — Tusquets, Barcelona, 2014.
228 pp. || CuH, 2015, núm. 778, 137140 (Alberca).

$$
\text { Larrea, Juan }
$$

V. núm. 1235.

$$
\text { Lauer, Mirko }
$$

65-1307. Lauer, Mirko - Alcools. Paracaídas, Lima, 2013. || Inti, 78-79 (2014), 327-328 (Lafferranderie). [Poesía].

$$
\text { Lemebel, Pedro }
$$

65-1308. Simari, Leandro Ezequiel "La ciudad y sus observadores: miradas sobre Santiago en Nocturno de Chile de Roberto Bolaño y Loco afán de Pedro Lemebel". - Ibero, 2016, núm. 62, 149-166.

\section{Leñero, Vicente}

65-1309. García Rodríguez, Juan CarLOS - "Asesinato de Leñero, periodismo y realidad". - Semiosis, 2015, núm. 21, 107-128.

\section{León, María Teresa}

65-1310. Emiliozzi, Irma - "Cartas de María Teresa León a Perla y Enrique Rotzair (1960-1971): memoria de una amistad". - CAISPI, 2014, núm. 3, 193-212.

\section{Lezama Lima, José}

65-1311. Atencio, CARIDAD - "Martí en Lezama Lima: intensificaciones de un concepto que avanza en espiral". CuA, 2015, núm. 154, 89-97. 
65-1312. Monti, Silvia — "La escritura dramática de Angélica Liddell: Belgrado. Canta lengua el misterio del cuerpo glorioso". — CAISPI, 2016, núm. 7, 155-171.

\section{Llamazares, Julio}

65-1313. Llamazares, Julio - Distintas formas de mirar el agua. - Alfaguara, Madrid, 2015. 186 pp. || CuH, 2015, núm. 779, 159-161 (Rodríguez Fisher). [Novela].

\section{Llorente, Mariano}

65-1314. RovecCHio, Laeticia - " $E l$ triángulo azul. El teatro-testimonio de Mariano Llorente y Laila Ripoll”. CAISPI, 2016, núm. 7, 95-108.

\section{Lojo, María Rosa}

65-1315. Luesakul, Pasuree - "Voces excéntricas de la Argentina del siglo xix en Finisterre de María Rosa Lojo”. - RILCE, 32 (2016), 182-200.

\section{Longares, Manuel}

65-1316. Eusebio, Carmen De "Manuel Longares: «El estilo es el modo de abordar la realidad con la palabra»". - CuH, 2015, núms. 781/782, 202-211. [Entrevista].

65-1317. SANFELICI, LAURA — "Elementos culturales en la traducción: Romanticismo de Manuel Longares y los estigmas de la (in) traductibilidad". — CAISPI, 2015, núm. 6, 221-234.

\section{López Manrique, Laia}

65-1318. López ManriQue, Laia - La mujer cíclica. - La Garúa, Barcelona, 2014. 92 pp. || CuH, 2015, núm. 777, 172-175 (Chico). [Poesía].
65-1319. Ramos Ortega, Manuel José — "El homenaje a Machado de 1966: la correspondencia a J.M. Caballero Bonald". — CAISPI, 2014, núm. 3, 91-109.

65-1320. Swiderski, Liliana — "Ficciones de autor y subjetividad en los albores del siglo xx". - Íns, 2015, núm. 827, 34-37.

\section{Maillard, Chantal}

65-1321. Maillard, Chantal - La mujer de pie. - Galaxia Gutenberg, Barcelona, 2016. 320 pp. || CuH, 2015, núm. 790, 188-191 (Aguado). [Novela].

\section{Mallea, Eduardo}

V. núm. 1440.

\section{Mantero, Manuel}

65-1322. Gómez Bedate, Pilar — "La espiritualidad en la poesía de Manuel Mantero". - CuH, 2015, núm. 775, 88-97.

$$
\text { Maquieira, Diego }
$$

65-1323. Riveros Soto, Ana María "El sujeto eclipsado en la poesía de Diego Maquieira”. - EFil, 2015, núm. $55,109-128$.

\section{Marcos, Juan Manuel}

65-1324. Weldt-Basson, Helene C. "Posmodernidad y género literario en El invierno de Gunter de Juan Manuel Marcos”. - Hij, 37 (2016), núm. 1, 139-152.

\section{Marechal, Leopoldo}

65-1325. Bueno, Mónica — "Celebración del lector: una nueva edición 
de Adán Buenosayres". — Inti, 78/79 (2014), 265-268.

Marías, Fernando

65-1326. Eusebio, Carmen de - "Fernando Marías: «La memoria es una novela»". - CuH, 2015, núm. 784, 134-143. [Entrevista].

\section{Marias, Javier}

65-1327. MARÍAs, JAVIER - Así empieza lo malo. - Alfaguara, Madrid, 2014. 534 pp. || CuH, 2015, núm. 775, 125-128 (Juristo); Íns, 2015, núm. 825, 43-47 (Valls). [Novela].

\section{Marsé, Juan}

65-1328. Marsé, JuAn — Noticias felices en aviones de papel. — Lumen, Barcelona, 2014. 96 pp. || CuH, 2015, núm. 778, 134-136 (Juristo). [Novela].

65-1329. Cuenca, Josep Maria - Mientras llega la felicidad. Una biografía de Juan Marsé. - Anagrama, Barcelona, 2015. 751 pp. || CuH, 2015, núm. 784, 154-157 (Sanz Villanueva).

\section{Martín Gaite, Carmen}

65-1330. Martín Gaite, Carmen — Obra completa. T. 4: Ensayos I. Investigación histórica. Ed. de José Teruel. —- EspasaCírculo de Lectores, Barcelona, 2015. 1450 pp. || CuH, 2015, núm. 783, 145148 (Juristo).

65-1331. Vittoria Calvi, Maria - "La Correspondencia entre Carmen Martín Gaite y Juan Benet: ensayos de un género". - CAISPI, 2014, núm. 3, 111124.

\section{Martínez, Guillermo}

65-1332. Price, Gillian - "Guillermo Martínez”. - Hispam, 2015, núm. 131, 47-56. [Entrevista].
Masoliver Ródenas, Juan Antonio

65-1333. Eusebio, Carmen de - "Juan Antonio Masoliver Ródenas: «Lo que nos hace grandes no es lo que sabemos, sino lo que queremos saber»". - CuH, 2016, núm. 789, 108-115. [Entrevista].

\section{Matos Paoli, Francisco}

65-1334. Ortega, Julio - "Francisco Matos Paoli: el discurso de la locura

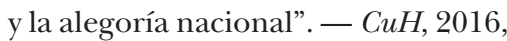
núm. 789, 20-37.

\section{Mayorga, Juan}

65-1335. Mayorga, JUAN - Teatro sulla Shoah. Himmelweg - Il cartofrafo - JK. Est. e trad. di Enrico Di Pastena. - ETS, Pisa, 2014. 251 pp. || CAISPI, 2015, núm. 6, 246-249 (Londero).

65-1336. RodríguEz-SOLÁs, DAVID - "El espacio de la crítica, el lugar de la utopía: el teatro de Juan Mayorga". — Ibero, 2016, núm. 62, 225-234.

V. también núm. 1193.

\section{Medina, Vicente}

65-1337. Navarro Avilés, Juan José "La evolución lingüística en Aires murcianos, de Vicente Medina". — AFA, 70 (2014), 201-226.

\section{Mejia Vallejo, Manuel}

65-1338. Carvajal Córdoba, Edwin, Héctor Fabio Buitrago Correa y Wilfer Andrés Campuzano CalDERÓN - "Edición crítica de textos: estudio de las ediciones de La Casa de las dos Palmas (1988) de Manuel Mejía Vallejo". - LinL, 2015, núm. $68,107-127$. 
65-1339. Méndez Guédez, Juan Carlos - Los maletines. - Siruela, Madrid, 2014. 386 pp. || CuH, 2015, núm. 777, 150-153 (Juristo). [Novela].

65-1340. Eusebio, Carmen de — "Juan Carlos Méndez Guédez: «La novela negra, cuando viaja al Caribe, baila aunque sea de dolor»". - $\mathrm{CuH}, 2015$, núm. 777, 136-148.

\section{Mendoza, Eduardo}

V. núm. 1467.

\section{Meruane Boza, Lina}

65-1341. Meruane, Lina - Sangre en el ojo. - Random House-Mondadori, Santiago de Chile, 2012. || Inti, 78-79 (2014), 337-339 (Fernández).

Miró, Gabriel

65-1342. Castillo, Fernando - "Evocación de Gabriel Miró”. - $\mathrm{CuH,} \mathrm{2016,}$ núm. 787, 98-107.

\section{Moga, Eduardo}

65-1343. Moga, EduARdo - El corazón, la nada. - Amargord Ediciones, Madrid, 2014. || Íns, 2015, núm. 828, 40-44 (Lostalé).

Moix, Ana María

V. núm. 1212.

Molina, Enrique

65-1344. Cassara, Walter - "Enrique Molina. En la latitud esencial de la poesía”. - CuH, 2015, núm. 777, 119127.
65-1345. Dolores Cuecuecha MendoZA, M. del Carmen - "La autoficcionalización de Silvia Molina en las novelas La familia vino del norte e Imagen de Héctor". - Semiosis, 2014, núm. 20, 195-206.

Monsiváis, Carlos

65-1346. García de la Sienra, Rodrigo - "Imágenes de la tradición viva. Ambivalencia y pluralidad de la cultura en México". - Semiosis, 2014, núm. 20, 89-99.

\section{Monterroso, Augusto}

65-1347. Lámbarry, Alejandro (ed.) - La mosca en el canon. Ensayos sobre Augusto Monterroso. - Tierra Adentro, México, 2013. 160 pp. || Ibero, 2016, núm. 61, 324-327 (Van Hecke).

\section{Montoya, Pablo}

V. núm. 1421.

\section{Morábito, Fabio}

65-1348. Morábito, Fabio - El idioma materno. - Sexto Piso, México, 2014. 182 pp. || CuH, 2015, núm. 775, 111114 (Serrano). [Prosa breve].

65-1349. Abril, Juan Carlos - "Poesía y metapoesía en Fabio Morábito”. CuH, 2015, núm. 775, 78-87.

65-1350. Lozada Pastoressa, Yessica — "También Berlín se olvida: aproximaciones y reflexiones sobre un relato de viaje". - Semiosis, 2014, núm. 20, 207-220.

\section{Morales, Gregorio}

65-1351. Villena, Fernando de — "Despedida de Gregorio Morales". - Íns, 2015, núm. 828, 14-15. 
Morales, Rafael

65-1352. Dolfi, LaUra - "Rafael Morales escribe a Oreste Macrí (once cartas inéditas)". - CAISPI, 2014, núm. 3, 213-235.

\section{Morales Ortiz, Gracia}

65-1353. Morales Ortiz, Gracia La voz en pie. - Eds. Dauro, Granada, 2014. 71 pp. || PHisp, 29 (2015), núms. 1/2, 104-105 (Gallego Cuiñas).

Muñoz Molina, Antonio

65-1354. Riosalido Villar, Patricia - "La intención de El jinete polaco de Antonio Muñoz Molina: recuperar la memoria histórica". - Cincuentenario de la AIH, ed. R. Barros Roel (A Coruña, 2014), pp. 407-414.

\section{Muslip, Eduardo}

65-1355. Muslip, Eduardo - Avión. - Blatt \& Ríos, Buenos Aires, 2015. || Hispam, 2015, núm. 132, 122-123 (Nuriel). [Novela].

\section{Mutis, Álvaro}

65-1356. Roca Escalante, Pilar - "La presencia de Cervantes en la obra de Álvaro Mutis. La sombra cervantina que proyecta Maqroll el Gaviero". ABEH, 26 (2016), 93-99.

\section{Navascués, Javier de}

65-1357. Calvo Revilla, Ana — "Desencanto utópico y distopía en «Los mitos del mundo moderno»: las confabulaciones de Javier de Navascués". - I, 83 (2016), 56-70.
Neruda, Pablo

65-1358. EnRíouez HernáNDEZ, GABRIEL M. - "Melancolía y anarquismo en los Cuadernos de Neftali Reyes". - Semiosis, 2015, núm. 21, 27-61.

\section{Nervo, Amado}

65-1359. Flores, Milenka - "Voces escriturales y representaciones femeninas en la crónica de Amado Nervo (1895-1899)". - Semiosis, 2014, núm. $20,143-174$

\section{Ocampo, Silvina}

65-1360. Rossi, María Julia — "Silvina Ocampo: la identidad desafiada y los dobleces de la infancia”. - Hispam, 2015, núm. 131, 11-18.

\section{Ollé, Carmen}

65-1361. Iubini Vidal, Giovanna "Noches de adrenalina de Carmen Ollé como poesía integral neovanguardista”. —EFil, 2015, núm. 55, 77-92.

\section{Olmos de Ita, Enrique}

V. núm. 1398.

\section{Onetti, Juan Carlos}

65-1362. Negrete Sandoval, Julia ÉRIKA - "Mecanismos de representación del sueño y la imaginación en dos cuentos de Juan Carlos Onetti”. Semiosis, 2014, núm. 20, 49-65.

$$
\text { Ortega, Julio }
$$

65-1363. Álvarez, María Auxiliadora — "El otro lado del túnel y el itinerario moral del lenguaje". - Inti, 78/79 (2014), 179-192. 
Ortega y Gasset, José

65-1364. Gracia, Jordi - José Ortega y Gasset (N. 63-2966). || Íns, 2015, núm. 825, 29-31 (Serrano).

\section{Ortiz, Miguel Ángel}

65-1365. Ortiz, Miguel Ángel - La inmensa minoria. - Random House, Barcelona, 2014. 384 pp. || CuH, 2015, núm. 776, 111-114 (Sanz Villanueva). [Novela].

Oryazábal Smith, Isabel

65-1366. OryazÁbal Smith, IsAbel Mujer, voto y libertad. Textos periodísticos. Ed., introd. y notas de A. Quiles Faz (N. 64-2935). || CAISPI, 2015, núm. 5, 241-243 (Ortega Garrido).

\section{Pacheco, José Emilio}

65-1367. García Montero, Luis - "La inmovilidad del movimiento. Poética de José Emilio Pacheco". - $\mathrm{CuH}$, 2015, núm. 784, 2-13.

65-1368. RANGEL, A. - La pulsión por el viaje de José Emilio Pacheco: su periplo al romanticismo (N. 62-1126). || NRFH, 64 (2016), 614-732 (Alemany Bay).

\section{Panero, Leopoldo}

65-1369. Moga, Eduardo — "Battersea park y un amor obviamente posible”. - CuH, 2015, núm. 784, 83-91.

\section{Parra, Nicanor}

65-1370. Valenzuela Rettig, Pilar "Lo humano y no-humano en Poemas y antipoemas de Nicanor Parra". - EFil, 2014, núm. 54, 177-192.
Paz, Octavio

65-1371. Domínguez Michael, ChristoPHer - Octavio Paz en su siglo. - Aguilar, México, 2014. 653 pp. || CuH, 2015, núm. 778, 144-147 (Valencia).

65-1372. Escalante, Evodio - Las sendas perdidas de Octavio Paz. — UAM Iztapalapa-Ediciones Sin Nombre, México, 2013. 184 pp. || Ibero, 2015, núm. 59, 250-252 (Velázquez Toledo). 65-1373. Moya Ávila, Francisco "Octavio Paz y su Laurel: lector de Rubén Darío y Juan Ramón Jiménez”. — PHisp, 29 (2015), núms. 3/4, 41-53.

\section{Paz Pasamar, Pilar}

65-1374. Gatica Cote, Paulo Antonio - "Desplegando la estación del abanico: la poesía de senectud de Pilar Paz Pasamar". — Dicenda, 32 (2014), 205-229.

V. también núm. 1216.

$$
\text { Pazó, José }
$$

65-1375. Pazó, José — Banteki (El salvaje). - Libros de la Ballena, Madrid, 2015. 208 pp. || CuH, 2016, núm. 789, 136139 (Baquero). [Novela].

\section{Pedro, Valentín de}

65-1376. Pedro, Valentín de - La vida por la opinión. Novela del asedio de Madrid. Ed. e introd. de Aníbal Salazar Anglada. - Renacimiento, Sevilla, 2014. || Íns, 2015, núm. 828, 29-31 (Russo).

\section{Pellicer, Carlos}

65-1377. Ruiz Abreu, Álvaro - La esfera de las rutas. El viaje poético de Pellicer. Iberoamericana-Bonilla Artigas Editores, Madrid-México, 2013. 339 pp. ( $L a$ Crítica Practicante, 10). || Ibero, 2016, núm. 61, 321-324 (Van Hecke). 
Pérez Álvarez, José María

65-1378. Pérez Álvarez, José María Examen final. - Trifolium, A Coruña, 2014. 136 pp. || CuH, 2016, núm. 787, 130-133 (Juristo). [Novela].

65-1379. Eusebio, Carmen de - "José María Pérez Álvarez: «Humor e ironía son las armas defensivas contra la vida»". - CuH, 2016, núm. 787, 118127. [Entrevista].

\section{Pérez Andújar, Javier}

65-1380. Alemany, Raúl Alonso y Oriol Gálvez Roca - "Una tarde con Javier Pérez Andújar". - $\mathrm{CuH}$, 2016, núm. 787, 86-97. [Entrevista].

\section{Pérez-Reverte, Arturo}

65-1381. Navascués, Javier de — "Proyecto de nación y discurso liberal en novelas españolas”. - EFil, 2014, núm. 54, 111-125.

\section{Perezagua, Marina}

65-1382. Perezagua, Marina - Yoro. Los Libros del Lince, Barcelona, 2015. 320 pp. || CuH, 2016, núm. 787, 153156 (Serrano). [Novela].

\section{Peri Rossi, Cristina}

65-1383. Mérida Jiménez, Rafael M. "Cristina Peri Rossi en Triunfo: género y sexualidad en la prensa de la transición española”. - CuIF, 41 (2015), 129-139.

\section{Piera, Carlos}

65-1384. Gómez Toré, José LuIs — "Otra defensa de la poesía: los ensayos de Carlos Piera”. - CuH, 2016, núm. 787, 108-117.
Piglia, Ricardo

65-1385. Piglia, Ricardo - Por un relato futuro. Conversaciones con Juan José Saer. Ed. y pról. de Patricia Samosa. - Anagrama, Barcelona, 2015. 129 pp. || CuH, 2016, núm. 788, 137-139 (Eusebio).

\section{Piñera Llera, Virgilio}

65-1386. Bennett, Andrew - "Una nación burlona: Virgilio Piñera y el «choteo» cubano". - CuA, 2015, núm. 153, 49-66.

65-1387. Lima, Dolores - "La risa blanca de Virgilio Piñera: inmunidad y soberanía”. - Hispam, 2015, núm. $132,43-49$.

65-1388. Machado Vento, Dainerys - "El discernir piñeriano". - CuA, 2015, núm. 153, 11-28.

65-1389. Navarrete Turrent, Lucila "Del destino aciago al eros de la creación: apuntes sobre la cuenstística de Virgilio Piñera”. - CuA, 2015, núm. $153,29-47$.

65-1390. Zilinskaite, Milda — “"¿Qué tal? ¿Virgilio?»: apuntes sobre la relación intelectual entre Virgilio Piñera y Witold Gombrowicz". — CuA, 2015, núm. 153, 67-85.

\section{Pitol, Sergio}

65-1391. Corral, Elizabeth - La escritura insumisa. Correspondencias en la obra de Sergio Pitol. - El Colegio de San Luis, México, 2013. || Semiosis, 2015, núm. 21, 219-224 (Pérez Esperanza).

\section{Pizarnik, Alejandra}

65-1392. Chatellus, A. De y M. EzQueRRO - Alejandra Pizarnik: el lugar donde todo sucede (N. 64-1396). || CAISPI, 2015, núm. 5, 230-232 (Minardi). 


$$
\text { Pla, Josep }
$$

65-1393. Pla, Josep — La vida lenta. Nota para tres diarios (1956, 1957, 1964). Ed. y pról. de Xavier Pla, trad. de Concha Cardeñoso. - Destino, Barcelona, 2014. 320 pp. || CuH, 2015, núm. 776, 102-107 (Sotelo Vázquez).

\section{Pron, Patricio}

65-1394. Pron, Patricio - El libro tachado. Prácticas de la negación y el silencio en la crisis de la literatura. - Turner, Madrid, 2014. 306 pp. || CuH, 2015, núm. 775, 107-110 (Corral). [Ensayo].

\section{Puig, Manuel}

65-1395. Kim, EUISUk - "Libertad y sometimiento del sujeto en The Buenos Aires affair de Manuel Puig". Hispam, 2015, núm. 132, 107-110.

\section{Ramón, Esther}

65-1396. Ramón, Esther - Desfrío. Varasek, Madrid, 2015. 84 pp. \| CuH, 2015, núm. 784, 158-161 (Martín Gijón). [Poesía].

\section{Raphael, Pablo}

65-1397. Eusebio, Carmen de - "Pablo Raphael: «Somos la sociedad de los distintos que forma el gran mosaico de los individuales»". - $\mathrm{CuH}, 2015$, núm. 785, 112-123. [Entrevista].

\section{Rascón Banda, Víctor Hugo}

65-1398. BiXleR, JACQUELINE — “«In Yer Face»: la irrupción de lo real en el teatro de Rascón Banda, Olmos, Legom y Ricaño". - Semiosis, 2015, núm. 21, 171-180.
Rebolledo, Efrén

65-1399. Pellicer, Juan - "Poeta en Christiania. Atisbo histórico-literario al modernismo de Efrén Rebolledo". — RRo, 49 (2014), 147-157.

\section{Revueltas, José}

65-1400. Pérez Domínguez, Josué FedeRICO - "José Revueltas: conocimiento estético y militancia comunista". —Diánoia, 2016, núm. 76, 113-138.

\section{Ribeyro, Julio Ramón}

65-1401. Baudry, Paul — "Ribeyro y su cruz desde Vida y pasión de Santiago, el pajarero (1958)". - Íns, 2015, núm. 826, 33-36.

65-1402. Cabrejos, IrENE - "Estilo y vida en Ribeyro”. - Íns, 2015, núm. 826, 12-15.

65-1403. Cueto, Alonso - "Una utopía de la soledad". — Íns, 2015, núm. 826, 2-5.

65-1404. Elmore, Peter - “Julio Ramón Ribeyro: la condición del autor”. Íns, 2015, núm. 826, 5-8.

65-1405. Esteban, Ángel - "Julio Ramón Ribeyro y Mario Vargas Llosa ante el "principio del distanciamiento mínimo» y el "pacto autobiográfico»". -Íns, 2015, núm. 826, 15-18.

65-1406. González Montes, Antonio — "El tema del futbol en Julio Ramón Ribeyro (cuento y teatro)". - Íns, 2015, núm. 826, 29-33.

65-1407. Navascués, Javier DE — "Ribeyro: un puesto en el canon entre dos mundos". - Íns, 2015, núm. 826, $18-21$.

65-1408. Prado Alvarado, Agustín "A la sombra de las muchachas en flor en Relatos santacrucinos, de Ribeyro". - Íns, 2015, núm. 826, 25-28.

65-1409. Rodero, Jesús — "Un inventario de enigmas. Los cuentos fantásticos de Julio Ramón Ribeyro". - Íns, 2015, núm. 826, 22-25.

65-1410. Valero Juan, Eva — " «Con algunos tiempos de retraso»... Madrid 
en la obra de Ribeyro». - Íns, 2015, núm. 826, 9-12.

\section{Riera, Carme}

V. núm. 1467.

$$
\text { Rimsky, Cynthia }
$$

V. núm. 1213.

$$
\text { Ripoll, Laila }
$$

V. núm. 1314.

\section{Risco, Vicente}

65-1411. Sotelo VÁzQUez, Adolfo - "El grupo Nós y las letras peninsulares: Vicente Risco". - CuH, 2015, núm. $779,81-91$.

\section{Rivas Panedas, José}

65-1412. Rivas Panedas, José - Poeta ultraísta, poeta exiliado. Ed. de Carlos García y Pilar García Sedas. - Iberoamericana-Vervuert, MadridFrankfurt/M., 2015. 320 pp. (El Fuego Nuevo. Textos Recobrados, 12). || Ibero, 2016, núm. 62, 344-347 (Rojas).

\section{Rivera Garza, Cristina}

65-1413. Sy, ANAHI — "De la literatura a la historia: cuando la locura se convierte en desviación social". - EFil, 2015, núm. 55, 129-141.

\section{Rodríguez, Claudio}

65-1414. Gómez Toré, José LuIs — "Don y precio: el dinero en la poesía de Claudio Rodríguez". - $\mathrm{CuH}, 2015$, núm. 776, 58-67.
Roffé, Reina

65-1415. Jiménez-Salazar, Arturo "Ambigüedad en tres cuentos de Aves exóticas de Reina Roffé". - HiJ, 37 (2016), núm. 1, 29-45.

\section{Roncagliolo, Santiago}

65-1416. Domínguez CÁceres, Roberто - "La identidad como download. Nuevas migraciones en el cine de Alex Rivera y en una novela de Santiago Roncagliolo". — Inti, 78/79 (2014), 127-136.

\section{Rosales, Guillermo}

65-1417. Leyva Martínez, Ivette "Guillermo Rosales y Carlos Victoria: visiones errantes de Miami”. - $\mathrm{CuH}$, 2015, núm. 779, 24-33.

\section{Rosales, José Carlos}

65-1418. Rosales, José Carlos - Y el aire de los mapas. - Fundación José Manuel Lara, Sevilla, 2014. 128 pp. || CuH, 2015, núm. 775, 115-117 (Pérez Zúñiga). [Poesía].

\section{Rosemann-Taub, David}

65-1419. Merlo, Pepa - "David Rosemann-Taub. Inédito". - $\mathrm{CuH}, 2015$, núm. 784, 122-126.

\section{Rosero, Evelio}

65-1420. Gil Alzate, David — "La carroza de Bolívar, simetría de dos revoluciones fracasadas en Colombia". - ELC, 2016, núm. 38, 145-162.

65-1421. VANegas VásQuez, Orfa KeliTA - "Simbolismo de la decapitación en Los ejércitos de Evelio Rosero y Los derrotados de Pablo Montoya". - ELC, 2016, núm. 38, 39-56. 
65-1422. Ruiz Sosa, Eduardo - Anatomía de la memoria. - Candaya, Barcelona, 2014. 576 pp. || CuH, 2016, núm. 787, 138-140 (Martín Gijón). [Novela].

\section{Rulfo, Juan}

65-1423. Meza García, Gerardo y MarTHA Elia ArizMendi Domínguez "Semiótica de la vida social en El Llano en llamas de Juan Rulfo + «La ternura de la muerte»". — Semiosis, 2014, núm. 20, 187-194.

65-1424. Popovic Karic, Pol — "Las mentiras en Pedro Páramo". — RRo, 50 (2015), 68-80.

65-1425. Quintero Ramírez, SArA -

"Sintagmas nominales y la operación de determinación en "Macario» de Juan Rulfo en español y francés”. SEFS, 2015, núm. 28, 187-210.

V. también núm. 1224

\section{Ruy Sánchez, Alberto}

65-1426. Eusebio, Carmen de - "Alberto Ruy Sánchez: «Me interesa reactivar por la palabra la música del cuerpo»". - CuH, 2015, núm. 778, 103-119. [Entrevista].

Saer, Juan José

V. núms. 1385, 1413.

Salinas, Pedro

V. núm. 1286.

Samperio, Guillermo

65-1427. Samperio, Guillermo - Maravillas malabares. - Cátedra, Madrid, 2015. 408 pp. || CuH, 2015, núm. 779, 147-150 (Serrano). [Antología de prosa].
65-1428. Sánchez Ferlosio, Rafael Campo de retamas. Pecios reunidos. Random House, Barcelona, 2015. 195 pp. || CuH, 2015, núms. 781/782, 222225 (Juristo). [Prosa breve].

\section{Sánchez Robayna, Andrés}

65-1429. SÁnchez Robayna, Andrés El espejo de tinta (Antología 1970-2010). Ed. de José Francisco Ruiz Casanova. — Cátedra, Madrid, 2012. || Íns, 2015, núm. 825, 38-43 (Le Bigot). [Poesía]. 65-1430. SÁnchez Robayna, Andrés - Variaciones sobre el vaso de agua. Galaxia Gutenberg, Barcelona, 2015. 410 pp. || CuH, 2015, núm. 780, 105108 (Morales). [Ensayo].

65-1431. Eusebio, CARMEn de - "Andrés Sánchez Robayna: «Los ojos son el lugar de encuentro del espíritu y el mundo»". - CuH, 2015, núm. 780, 50-58. [Entrevista].

\section{Sastre, Alfonso}

65-1432. Sastre, Alfonso - Squadra verso la morte. Ed. e trad. di Enrico Di Pastena. — ETS, Pisa, 2014. 263 pp. II CAISPI, 2014, núm. 4, 240-243 (Garofalo).

\section{Saussol, José María}

65-1433. Saussol, José María - Le risposte dell'acqua. Ed. di Marta Mazzini. - Il Canneto Editore, Genova, 2013. 502 pp. || CAISPI, 2014, núm. 4, 245248 (Bianchi).

\section{Sender, Ramón J.}

65-1434. SENDER, RAMón J. - Racconti di frontiera. Trad. di Federica Cappelli. - ETS, Pisa, 2014. 326 pp. || CAISPI, 2015, núm. 6, 255-257 (Polverini). 
Serna, Enrique

65-1435. Serna, Enrique - Genealogía de la soberbia intelectual. - Taurus, Madrid, 2014. 296 pp. || CuH, 2015, núm. 783, 140-144 (Corral). [Crítica].

Solís Llorente, Ramón

V. núm. 1381.

\section{Sologuren, Javier}

65-1436. Chirinos, Eduardo - "Una lectura de Recinto de Javier Sologuren”. - CuH, 2015, núm. 778, 55-68.

\section{Sucre, Guillermo}

65-1437. Antzus Ramos, IoAnnis "Guillermo Sucre. La búsqueda de la transparencia”. - Inti, 78/79 (2014), 161-178.

\section{Tomeo, Javier}

65-1438. González García, Francis$\mathrm{CO}$ - "Un recorrido por los monstruos de Javier Tomeo". — Dicenda, 32 (2014), 231-249.

\section{Torre, Guillermo de}

65-1439. Martí Monterde, Antoni "Guillermo de Torre y la literatura comparada”. — I, 82 (2015), 185-201.

65-1440. Ródenas de Moya, Domingo "Peregrinos en la misma senda: Mallea y Torre, corresponsales". - CAISPI, 2014, núm. 3, 145-168.

\section{Umbral, Francisco}

65-1441. Garbisu Buesa, Margarita "Los inicios en prensa de Francisco Umbral: las colaboraciones en La Estafeta Literaria”. — Dicenda, 32 (2014), 155-183.
Unamuno, Miguel de

65-1442. Briganti, ANDrEA — "Las preguntas de un traductor: cartas de Gilberto Beccari a Miguel de Unamuno”. - CAISPI, 2014, núm. 3, 41-57.

65-1443. Maura, JuAn Francisco "Ciencia, progreso y ética en Unamuno y Santayana”. - CuH, 2015, núm. 775, 69-77.

65-1444. Moreira, SANdra Regina "La recreación quijotesca en Niebla de Unamuno". - ABEH, 26 (2016), 49-63.

65-1445. Perotti, Olga - "Las cartas inéditas de Víctor Said Armesto a Miguel de Unamuno". - CAISPI, 2014, núm. 3, 27-39.

65-1446. Simon, Robert - "El ser sin ser: la poética del existencialismo kierkegaardiano y nietzscheano en las obras de Miguel de Unamuno, Miguel Torga, Ramón Gómez de la Serna y Vergílio Ferreira”. — HiJ, 37 (2016), núm. 1, 81-107.

\section{Valencia, Guillermo}

65-1447. SHu-Ying CHANG, Luisa — "Las «bellas infieles»: Guillermo Valencia, traductor de poesía china". - $\mathrm{CuH}$, 2015, núm. 780, 91-103.

$$
\text { Valente, José Ángel }
$$

65-1448. VAlente, José Ángel - Palais de Justice. Ed. de Andrés Sánchez Robayna. - Galaxia Gutenberg, Barcelona, 2014. 100 pp. || CuH, 2015, núm. 777, 168-171 (Gómez Toré).

65-1449. Aguirre Martínez, Guillermo - "Forma y abstracción en la poesía de José Ángel Valente". — RILCE, 32 (2016), 5-31.

\section{Valero, Vicente}

65-1450. Valero, Vicente - Canción del distraído. - Vaso Roto, Madrid, 2015. 150 pp. || CuH, 2015, núm. 779, 143146 (Moga). [Poesía]. 
Valle-Inclán, Ramón del

65-1451. Campoy-Cubillo, Adolfo "Imperial trade: Valle-Inclán's La pipa de kif and the dark side of the artificial paradises". — HiJ, 36 (2015), núm. 2, 179-196.

65-1452. Llera, José Antonio — "El águila y el topo: Valle-Inclán y Gaziel ante la Gran Guerra”. - CuH, 2015, núm. 784, 14-33.

65-1453. Mascato Rey, R. - Valle-Inclán lusófilo: documentos (1900-1936) (N. 64-3006). || Dicenda, 32 (2014), 381385 (Martínez Navarro).

65-1454. Torres Begines, Concepción - España vista desde el aire: influencia del esperpento de Valle-Inclán en el cine de García Berlanga. — Universidad, Málaga, 2014. 239 pp. || Ibero, 2016, núm. 61, 292-294 (López Fernández).

\section{Vallejo, César}

65-1455. Campesino, Juan — "Cuando duele la dicha. ¿Ironía romántica o forma de la paradoja?”. — TdS, 2015, núm. 34, 107-129.

65-1456. Fernández-Jáuregui Rojas, Carlota - El poema y el gesto. Dactilécticas de Dante, Paul Celan, César Vallejo y Antonio Gamoneda. - Universidad Autónoma de Madrid, Madrid, 2015. 283 pp. || Ibero, 2015, núm. 60, 218-220 (Corral Cañas).

65-1457. Ortega, Julio - César Vallejo. La escritura del devenir. - Taurus, Barcelona, 2014. 304 pp. || Ibero, 2015, núm. 59, 248-250 (Fernández).

\section{Vallejo, Fernando}

65-1458. Munguía Zatarain, Martha Elena - "La festiva convivencia de literatura y ética. Una lectura de Entre fantasmas de Fernando Vallejo". Semiosis, 2014, núm. 20, 29-48.

65-1459. Polanco IzQuierdo, MauriCIO - "Pluralisme et choralité dans La Virgen de los sicarios et El desbarrancadero de Fernando Vallejo". — LinL, 2015, núm. 68, 129-144.
65-1460. Romero, María de los ÁngeLES - Narrativa de la violencia: hiperrealismo de Rubem Fonseca y Fernando Vallejo. - Antithesis, Montevideo, 2014. 166 pp. (Hermenéuticas, 2). I Ibero, 2015, núm. 60, 234-236 (Cuya Gavilano).

\section{Valverde, Álvaro}

65-1461. VAlverde, Álvaro - Más allá, Tánger. - Tusquets, Barcelona, 2014. 112 pp. || CuH, 2015, núm. 786, 110113 (Neila). [Poesía].

65-1462. GARcía Ríos, BEATriz — “Álvaro Valverde: «En la claridad está la mayor profundidad»”. - $\mathrm{CuH}, 2015$, núm. 786, 92-107.

\section{Vargas Llosa, Mario}

65-1463. Arrizabalaga, Carlos "Creatividad léxica y tratamiento lexicográfico: el caso de Vargas Llosa y $L a$ casa verde". — RLex, 20 (2014), 7-17.

65-1464. Benavides, Jorge EduARdo "Los «iluminados» de Vargas Llosa". - CuH, 2015, núm. 783, 61-71.

V. también núm. 1405.

\section{Vásconez, Javier}

65-1465. Ampuero, Fernando - “La otra muerte del doctor de Javier Vásconez". Inti, 78/79 (2014), 261-264.

\section{Vázquez Montalbán, Manuel}

65-1466. Colmeiro, J. - El ruido y la furia. Conversaciones con Manuel Vázquez Montalbán, desde el planeta de los simios (N. 64-3013). || CAISPI, 2014, núm. 3, 241-244 (Cattaneo).

65-1467. Ramón García, Emilio "Miradas «noir» de Barcelona: desde Vázquez Montalbán y Mendoza a Riera”. - Dicenda, 32 (2014), 313-340. 
Velasco, María

65-1468. Fox, Manuela - "La producción de María Velasco en el actual panorama teatral español". - CAISPI, 2016, núm. 7, 125-137.

\section{Vidales, Luis}

65-1469. Zuluaga Hernández, Esnedy - "Idiotismo y crítica: una aproximación al carácter demoledor de Suenan timbres de Luis Vidales". - ELC, 2016, núm. 38, 125-144.

\section{Villaespesa, Francisco}

65-1470. Orta Carrique, Estefanía "Francisco Villaespesa y Juan Ramón Jiménez, abanderados de un modernismo de combate". - PHisp, 29 (2015), núms. 3/4, 69-81.

\section{Villoro, Juan}

65-1471. Villoro, Juan - ¿Hay vida en la Tierra?. - Anagrama, Barcelona, 2014. 376 pp. || CuH, 2015, núm. 779, 162-165 (Alberca).

65-1472. Contreras, José Alfredo, Melissa González-Contreras y María Cristina Monsalve - "Juan Villoro". - Hispam, 2015, núm. 132, 51-61. [Entrevista].

\section{Viñas, David}

65-1473. Setton, Román - "Las biografías criminales de David Viñas". EFil, 2014, núm. 53, 161-170.

Vitale, Ida

65-1474. Vitale, IDA - Todo de pronto es nada. Ed. e introd. de María José Bruña Bragado. - Universidad, Salamanca, 2015. 300 pp. || CuH, 2016, núm.
788, 130-132 (Gómez Toré). [Antología poética].

$$
\text { Volpi, Jorge }
$$

65-1475. VolPI, JoRgE - Ficciones criminales. Estampas de la crisis (2008-2014). La Pereza, Miami, FL, 2014. 230 pp. ॥ CuH, 2015, núm. 784, 162-165 (Fernández Fe). [Ensayo].

\section{Westphalen, Emilio Adolfo}

65-1476. Zegarra, Chrystian - El celuloide mecanografiado. La poesía cinemática de E.A. Westphalen. - Verbum, Madrid, 2013. || Hispam, 2015, núm. 131, 127-128 (Santiváñez).

\section{Wilms Montt, Teresa}

65-1477. Traverso, Ana - "Anomalía y enfermedad en escritoras de inicios del s. xx”. - EFil, 2014, núm. 54, 157-175.

$$
\text { Yánez, María Flora }
$$

V. núm. 1477.

\section{Zambrano, María}

65-1478. Laurenzi, Elena (ed.) - Elena Croce, María Zambrano. A presto, duque, e a sempre. Lettere 1955-1990. - Archinto, Milano, 2015. || ERM, 24 (2015), 227-230 (Hernández González).

65-1479. Moga, EduARdo - "María Zambrano, poeta”. - CuH, 2015, núm. 783, 82-90.

$$
\text { Zayas, Antonio de }
$$

65-1480. Nebot Nebot, Vicente José"Poéticas parnasianas y simbolismo en Retratos antiguos de Antonio de Zayas". - CuIF, 41 (2015), 47-75. 


\section{ABREVIATURAS}

ABEH-Anuario Brasileño de Estudios Hispánicos. Brasilia.

$A F A$-Archivo de Filología Aragonesa. Zaragoza.

$A F B$-Anuari de Filologia. Estudis de Lingüística. Barcelona.

$A L M$-Anuario de Letras. Lingüística y Filología. México.

Babel_Babel. Revue Internationale de la Traduction. Amsterdam.

Borealis-Borealis. An International Journal of Hispanic Linguistics. Tromsø.

CAISPI-Cuadernos AISPI. Estudios de Lenguas y Literaturas Hispánicas. Roma.

CatJL-Catalan Journal of Linguistics. Barcelona.

CEHM-Cahiers d'Études Hispaniques Médiévales. Paris.

$C E R$ - Cervantes. Bulletin of the Cervantes Society of America. Normal, IL.

Chimera-Chimera. Romance Corpora and Linguistic Studies. Madrid.

$C L A C$-Círculo de Lingüística Aplicada a la Comunicación. Madrid.

CLECM — Cuadernos de Lingüística de El Colegio de México. México.

CLex-Cahiers de Lexicologie. Revue Internationale de Lexicologie et Lexicographie. Paris.

CuA-Cuadernos Americanos. México.

CuDie_Cuadernos Dieciochistas. Salamanca.

CuH-Cuadernos Hispanoamericanos. Madrid.

CuIF-Cuadernos de Investigación Filológica. Logroño.

CuIR-Cuadernos de Ilustración y Romanticismo. Cádiz.

Diánoia-Diánoia. Anuario de Filosofía. México.

Dicenda-Dicenda. Cuadernos de Filología Hispánica. Madrid.

$e$-AESLA - e-AESLA. Revista Digital. Madrid.

EAc-Español Actual. Revista de Español Vivo. Madrid.

EFil_-Estudios Filológicos. Valdivia.

ELAp_Estudios de Lingüística Aplicada. México.

ELC-Estudios de Literatura Colombiana. Antioquia.
ERM-Estudios Románicos. Murcia.

Graffylia-Graffylia. Revista de la Facultad de Filosofía y Letras. Puebla.

Hij-Hispanic Journal. Indiana, PA.

Hipogrifo-Hipogrifo. Revista de Literatura y Cultura del Siglo de Oro. Pamplona.

Hispam-Hispamérica. Revista de Literatura. Takoma Park, MD.

I-Ibero-Romania. Tübingen.

Ibero-Iberoamericana. LateinamerikaSpanien-Portugal. Frankfurt/M.

IJLex-International Journal of Lexicography. Oxford.

Incipit-Incipit. Buenos Aires.

Ins-Insula. Madrid.

Inti-Inti. Revista de Literatura Hispánica. Providence, RI.

$J C h L$ - Journal of Child Language. Cambridge.

$J L-J o u r n a l$ of Linguistics. Cambridge.

$J M M D$ - Journal of Multilingual and Multicultural Development. Clevedon.

JSem-Journal of Semantics. New York. JSLT-Journal of Spanish Language Teaching. Abingdon.

La Perinola-La Perinola. Revista de Investigación Quevediana. Pamplona.

LEA-Lingüística Española Actual. Madrid.

LexisL-Lexis. Revista de Lingüística y Literatura. Lima.

LinALFAL_Lingüística. Revista de la ALFAL. Madrid.

LinL_Lingüística y Literatura. Medellín.

$L M i$-Lengua y Migración. Alcalá de Henares-Madrid.

LMod-Lenguas Modernas. Santiago de Chile.

Normas-Normas. Revista de Estudios Lingüísticos Hispánicos. València.

NRFH-Nueva Revista de Filología Hispánica. México.

Onomázein-Onomázein. Revista de Lingüística, Filología y Traducción. Santiago de Chile.

Oralia-Oralia. Análisis del Discurso Oral. Almería.

PHisp_Philologia Hispalensis. Sevilla.

PLSA_Proceedings of the Linguistic Society of America. Washington, DC.

$\mathrm{PrSc}$-Pragmática Sociocultural / Sociocultural Pragmatics. Revista Internacional sobre Lingüística del español. 
An International Journal of Spanish Linguistics. Stockholm.

RdiL-Italian Journal of Linguistics. Pisa. $R E L-$ Revista Española de Lingüística. Madrid.

$R E s L A-$ Revista Española de Lingüística Aplicada / Spanish Journal of Applied Linguistics. Amsterdam-Philadelphia.

RFE—Revista de Filología Española. Madrid.

RFilR-Revista de Filología Románica. Madrid.

RFLUCR-Revista de Filología y Lingüística de la Universidad de Costa Rica. San José.

RHLE-Revista de Historia de la Lengua Española. Madrid.

RILCE_RILCE. Revista de Filología Hispánica. Pamplona.

RILI-Revista Internacional de Lingüística Iberoamericana. MadridFrankfurt/M.

$R L A-$ Revista de Lingüística Teórica y Aplicada. Concepción.

RLex-Revista de Lexicografía. A Coruña.

$R L i R-$ Revue de Linguistique Romane. Zürich.

RRo-Revue Romane. Copenhague.

Scriptum-Scriptum Digital. Revista de Corpus Diacrónicos y Edición Digital en Lenguas Iberorrománicas. Barcelona.

Semiosis-Semiosis. Xalapa.

SHLL-Studies in Hispanic and Lusophone Linguistics. Saint Paul, MN.

$S L T$-Sophia Lingüística. Tokio.

$S p C-$ Spanish in Context. AmsterdamPhiladelphia.

$S \mathcal{E} S$-Signo y Seña. Revista del Instituto de Lingüística. Buenos Aires.

$T d S$-Tópicos del Seminario. Puebla.

UniverSOS-UniverSOS. Revista de Lenguas Indígenas y Universos Culturales. València.

Verba-Verba. Anuario Galego de Filoloxía. Santiago de Compostela.

$Y M-$ Morphology. Berlin.

\section{ÍNDICE DE INVESTIGADORES}

Aaron, Jessi E. 65-158.

Abbate, Florencia 65-1231.

Abril, Juan Carlos 65-1057; 65-1349.
Acedo Matellán, Víctor 65-276.

Acín Villa, Esperanza 65-566.

Adelmo Giorgini, Massimiliano 65-827.

Adriaensen, Brigitte 65-1100; 65-1178.

Adricaín, Sergio 65-1049.

Agost, Rosa 65-606.

Agreda, Eduardo de 65-398.

Aguado, Jesús 65-1321.

Agüero San Juan, Claudio 65-225.

Aguilar Ruiz, Mary Carmen 65-31.

Aguirre Martínez, Guillermo 65-1449.

Albano, Hilda 65-199.

Albelda Marco, Marta 65-159; 65-160; 65-203.

Alberca, Manuel 65-1074; 65-1101; 65-1282; 65-1306; 65-1471.

Albesa Pedrola, Elena 65-338; 65-444.

Albiac, María Dolores 65-706.

Alcalá-Galán, Mercedes 65-828.

Alcántara Mejía, José Ramón 65-786.

Alcantud, Victoriano 65-1050.

Alcatena, María Eugenia 65-770.

Alcoba, Santiago 65-68.

Alemany Bay, Carmen 65-1368.

Alemany, Raúl Alonso 65-1380.

Aletto, Carlos Daniel 65-1217.

Alhmoud, Zeina 65-520.

Alloati, Norma 65-1038.

Almeida Cabrejas, Belén 65-308; 65-798.

Almeida, Erica 65-654.

Alonso, Álvaro 65-775; 65-676; 65-925; 65-1287.

Alonso, Irene 65-520.

Alonso, José Antonio 65-430.

Alva Canto, Elda A. 65-479.

Alvar, Carlos 65-730; 65-733.

Alvar Ezquerra, Manuel 65-7.

Alvarado Borgoño, Miguel 65-665.

Alvarado Ortega, M. Belén 65-161; 65-162; 65-213.

Alvarado Teodorika, Tatiana 65-820.

Álvarez, María Auxiliadora 65-1363.

Alvarez Roblin, David 65-829; 65-910; 65-924.

Álvarez Barrientos, Joaquín 65-688; 65-689; 65-690.

Álvarez de Miranda, Pedro 65-8; 65-310.

Álvarez Garriga, Carles 65-1219.

Álvarez Jurado, Manuela 65-607.

Álvarez López, Cristóbal José 65-997.

Álvarez López, Laura 65-467.

Álvarez Moreno, Raúl 65-925.

Álvarez Pérez, Xosé Afonso 65-360.

Álvarez Rosa, Vanesa 65-226. 
Álvarez Tejedor, Antonio 65-294.

Álvarez Touriño, Andrés 65-1134. Alviti, Roberta 65-790.

Amar y Borbón, Josefa 65-981.

Amend, Tracie 65-994.

Amengual, Mark 65-439.

Amengual Pizarro, Marian 65-2.

Amícola, José 65-1218.

Ampuero, Fernando 65-1465.

Anaya Revuelta, Inmaculada 65-227.

Ancira, Selma 65-608.

Andersen, Katrine Helene 65-1052.

Andreani, Héctor 65-431.

Andrés Gutiérrez, Mariano de 65-1304.

Andújar Moreno, Gemma 65-609.

Anfuso, Matteo 65-610.

Anipa, K. 65-957.

Antonucci, Fausta 65-830.

Antzus Ramos, Ioannis 65-1437.

Aparicio Aguadas, Pep 65-444.

Aponte Alequín, Héctor 65-361.

Appratto, Roberto 65-1073.

Arancibia Gutiérrez, Beatriz 65-478.

Araújo, Paula Renata de 65-831.

Aráujo Branco, Isabel 65-1119.

Arbeláez, Olga 65-1016.

Ardila Ariza, Jineth 65-1102.

Arellano, Ignacio 65-787; 65-832; 65-833; 65-919; 65-932.

Arellano, Jorge Eduardo 65-1026.

Arellano Hermosilla, Claudia 65-1053.

Arias, Giovanna 65-794.

Arias Álvarez, Beatriz 65-292.

Arias Trejo, Natalia 65-479.

Ariolfo, Rosana 65-26; 65-201; 65-511.

Arizmendi Domínguez, Martha Elia 65-1423.

Armand Ugón, Pablo 65-1018.

Armas, Frederick A. de 65-834.

Armstrong, Grant 65-69.

Arnal Purroy, M. Luisa 65-126.

Arnau, Joaquim 65-432.

Arranz, Manuel 65-696.

Arrizabalaga, Carlos 65-1463.

Arumi Ribas, Marta 65-623.

Asención-Delaney, Yuly 65-512.

Astigarraga, Jesús 65-969.

Atencio, Caridad 65-1311.

Avelino, Rosnátaly 65-465; 65-493.

Ávila, Raúl 65-32.

Ávila Gallego, Daniel de 65-799.

Avilés Vergara, Tania 65-332; 65-364.

Ayalamacedo, Duilio 65-833.

Ayerbe Betrán, María José 65-706; 65-758.
Azcue Castillón, Verónica 65-1059.

Azevedo, Clara S. 65-509.

Azpiazu Torres, Susana 65-179; 65-365.

Azúa, Félix de 65-1248.

Bada, Ricardo 65-835.

Baena Bradaschia, M.J. 65-556.

Báez de Aguilar González, Francisco 65-965.

Bagna, Carla 65-388.

Bail, Amelie 65-480.

Bajus, Mark L. 65-724.

Balam, Osmer 65-433.

Baldellou Monclús, Daniel 65-964.

Baldissera, Andrea 65-567.

Ballestrazzi, Elisa 65-622.

Baltasar, Raquel 65-1119.

Baquero, Julia 65-1375.

Barbáchano, Carlos 65-1167.

Barbosa, Afranio 65-654.

Barcroft, Joe 65-513.

Barletta, Vincent 65-724.

Barnes, Hilary 65-33.

Barnes, Sonia 65-434; 65-435.

Barni, Monica 65-388.

Barrera, Trinidad 65-792.

Barreto, Mafra 65-554.

Barriga Puente, Francisco 65-1.

Barriga Villanueva, Rebeca 65-1; 65-366; 65-481.

Barrio de la Rosa, Florencio del 65-127; 65-293; 65-323.

Barrios, Elvira 65-482.

Barrios Sabador, María José 65-163.

Barros Dias, Isabel 65-745.

Barros García, M. Jesús 65-160.

Barros Roel, Rocío 65-666.

Bartol Hernández, José A. 65-294.

Basterrechea, Martín 65-135.

Batiukova, Olga 65-70.

Batllori, Montserrat 65-71.

Batres, Izara 65-1114.

Baudry, Paul 65-1401.

Baumgarten, Nikole 65-377.

Bautista, Francisco 65-691; 65-728; 65-734; 65-746.

Beauclair, Nicolas 65-295.

Beaudrie, Sara M. 65-436.

Bec, Caroline 65-967.

Becerra Méndez, Claudia 65-1157.

Beckert, Ronny 65-13.

Bellini, Giuseppe 65-807; 65-1093.

Bellomi, Paola 65-1060.

Belloro, Valeria 65-72. 
Beltrán Almería, Luis 65-677.

Benavides, Jorge Eduardo 65-1239; 65-1464.

Benítez Guerrero, Carmen 65-729.

Benítez Rosete, Valeria A. 65-73.

Bennett, Andrew 65-1386.

Bermejo Calleja, Felisa 65-127.

Bermúdez, Fernando 65-74; 65-164.

Bernal Salgado, José Luis 65-1235.

Bernárdez, Aurora 65-1219.

Bersett, Jeffrey T. 65-688.

Bertolotti, Virgina 65-296.

Bertozzi, Michela 65-611.

Berty, Romuald 65-668.

Betancour Sánchez, Sonia 65-1292.

Betancourt Córdoba, Yamileth 65-492.

Bianchi, Marina 65-1433.

Biber, Douglas 65-241.

Bischoff, Christina Johanna 65-1051.

Bixler, Jacqueline 65-1398.

Bizama Muñoz, Marcela 65-478.

Bizarri, Hugo O. 65-667.

Blackshaw Naberhaus, Christine 65-994.

Blake, Robert J. 65-514.

Blanco Canales, Ana 65-483.

Blanco, Javier 65-568.

Blanco, Lucas 65-1268.

Blanco, Mercedes 65-914.

Blas Arroyo, José Luis 65-297; 65-298.

Blasco, Javier 65-836.

Blecua Falgueras, Beatriz 65-34; 65-35.

Bleorțu, Cristina 65-371.

Blesa, Túa 65-1249.

Blestel, Élodie 65-437.

Boccanera, Jorge 65-1099.

Bocchino, Adriana A. 65-1220; 65-1221.

Boers, Frank 65-563.

Bolaños Medina, Alicia 65-612.

Bongiovanni, Silvina Carla 65-36; 65-484.

Bonilla, Juan 65-1263; 65-1295.

Bonilla Cerezo, Rafael 65-915; 65-966.

Bonne Bravo, Arcilio 65-438.

Boomershine, Amanda 65-397.

Borden Eng, Rubén 65-771.

Borges, Adriana de 65-837.

Borges, Margarida 65-1119.

Borreguero Zuloaga, Margarita 65-165; 65-166; 65-236; 65-485.

Borsò, Vittoria 65-692.

Bosch Andreu, Emma 65-515.

Botero, Mary Luz 65-1153.

Botrel, Jean-François 65-1150.

Botta, Patrizia 65-693.

Bou, Enric 65-1286.
Boylan, Geraldine 65-618.

Brandimonte, Giovanni 65-613.

Bravo, Diana 65-167.

Bravo García, Eva 65-344; 65-516.

Bravo Herrera, Fernanda 65-694.

Brennan, Brian 65-517.

Brescia, Pablo 65-1148.

Breva Iscla, María E. 65-747.

Brickle, Patricio 65-1240.

Briganti, Andrea 65-1442.

Brioso Santos, Héctor 65-883.

Brown, Esther L. 65-439.

Bruil, Martine 65-64.

Bruno, Paula 65-1001.

Bruña Bragado, María José 65-1474.

Bruyèl Olmedo, Antonio 65-440.

Buenafuentes de la Mata, Cristina 65-68. 65-71; 65-75; 65-76.

Bueno, Mónica 65-1325.

Bugarski, Rango 65-544.

Bugel, Talia 65-367; 65-368.

Buitrago Correa, Héctor Fabio 65-1338.

Burdiles, Gina 65-262.

Burgoyne, Jonathan 65-735.

Burset Burillo, Silvia 65-515.

Bustos Gisbert, José M. 65-486.

Buzek, Ivo 65-569.

Byrne, Susan 65-838.

Caballé, Anna 65-1074; 65-1103.

Caballero, Rosario 65-192.

Caballero Meneses, Jonathan Azael 65-37.

Cabedo Nebot, Adrián 65-38.

Cabezas Holgado, Emilio 65-168; 65-169.

Cable, Seth 65-170.

Cabrejos, Irene 65-1402.

Cáceres Lorenzo, M. Teresa 65-128; 65-518.

Cajero Vázquez, Antonio 65-1144.

Calabrese, Elisa 65-1222.

Calafat Vila, Rosa 65-970.

Calderón Calderón, Manuel 65-839.

Calderón Campos, Miguel 65-299.

Callou, Dinah 65-654.

Callsen, Berit 65-1075.

Calvo, Hortencia 65-921.

Calvo Pérez, Julio 65-333.

Calvo Revilla, Ana 65-1291; 65-1357.

Camacho Delgado, José Manuel 65-793.

Cámara, Mario 65-1112.

Cámara Aguilera, Elvira 65-614.

Camino Bueno-Alastuey, María 65-540.

Campa, Mariano de la 65-933.

Campese, Andrea 65-675. 
Campesino, Juan 65-1455.

Campillos Llanos, Leonardo 65-659.

Campos Fernández-Fígares, Mar 65-589.

Campos Souto, Mar 65-300.

Campos Souto, María Begoña 65-779.

Campos Vargas, Henry 65-277.

Campoy-Cubillo, Adolfo 65-1451.

Campra, Rosalba 65-694.

Camps, Martín 65-1104

Campuzano Calderón, Wilfer Andrés 65-1338.

Camus Bergarache, Bruno 65-77; 65-441; 65-442.

Canale, Germán 65-369; 65-370.

Cancino Cabello, Nataly 65-228.

Cancino Troncoso, Hugo 65-691.

Candel, Xelo 65-1162.

Candia Gajá, Andrea 65-1076

Cano, María Ángeles 65-78.

Cánovas, Rodrigo 65-1192.

Cantrell, Lisa M. 65-479.

Canuto Castillo, Felipe 65-443.

Cañas Murillo, Jesús 65-821; 65-982.

Cappelli, Federica 65-1434.

Capponi, Paola 65-615.

Carabias Orgaz, Miguel 65-301.

Caravedo, Rocío 65-371.

Cardeñoso, Concha 65-1393.

Carmona Tierno, Juan Manuel 65-927.

Carnero, Guillermo 65-1160.

Caro Bragado, David 65-796.

Carpi, Elena 65-570; 65-981.

Carranza Vera, Claudia 65-678.

Carrasco Cantos, Inés 65-302.

Carreira, Antonio 65-781.

Carreño, Antonio 65-1002.

Carrera Díaz, Manuel 65-616.

Carrera Troyano, Miguel 65-519.

Carrete Montaña, José Ricardo 65-294.

Carter, Phillip M. 65-39.

Carvajal Córdoba, Edwin 65-1338.

Casado Velarde, Manuel 65-260.

Casais, Alejandro 65-756.

Casanova, Emili 65-444.

Casas, Ana 65-1077.

Casas-Delgado, Inmaculada 65-679.

Casas-Tost, Helena 65-617.

Casellas, Jordi 65-520.

Cassara, Walter 65-1214; 65-1344.

Castany Prado, Bernat 65-819; 65-1137; 65-1183; 65-1257.

Castañeda Castro, Alejandro 65-520; 65-557.

Castañer Martín, Rosa M. 65-5; 65-1031.
Castañón, Adolfo 65-1026.

Castilla, Carlos Enrique 65-409.

Castillo, Fernando 65-1342.

Castillo Cáceres, Fernando 65-1023.

Castillo Carrillo, Gerardo 65-1078.

Castillo Lluch, Mónica 65-303.

Castillón, Juan Carlos 65-1105.

Castro Ferrer, María Inés 65-304.

Cattaneo, Simone 65-1283; 65-1466.

Causse Cathcart, Mercedes 65-438.

Caymad-Freixas, Erik 65-695.

Cazés Gryj, Dann 65-786; 65-789.

Cazorla Vivas, Carmen 65-9; 65-15.

Ceballos Domínguez, Rubí 65-481.

Ceballos Viro, Álvaro 65-1035; 65-1050.

Cebreiro Rábade, María do 65-1024.

Cegarra, Juan José 65-171.

Cenname, Anne 65-278.

Cenoz, Jasone 65-508.

Censabella, Marisa 65-445.

Cepeda Ruiz, Cristal Yeseidy 65-296.

Cerezo Soler, Juan 65-840.

Cerrón Palomino, Álvaro 65-372.

Cerrudo Aguilar, Alba 65-79.

Cervera Salinas, Vicente 65-1184.

Chamoreau, Claudine 65-457.

Chamorro, M. Dolores 65-520.

Chatellus, Adélaide de 65-1392.

Chatterjee, Avik 65-521.

Chavarría Vargas, Juan Antonio 65-129.

Checa, Elena 65-491.

Checa Beltrán, José 65-1003.

Chen Sham, Jorge 65-1229.

Chico, Álex 65-1318.

Childers, William P. 65-841.

Chirinos, Eduardo 65-1436.

Ciapuscio, Guiomar E. 65-10.

Cicres, Jordi 65-34.

Cid, Jesús Antonio 65-680.

Cidrás, Francisco 65-80.

Cifuentes Honrubia, José Luis 65-530.

Cívico Lyons, Inma 65-552.

Claes, Jeroen 65-373; 65-374.

Clark, Ben 65-1215.

Clavería Nadal, Gloria 65-68; 65-71; 65-75; 65-305; 65-571.

Coduras Bruna, María 65-730.

Coello Gutiérrez, Emiliano 65-1238.

Colantoni, Laura 65-40.

Coleto Camacho, Ana 65-1264.

Coll, Magdalena 65-369; 65-370.

Collentine, Joseph G. 65-512.

Collentine, Karina 65-512.

Colmeiro, José 65-1466. 
Colmenares, Jersus 65-512.

Colombi, Beatriz 65-921.

Colón Calderón, Isabel 65-796; 65-803; 65-915.

Compagnon, Antoine 65-696.

Company Company, Concepción 65-306; 65-307; 65-736.

Comsa, Mihaela 65-1256.

Conca, Maria 65-279.

Conde Noguerol, María Eugenia 65-572.

Contemori, Carla 65-524.

Conti García, Carmen 65-379.

Contreras, José Alfredo 65-1472.

Corbella, Dolores 65-573.

Cornejo, Felipe 65-532.

Corral, Elizabeth 65-1391.

Corral, Wilfrido H. 65-1106; 65-1189; 65-1394; 65-1435.

Corral Cañas, Celia 65-1456.

Corral Pérez, Isabel 65-375.

Correa Chiarotti, Guadalupe 65-991.

Cortés Rodríguez, Francisco J. 65-172.

Cortés Rodríguez, Luis 65-173; 65-229; 65-230.

Cortínez, Verónica 65-842.

Costa Vieira, Maria Augusta da 65-843; 65-844; 65-845.

Couceiro, María del Pilar 65-704; 65-737.

Crespo Fernández, Eliecer 65-231.

Crida Álvarez, Carlos Alberto 65-130.

Cristóbal, Vicente 65-748.

Crusat, Cristian 65-1179.

Cruschina, Silvio 65-280.

Cruz Enríquez, Maura 65-446.

Cruz Piñol, Mar 65-522.

Cuenca, Josep Maria 65-1329.

Cuenca, Luis Alberto de 65-846.

Cuenca, Maria Josep 65-232.

Cuenca Cabeza, Manuel 65-995.

Cuesta, Mabel 65-1195.

Cueto, Alonso 65-1403.

Cull, John 65-847.

Cunha Teixeira, Karoline da 65-271.

Cussen, Felipe 65-1273.

Cuvardic García, Dorde 65-1079.

Cuya Gavilano, Lorena 65-1460.

D'Alessandro, María Natalia

D'Alessio, Josefina 65-487.

D'Angelis, Antonella 65-574.

D'Onofrio, Julia 65-848; 65-849.

Dahmen, Wolfgang 65-605.

David, E.J.R. 65-662.

De Cock, Barbara 65-174.
De Cort, Stephenie 65-233.

De Santis, Francesca 65-850.

De Schutter, An 65-233.

De Vries, Henk 65-906.

Degiovanni, Fernando 65-1230.

Dehaene, Stanislas 65-488.

Deignan, Alice 65-198.

Delbecque, Nicole 65-220.

Delicado Cantero, Manuel 65-523.

Dewaele, Jean-Marc 65-489.

Díaz, Chaxiraxi 65-41; 65-43.

Díaz, Lourdes 65-542.

Díaz Campos, Manuel 65-376; 65-378; 65-391; 65-423.

Díaz de Guereñu, Juan Manuel 65-1235.

Díaz Lage, Santiago 65-971.

Díaz Moreno, Rocío 65-308.

Díaz Narbona, Inmaculada 65-668.

Díaz Peralta, Marina 65-618.

Díaz Pérez, Francisco Javier 65-619.

Díaz y Morales, Magda 65-1182.

Diego, José Luis de 65-697; 65-1107.

Díez, Julián 65-1080.

Diez del Corral Areta, Elena 65-303; 65-309.

Díez Bedmar, María Belén 65-2.

Díez de Revenga, Francisco Javier 65-1216.

Djermanovic, Tamara 65-1108.

Doiz, Aintzane 65-537.

Dolfi, Laura 65-916; 65-1352.

Dolle, Verena 65-1061.

Dolores Cuecuecha Mendoza, M. del Carmen 65-1345.

Domínguez, Laura 65-490.

Domínguez Cáceres, Roberto 65-1416.

Domínguez Lasierra, Juan 65-1296.

Domínguez Michael, Christopher 65-1371.

Donoso Rodríguez, Miguel 65-794; 65-918.

Dorta, Josefa 65-41; 65-43.

Du Bois, Inke 65-377.

Duarte, J. Enrique 65-914.

Duclos, G. Cory 65-851.

Dulfano, Isabel 65-447.

Durá Celma, Rosa 65-788.

Durán López, Fernando 65-688; 65-965; 65-972; 65-1004; 65-1020; 65-1021.

Durand, Jorge 65-430.

Dussias, Paola E. 65-524.

Duttenhofer, Alexandra 65-236.

Dvoskin, Gabriel 65-234.

Dworkin, Steven N. 65-310.

Ebenhoch, Markus 65-973.

Eberenz, Rolf 65-311. 
Echenique Elizondo, María Teresa 65-312.

Egido, Aurora 65-698; 65-1109.

Ehrlicher, Hanno 65-1032.

Eichmann Oehrli, Andrés 65-782; 65-951.

Elmore, Peter 65-1404.

Elvira-García, Wendy 65-43.

Emiliozzi, Irma 65-1310.

Enguita Utrilla, José M. 65-1275; 65-1296.

Enrique-Arias, Andrés 65-378.

Enríquez Aranda, Mercedes 65-620; 65-621.

Enríquez Hernández, Gabriel M. 65-1358.

Enzinna, Naomi 65-448.

Errico, Elena 65-622.

Ertler, Klaus-Dieter 65-974.

Escaja, Tina 65-1012.

Escalante, Evodio 65-1372.

Escamilla Morales, Julio 65-175.

Escandell Montiel, Daniel 65-699; 65-702.

Escartín Gual, Montserrat 65-1081.

Escudero, Juan Manuel 65-938.

Esher, Louise 65-81.

Espinosa Elorza, Rosa María 65-354.

Espinosa Guerri, Guadalupe 65-235.

Espinosa H., Patricia 65-1180; 65-1245.

Esteban, Ángel 65-1405.

Esteban-Guitart, Moisés 65-449.

Esteras Martínez, José Ángel 65-738.

Estévez Rionegro, Noelia 65-176.

Estigarribia, Bruno 65-177.

Estrada, Oswaldo 65-1110.

Estrella, Alfredo 65-604.

Estrella, Emilio 65-604.

Estrella, Salomón 65-604.

Estupiñán Serrano, Mary Luz 65-1111.

Ettinghausen, Henry 65-930.

Eusebio, Carmen de 65-1173; 65-1175; 65-1207; 65-1228; 65-1254; 65-1316; 65-1326; 65-1333; 65-1340; 65-1379; 65-1385; 65-1397; 65-1426; 65-1431.

Ezquerro, Milagros 65-1392.

Faber, Pamela 65-614.

Fábregas, Antonio 65-82; 65-83; 65-84; $65-85 ; 65-123$.

Face, Timothy L. 65-42.

Fafulas, Stephen 65-378; 65-525.

Fairclough, Marta 65-436.

Falk, Johan 65-527.

Fallows, Noel 65-763.

Faúndez, Edson 65-1022.

Faúndez Carreño, Rodrigo 65-959.

Faya Cerqueiro, Fátima 65-791.
Faya Ornia, Goretti 65-655.

Fecht Gris, Crystal 65-1047.

Federici, Marco 65-800.

Feldhausen, Ingo 65-178.

Felíu Arquiola, Elena 65-86; 65-379.

Feria, Miguel Ángel 65-992.

Fernandes, Ángela 65-1119.

Fernández, Esther 65-852.

Fernandez, Francesc 65-623.

Fernández, Hans 65-1457.

Fernández, Julieta 65-526.

Fernández, Nancy 65-1112

Fernández, Nona 65-1341.

Fernández, Susana S. 65-382; 65-527.

Fernández de Córdova Miralles, Álvaro $65-801$.

Fernández de Gobeo Díaz de Durana, Nerea 65-576.

Fernández Díaz, D.F. 65-1048.

Fernández Durán, David 65-772.

Fernández Fe, Gerardo 65-1132; 65-1241; 65-1278; 65-1475.

Fernández García, Francisco 65-379.

Fernández Gómiz, Sara 65-546.

Fernández Guillermo, Leonor 65-949.

Fernández Jaén, Jorge 65-213; 65-313; 65-314.

Fernández Juncal, Carmen 65-380.

Fernández Lorences, Teresa 65-179.

Fernández Merino, Pablo 65-377.

Fernández Pérez, Milagros 65-656.

Fernández Planas, Ana María 65-43.

Fernandez Rodriguez, Aurea 65-624.

Fernández Rubiera, Francisco José 65-87.

Fernández Ruiz, Graciela 65-217.

Fernández San Emeterio, Gerardo 65-820.

Fernández Trinidad, Marianela 65-44.

Fernández Urquiza, Maite 65-657.

Fernández Vitores, David 65-381.

Fernández-Díaz, David F. 65-1048.

Fernández-Jáuregui Rojas, Carlota 65-1456.

Ferrari, Ángela 65-236.

Ferraz Castán, Vicente 65-131.

Ferreira Cabrera, Anita 65-132; 65-528.

Ferreira Martins, Viviane 65-529.

Ferrero, Adrián 65-1252.

Feuillastre, Anne-Laure 65-1062.

Figueroa, Alexis 65-1056.

File-Muriel, Richard 65-382.

Fine, Ruth 65-853.

Fleck, David W. 65-604.

Flores, Milenka 65-1359. 
Flores, Valerie 65-662.

Flores Acuña, Estefanía 65-625; 65-626.

Flores Ohlson, Linda 65-207.

Flores Requejo, María José 65-1194.

Flores Treviño, María Eugenia 65-180; 65-245.

Fontecilla, Walezka 65-537.

Fontela Fernández, María Jesús 65-948.

Fortuño Llorens, Santiago 65-1293.

Fosalba, Eugenia 65-912.

Fox, Manuela 65-1468.

Fragapane, Federica 65-386.

Frago Gracia, Juan Antonio 65-854.

Franco, Jean 65-1257.

Franco Rodríguez, José M. 65-411.

Francomano, Emily C. 65-739.

Franz, Carlos 65-1242.

Freixas, Margarita 65-12; 65-71.

Frisch, Mark 65-1271.

Frisch, Stefan A. 65-45.

Fu, Rongbo 65-639.

Fuentes, Juan H. 65-731.

Fuentes Rodríguez, Catalina 65-181; 65-237.

Fuenzalida, Mauricio 65-281.

Fuertes Arboix, Mònica 65-1035.

Fuertes Olivera, Pedro 65-577.

Fuller, Janet M. 65-450.

Fumagalli, Julieta 65-488.

Funes, Leonardo 65-669; 65-745.

Funk, Johannes 65-13.

Fuster García, Francisco 65-1165; 65-1297.

Gagliardi, Lucas 65-6.

Gago Jover, Francisco 65-315.

Galán, Julio César 65-1039; 65-1158; 65-1209.

Galanes Santos, Iolanda 65-624.

Galbarro García, Jaime 65-795.

Galeote, Miguel 65-491.

Galera Masegosa, Alicia 65-182.

Galicia Isasmendi, Iván 65-31.

Gallardo Paúls, Beatriz 65-238; 65-239; 65-657.

Gallardo Saborido, Emilio 65-516.

Gallego, Ángel J. 65-183; 65-282.

Gallego Cuiñas, Ana 65-1113; 65-1353.

Gallo González, Danae 65-1061.

Gallucci, María José 65-383.

Galván González, Victoria 65-990.

Galván Reyes, Zurisadai 65-492.

Gálvez Roca, Oriol 65-1380.

Gamba Corradine, Jimena 65-720; 65-814.
Gámez García, Mar 65-1185.

Gandulfo, Carolina 65-451; 65-452.

Garachana Camarero, Mar 65-316; 65-319; 65-323.

Garbisu Buesa, Margarita 65-1441.

Garcés Gómez, María Pilar 65-240; 65-317; 65-318; 65-319.

García, Aldo J. 65-381.

García, Carlos 65-1412.

García, Carmen 65-184.

Garcia, MaryEllen 65-436.

Garcia, Michel 65-732.

García, Miguel Ángel 65-1027; 65-1052; 65-1211.

García Abelleira, Naír 65-384.

García Aranda, M. Ángeles 65-9; 65-133; $65-578$.

García C., Pilar 65-715.

García Caro, Pedro 65-1184; 65-1257.

García Cornejo, Rosalía 65-1184; 65-305.

García de la Sienra, Rodrigo 65-1346.

García Díaz, Noelia 65-983.

García Domínguez, María J. 65-618.

García Folgado, María José 65-11.

García Galiano, Ángel 65-805; 65-1114.

García Godoy, M. Teresa 65-320.

García Gual, Carlos 65-627.

García Jiménez, Rocío 65-628.

García Landa, Laura 65-548.

García Mercadal, Fernando 65-131.

García Montero, Luis 65-1367.

García Moreno, Aitor 65-997.

García Navarro, Carmen 65-979.

García Padrón, Dolores 65-385.

García Pérez, Rafael 65-134.

García Platero, Juan Manuel 65-427.

García Ríos, Beatriz 65-1146; 65-1462.

García Rodríguez, Joseph 65-579.

García Rodríguez, Juan Carlos 65-1309.

García Sánchez, Jairo Javier 65-283.

García Santo-Tomás, Enrique 65-724; $65-797 ; 65-860 ; 65-950 ; 65-954$.

García Sedas, Pilar 65-1412.

García Suárez, Pedro 65-998.

García Varela, Ana Patricia 65-243.

García-Quismodo, Judith 65-802.

Gargano, Antonio 65-776; 65-934.

Garofalo, Giovanni 65-1432.

Garralón, Ana 65-700; 65-1115.

Garrido, Marisol 65-474.

Garrido Gallardo, Miguel Ángel 65-670.

Garrido Martín, Blanca 65-321; 65-344.

Garriga, Cecilio 65-305.

Garriga Escribano, Cecilio 65-580. 
Garriga Espino, Ana 65-952.

Garrot Zambrana, Juan Carlos 65-822.

Gascón Martín, Eugenio 65-386.

Gates Tapia, Anna 65-241.

Gatica Cote, Paulo Antonio 65-1374.

Gaviño Rodríguez, Victoriano 65-242.

Geeregat Vera, Orietta 65-1292.

Geeslin, Kimberly L. 65-493; 65-494.

Geist, Ljudmila 65-111.

Gelpí, Juan G. 65-1116.

Gerber, Clea 65-855.

Gibert Sotelo, Elisabeth 65-185.

Gidi, Claudia 65-1063.

Gil, Juana 65-34; 65-46.

Gil Alzate, David 65-1420.

Gil-Albarellos Pérez-Pedrero, Susana 65-688.

Gil-Olse, Juan Pablo 65-856.

Giles, Howard 65-449.

Giles, Ryan 65-755.

Gille, Johan 65-322.

Gimber, Arno 65-1121.

Gimeno Puyol, María Dolores 65-975.

Giné, Marta 65-1005.

Giordano, Roberta 65-88.

Girón Alconchel, José Luis 65-323.

Gironzetti, Elisa 65-552; 65-658.

Giuliana, Virginie 65-1298.

Giusso, Lorenzo 65-1117.

Godoy, Lucía Francisca 65-258.

Gogazeh, Ziyad Mohammad 65-629.

Goloboff, Mario 65-1223.

Gómez Asencio, José J. 65-486.

Gómez Bedate, Pilar 65-1322.

Gómez Canseco, Luis 65-812.

Gómez Castro, Cristina 65-630.

Gómez de Enterría, Josefa 65-799.

Gómez González, María de los Ángeles 65-243.

Gómez Sánchez, M. Elena 65-135.

Gómez Seibane, Sara 65-324; 65-441; 65-442.

Gómez Soler, Inmaculada 65-495.

Gómez Toré, José Luis 65-1384; 65-1414: 65-1448; 65-1474.

Gómez-Pablos, Beatriz 65-581.

Gomila Albal, Marina 65-362.

Gomis Coloma, Juan 65-681; 65-682.

González, Aurelio 65-736; 65-857; 65-858.

González, Carina 65-1125.

González, Santiago 65-47.

González Arce, Teresa 65-1151.

González Argüello, Vicenta 65-515.
González Echevarría, Roberto 65-859; 65-958.

González Estera, Orlando 65-1039.

González Fernández, Helena 65-1024.

González García, Francisco 65-1438.

González Gómez, Jaime 65-406.

González Iglesias, Juan Antonio 65-1094.

González Jurado, Margarita 65-582.

González Martínez, Deborah 65-749.

González Martínez, Juan 65-297.

González Montes, Antonio 65-1406.

González Muñoz, Irene 65-1191.

González Ollé, Fernando 65-12; 65-325; 65-326.

González Pérez, Rosario 65-380.

González Vergara, Carlos 65-89.

González Zunini, Macarena 65-296.

González-Allende, Iker 65-1204.

González-Contreras, Melissa 65-1472.

González-Ocaña, Jaime 65-1040.

Goñi, Javier 65-1236.

Goñi, José María 65-1005.

Gottschalk, Aenne 65-973.

Gracia, Jordi 65-1364.

Graná, Leonardo 65-1037.

Granados Reyes, Nancy 65-1045.

Grande Alija, Francisco Javier 65-186.

Granvik, Anton 65-90.

Greene, Roland 65-860.

Grosse, Sybille 65-13.

Grümpel, Claudia 65-530.

Grupo FITISPos 65-583.

Gudmestad, Aarnes 65-494; 65-496.

Guerra Salas, Luis 65-135.

Guerrero González, Silvana 65-387.

Guerrero Hernández, Noemí 65-91.

Guia, Josep 65-279.

Guillén Escamilla, Josaphat 65-54.

Guimaraes Savedra, Mônica Makria 65-467.

Guinot Ferri, Laura 65-683.

Gutiérrez, Antonio 65-516.

Gutiérrez, César 65-327.

Gutiérrez, Manuel 65-378.

Gutiérrez, Miguel 65-1082.

Gutiérrez, Rodolfo 65-430.

Gutiérrez Cuadrado, Juan 65-317.

Gutiérrez de Velasco, Luzelena 65-722.

Gutiérrez Meza, José Elías 65-1069; 65-1183.

Gutiérrez Ordóñez, Salvador 65-92.

Gutiérrez Pérez, Víctor Miguel 65-787.

Gutiérrez Plaza, Arturo 65-1197.

Gutiérrez Rodilla, Bertha M. 65-136. 
Gutiérrez Rodríguez, Virginia 65-113.

Gutiérrez Sanz, Víctor 65-950.

Gutiérrez Sebastián, Raquel 65-996.

Guzmán, Rocío 65-252.

Haghenbeck, Francisco 65-1083.

Hamlin, Cinthia María 65-757.

Hanegreefs, Hilde 65-187.

Harrington, Sophie 65-93.

Hart, Sarah 65-750.

Hasson, Or 65-804.

Heidinger, Steffen 65-94.

Hélot, Christine 65-388.

Hennemann, Anja 65-244.

Henry Vega, Grandfield 65-175.

Herd, Wendy 65-497.

Heredia, Lerdys 65-583.

Heredia Mantis, María 65-896.

Hériz, Ana Lourdes de 65-26.

Herling, Sandra 65-389.

Hernán-Gómez Prieto, Beatriz 65-584.

Hernández, Esther 65-390.

Hernández, Gabriel 65-188.

Hernández, Humberto 65-575.

Hernández Díaz, Axel 65-328.

Hernández González, M. Belén 65-1478.

Hernández Guerrero, María José 65-631.

Hernández Lorenzo, Laura 65-701.

Hernández Martínez, Manuel 65-1275.

Hernández Sacristán, Carlos 65-498.

Hernando García-Cervigón, Alberto 65-14; 65-59.

Heros, Susana de los 65-189.

Herrera Soler, Honesto 65-2.

Herrera Zendejas, Esther 65-1.

Herrero Ruiz de Loizaga, Francisco Javier 65-95.

Heusch, Carlos 65-740.

Hiergeist, Teresa 65-966.

Higashi, Alejandro 65-771.

Hijano Villegas, Manuel 65-751.

Hipperdinger, Yolanda 65-137; 65-453.

Hobisch, Elisabeth 65-974.

Hoff, Mark 65-391.

Hoffman, Joan H. 65-1046.

Hoffman, Zsuzsa 65-454.

Holtus, Günter 65-605.

Hopkins Rodríguez, Eduardo 65-861.

Hsueh Lu, Lo 65-531.

Hualde, José Ignacio 65-441.

Hudgens Henderson, Mary 65-392.

Huelva Unternbäumen, Enrique 65-190.

Huertas, Sheila 65-71.

Huisa Téllez, José Carlos 65-585.
Humpl, Andrea Maria 65-974.

Hurtado, Luz Marcela 65-191.

Hutchinson, Steven 65-862.

Ibáñez, Fernando 65-1022.

Ibáñez, Romualdo 65-532.

Ibáñez, Sergio 65-96.

Ibarretxe Antuñano, Iraide 65-192; 65-527.

Iffland, James 65-833; 65-935; 65-1247.

Iglesias Ovejero, Ángel 65-138.

Illades Aguiar, Gustavo 65-863.

Imperiale, Louis 65-924.

Infante Bonfiglio, José María 65-245.

Infante, Patricia 65-48.

Insúa, Mariela 65-794.

Iraceburu Jiménez, Maite 65-956.

Isava, Luis Miguel 65-1198.

Iubini Vidal, Giovanna 65-1361.

Ivanova, Olga 65-390; 65-493.

Iwasaki, Fernando 65-864.

Iza Erviti, Aneider 65-182.

Izquierdo, Amparo 65-822; 65-959.

Jacinto García, Eduardo José 65-586.

Jacobson, Rebecca 65-505.

Jaichenco, Virginia 65-487.

Janin, Érika 65-773.

Jansegers, Marlies 65-120.

Janssen, Rudi 65-388.

Jaque Hidaldgo, Matías 65-193.

Jasinski, Isabel 65-1164.

Jaume, Andreu 65-1170.

Jauralde, Pablo 65-914.

Jensen, Julio 65-1299.

Jeppesen Kragh, Kirsten 65-284.

Ji, Meng 65-639.

Jiménez, Jesús 65-285.

Jiménez, Juan Carlos 65-393.

Jiménez Belmonte, Javier 65-865.

Jiménez Calderón, Francisco 65-507.

Jiménez Carra, Nieves 65-621.

Jiménez Catalán, Rosa María 65-533.

Jiménez Fernández, Concepción María 65-907.

Jiménez Morales, Belén 65-394.

Jiménez Ríos, Enrique 65-15; 65-329.

Jiménez-Salazar, Arturo 65-1415.

Jimeno Zuazu, Ana 65-260.

Jojima, Paula 65-815.

Jongman, Allard 65-497.

Jordan Núñez, Kenneth 65-139.

Juan Lázaro, Olga 65-534.

Juan-Garau, Maria 65-440. 
Juárez Cabañas, María Guadalupe 65-292. Judy, Tiffany 65-490; 65-499.

Juliá, Mercedes 65-1297.

Julià, Carolina 65-71; 65-305

Julián, Gisele 65-184; 65-194.

Julián Mariscal, Olga 65-330.

Junquera, Macarena 65-6.

Jurado Santos, Agapita 65-976.

Juristo, Juan Ángel 65-1145; 65-1154; 65-1166; 65-1170; 65-1174; 65-1196; 65-1227; 65-1253; 65-1272; 65-1327; 65-1328; 65-1330; 65-1339; 65-1378; 65-1428.

Juste, Mélanie 65-764.

Kabatek, Johannes 65-3.

Kallendorf, Hilaire 65-786.

Kaller, Andrés 65-199.

Kanwit, Matthew 65-562.

Kapovic, Marko 65-395.

Katona, Eszther 65-1193.

Kaul de Marlangeon, Silvia 65-246.

Kawasaki, Yoshifumi 65-331.

Kern, Joseph 65-247.

Kim, Euisuk 65-1395.

Kítova-Vasílieva, María 65-16.

Kohut, Karl 65-931.

Kordic Riquelme, Raïssa 65-332.

Kornfeld, Laura Malena 65-195.

Kortazar, Paulo 65-1161.

Kramer, Johannes 65-605.

Krauel, Javier 65-1163.

Kressner, Ilka 65-1224.

Ku, Menghsuan 65-632.

Kudaibergen, Jania 65-1118.

Kuguel, Inés 65-97.

L'Homme, Marie Claude 65-577.

Labandeira, Amancio 65-1304.

Labarre, Françoise 65-789.

Labarre, Roland 65-789.

Laborda Gil, Xavier 65-248; 65-249.

Lacarra Lanz, Eukene 65-741.

Lacomba, Marta 65-752.

Lacorte, Manel 65-658.

Lafferranderie, Emilio J. 65-1307.

Lafleur, Nahum 65-528.

Lagos, María Inés 65-806.

Lama, Miguel Ángel 65-965.

Lamari, Naima 65-955.

Lámbarry, Alejandro 65-1347.

Lamberti, Mariapia 65-866.

Lamy, Delano S. 65-455.

Landa, Alazne 65-378.
Landone, Elena 65-269.

Lang-Rigal, Jennifer 65-396.

Lanz, Juan José 65-1226.

Lapidus Shin, Naomi 65-475.

Lara Barbosa-Paiva, Crisciene 65-535; 65-536.

Lara, Luis Fernando 65-333; 65-587.

Lario, Carmen 65-156.

Larraz, Fernando 65-697.

Larsen, Kevin S. 65-867.

Lasagabaster Herrarte, David 65-456; 65-537.

Lauer, Mirko 65-1307.

Laurenzi, Elena 65-1478.

Lauria, Daniela 65-357.

Lavric, Eva 65-196.

Layna Ranz, Francisco 65-868.

Le Bigot, Claudia 65-1429.

Leal Abad, Elena 65-17.

Leal, Tania 65-499.

Lebsanft, Franz 65-358.

Léglise, Isabelle 65-457.

León Rivero, Francisco 65-1019.

Leone, Andrea R. 65-432.

Leonetti, Francesca 65-928.

Leow, Ronald P. 65-538.

Lerner, Isaías 65-18.

Leuzinger, Mirjam 65-1077.

Levelt, Willem J. 65-19.

Lewis, Greg 65-397.

Leyva Martínez, Ivette 65-1417.

Lima, Dolores 65-1387.

Lindschouw, Jan 65-284.

Lindstrom, Naomi 65-1259.

Link, Daniel 65-20.

Linke, Kathrin 65-64.

Lipscomb, Antonella 65-704.

Lipski, John M. 65-458.

Liviu, Lutas 65-1187.

Llamas, Jacobo 65-936.

Llera, José Antonio 65-1210; 65-1265; 65-1452.

Llompart Esbert, Júlia 65-459.

Llompart, Miquel 65-460.

Llopis Cardona, Ana 65-197; 65-250.

Llopis García, Reyes 65-539.

Lloret, María Rosa 65-98; 65-285.

Lloret, Yannick 65-1284.

Llosa Sanz, Álvaro 65-702.

Loaiza Cano, Gilberto 65-1006.

Logie, Ilse 65-1085.

Lojo, María Rosa 65-1037.

Lombardo, Martín 65-1289.

Londero, Renata 65-1335. 
Long, Avizia Y. 65-484.

López, Magdalena 65-1085; 65-1119.

López, Paloma 65-156.

López Bernal, Desirée 65-946.

López Castro, Armando 65-953; 65-1261.

López de Mariscal, Blanca 65-807; 65-911.

López Drusetta, Laura 65-766.

López Fernández, Álvaro 65-1454.

López Forjas, Manuel 65-1234.

López García, Tibisay 65-1300.

López Ortega, Antonio 65-1199.

López Pellisa, Teresa 65-1084.

López Pérez, María Victoria 65-540.

López Pielow, Fátima 65-1266.

López Poza, Sagrario 65-703; 65-930.

López Serena, Araceli 65-251.

López Torres, Nora Danira 65-684.

López-Baralt, Luce 65-869.

Lorca, Daniel 65-870.

Lorenza Arribas, Josemi 65-738.

Lorenzo Álvarez, Elena de 65-983; 65-987; 65-988.

Lorenzo González, Guillermo 65-4.

Losada Goya, José Manuel 65-704.

Lostalé, Javier 65-1343.

Loureda, Oscar 65-260.

Loyola López, David 65-1007; 65-1008; 65-1210.

Lozada Pastoressa, Yessica 65-1350.

Lozano, Cristóbal 65-541.

Lozano Rodríguez, Ann Christine 65-705.

Lucha, Rosa 65-542.

Lucía Megías, José Manuel 65-871; 65-872.

Lüdtke, Jens 65-334.

Luengo Cuervo, Sara 65-1025.

Luesakul, Pasuree 65-1315.

Luján Atienza, Ángel L. 65-966.

Luján García, Carmen 65-231.

Luna Mariscal, Karla Xiomara 65-736; 65-763.

Luque, Rocío 65-140.

Luti, Francisca 65-1281.

MacArthur, Fiona 65-198.

Machado Vento, Dainerys 65-1388.

Machín Lucas, Jorge 65-1176.

Mackenzie, J. Lachlan 65-500.

Mackey, Alison 65-548.

Maddox, John 65-1156.

Madroñal, Abraham 65-937.

Maeseneer, Rita de 65-1085.

Maestro, Jesús G. 65-705.

Magaña, Dalia 65-543.
Maiden, Martin 65-280.

Mainer, José Carlos 65-671; 65-706.

Maldonado, Ricardo 65-252.

Malik, Cici 65-724.

Malovrh, Paul A. 65-501.

Malpartida, Juan 65-1243.

Mancera Rueda, Ana 65-398; 65-795.

Mangado Martínez, José Javier 65-16.

Manso Flores, Ana Alicia 65-399.

Manson, William R. 65-962.

Marácz, Lászió 65-544.

Marchis Moreno, Mihaela 65-99.

Marcos Fernández, Marco Antonio 65-1080.

Marcos Miguel, Nausica 65-545.

Marcovecchio, Ana M. 65-199.

Mare, María 65-100.

Marías Martínez, Clara 65-796.

Marimón Llorca, Carmen 65-141.

Marín, Maria Josep 65-232.

Mariottini, Laura 65-388.

Mariscal Ríos, Alicia 65-511.

Marqués, Juan 65-1203.

Marqueta Gracia, Bárbara 65-101.

Márquez Guerrero, María 65-253.

Marrero Aguiar, Victoria 65-49.

Marroquín Arredondo, Jaime 65-793.

Marti, Melisa Laura 65-725.

Martí Monterde, Antoni 65-1439.

Martí Sánchez, Manuel 65-546.

Martin, Philippe 65-50.

Martín, Adrienne L. 65-873.

Martín, Oscar 65-761.

Martín Aizpuru, Leyre 65-351.

Martín Butragueño, Pedro 65-51; 65-366; 65-390; 65-400.

Martín Colorado, Paula 65-723.

Martín Gascueña, Rosa 65-254.

Martín Gijón, Mario 65-1120; 65-1123; 65-1210; 65-1290; 65-1396; 65-1422.

Martín Gómez, José Antonio 65-43.

Martín Iglesias, José Carlos 65-760.

Martín Monje, Elena 65-565.

Martín Morán, José Manuel 65-874.

Martín Padilla, Kenia 65-200.

Martín Zorraquino, María Antonia 65-5.

Martinengo, Alessandro 65-938.

Martínez, Angelita 65-6.

Martínez, Érika 65-1113.

Martínez, José Enrique 65-1215.

Martínez, María Luisa 65-1022.

Martínez, Rocío Anabel 65-401.

Martínez Alcorlo, Ruth 65-767.

Martínez Arias, Rosario 65-2. 
Martínez Atienza, María 65-201.

Martínez Baro, Jesús 65-1007; 65-1008.

Martínez Berbel, Juan Antonio 65-787.

Martínez Bogo, Enrique 65-939.

Martínez Caro, Elena 65-500.

Martínez Carro, Elena 65-907.

Martínez Celdrán, Eugenio 65-43.

Martínez Diez, Gonzalo 65-762.

Martínez Enamorado, Virgilio 65-129.

Martínez García, Paula 65-778.

Martínez González, Antonio 65-9.

Martínez Hernández, Ángela 65-1110.

Martínez Millán, José 65-808.

Martínez Navarro, María del Rosario 65-1453.

Martínez Salazar, Elisa 65-1121.

Martínez Yépez, Heriberto 65-1086.

Martino, Luis Marcelo 65-1009.

Martos, Josep Lluís 65-742.

Martos García, Paula 65-588.

Martos Nuñez, Eloy 65-589.

Mas, Lluís 65-52.

Mascato Rey, Rosario 65-1453.

Massaguer Comes, Marina 65-376.

Mata Induráin, Carlos 65-794.

Matamoro, Blas 65-696; 65-1168

Mateo, José 65-633.

Mateo Palacios, Ana 65-634; 65-759.

Mateu Serra, Rosa 65-248.

Matteis, Lorena M.A. de 65-142.

Matute Martínez, Cristina 65-286.

Maura, Juan Francisco 65-1443.

Maurer, Karl 65-931.

Mauro, Karina 65-1064.

Maxey, Bryce 65-875.

Máynez, Pilar 65-957.

Mayoral Hernández, Roberto 65-547.

Mayr, Robert 65-502.

Mazzaro, Natalia 65-402.

Mazzini, Marta 65-1433.

Mazzocchi, Giuseppe 65-590.

Mazzucchelli, Aldo 65-1188.

McCloskey, James 65-489.

McDonough, Kim 65-548.

McGregor Mendoza, Patricia 65-403.

Medina López, Javier 65-255.

Medina Poveda, Diego 65-796.

Medina Rivera, Antonio 65-461.

Mehrez, Nagwa 65-549.

Mejías Bikandi, Errapel 65-202.

Melchers, Gunnel 65-454.

Melero García, Fernando 65-53.

Melis, Chantal 65-96.

Mella, Olga Guadalupe 65-1010.
Méndez G. de Paredes, Elena 65-429.

Méndez Vallejo, Dunia Catalina 65-363.

Mendivelso Mogollón, Mery 65-492.

Mendívil Giró, José Luis 65-102.

Mendoza Posadas, Mauro Alberto 65-292; 65-462.

Mendoza Vázquez, Érika 65-54.

Mercer, Johnathan D. 65-538.

Mérida Jiménez, Rafael M. 65-1383.

Merino Claros, Emilia 65-965.

Merlo, Pepa 65-1419.

Meseguer, Purificación 65-1122.

Metzeltin, Michael 65-550; 65-605.

Meza García, Gerardo 65-1423.

Meza, Paulina 65-256.

Miceli, Sonia 65-1119.

Michaud Maturana, Daniel 65-174.

Michnowicz, Jim 65-33; 65-471.

Miguel, Elena de 65-143.

Miguel Magro, Tania de 65-876.

Mihailescu, Calin-Andrei 65-1258.

Mihatsch, Wiltrud 65-203.

Millán, Mónica 65-474.

Minardi, Adriana 65-1276.

Minardi, Giovanna 65-1294; 65-1392.

Miñana, Rogelio 65-877.

Miquel, Lourdes 65-520.

Miranda Márquez, Gonzalo 65-55.

Missana, Sergio 65-1087.

Mitre, Eduardo 65-1233.

Móccero, María Leticia 65-56.

Moga, Eduardo 65-635; 65-1162; 65-1274; 65-1280; 65-1288; 65-1369; 65-1450; 65-1479.

Molés Cases, Teresa 65-636.

Molina, Hebe Beatriz 65-1038.

Molina Huete, Belén 65-965.

Molina Lora, Luis 65-1088.

Molina Sangüesa, Itziar 65-144; 65-145; 65-146.

Moll, Antoni L. 65-979.

Monsalver, María Cristina 65-1472.

Montanari, Simona 65-502.

Montañez Mesas, Marta Pilar 65-319.

Montero Reguera, José 65-707; 65-878; 65-948.

Montes Alcalá, Cecilia 65-463.

Montes Fano, Mateo 65-131.

Montes Hernández, Alma Laura 65-551.

Montesinos, Toni 65-708.

Monti, Silvia 65-1312.

Montolío Durán, Estrella 65-257.

Montoya Abat, Brauli 65-464.

Montrul, Silvina 65-465. 
Mora, Vicente Luis 65-1089.

Moral del Hoyo, María del Carmen 65-335.

Morala, José Ramón 65-294; 65-336; 65-337; 65-351; 65-353.

Morales, Carlos Javier 65-1430.

Morales Escorcia, Efraín 65-175.

Morales Ortiz, Gracia 65-1353.

Morán, Gregorio 65-1123.

Morant Marco, Ricardo 65-147.

Moreira, Sandra Regina 65-879; 65-880; 65-1444.

Morelli, Mara 65-610.

Moreno, Fernando Ángel 65-1080.

Moreno, Vicent 65-710; 65-1140.

Moreno Fernández, Francisco 65-404.

Moreno Lara, María Ángeles 65-204.

Moreno Sandoval, Antonio 65-659.

Moreno Torres, Ignacio 65-660.

Moret Oliver, María Teresa 65-338.

Morimoto, Yuko 65-591.

Morin, Regina 65-405.

Morini, Giovanna 65-480.

Moro Martín, Alfredo 65-823.

Morón Usandivaras, Mariana 65-401.

Morong Reyes, Germán Adolfo 65-913.

Morrison, Robert G. 65-662.

Mosquera Novoa, Lucía 65-726.

Moya Ávila, Francisco 65-1373.

Munguía Zatarain, Martha Elena 65-1458.

Muñoz, Alicia 65-1149.

Muñoz Basols, Javier 65-466; 65-552.

Muñoz, Laura 65-71.

Muñoz Pérez, Carlos 65-103.

Muñoz Sempere, Daniel 65-1011.

Murguía Verónica 65-1124.

Murrieta Bello, Laura 65-57.

Nadal Palazón, Juan 65-292.

Namer, Fiammetta 65-280.

Naranjo Sánchez, Beatriz 65-637.

Narbona, Aránzazu 65-393.

Narbona Jiménez, Antonio 65-309; 65-406.

Narvaja, Elvira 65-258; 65-407.

Nava, Gabriela 65-881.

Navarrete Turrent, Lucila 65-1389.

Navarro, Federico 65-259.

Navarro, Mario 65-99.

Navarro Andúgar, Juan 65-638.

Navarro Avilés, Juan José 65-1337.

Navarro Flores, Célia 65-882.

Navarro Gala, Rosario 65-339; 65-340.

Navascués, Javier de 65-783; 65-1090;
65-1381; 65-1407.

Nebot Nebot, Vicente José 65-1480.

Negrete Sandoval, Julia Érika 65-1362.

Neila, Manuel 65-709; 65-1461.

Neira, Julio 65-1194.

Nemrava, Daniel 65-1090.

Newman, Rochelle S. 65-480.

Nicolás Martínez, Carlota 65-661.

Nicolosi, Frédéric 65-358.

Nider, Valentina 65-940; 65-941.

Nieuwenhuijsen, Dorien 65-341.

Noguerol, Francisca 65-710.

Nogueroles López, Marta F. 65-483.

Nolting-Hauff, Ilse 65-931.

Nothstein, Susana 65-407.

Noyaret, Natalie 65-1091.

Núñez Rivera, Valentín 65-883.

Núñez Román, Francisco 65-148.

Nuriel, Patricia 65-1355.

Nussbaum, Luci 65-452.

O'Neill, Paul 65-104.

Oakes, Michael P. 65-639.

Obrist, Philipp 65-389.

Ocampo, Francisco 65-378.

Ochs, Kurt 65-931.

Octavio de Toledo y Huerta, Álvaro 65-344.

Odicio, Ricardo 65-604.

Oggiani, Carolina 65-97.

Ojea López, Ana Isabel 65-105.

Olay Valdés, Rodrigo 65-975; 65-983; 65-985; 65-986.

Olea Franco, Rafael 65-1189.

Olid Guerrero, Eduardo 65-884.

Olivieri, Federico 65-561.

Olmo Iturriarte, Almudena de 65-1301.

Olmos, Miguel Á. 65-1287.

Olza, Inés 65-260.

Oncins Martínez, José Luis 65-198.

Ong, Teresa 65-388.

Ontiveros, Adriana 65-786.

Oñoro, Cristina 65-1065.

Orazi, Veronica 65-1066; 65-1067.

Ordóñez López, Pilar 65-606.

Orna Montesinos, Concepción 65-261.

Ornelas de Avelar, Juanito 65-467.

Oropesa Márquez, Salvador A. 65-1012.

Orozco, Leonor 65-58; 65-400.

Orozco, Rafael 65-382; 65-408.

Orozco Jutorán, Mariana 65-641.

Orringer, Nelson R. 65-1267.

Orsanic, Lucía 65-795.

Orta Carrique, Estefanía 65-805; 65-1470. 
Ortega, Alfonso 65-583.

Ortega, Jenaro 65-520.

Ortega, Julio 65-1334; 65-1457.

Ortega Garrido, Andrés 65-1366.

Ortiz Aguirre, Enrique 65-1028.

Ortiz Gambetta, Eugenia 65-817; 65-1037.

Ortiz López, Luis A. 65-361.

Ortiz Lottman, Maryrica 65-954.

Österbauer, Veronika 65-973.

Oteiza Pérez, Blanca 65-819.

Oteíza Silva, Teresa 65-263; 65-555.

Paatz, Annette 65-1024; 65-1091.

Pablo Núñez, Luis 65-711.

Pablos-Ortega, Carlos de 65-207.

Padilla Herrada, María Soledad 65-245.

Padrón Iglesias, Wilfredo 65-1041.

Palacio Ortiz, Nortan 65-942.

Palacios, María Fernanda 65-1200.

Palacios, Niktelol 65-427

Palenque, Marta 65-1005.

Paleologos, Konstantinos 65-640.

Pano Alamán, Ana 65-398.

Pardo Herrero, Pilar 65-580.

Paredes, Demian 65-1205.

Parodi, Giovanni 65-262.

Parra, Richard 65-913.

Partzsch, Henriette 65-1000.

Pas, Hernán 65-1013.

Pascual Argente, Clara 65-743.

Pascual y Cabo, Diego 65-503.

Pastena, Enrico di 65-1335; 65-1432.

Patzelt, Carolin 65-389.

Pauer González, María Gabriela 65-420.

Pavón Lucero, María Victoria 65-592.

Paz, Ana 65-71.

Paz Aparicio de Soto, Valentina 65-1014.

Paz García, María de la 65-521.

Paz Oliver, Maria 65-1212.

Peale, C. George 65-962.

Pédeflous, Justine 65-685.

Pedraza García, Manuel José 65-818.

Pedraza Jiménez, Felipe B. 65-885.

Pedrote Romero, Antonio 65-308.

Pellen, René 65-768.

Pellicer, Juan 65-1299; 65-1399.

Pellicer, Rosa 65-1109.

Pellicer Sánchez, Ana 65-553.

Pena Sueiro, Nieves 65-809.

Penas Ibáñez, María Azucena 65-59.

Pensado Figueiras, Jesús 65-744.

Peña Arce, Jaime 65-60.

Peñalver Castillo, Manuel 65-21.

Peñas Ruiz, Ana 65-1004; 65-1011; 65-1044.
Peral Vega, Emilio 65-1268.

Perea Siller, Francisco Javier 65-558.

Pereira, Ricardo 65-604.

Pereyra, Marisa 65-1152.

Pérez, Alberto Julián 65-1125.

Pérez, Yolanda 65-552.

Pérez Aguiar, José R. 65-113.

Pérez Aguilar, Raúl Arístides 65-149.

Pérez Cabrera, Ana Beatriz 65-554.

Pérez Calarco, Martín 65-1219.

Pérez Domínguez, Josué Federico 65-1400.

Pérez Esperanza, Silvia 65-1391.

Pérez Giménez, Montserrat 65-61.

Pérez Leroux, Ana Teresa 65-93.

Pérez López, María Ángeles 65-710.

Pérez Martínez, Ángel 65-886.

Pérez Pascual, José Ignacio 65-22; 65-593.

Pérez Sabater, Carmen 65-205.

Pérez Salazar, Carmela 65-546.

Pérez Saldanya, Manuel 65-206.

Pérez Serrano, Mercedes 65-594.

Pérez Toral, Marta 65-342.

Pérez Vázquez, María Enriqueta 65-26; 65-106.

Pérez Vicente, Nuria 65-981.

Pérez Zúñiga, Ernesto 65-1201; 65-1418.

Pérez-Rasilla, Eduardo 65-1068.

Pericchi Pagá, Natalia 65-324.

Perna, Carlos Gabriel 65-409; 65-468; 65-1033.

Perotti, Olga 65-1445.

Perpiñán, Silvia 65-499.

Perromat, Kevin 65-1126.

Piedras, Ernesto 65-674.

Pineda Buitrago, Sebastián 65-1102.

Pineda Orejuela, Daniel 65-1127.

Pinheiro Correa, Paulo 65-215.

Pino, José M. del 65-1128.

Pinto, Derrin 65-207.

Pinuer Rodríguez, Claudio 65-263; 65-555.

Piñero Piñero, Gracia 65-618.

Piquer Píriz, Ana María 65-198.

Piquero Rodríguez, Álvaro 65-1030.

Pla Colomer, Francisco P. 65-777.

Pla, Xavier 65-1393.

Placencia, María Elena 65-184.

Planas Morales, Sílvia 65-62.

Plata, Fernando 65-943.

Plonsky, Luke 65-512.

Polanco Izquierdo, Mauricio 65-1459.

Polic Bobic, Mirjana 65-810.

Polizzi, Assunta 65-805; 65-1114. 
Pöll, Bernhard 65-410.

Pollarolo, Giovanna 65-1073.

Polo, Nuria 65-59.

Polverini, Sara 65-1434.

Ponce Cárdenas, Jesús 65-905.

Pons Rodríguez, Lola 65-343; 65-344; 65-411.

Popovic Karic, Pol 65-1424.

Porcar Miralles, Margarita 65-298; 65-345.

Porroche Ballesteros, Margarita 65-264; 65-556.

Portilla, Mario 65-150.

Pörtl, Klaus 65-1270.

Portolés Lázaro, José 65-265.

Pose Furest, Francisca 65-208.

Posio, Pekka 65-209.

Prada Pérez, Ana de 65-465.

Pradel, Stefano 65-1261.

Prado Alvarado, Agustín 65-1408.

Prat, Marta 65-71.

Presas, Adela 65-887; 65-968.

Presberg, Charles D. 65-888.

Presotto, Marco 65-889.

Price, Gillian 65-1332.

Prieto Entrialgo, Clara Elena 65-286; 65-584.

Prieto García-Seco, David 65-956.

Prieto Mendoza, Alejandro 65-604.

Prieto Ramos, Fernando 65-641.

Profeti, Maria Grazia 65-790; 65-947.

Puente, Marta 65-366.

Pueyo, Carlos Miguel 65-672.

Puig Guisado, Jaime 65-1302.

Pujol, Isabel 65-71; 65-75; 65-185; 65-346.

Qin, Li 65-521.

Quero, Alberto 65-774.

Quiles Faz, Amparo 65-1366.

Quinn, Mary Q. 65-797.

Quintana Hernández, Lucía 65-107.

Quintanilla, José 65-412.

Quintero Ramírez, Sara 65-266; 65-1425.

Quintrileo Llancao, Cecilia 65-267.

Quirós García, Mariano 65-151.

Quiroz, Beatriz 65-210.

Raab, Matthias 65-287.

Rainey, Vanessa R. 65-662.

Ramallo, Fernando 65-413.

Ramírez Castellanos, Ronald Antonio 65-1206.

Ramírez Luengo, José Luis 65-151; 65-152; 65-307.

Ramírez Rojas, Marco 65-1285.
Ramírez Santacruz, Francisco 65-890.

Ramírez-Pimienta, Juan Carlos 65-686.

Ramón García, Emilio 65-1467.

Ramón, Noelia 65-642.

Ramos, Carlos 65-1129.

Ramos, Miguel 65-347.

Ramos González, Alicia 65-824.

Ramos Lavalle, Florencia 65-1076.

Ramos Ortega, Manuel José 65-1319.

Rangel, Asunción 65-1368.

Rao, Rajiv 65-504.

Raposo, Berta 65-712.

Rearte, Juan Lázaro 65-589.

Recasens, Daniel 65-288; 65-348.

Redondo, Augustin 65-713.

Regueiro Rodríguez, María L. 65-558.

Reina Ruiz, M. 65-852.

Reisz, Susana 65-1092.

Remiro Fondevilla, Sonia 65-721.

Renau Araque, Irene 65-595.

Rey, Alfonso 65-929.

Rey Quesada, Santiago del 65-211; 65-349; 65-651.

Reyna, Iván R. 65-811.

Ribeiro Berger, Isis 65-469.

Ribeiro Fante, Bárbara 65-218.

Richmond, Carolyn 65-1163

Rico, Pablo 65-108.

Ridao Rodrigo, Susana 65-59.

Ridruejo, Emilio 65-768.

Riedemann Vásquez, Clemente 65-1053.

Riera, Carme 65-1250.

Riera Sans, Jaume 65-714.

Rifón, Antonio 65-109; 65-350.

Ríos Ávila, Rubén 65-1305.

Riosalido Villar, Patricia 65-1354.

Ripoll Sintes, Blanca 65-1130.

Rivas Velázquez, Alejandro 65-670.

Riveros Soto, Ana María 65-1323.

Robles, Ferrán 65-712.

Robles Garrote, Pilar 65-160; 65-663.

Robles Nagata, Eva 65-475.

Roca Escalante, Pilar 65-1356.

Rocca, Pablo 65-993.

Rodas, Giselle Carolina 65-720.

Ródenas de Moya, Domingo 65-1440.

Rodero, Jesús 65-1409.

Rodilla, María José 65-678.

Rodrigo Mora, María 65-23; 65-769.

Rodríguez, Adriana Azucena 65-891.

Rodríguez, Francesc 65-305.

Rodríguez, Juan 65-412.

Rodríguez, Mercet 65-351.

Rodríguez Arrizabalaga, Beatriz 65-500. 
Rodríguez Barcia, Susana 65-413.

Rodríguez Cachón, Irene 65-963.

Rodríguez de Ramos, Alberto 65-905.

Rodríguez Fisher, Ana 65-977; 65-1313.

Rodríguez Freire, Raúl 65-673.

Rodríguez Gutiérrez, Borja 65-996.

Rodríguez López-Abadía, Arturo 65-962.

Rodríguez Mansilla, Fernando 65-908.

Rodríguez Manzano, Marta 65-339.

Rodríguez Martín, Gustavo A. 65-643.

Rodríguez Medina, María Jesús 65-470.

Rodríguez Molina, Javier 65-312; 65-320; 65-325; 65-351.

Rodríguez Muñoz, Francisco J. 65-268; 65-656.

Rodríguez Ramalle, Teresa María 65-110.

Rodríguez Ramos, Alberto 65-796; 65-905.

Rodríguez Rodríguez, Catalina 65-1017.

Rodríguez Rubio, Raquel 65-516.

Rodríguez Temperley, María Mercedes 65-644.

Rodríguez Toro, José Javier 65-294.

Rodríguez Valle, Nieves 65-881; 65-949.

Rodríguez-Rodríguez, Ana María 65-812.

Rodríguez-Solás, David 65-1336.

Roffé, Reina 65-708.

Rogers, Brandon M.A. 65-414.

Rojas, Darío 65-24; 65-25; 65-415.

Rojas, Pablo 65-1412.

Rojas, Rafael 65-1131; 65-1132.

Rojas Berscia, Luis Miguel 65-416.

Rojas Castro, Antonio 65-915.

Rojo, Ana 65-1122.

Rojo, Grínor 65-715.

Rolle, Carolina 65-1133.

Román López, María 65-983; 65-984.

Román, Patricia 65-524.

Romanos, Melchora 65-1171.

Romera Castillo, José 65-716; 65-1069.

Romera, Magdalena 65-417.

Romero, Juan Manuel 65-1262.

Romero, María de los Ángeles 65-1460.

Romero Contreras, Arturo 65-922.

Romero Ferrer, Alberto 65-996.

Romero López, Dolores 65-1134.

Romero Manzanares, Ana María 65-301.

Romero Tobar, Leonardo 65-717.

Romeu Ferré, Pilar 65-799.

Romo Feito, Fernando 65-892.

Romo Simón, Francisco 65-559.

Ronquest, Rebecca 65-504.

Rosal Nadales, María 65-1054; 65-1135; 65-1136.
Roseano, Paolo 65-43.

Rosell, Maria 65-690; 65-1269

Rosello, Mireille 65-544.

Rosemeyer, Malte 65-284.

Rossi, María Julia 65-1360.

Rost Bagudanch, Assumpció 65-35; 65-71; 65-418.

Rottenberg, Débora 65-1303.

Rouhi, Leyla 65-960.

Rovecchio, Laeticia 65-1314.

Rovira i Cerdà, Helena 65-784.

Rowe, Lindsey 65-505.

Roy, Isabelle 65-111.

Rubio, Fernando 65-447.

Rubio Alcalá, Carlos 65-212.

Rubio Árquez, Marcial 65-944.

Rubio San Román, Alejandro 65-907.

Rubio Tovar, Joaquín 65-644.

Rueda, Ana 65-978.

Ruffinatto, Aldo 65-893; 65-894.

Ruggeri Marchetti, Magda 65-916.

Ruhstaller, Stefan 65-129.

Ruiz, Julio Juan 65-825.

Ruiz Abreu, Álvaro 65-1377.

Ruiz Barrionuevo, Carmen 65-1184.

Ruiz Casanova, José Francisco 65-1429.

Ruiz González, Natalia 65-419.

Ruiz Gurillo, Leonor 65-213.

Ruiz Pérez, Pedro 65-1260.

Ruiz Tinoco, Antonio 65-112.

Russo, Antonella 65-1005; 65-1376.

Russo, Mariachiara 65-645.

Sabaj, Omar 65-256.

Sabo, María José 65-1093.

Sáez, Adrián J. 65-895; 65-941.

Sáez Carrillo, Katia 65-478.

Sáez Delgado, Antonio 65-1055.

Sáez Godoy, Leopoldo 65-596.

Sáez Rivera, Daniel M. 65-323; 65-379; 65-558.

Sainz, Eugenia 65-269.

Salameh Jiménez, Shima 65-250.

Salazar, Danica 65-466.

Salazar Anglada, Aníbal 65-1376.

Salazar Campillo, Patricia 65-506.

Salcedo, Hugo 65-1070.

Salcedo, Pedro 65-132.

Salvo García, Irene 65-753; 65-754.

Samper Suárez, Josefa 65-175.

Sampson, Rodney 65-288.

San José Lera, Javier 65-1267.

San José Vázquez, Eduardo 65-984.

San Martín Núñez, Abelardo 65-270. 
San Segundo Cachero, Rosabel 65-352.

San Segundo, Eugenia 65-46.

San Vicente, Félix 65-26.

Sánchez, Daniel 65-517.

Sánchez, Joana 65-1065.

Sánchez, María Carolina 65-999.

Sánchez, Mercedes 65-420.

Sánchez, Soledad 65-1113.

Sánchez Aparicio, Vega 65-710.

Sánchez Berriel, Isabel 65-113.

Sánchez Carbó, José 65-692.

Sánchez García, Manuel 65-198.

Sánchez González de Herrero, M. Nieves 65-299; 65-353.

Sánchez Jiménez, Antonio 65-712; 65-1003.

Sánchez Jiménez, Santiago U. 65-354.

Sánchez Martín, Francisco Javier 65-597.

Sánchez Palacios, Concepción 65-491.

Sánchez Portero, Antonio 65-896.

Sánchez Robayna, Andrés 65-671; 65-917; 65-1280; 65-1448.

Sánchez Romo, Raquel 65-351.

Sánchez Rufat, Anna 65-507; 65-520.

Sánchez Sánchez, Mercedes 65-929.

Sánchez Suárez, M.E. 65-565.

Sancho Pascual, María 65-421.

Sanfelici, Laura 65-1317.

Sangorrín Guallar, Francisco 65-289.

Sanjinés, José 65-1225.

Santa A., Sara 65-938.

Santaemilia Ruiz, José 65-646.

Santamaría Busto, Enrique 65-63.

Santamaría Pérez, Isabel 65-598.

Santana, Adalberto 65-1042.

Santana, Andrea 65-532.

Santana Suárez, Octavio 65-113.

Santiváñez, Roger 65-1476.

Santonocito, Daniela 65-759.

Santos, Manuel 65-674.

Santos de la Rosa, Inmaculada 65-516.

Santos López, Javier 65-239; 65-599.

Santos Rovira, José María 65-153.

Santos Sánchez, Diego 65-1071.

Sanz Manzano, María Ángeles 65-1297.

Sanz Villanueva, Santos 65-1155; 65-1208; 65-1329; 65-1365.

Saraceni, Gina 65-1202.

Saracino, Pablo E. 65-731.

Sartori, María Florencia 65-407.

Sáseta Naranjo, Rafael 65-718.

Satorre Grau, Francisco Javier 65-312.

Saura Rami, José Antonio 65-131.

Saylor, Megan M. 65-505.
Scham, Michael 65-897.

Schinasi, Michael 65-1048.

Schlieper, Hendrik 65-1000.

Schmidt, Lauren B. 65-560.

Schmidt, Rachel 65-898.

Schmigalle, Günther 65-1026.

Schulte, Kim 65-124.

Schweickard, Wolfgang 65-605.

Schwenter, Scott A. 65-422.

Scliar Cabral, Leonor 65-647.

Scrivner, Olga 65-423.

Sebastián, Eugenia 65-491.

Seco, María Alejandra 65-114.

Segas, Lise 65-785.

Segovia Gordillo, Ana 65-27.

Sepúlveda Eriz, Magda 65-1056.

Sereno, Joan 65-497.

Serna, Mercedes 65-819; 65-926.

Serra, Maurizio 65-1244.

Serra Pfenning, Isabel 65-214.

Serra Sepúlveda, Susana 65-115.

Serrano, Julio 65-450.

Serrano, Julio 65-1237; 65-1348; 65-1382; 65-1427.

Serrano, María José 65-116.

Serrano Asenjo, José Enrique 65-1364.

Serrano Avilés, Javier 65-561.

Serrano Cueto, Antonio 65-682; 65-1094.

Serrano Dolader, David 65-117.

Serrano Navarro, Bruno 65-1051.

Sessarego, Sandro 65-471.

Setton, Román 65-1473.

Sevilla Muñoz, Julia 65-130.

Shaban Mursi, Ebtisam 65-925.

Sherman, Kátia 65-899.

Shively, Rachel L. 65-658.

Shu-Ying Chang, Luisa 65-1447.

Sierra, Juan Carlos 65-1057.

Sierra, Juan Manuel 65-537.

Silton, Rebecca L. 65-662.

Silva, Silmara dela 65-271.

Silva Moraes, Valéria da 65-900.

Silva Villena, Omer 65-19.

Silva-Corvalán, Carmen 65-508.

Silveira Moura, Fernanda 65-215.

Silvestri, Laura

Simari, Leandro Ezequiel 65-1308.

Simon, Robert 65-1446.

Simonatti, Selena 65-355.

Sinatra, Chiara 65-648.

Sinclair, Alison 65-687.

Šinková, Monika 65-118.

Siskind, Mariano 65-1137.

Smith, Daniel 65-472. 
Smith, John Charles 65-280.

Smith, Linda B. 65-479.

Smith, Paul Julian 65-1095.

Smith, Wendell P. 65-901.

Sobrino Triana, Roxana 65-424.

Soheim, El Sayed Ibrahm 65-925.

Soler Bonafont, M. Amparo 65-216.

Soler Montes, Carlos 65-517.

Soler Pardo, Betlem 65-646.

Solervicens, Josep 65-979.

Solon, Megan 65-484; 65-562.

Solsona Martínez, Carmen 65-272.

Somosa, Patricia 65-1385.

Sosenski, Susana 65-1138.

Sotelo Vázquez, Adolfo 65-1096; 65-1393; 65-1411.

Soto Barba, Jaime 65-664.

Soto, Pilar 65-491.

Sotomayor, Áurea María 65-1058.

Sozzi, Martín 65-921.

Spence, Paul 65-711; 65-719.

Speranza, Adriana 65-217.

Stafford, Catherine A. 65-509.

Stala, Ewa 65-600.

Steed, William 65-523.

Stehlík, Petr 65-119.

Stengers, Helene 65-563.

Stockler, Sarah 65-425.

Stoll, Pamela 65-530.

Storti Garcia, Talita 65-218.

Strosetzki, Christoph 65-813.

Strycharczuk, Patrycja 65-64.

Sutherland-meier, Madeline 65-989.

Svobodová, Iva 65-119.

Sweetnich, Lindsey 65-463.

Swiderski, Liliana 65-1320.

Swiggers, Pierre 65-11.

Sy, Anahi 65-1413.

Szkwarek, Magdalena 65-28.

Tabares Plasencia, Encarnación 65-154; 65-601.

Tacconi, Maria del Carmen 65-1190.

Talwalkar, Jaideep S. 65-521.

Tanganelli, Paolo 65-915.

Tanghe, Sanne 65-120.

Tanico, Matthew S. 65-902.

Tapia, Miguel 65-1177.

Tarp, Sven 65-577.

Tedeschi, Stefano 65-695; 65-792.

Teixeira, Annalisa 65-510.

Temelli, Yasmin 65-692.

Tenorio Trillo, Mauricio 65-1139.

Teruel, José 65-1330.
Thiem, Annegret 65-1051.

Thornberry, Philip A. 65-65.

Tobar, Carolina 65-1172.

Tobar Quintanar, María José 65-923.

Toledo Vega, Gloria 65-564.

Tollis, Francis 65-768.

Tomás Faci, Guillermo 65-338.

Tomasin, Lorenzo 65-290.

Tonin, Raffaella 65-649.

Toro, Alfonso de 65-1255.

Torres, Nadiezdha 65-457.

Torres Begines, Concepción 65-1454.

Torres Bustos, Valeska 65-664.

Torres Cacoullos, Rena 65-422.

Torres de la Rosa, Danaé 65-1097.

Torres Martínez, Marta 65-121; 65-308; 65-379; 65-421.

Torres Roncallo, Luz Marina 65-175.

Torruella, Joan 65-71; 65-305.

Tosar López, Javier 65-765.

Trambaioli, Marcella 65-961.

Traverso, Ana 65-1477.

Trecca, Simone 65-1072.

Treinsoutrot, Pascal 65-122.

Trevisan, Ana Lúcia 65-1084.

Triano López, Manuel 65-273.

Triano López, Patricia 65-273.

Trommer, Jochen 65-123.

Trujillo Peña, Sandra Milena 65-1029.

Ubilla Espinoza, Lorena 65-1036.

Uclés Ramada, Gloria 65-650.

Ueda, Hiroto 65-155; 65-356.

Uriagereka, Juan 65-183.

Urzainqui, Inmaculada 65-984.

Uzcanga Meinecke, Francisco 65-974.

Vaiopoulos, Katerina 65-826.

Valdeón, Robert A. 65-651.

Valdés Gázquez, Ramón 65-945.

Valdez, Juan R. 65-426.

Valencia, Leonardo 65-1106; 65-1371.

Valencia, Roberto 65-1140.

Valenzuela, Pilar 65-1053.

Valenzuela Magaña, Juan Fernando 65-1098; 65-1147.

Valenzuela Manzanares, Javier 65-219.

Valenzuela Rettig, Pilar 65-665; 65-1370.

Valero Gisbert, María Joaquina 65-602.

Valero Juan, Eva 65-1410.

Valle, José del 65-357.

Valle, María del 65-132.

Vallejo Rubinstein, Claudia 65-473.

Valls, Fernando 65-1327. 
Van 't Veer, Marijn 65-64.

Van Gorp, Lise 65-220.

Van Hecke, An 65-1347; 65-1377.

Vanden Berghe, Kristine 65-1110.

Vanderschueren, Clara 65-124.

Vanegas Vásquez, Orfa Kelita 65-1421.

Vangehuchten, Lieve 65-233.

Vanrell, María del Mar 65-178.

Vara, Ana María 65-1099.

Varela Tembra, Juan José 65-1246.

Vares González, Elena 65-66.

Vargas, Kerlys 65-383.

Vargas Montes, Paloma 65-909.

Variano, Angelo 65-605.

Vásquez, Malva Marina 65-1181.

Vauthier, Bénédicte 65-720.

Vázquez Amador, María 65-156; 65-603.

Vázquez Cano, Esteban 65-565.

Vázquez Carranza, Ariel 65-221.

Veland, Reidar 65-157.

Velázquez, Isabel 65-474.

Velásquez Upegui, Eva Patricia 65-67.

Velásquez Vásquez, Libia 65-1034.

Velázquez Toledo, Oliver 65-1372.

Veleiro, Ana 65-222.

Velykodna, Olena 65-1141.

Ventura Ramos, Lorena 65-1015.

Viamonte Lucientes, Ernesto 65-975; 65-1169.

Vila, Juan Diego 65-903.

Vila Carneiro, Zaida 65-791.

Vila Rubio, Neus 65-427.

Viladot, Maria Àngels 65-449; 65-652.

Vilar Sánchez, Karin 65-428.

Villa, Daniel J. 65-475.

Villalba, Manuel J. 65-29.

Villalba Ibáñez, Cristina 65-223.

Villalobos Villalobos, Carlos Manuel 65-1159.

Villamediana González, Leticia 65-969; 65-980.

Villanueva, Darío 65-1142.

Villar Díaz, María Belén 65-224.

Villena, Fernando de 65-1351.

Vincent, Nidia 65-1279.

Vinther, Thora 65-527.

Viñuales, Antonio 65-1251.

Viseneber, Karolin 65-692.

Vito Luigio, Castrignanò 65-291.
Vittoria Calvi, Maria 65-1331.

Viú Adagio, Julieta 65-1277.

Vivanco Roca Rey, Lucero de 65-721.

Vives, Anna 65-1270.

Volpe, Germana 65-675; 65-961.

Von der Walde Moheno, Lillian 65-736.

Von Stecher, Pablo 65-274.

Wasem, Marcos 65-1224.

Weber, Andrea 65-476.

Wehr, Barbara 65-358.

Weinberg, Liliana 65-722.

Weldt-Basson, Helene C. 65-1324.

Westall, Debra 65-275.

Wieser, Doris 65-1119.

Williamson, Edwin 65-904.

Willis, Erik W. 65-484.

Winkelmann, Otto 65-605.

Wolford, Tonya 65-39.

Wolfson Reyes, Gabriel 65-1143.

Wood, Yolanda 65-1043.

Wrobel, Jasmin 65-1075.

Wyszynski, Matthew A. 65-856.

Yada, Yoko 65-653.

Yelin, Julieta 65-1121.

Yúfera Gómez, Irene 65-558.

Zacarías Ponce de León, Ramón F. $65-125 ; 65-400$.

Zaccari, Verónica 65-258.

Zamarreño, Fabio 65-767.

Zapata, Juan 65-723.

Zariquiey, Roberto 65-604.

Zavala, Virginia 65-477.

Zavala Gómez del Campo, Mercedes 65-678.

Zegarra, Chrystian 65-1476.

Zepeda, Jorge 65-920.

Zielinski, Andrzej 65-359.

Zilinskaite, Milda 65-1390.

Zimmermann, Klaus 65-429.

Zonana, Víctor Gustavo 65-1232.

Zubillaga, Carina 65-727; 65-780.

Zuili, Marc 65-30.

Zulaica López, Martín 65-816.

Zuleta Carrandi, Joaquín 65-951.

Zuluaga Hernández, Esnedy 65-1469.

Zyzik, Eve C. 65-514. 